\author{
UNIVERSIDADE DE SÃO PAULO \\ FACULDADE DE SAÚDE PÚBLICA \\ DEPARTAMENTO DE NUTRIÇÃO
}

\title{
Perfil de ácidos graxos ômega-3 nas membranas eritrocitárias e sua associação com equações preditivas aplicadas à estimativa do risco cardiovascular
}

Gustavo Henrique Ferreira Gonçalinho

Dissertação apresentada ao Programa de Pós-Graduação em Nutrição em Saúde Pública da Universidade de São Paulo para obtenção do título Mestre em Ciências.

Área de concentração: Nutrição em Saúde Pública.

Orientadora: Profa. Assoc. Dra. Nágila Raquel Teixeira Damasceno

São Paulo 


\section{Perfil de ácidos graxos ômega-3 nas membranas eritrocitárias e sua associação com equações preditivas aplicadas à estimativa do risco cardiovascular}

Gustavo Henrique Ferreira Gonçalinho

Dissertação apresentada ao Programa de Pós-Graduação em Nutrição em Saúde Pública da Universidade de São Paulo para obtenção do título Mestre em Ciências.

Área de concentração: Nutrição em Saúde Pública.

Orientadora: Profa. Assoc. Dra. Nágila Raquel Teixeira Damasceno

Versão corrigida

São Paulo 
Autorizo a reprodução e divulgação total ou parcial deste trabalho, por qualquer meio convencional ou eletrônico, para fins de estudo e pesquisa, desde que citada a fonte.

Catalogação da Publicação

Ficha elaborada pelo Sistema de Geração Automática a partir de dados fornecidos pelo(a) autor(a) Bibliotecária da FSP/USP: Maria do Carmo Alvarez - CRB-8/4359

Gonçalinho, Gustavo Henrique Ferreira

Perfil de ácidos graxos ômega-3 nas membranas

eritrocitárias e sua associação com equações preditivas aplicadas à estimativa do risco cardiovascular / Gustavo Henrique Ferreira Gonçalinho; orientadora Nágila Raquel Teixeira Damasceno. -- São Paulo, 2020.

$125 \mathrm{p}$.

Dissertação (Mestrado) -- Faculdade de Saúde Pública da Universidade de São Paulo, 2020.

1. Nutrição. 2. Metabolismo. 3. Cardiologia. 4. Lipidologia. I. Damasceno, Nágila Raquel Teixeira, orient. II. Título. 


\section{DEDICATÓRIA}

À minha família, por sempre ter me inspirado e apoiado, além de me incentivar a seguir meus sonhos. 


\section{AGRADECIMENTOS}

Agradeço à professora Nágila pela orientação, dedicação, oportunidades e pelo conhecimento que você me deu. Sua orientação foi crucial para a minha evolução pessoal e profissional.

Aos meus amigos Paula, Laís, João, Ismênia, Isabelle, Gustavo, Sara, Adélia, Mariana e Flávia pelo apoio, pelas risadas, pela confiança, e pelo conhecimento que muitas vezes vocês me deram. Vocês estiveram ao meu lado sempre que precisei. Me inspiro muito em todos vocês.

Às colegas do grupo de pesquisa OXILIPID, que sempre fizeram contribuições e críticas importantes para meu trabalho.

Às Dras. Rosana, Geni e Liânia, que me auxiliaram demais nas análises laboratoriais e sempre tiveram muita paciência para transmitirem seus conhecimentos.

À Coordenação de Aperfeiçoamento Pessoal de Nível Superior (CAPES), pela bolsa concedida.

À Fundação de Amparo à Pesquisa (FAPESP), ao Instituto Nacional de Ciência e Tecnologia em Fluidos Complexos (INCT-FCX) e ao Núcleo de Pesquisa em Fluidos Complexos - NAP-CX, pelo subsídio financeiro.

À Faculdade de Saúde Pública da Universidade de São Paulo, que transformou minha vida para melhor. 
GONÇALINHO, G. H. F. Perfil de ácidos graxos ômega-3 nas membranas eritrocitárias e sua associação com equações preditivas aplicadas à estimativa do risco cardiovascular [Dissertação]. São Paulo, Faculdade de Saúde Pública, Universidade de São Paulo, 2019.

\section{RESUMO}

Introdução: Embora diversos mecanismos indiquem o papel cardioprotetor dos ácidos graxos ômega-3 (AG n-3), há controvérsias quanto seu impacto nos desfechos cardiovasculares. Nós hipotetizamos que os AG n-3 das membranas eritrocitárias refletem melhor o consumo e metabolização desses AG, permitindo identificar seus reais benefícios cardiovasculares. Objetivo: Associar os AG n-3 com biomarcadores cardiometabólicos e com o risco cardiovascular (RC) global. Métodos: Estudo transversal baseado no ensaio clínico CARDIONUTRI $(n=356)$, com indivíduos de ambos os sexos (30-74 anos) e com pelo menos um dos seguintes fatores de risco: tabagismo, hipertensão, dislipidemia, diabetes mellitus ou obesidade. Foram analisados o lipidograma, subfrações de lipoproteínas, LDL(-), glicemia, HbA1c, insulina, HOMA-IR e biomarcadores de inflamação. Os AG dos eritrócitos foram analisados por meio de cromatografia gasosa. O RC global foi estimado pelos escores de Framingham (ERF), Reynolds (ERR) e da ACC/AHA 2013. Os resultados obtidos foram analisados no programa estatístico SPSS v.20.0 e Stata v.14.0. Resultados: Indivíduos com AG n-3 >6,24\% e com razão n-6/n-3 $\leq 1,27$ apresentaram menos colesterol não-HDL, Apo B, TG, LDL(-) e maior tamanho de LDL. O total de AG n-3 foi associado a menor RC estimado pelo ERF (OR=0,811; IC95\%=0,675-0,976) e o padrão de membranas que contém mais n-6 e menos n-3 foi associado a maior risco $(\mathrm{OR}=1,469$; IC95\%=1,056-2,043). Perfil semelhante foi associado a maior RC estimado pelo ERR (OR: 1,276; IC95\%=1,010-1,612), enquanto o padrão oposto, com mais n-3 e menos n-6, foi associado a menor RC (OR=0,747; IC95\%=0,589-0,948). Não houve associações significativas com o RC estimado segundo o ACC/AHA 2013. Conclusão: Membranas eritrocitárias com mais AG n-3 e menos n-6 foram associadas a um perfil lipídico com menos lipoproteínas aterogênicas, menos TG e menor modificação da LDL. Esse perfil reduziu a chance de os indivíduos apresentarem RC moderado ou alto estimado pelos Escores de Risco de Reynolds e de Framingham.

Descritores: Ácidos graxos ômega-3, Risco cardiovascular, Biomarcador, Dieta. 
GONÇALINHO, G. H. F. Erythrocyte membranes' omega-3 fatty acids profile and its association with predictive equations applied in the estimation of cardiovascular risk. [Dissertation]. São Paulo, School of Public Health, University of São Paulo, 2019.

\section{ABSTRACT}

Introduction: Although several mechanisms confirm the cardioprotective role of omega-3 fatty acids (n-3 PUFA), there is still controversy regarding the impact on cardiovascular outcomes. We hypothesized that the erythrocytes membranes' n-3 PUFA reflect better intake and metabolization of these fatty acids, allowing to identify their cardiovascular benefits. Objective: To evaluate the association of the n-3 PUFA with cardiometabolic biomarkers and absolute cardiovascular risk. Methods: A crosssectional study based on the CARDIONUTRI clinical trial $(\mathrm{n}=356)$ with individuals of both sexes (30-74 years) with at least one of the following risk factors: smoking, hypertension, dyslipidemias, diabetes mellitus or obesity. We analyzed the lipid profile, lipoprotein subfractions, LDL(-), glycemia, HbA1c, insulin, HOMA-IR and inflammation biomarkers. Fatty acids were analyzed by gas chromatography. The 10years projection of absolute cardiovascular risk was estimated by the Framingham (FRS), Reynolds (RRS) and ACC/AHA 2013 risk scores. The obtained results were analyzed by the statistical softwares SPSS v.20.0 and Stata v.14.0. Results: Individuals with n-3 PUFA $>6,24 \%$ and $n-6 / n-3 \leq 1,27$ had less plasma non-HDL cholesterol, Apo B, TG, LDL(-) and had bigger LDL size. Regarding FRS, the total n3 PUFA had association with lower cardiovascular risk $(\mathrm{OR}=0,811$; IC95\% $=0,675$ 0,976) and the membrane pattern containing more n-6 and less n-3 PUFA was associated with higher risk ( $\mathrm{OR}=1,469$; IC95\%=1,056-2,043). Regarding RRS, the same pattern had association with higher risk (OR: 1,276; IC95\%=1,010-1,612) whilst the opposite pattern, containing more n-3 and less n-6 PUFA, had association with lower risk $(\mathrm{OR}=0,747$; IC95\%=0,589-0,948). Associations with ACC/AHA 2013 were not significant. Conclusion: Erythrocyte membranes containing more n-3 and less n-6 PUFA were associated with a lipid profile characterized by less plasma atherogenic lipoproteins, less TG and fewer LDL modification. This membrane profile was associated with reduced chance to be classified as moderate or higher cardiovascular risk by the Reynolds and Framingham risk scores.

Descriptors: Omega-3; Cardiovascular Risk; Biomarker; Diet. 


\section{Sumário}

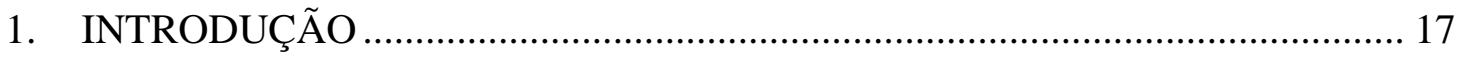

1.1. Epidemiologia das doenças cardiovasculares .............................................. 17

1.2. Estimativas do risco cardiovascular absoluto ............................................. 18

1.3. Lipídeos dietéticos e metabolismo de lipoproteínas ...................................... 22

1.4. Ácidos graxos poli-insaturados, inflamação e doença cardiovascular ............... 24

1.4.1. Biossíntese de ácidos graxos poli-insaturados ...................................... 25

1.4.2. Incorporação de ácidos graxos poli-insaturados na membrana celular e

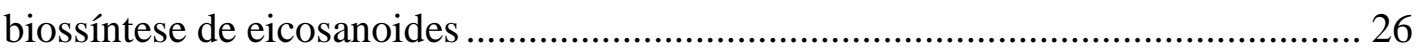

2. Ácidos graxos das membranas eritrocitárias como preditores de risco

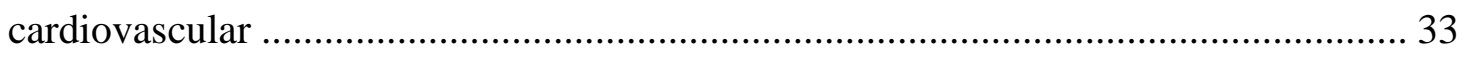

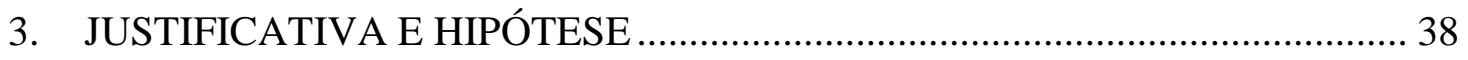

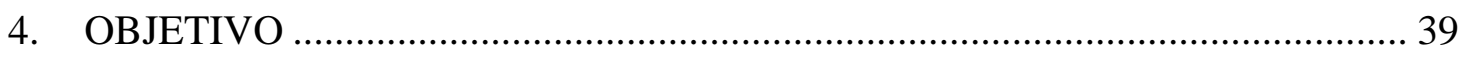

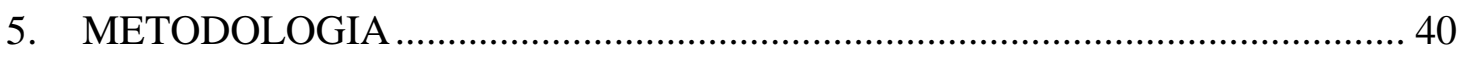

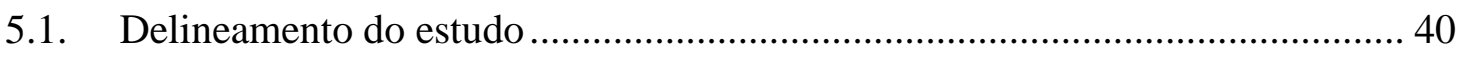

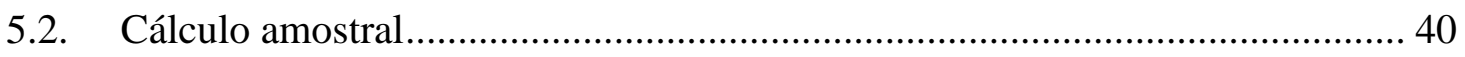

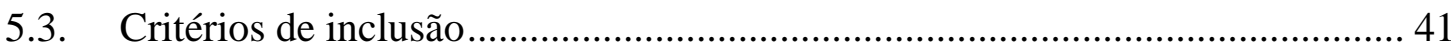

5.4. Critérios de não inclusão e exclusão ................................................................. 41

5.5. Avaliação socioeconômica e clínica .............................................................. 42

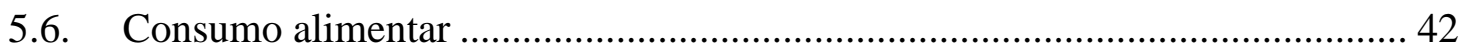

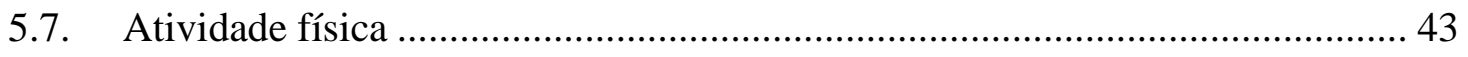

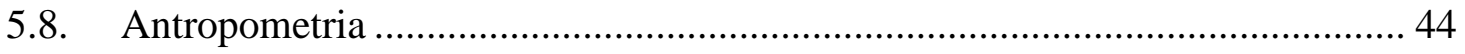

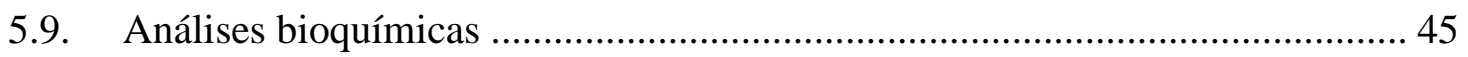

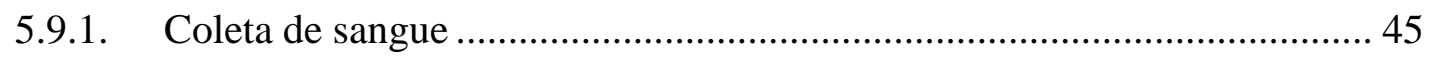

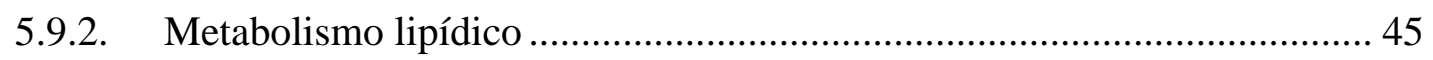

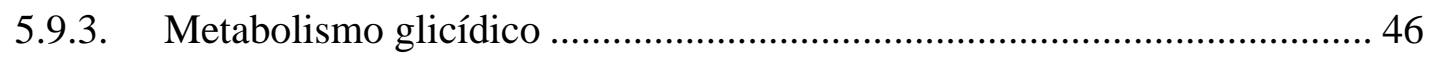

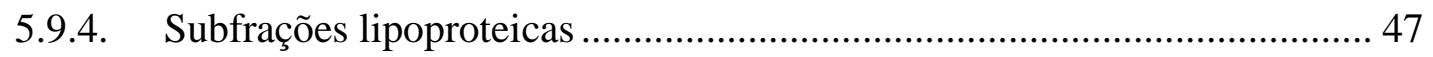

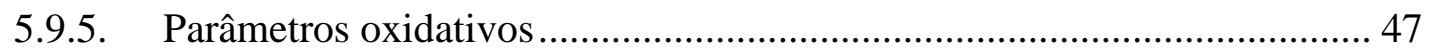


5.9.6. Parâmetros inflamatórios

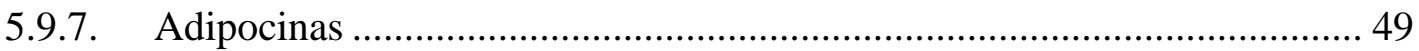

5.9.8. Perfil de ácidos graxos de membranas eritrocitárias ................................. 49

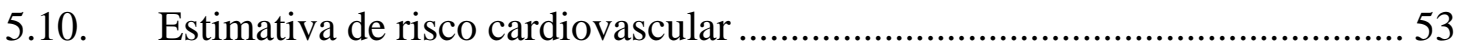

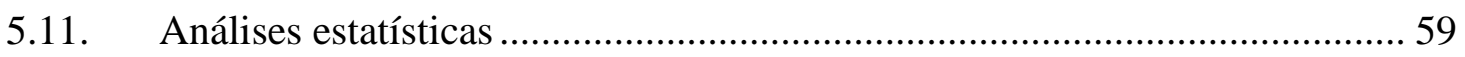

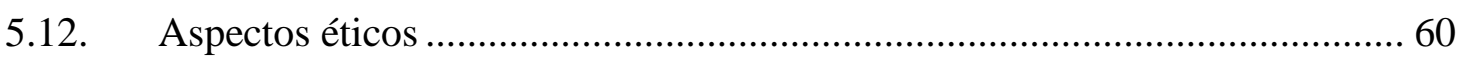

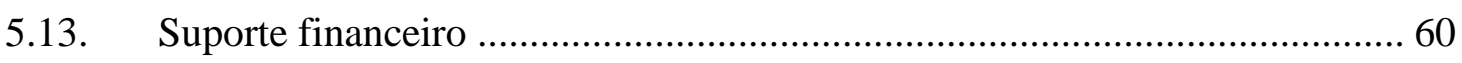

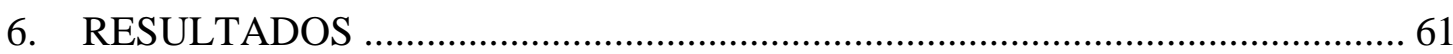

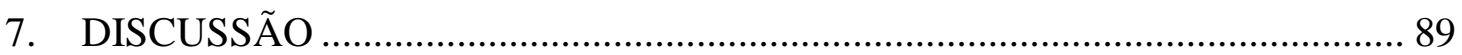

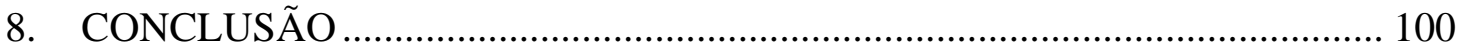

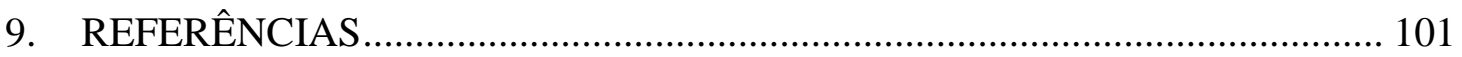

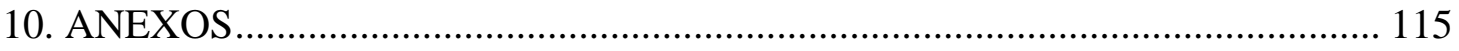

10.1. Anexo 1 - Termo de Consentimento Livre e Esclarecido (TCLE) .................... 115

10.2. Anexo 2 - Questionário para avaliações socioeconômica e clínica................... 116

10.3. Anexo 3 - Treinamento para aplicação dos inquéritos alimentares e recordatório

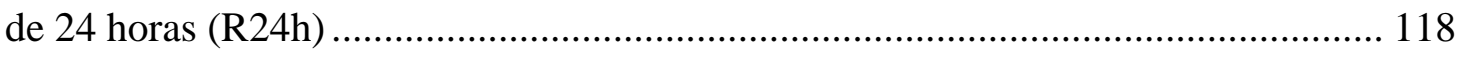

10.4. Anexo 4 - Questionário para avaliação de atividade física ............................ 122

10.5. Anexo 5 - Aprovação do Comitê de Ética em Pesquisa da Faculdade de Saúde

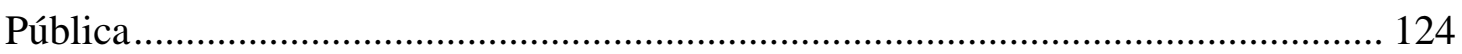

10.6. Anexo 6 - Aprovação do Comitê de Ética em Pesquisa do Hospital Universitário 


\section{ABREVIAÇÕES}

$\begin{array}{ll}\text { AA } & \text { Ácido araquidônico } \\ \text { ACAT-1 } & \text { Acil-colesterol-aciltransferase 1 } \\ \text { AG } & \text { Ácidos graxos } \\ \text { Apo } & \text { Apolipoproteína } \\ \text { ATP III } & \text { Adult Treatment Panel III } \\ \text { ACC/AHA } & \text { American College of Cardiology/American Heart Association } \\ \text { CETP } & \text { Proteína de transferência de colesterol esterificado } \\ \text { CT } & \text { Colesterol total } \\ \text { DAC } & \text { Doença arterial coronariana } \\ \text { DCV } & \text { Doenças cardiovasculares } \\ \text { DHA } & \text { Ácido docosaexaenoico } \\ \text { EEL } & \text { Exercício físico de lazer }\end{array}$

ELISA Enzyme-Linked Immunosorbent Assay

EPA Ácido eicosapentaenoico

ERF Escore de Risco de Framingham

ERR Escore de Risco de Reynolds

G-CSF Fator estimulador de colônias de granulócitos

GM-CSF Fator estimulador de colônias de granulócitos e macrófagos

HDL Lipoproteína de alta densidade

HDL-C Colesterol associado à HDL

HMG-CoA redutase Hidroxi-metil-glutaril coenzima A redutase

HOMA-IR Homeostasis model assessment - insulin resistance

ICAM-1 Molécula de adesão intercelular-1 


\begin{tabular}{|c|c|}
\hline IFN- $\gamma$ & Interferon-gama \\
\hline IL & Interleucina \\
\hline IKK & Quinase do inibidor de kappa B \\
\hline IMC & Índice de massa corporal \\
\hline INCT-FCx & Instituto Nacional de Ciência e Tecnologia de Fluidos \\
\hline Complexos & \\
\hline IO3 & Índice ômega-3 \\
\hline LDL & Lipoproteína de baixa densidade \\
\hline LDL(-) & LDL eletronegativa \\
\hline LDL-C & Colesterol associado à LDL \\
\hline LDLox & LDL oxidada \\
\hline $\mathrm{Lp}_{-\mathrm{PLA}}{ }_{2}$ & Fosfolipase $\mathrm{A}_{2}$ associada à lipoproteína \\
\hline LTB4 & Leucotrienos de série 4 \\
\hline LTB5 & Leucotrienos de série 5 \\
\hline MCP-1 & Proteína quimiotática de monócitos 1 \\
\hline MIP-1 $\beta$ & Proteína inflamatória de macrófagos $1 \beta$ \\
\hline Não-HDL-C & Colesterol não associado à HDL \\
\hline OMS & Organização Mundial da Saúde \\
\hline PCR & Proteína $\mathrm{C}$ reativa \\
\hline PGE2 & Prostaglandinas de série 2 \\
\hline PGE3 & Prostaglandinas de série 3 \\
\hline PON1 & Paraoxonase 1 \\
\hline PPAR & Receptores ativados pelos proliferadores de peroxissomos \\
\hline $\mathrm{R} 24 \mathrm{~h}$ & Recordatório alimentar de $24 \mathrm{~h}$ \\
\hline $\mathrm{RC}$ & Risco cardiovascular \\
\hline
\end{tabular}


SREBP

TAB-1

TAB-2

TAG

TAK-1

beta

TCLE

$\mathrm{TNF}-\alpha$

TXA2

TXA3

VCAM-1

VLDL
Proteína de ligação ao elemento regulatório de esterol

Proteína 1 de ligação a TAK-1

Proteína 2 de ligação a TAK-1

Triacilgliceróis

Quinase 1 ativada pelo fator de transformação do crescimento

Termo de Consentimento Livre e Esclarecido

Fator de necrose tumoral alfa

Tromboxanos de série 2

Tromboxanos de série 3

Molécula de adesão celular-vascular 1

Lipoproteína de muito baixa densidade 


\section{LISTA DE FIGURAS}

Figura 1 - Síntese e biotransformação dos ácidos graxos essenciais.

Figura 2 - Biossíntese de eicosanoides derivados de ácidos graxos poli-insaturados

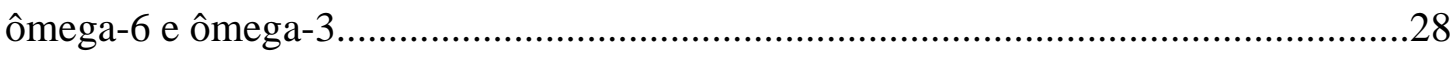

Figura 3 - Método de extração e esterificação dos ácidos graxos das membranas eritrocitárias

Figura 4 - Estratificação do risco cardiovascular global dos indivíduos de acordo com as diferentes equações preditivas... .65 


\section{LISTA DE QUADROS}

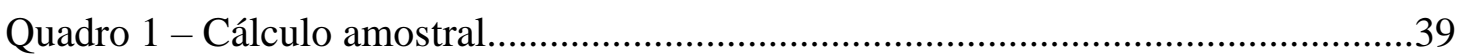




\section{LISTA DE TABELAS}

Tabela 1 - Risco cardiovascular de acordo com o índice ômega-3

Tabela 2 - Classificação de IMC de adultos e de idosos. 42

Tabela 3 - Classificação do risco de complicações metabólicas associados à circunferência abdominal de homens e mulheres

Tabela 4 - Ácidos graxos de membranas analisados no estudo .50

Tabela 5 - Atribuição de pontos de acordo com o risco global, para homens .52

Tabela 6 - Risco cardiovascular global em 10 anos, para homens .53

Tabela 7 - Atribuição de pontos de acordo com o risco global, para mulheres

Tabela 8 - Risco cardiovascular global em 10 anos, para mulheres. .54

Tabela 9 - Classificação do risco cardiovascular global em 10 anos de homens e mulheres segundo ERF.

Tabela 10 -Classificação do risco cardiovascular global em 10 anos de homens e mulheres segundo ERR .56

Tabela 11 - Classificação do risco cardiovascular global em 10 anos de homens e mulheres do ERR utilizada no estudo .56

Tabela 12 - Classificação do risco cardiovascular global em 10 anos de homens e mulheres segundo ACC/AHA (2013) utilizado no presente estudo .56

Tabela 13 - Caracterização clínica e sociodemográfica, segundo sexo. .60

Tabela 14 - Caracterização da composição corporal, segundo sexo 61

Tabela 15 - Caracterização dos nutrientes dietéticos, segundo sexo .62

Tabela 16 - Perfil de ácidos graxos de membrana eritrocitária, segundo sexo. .63

Tabela 17 - Caracterização bioquímica dos indivíduos dividida por sexo. .64

Tabela 18 - Frequência de fatores de risco cardiovascular, segundo sexo .65

Tabela 19 - Comparação de parâmetros clínicos e bioquímicos segundo tercis de ômega-3 total de membranas eritrocitárias .66 
Tabela 20 - Comparação de parâmetros clínicos e bioquímicos segundo tercis de ômega-6 total de membranas eritrocitárias. .68

Tabela 21 - Comparação de parâmetros clínicos e bioquímicos segundo tercis de Índice Ômega-3 total de membranas eritrocitárias .69

Tabela 22 - Comparação de parâmetros clínicos e bioquímicos segundo tercis da razão ômega-6/ômega-3 nas membranas eritrocitárias . .71

Tabela 23 - Cargas fatoriais dos padrões de ácidos graxos insaturados de membranas eritrocitárias

Tabela 24 - Correlações dos padrões de ácidos graxos insaturados de membranas eritrocitárias com diferentes escores de risco cardiovascular. .73

Tabela 25 - Associações dos ácidos graxos de membranas eritrocitárias com Escore de Risco da ACC/AHA 2013 .73

Tabela 26 - Associações dos ácidos graxos de membranas eritrocitárias com Escore de Risco de Reynolds. .74

Tabela 27 - Associações dos ácidos graxos de membranas eritrocitárias com Escore de Risco de Framingham. .75 


\section{INTRODUÇÃO}

\subsection{Epidemiologia das doenças cardiovasculares}

As doenças cardiovasculares (DCV) são definidas como um grupo de doenças que expressam disfunções cardíacas e/ou vasculares. As DCV causadas pela aterosclerose englobam a cardiopatia isquêmica, também chamada de doença arterial coronariana (DAC), a doença cerebrovascular e as doenças que acometem a aorta e outras artérias, como a hipertensão e a doença vascular periférica. As outras DCV incluem as cardiopatias congênitas, cardiopatias reumáticas, cardiomiopatias e arritmia cardíaca (American Heart Association - AHA, 2018).

Atualmente, as DCV representam 32\% da mortalidade no mundo, sendo a maior causa de mortes, superando a mortalidade por câncer e doenças do trato respiratório juntas. Das 17 milhões de mortes atribuíveis à DCV em 2013, a cardiopatia isquêmica foi responsável por 8,1 milhões das mortes, enquanto o acidente vascular encefálico isquêmico foi responsável por 3,3 milhões das mortes, evidenciando que a aterosclerose está associada a, aproximadamente, 67\% dos desfechos cardiovasculares fatais (ROTH et al., 2015). Para 2030, estima-se que as DCV sejam responsáveis por cerca de 23,6 milhões de mortes no mundo, representando um aumento de $40 \%$ na mortalidade atual (ROTH et al., 2015; AHA, 2018).

No Brasil, as DCV correspondem por $31 \%$ das causas de morte, sendo $31 \%$ atribuídas a cardiopatia isquêmica e 30\% às doenças cerebrovasculares, equivalendo a aproximadamente $42 \%$ das mortes por doenças crônicas não transmissíveis (World Health Organization -WHO, 2014; RIBEIRO et al., 2016). Esses dados mostram que as DCV permanecem sendo um grave problema de saúde pública mundial e que influenciam fortemente a expectativa de vida e a mobilização de recursos para prevenção e tratamento em todos os países.

O risco cardiovascular ( $\mathrm{RC})$ engloba fatores comportamentais e metabólicos. Os fatores comportamentais são: tabagismo, inatividade física, dietas hipercalórica, ricas em sódio e hiperlipídica e consumo excessivo de álcool. Os fatores de risco metabólicos abrangem pressão arterial sistêmica elevada (HAS - hipertensão), glicemia elevada (DM - diabetes mellitus), dislipidemias, sobrepeso e obesidade. Em conjunto, esses fatores de risco são classificados como fatores modificáveis ou 
controláveis. Existem também os fatores de risco não modificáveis, que incluem: sexo masculino, idade avançada e predisposição genética (AHA, 2018).

$\mathrm{Na}$ literatura científica é crescente o número de estudos sobre os fatores de risco cardiovascular não tradicionais. Alguns desses incluem os marcadores de inflamação crônica, como proteína $\mathrm{C}$ reativa, citocinas pró-inflamatórias, moléculas de adesão (ICAM-1 e VCAM-1), fibrinogênio, amiloide sérica A, homocisteína plasmática, lipoproteínas modificadas, frações de lipoproteínas, apolipoproteínas, lipoproteína (a)(Lp(a)), fosfolipase $\mathrm{A}_{2}$ associada à lipoproteína (Lp-PLA 2 ), marcadores de resistência insulínica e Índice Ômega-3 (IO3). Esses marcadores, no entanto, apresentam muitas inconsistências quanto ao impacto e a causalidade nos desfechos cardiovasculares (OPARIL E OBERMAN, 1999; HACKAM E ANAND, 2003; HARRIS E VON SCHACKY, 2004; SBC, 2017).

\subsection{Estimativas do risco cardiovascular absoluto}

É consenso que as DCV são um dos maiores problemas de saúde pública mundial. Pelo perfil insidioso, não é incomum o diagnóstico tardio dessas doenças. A identificação de fatores de risco modificáveis é primordial para a prevenção e tratamento da enfermidade. Inúmeros estudos mostram que os fatores de risco atuam de forma sinérgica no risco cardiovascular absoluto (WHO, 2011). Em função disso, equações que estimam o risco cardiovascular absoluto têm grande utilidade para relacionar intervenções com os eventos cardiovasculares e o custo-benefício dessas (D’AGOSTINO et al., 2008).

Os pesquisadores do estudo de Framingham foram os primeiros a desenvolver uma equação preditiva para estimar o RC (KANNEL et al., 1976). Esse algoritmo se mostrou um eficiente preditor de risco cardiovascular, porém, o HDL-C não fora incluído nas estimativas absolutas do risco. Posteriormente, os chamados fatores de risco clássicos de Framingham, como hipertensão arterial, hipercolesterolemia, HDLC baixo, diabetes mellitus, tabagismo, idade avançada e sexo masculino, foram validados como preditores do risco coronariano em uma projeção de 10 anos (WILSON et al., 1998). Posteriormente, o modelo preditivo de Framingham foi atualizado a fim de abranger todos os desfechos as doenças cardiovasculares, definidas então como eventos coronarianos (IAM, morte coronária, insuficiência coronária, angina), eventos cerebrovasculares (acidentes vasculares encefálicos isquêmicos e 
hemorrágicos e ataque isquêmico transitório), doença arterial periférica (claudicação intermitente) e insuficiência cardíaca (D’AGOSTINO, 2008). Nessa atualização também foi desenvolvido um escore que ao invés de utilizar os parâmetros laboratoriais de lipidograma utiliza IMC, e apresenta resultados semelhantes na predição eventos cardiovasculares (D’AGOSTINO, 2008). Apesar dessa estimativa de risco para $\mathrm{DCV}$, a interpretação desse escore não abrangia a singularidade do risco cardiovascular feminino. As mulheres apresentam fatores de risco para eventos cerebrovasculares, como a gravidez e terapia hormonal, apresentam maior prevalência de hipertensão em idades avançadas e diferentes benefícios e riscos associados à intervenções para reduzir os eventos em relação aos homens (MOSCA et al., 2011). Pelo fato de alguns estudos mostrarem que mulheres classificadas como risco moderado ou baixo ainda apresentavam mais eventos cardiovasculares que os homens, a atualização de 2011 das Diretrizes de Prevenção Cardiovascular em Mulheres da American Heart Association alteraram a forma de estratificação do risco em mulheres (MOSCA et al., 2011). A partir de então, as categorias de risco antigas parae mulheres $(<5 \%, 5 \%$ a $20 \%$ e $>20 \%)$ foram substituídas pelas categorias $<5 \%, 5 \%$ a $10 \%$ e $>10 \%$, além do acréscimo de histórico de pré-eclâmpsia, diabetes gestacional ou hipertensão induzida pela gravidez como fatores que colocam a mulher em maior RC. As mesmas classificações se mantiveram para os homens. O Escore de Risco de Framingham (ERF) tem caráter de prevenção primária, pois nos estudos não foram incluídos pacientes com evento cardiovascular prévio.

Em 1985, o Adult Treatment Panel (ATP) foi criado pelo National Cholesterol Education Program (NCEP) com o intuito de desenvolver diretrizes voltadas para a detecção, avaliação e tratamento da hipercolesterolemia em adultos, com foco na redução de LDL-C (TALWALKAR et al., 2013). O ATP-I enfatizou a prevenção primária da DAC em indivíduos com LDL-C alto (>160 mg/dL) ou então limítrofe (130-159 mg/dL), mas com mais de dois fatores de risco, e considera LDL-C <130 $\mathrm{mg} / \mathrm{dL}$ como ideal. Essa diretriz foca na dietoterapia, especificando a natureza da intervenção dependendo dos níveis de LDL-C. Recomenda-se realizar a farmacoterapia caso o LDL-C não fique abaixo dos níveis adequados após 6 meses de intervenção dietética.

Posteriormente, a diretriz do ATP-II teve como característica nova a prevenção secundária dos pacientes, utilizando categorizações do risco cardiovascular para 
determinar a intensidade do tratamento. Para cada grupo havia uma recomendação específica quanto ao LDL-C: $1^{\circ}$ ) para pacientes com $<2$ fatores de risco, o nível ideal de LDL-C é $<160 \mathrm{mg} / \mathrm{dL}$ para prevenção primária; $2^{\circ}$ ) para pacientes com $\geq 2$ fatores de risco, o nível ideal de LDL-C $<130 \mathrm{mg} / \mathrm{dL}$ para prevenção primária; $3^{\circ}$ ) em pacientes com evento cardiovascular prévio, o nível ideal de LDL-C passa a ser $<100$ $\mathrm{mg} / \mathrm{dL}$, com objetivo de prevenção secundária. Nessa diretriz foram acrescentados como fatores de risco cardiovascular o HDL-C baixo $(<35 \mathrm{mg} / \mathrm{dL})$ e triacilglicerois alto (TAG >200 mg/dL) (TALWALKAR et al., 2013).

A característica que mais distinguiu o ATP-III do ATP-I e ATP-II foi a utilização do Escore de Risco de Framingham para avaliar o risco cardiovascular em 10 anos. A diretriz recomenda que a intensidade da conduta terapêutica deve ser baseada no risco cardiovascular absoluto do paciente que é obtido através da aplicação do algoritmo. No ATP-III os pacientes são classificados em três grupos: baixo risco cardiovascular (pacientes com nenhum ou apenas um fator de risco); risco cardiovascular moderado (pacientes com dois fatores de risco ou mais e risco em 10 anos $\leq 20 \%$ ); e alto risco cardiovascular (pacientes com DAC ou risco equivalente e risco em 10 anos >20\%). Outros atributos relevantes são: pacientes com diabetes são classificados como alto risco cardiovascular; a mudança dos pontos de corte, para todos os adultos, de LDL-C para $<100 \mathrm{mg} / \mathrm{dL}$, HDL-C para $>40 \mathrm{mg} / \mathrm{dL}$ e TAG $<150 \mathrm{mg} / \mathrm{dL}$; e a introdução do colesterol não-HDL como alvo terapêutico em pacientes com síndrome metabólica e TAG $\geq 200 \mathrm{mg} / \mathrm{dL}$ (NCEP, 2002). Em sua atualização, em 2004, o ATP-III se mostrou mais agressivo com o tratamento hipolipemiante. Foi acrescentado o grupo de risco cardiovascular muito alto, que consiste em, além da presença estabelecida de doença cardiovascular, múltiplos fatores de risco (principalmente diabetes), fatores de risco graves e mal controlados (por exemplo, tabagismo), múltiplos fatores de risco da síndrome metabólica (principalmente $\mathrm{TAG} \geq 200 \mathrm{mg} / \mathrm{dL}$ associado à não-HDL-C $\geq 130$ $\mathrm{mg} / \mathrm{dL}$ e HDL-C $<40 \mathrm{mg} / \mathrm{dL}$ ) e pacientes com síndrome coronariana aguda. Para os pacientes que se encontram nesse grupo, a diretriz estabeleceu que LDL-C $<70 \mathrm{mg} / \mathrm{dL}$ seria ideal para cardioproteção. Os medicamentos hipolipemiantes, antes indicados somente para pacientes com LDL-C $\geq 130 \mathrm{mg} / \mathrm{dL}$, passaram a ser indicados como opção para pacientes que continuassem com LDL-C $\geq 100 \mathrm{mg} / \mathrm{dL}$ mesmo após mudanças terapêuticas de estilo de vida e dietoterapia. Essa atualização ressalta que, independentemente do nível de LDL-C do paciente, o controle dos fatores de risco 
modificáveis, como TAG, obesidade, sedentarismo, através de mudanças dietéticas e de estilo de vida é crucial para a diminuição de risco cardiovascular devido a mecanismos que agem além da diminuição de LDL-C (GRUNDY et al., 2004). Em 2013, houve atualização do ATP-III pela American College of Cardiology e American Heart Association (ACC/AHA). Essa diretriz foca mais no tratamento do risco cardiovascular absoluto e abrange o risco de todas as doenças cardiovasculares ateroscleróticas. Nessa atualização os alvos terapêuticos de LDL-C foram abandonados, sendo substituídos pelos tratamentos de intensidade moderada ou alta de estatinas, definidos como redução de $30 \%$ a $50 \%$ e mais de $50 \%$ do LDL-C, respectivamente. Para os pacientes com aterosclerose clínica ou com elevação primária de LDL-c (> $190 \mathrm{mg} / \mathrm{dL}$ ), a terapia de alta intensidade com estatinas é recomendada, assim como a combinação medicamentosa caso não atinja $50 \%$ de redução de LDL-C. Para as pessoas com o risco estimado em 10 anos maior que 7,5\% a terapia de intensidade moderada ou alta com estatina é recomendada, ao passo que para as pessoas com risco entre $5 \%$ e $7,5 \%$ a terapia de intensidade moderava deve ser levada em consideração. Outro diferencial dessa atualização foi a inclusão da etnia como fator de risco (GOFF et al., 2014; STONE et al., 2014).

O Escore de Risco de Reynolds (ERR), desenvolvido em 2007 a partir das coortes Women's Health Study e Physician's Health Study, evidenciou maior precisão na estimativa de risco cardiovascular em homens e mulheres quando histórico familiar de infarto do miocárdio prematuro (antes dos 60 anos) e proteína $\mathrm{C}$ reativa de alta sensibilidade (PCR) foram considerados (RIDKER et al., 2007; RIDKER et al., 2008). No ERR também há a predição do risco em 10 anos, porém as categorias de risco são: $<5 \% ; \geq 5 \%$ e $<10 \% ; \geq 10 \%$ e $<20 \% ; \geq 20 \%$. Nesses estudos, observou-se que, ao ser aplicado, o ERR reclassificou aproximadamente $30 \%$ das mulheres e aproximadamente $20 \%$ dos homens. Muitos que eram classificados como baixo ou moderado risco pelo ERF ou ATP-III acabaram sendo considerados pacientes de alto risco cardiovascular, demonstrando a importância dos fatores genéticos e inflamatórios na estimativa do risco. O ERR também tem desfechos mais ampliados em relação ao ERF e ATP-III, pois avalia, além dos riscos de mortalidade cardiovascular e infarto do miocárdio, os riscos de acidente vascular encefálico isquêmico e revascularização coronária. 
Um fator limitante nesses algoritmos é que eles foram validados em populações homogêneas dos Estados Unidos. Isso faz com que não necessariamente sejam adequados para outras populações, visto que fatores genéticos, culturais, dietéticos, de estilo de vida, e até econômicos interferem na eficácia dessas estimativas de risco cardiovascular (BAZO-ALVAREZ et al., 2015). Assim, é necessário que haja validação das equações de estimativa de risco cardiovascular para diferentes populações, utilizando fatores de risco que consigam agregar mais precisão nas estimativas.

\subsection{Lipídeos dietéticos e metabolismo de lipoproteínas}

Os fatores dietéticos exercem influência direta sobre o metabolismo das lipoproteínas, que, por sua vez, alteram a suscetibilidade dos indivíduos em relação à aterosclerose. Ácidos graxos, colesterol, fibras, fitosteróis, consumo de álcool e balanço energético da dieta são os principais componentes nutricionais capazes de modular os fatores de risco para doenças cardiovasculares. Apesar dos múltiplos compostos alimentares com potencial modulador, no presente estudo daremos foco aos componentes lipídicos.

O colesterol dietético tem sido associado ao aumento do risco cardiovascular devido seu efeito de aumentar o LDL-C e o colesterol total no plasma, mas os estudos não mostram relação com calcificação das artérias coronárias e com eventos cardiovasculares (KRATZ et al., 2005; BERGER et al., 2015; RHEE et al., 2017). Apesar de algumas diretrizes terem estabelecido um limite de consumo de colesterol de $300 \mathrm{mg} / \mathrm{dL}$ (LICHTENSTEIN et al., 2006) e também $200 \mathrm{mg} / \mathrm{dL}$ para proteção cardiovascular (JACOBSON et al., 2015), a diretriz Dietary Guidelines Advisory Committee, em 2015, decidiu retirar as recomendações de consumo de colesterol, devido à falta de evidências na literatura de que há modulação do risco cardiovascular através deste nutriente.

A quantidade do consumo de gorduras, os tipos de ácidos graxos na dieta e o balanço energético são os fatores dietéticos que têm maior impacto no metabolismo de lipoproteínas. Os ácidos graxos saturados (AGS) são os lipídeos mais abundantes na natureza e, consequentemente, nas dietas. Os AGS são encontrados principalmente em alimentos de origem animal. Tem sido mostrado na literatura que os AGS apresentam associações com aumento do colesterol total circulante, do LDL-C, e também da 
relação CT:HDL-C, aumentando o risco cardiovascular, porém ainda há resultados controversos, principalmente em estudos observacionais devido à falta de relação com eventos cardiovasculares. Muitos desses estudos pecam na metodologia porque não fazem ajustes por diversos fatores de confusão. Apesar dessas discordâncias, encontrase associação de AGS com risco cardiovascular quando há a substituição isocalórica por outros nutrientes com efeito neutro ou positivo na saúde cardiovascular. Muitos desses estudos fazem substituição por carboidratos com alto índice glicêmico, ocultando o real efeito dessa intervenção (SIRI-TARINO et al., 2010; RUIZ-NÚÑ̃Z et al., 2016; BRIGGS et al., 2017; BOWEN et al., 2018).

As ações entre esses ácidos graxos com a saúde cardiovascular são associadas, principalmente, aos ácidos láurico (C12:0), mirístico (C14:0) e o palmítico (C16:0), que têm maior efeito hipercolesterolêmico. Esses AGS elevam a colesterolemia por meio da diminuição da atividade, quantidade e expressão dos receptores hepáticos B/E de LDL, diminuindo o clearance dessa partícula, além de aumentarem o conteúdo de colesterol nas partículas LDL por causa da conformação química desses ácidos, possibilitando maior interação da lipoproteína com o colesterol (FERNANDEZ e WEST, 2005). Os AGS também aumentam a atividade da acil-colesterolaciltransferase 1 (ACAT-1) hepática, que transfere CE para as lipoproteínas contendo Apo B, aumentando também a secreção de VLDL (LEE e CARR, 2004).

Mais recentemente, tem sido descrito o papel modulador dos AGS na inflamação e estresse oxidativo. Os AGS são ligantes naturais do TLR4 e TLR2 (Toll-like receptors), que desencadeiam respostas inflamatórias de forma similar a lipopolissacarídeos (LPS). Os AGS são moduladores da microbiota intestinal, podendo causar disbiose e, posteriormente, endotoxemia, deflagrando respostas inflamatórias crônicas de baixa intensidade e estresse oxidativo. Com esse estímulo, os AGS acabam aumentando a quantidade de LDL eletronegativas [LDL(-)], LDL oxidadas (LDLox), óxidos de colesterol e fosfolipídeos oxidados no organismo, além de induzir apoptose de células endoteliais, induzindo e agravando o processo aterosclerótico (ROCHA et al., 2016). Outro mecanismo importante é a formação de ceramidas a partir dos AGS. As ceramidas participam intensamente da resistência à insulina e acúmulo de diacilglicerol (DAG) intracelular, que retroalimenta positivamente o processo inflamatório celular, causando distúrbios metabólicos que precedem as doenças cardiovasculares (KENNEDY et al., 2009; IGGMAN e RISÉRUS, 2011). 
O ácido graxo oleico (C18:1 n-9) possui somente uma insaturação, sendo denominado de ácido graxo monoinsaturado (AGM). É o AGM mais abundante e está presente em gorduras animais e em óleos vegetais, como de canola, de oliva e de palma. Existem associações com a redução de LDL-C e de risco coronariano quando AGS são substituídos por AGM. O enriquecimento das partículas de LDL com ácido oleico diminui a afinidade e ligação da partícula com proteoglicanos da camada íntima das artérias. Desse modo, o desenvolvimento da aterosclerose é diminuído (JONES et al., 2014). O ácido oleico contribui também para o aumento da atividade da lipase lipoproteica (LPL) que favorece a diminuição do TAG plasmático. Esse aumento na lipólise permite maior oferta muscular de ácido oleico e sua oxidação com possível efeito favorável na prevenção e controle da obesidade (BERGOUIGNAN et al., 2009).

Os ácidos graxos poli-insaturados (AGPI) são AG com mais de uma instauração na cadeia carbônica e os mais relevantes para a relação saúde e doença são os AG das famílias ômega-3 (n-3) e ômega-6 (n-6). Os AG n-6 são encontrados em carnes (ácido araquidônico - C20:4 n-6) e em óleos vegetais, como de cártamo, de milho, de soja, entre outros (ácido linoleico - C18:2 n-6). Já os ácidos graxos n-3 são encontrados em alimentos de origem vegetal, como óleo de soja e canola, e em sementes como linhaça (ácido $\alpha$-linolênico - ALA, C18:3 n-3), como também são encontrados em alimentos de origem marinha (ácido eicosapentaenoico - EPA, C20:5 n-3 - e ácido docosaexaenoico - DHA, C22:6 n-3), presentes em algas e peixes de águas frias (salmão e atum), mas também encontrados na sardinha e tucunaré. Os AG n-6 e n-3 de origem vegetal (C18:2 n-6 e C18:3 n-3) são essenciais, ou seja, não são sintetizados endogenamente, e, portanto, seu consumo é necessário.

\section{4.Ácidos graxos poli-insaturados, inflamação e doença cardiovascular}

Os AG n-3 têm ganhado importância devido sua associação inversa com a incidência de DCV. Esses ácidos graxos apresentam efeitos protetores contra DCV, e alguns mecanismos atribuídos a esses efeitos benéficos incluem o papel antiarrítmico, melhora da função autonômica, diminuição da agregação plaquetária e pressão arterial, melhora da função endotelial e vasodilatação, estabilização da placa de ateroma, redução da trigliceridemia, aumento da síntese de adiponectina, redução da deposição de colágeno nos vasos e, por último, ação anti-inflamatória (LAVIE et al., 2009). Apesar desses mecanismos mostrarem o papel cardioprotetor dos AG n-3, uma metaanálise recente com 77.917 pacientes classificados como alto risco cardiovascular 
mostrou que a utilização de suplementos de óleo de peixe contendo entre 226 e 1.800 mg de AG n-3 por dia, durante uma média de 4 anos, não apresentou associações significativa com desfechos cardiovasculares - entre esses, morte atribuída a DAC, infarto do miocárdio não fatal, algum evento coronário agudo ou eventos vasculares -, mostrando que não há evidências para o uso de óleo de peixe para prevenção secundária (AUNG et al., 2018). No entanto, um limitante do estudo foi que não foram avaliadas doses altas de óleo de peixe (acima de $3 \mathrm{mg} / \mathrm{dia}$ ). Outro limitante é que as doses de C20:5 n-3 e C22:6 n-3 variavam entre os estudos, dificultando avaliar o real benefício desses ácidos graxos, já que eles apresentam ações fisiológicas distintas.

Essas controvérsias mostram que novos estudos envolvendo AG n-3 devem ser realizados.

\subsubsection{Biossíntese de ácidos graxos poli-insaturados}

A biossíntese de AG ocorre no compartimento extramitocondrial por enzimas chamadas ácido graxo sintetases. O processo envolve a combinação sequencial de unidades de acetil-CoA com uma sucessão de moléculas de malonil-CoA (STRANDBERG et al., 2014; PARK et al., 2016). Esse processo ocorre predominantemente no fígado e é menos ativo em outros tecidos. Nos mamíferos, o ácido palmítico (C16:0) é o resultado da síntese endógena de ácidos graxos. A partir de C16:0 é possível sintetizar outros AG por meio da elongação de cadeia e, que ocorre na via microssomal através da elongase, e também é possível gerar AG insaturados através das dessaturases, processo que ocorre predominantemente nas membranas do retículo endoplasmático. No fígado, as dessaturações são realizadas

pelas enzimas $\Delta^{9}, \Delta^{6}, \Delta^{5}$ e $\Delta^{4}$, que estão envolvidas na dessaturação das famílias do ácido palmitoleico (C16:1 n-7), do C18:1 n-9, do C18:2 n-6 e do C18:3 n-3 (Figura 1) (STRANDBERG et al., 2014; PARK et al., 2016). Estima-se que, em humanos, a taxa de conversão de ALA para EPA seja de $0,2 \%$ a $21 \%$ e para DHA seja de $<0,01 \%$ a 10\% (BAKER et al., 2016). As famílias de n-3, n-6 e n-9 competem entre si pela afinidade das dessaturases, principalmente pela $\Delta^{6}$, que é uma etapa limitante. Geralmente as enzimas exibem uma afinidade mais elevada por substratos mais altamente insaturados, sendo a ordem de preferência: família n-3 > família n-6 > família n-9 > família n-7> família do ácido elaídico (n-9, trans). Por causa dessa competição natural entre os ácidos graxos essenciais pela dessaturação e elongação, cada classe pode interferir no metabolismo da outra, e, consequentemente, impactar na 
resposta biológico de um determinado AG. Também é possível que ocorra, nos peroxissomos, um fenômeno chamado retroconversão. Neste fenômeno, ocorre o encurtamento da cadeia carbônica dos produtos finais da cadeia de biotransformação (Figura 1) em um AG antecessor, gerando, por exemplo, EPA a partir de DHA e ácido araquidônico a partir de ácido docosapentaenoico n-6 (DPA n-6) (STRANDBERG et al., 2014; PARK et al., 2016).

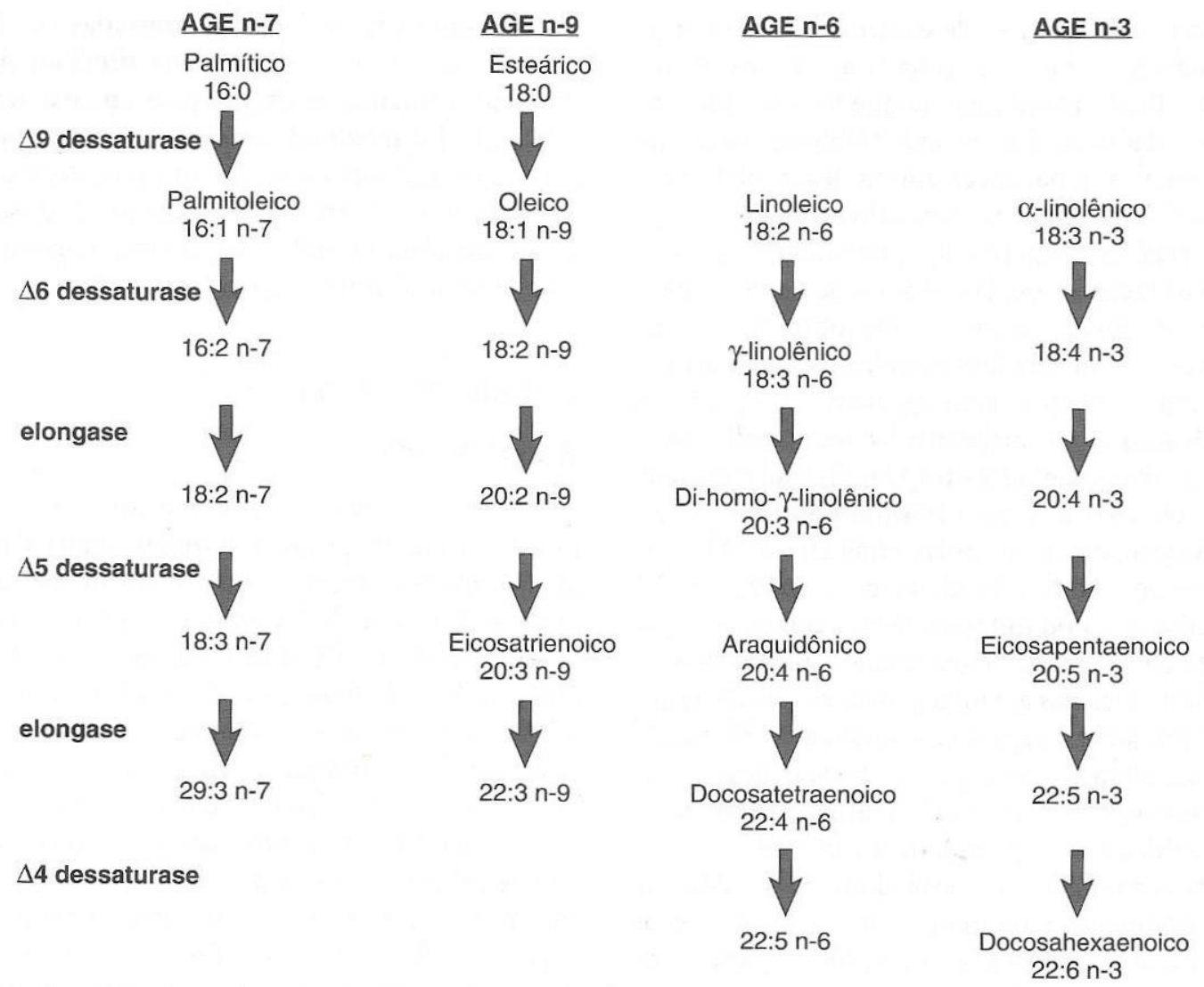

Figura 1 - Síntese e biotransformação dos ácidos graxos. Fonte: JONES, P. J. H.; RIDEOUT, T. Lipídios, esteróis e seus metabólitos. In: ROSS, A. C. et al. Nutrição Moderna de Shils na Saúde e na Doença, $11^{\text {a }}$ ed., Barueri, SP. Manole, 2016. p.65-85.

1.4.2. Incorporação de ácidos graxos poli-insaturados na membrana celular e biossíntese de eicosanoides

Sabe-se que os distintos tipos de ácidos graxos modulam diferentes vias metabólicas. O C18:2 n-6 e o C18:3 n-3, quando ingeridos, têm uma proporção que é oxidada para geração de energia, até mais rapidamente que os ácidos graxos saturados ou monoinsaturados, enquanto a outra parte é distribuída entre os TAG e lipídeos estruturais das membranas celulares. Uma parcela menor é biotransformada em outros AGPI, conforme descrito na Figura 1. Em relação ao C18:3 n-3 e ao C18:2 n-6, os 
AGPI de cadeia longa, como o C20:4 n-6, C20:5 n-3 e C22:6 n-3, apresentam uma tendência de se incorporarem nos lipídeos estruturais em vez de fornecerem energia. Portanto, a composição tecidual final é o resultado dos processos de biossíntese de AGPI juntamente com fatores dietéticos. Essa composição lipídica, por sua vez, acaba influenciando diretamente a estrutura e função celular (ARTERBURN et al., 2006).

Existe uma grande quantidade de AGPI nos fosfolipídeos das membranas celulares. O ácido araquidônico é o AGPI mais abundante nos fosfolipídeos, seguido pelos AG n-3, sendo o C20:5 n-3 e o C22:6 n-3 os mais abundantes dessa família. Pelo alto teor de AGPI, os fosfolipídeos de membrana celular são altamente vulneráveis à lesão oxidativa (DRAPER, 1990). A peroxidação dos lipídeos incorporados às membranas celulares resulta em perda de AGPI, menor fluidez e maior permeabilidade a substâncias como $\mathrm{Ca}^{2+}$, afetando a função das enzimas acopladas às membranas. A lesão oxidativa continuada pode causar a perda da integridade da membrana e levar a morte celular. A dieta, portanto, se mostra capaz de modular a função da membrana celular e sua peroxidação através da ingestão de ácidos graxos insaturados, vitamina $\mathrm{E}$ e outros compostos antioxidantes. Existe uma tendência de os ácidos graxos altamente insaturados presentes nos óleos de peixe serem mais suscetíveis à peroxidação lipídica das membranas celulares, provavelmente pelo fato do óleo ter um conteúdo baixo de vitamina E, que previne essas modificações (DRAPER, 1990; GIRELLI et al., 1994).

Nas membranas plasmáticas das células existem microdomínios funcionais chamados lipid rafts. Essas estruturas apresentam grande quantidade de colesterol, esfingolipídeos e fosfolipídeos ricos em AGS, e têm uma grande concentração de proteínas que atuam no início e propagação de sinalização celular, incluindo diversos receptores imunológicos que medeiam respostas quimiotáticas e inflamatórias. TLR2, TLR4, receptores de imunoglobulina E (IgE), CD14, CD36, CD90 e receptores de LDLox são algumas proteínas que se localizam nas lipid rafts. Quando há a ativação de uma proteína acoplada nesses microdomínios, ocorre transdução de sinal para as outras proteínas nas proximidades, causando ativação destas e amplificando a sinalização das respostas imunológica e inflamatória (KARNOVSKY et al., 1982; XAVIER et al., 1998; JANES et al.; 1999; SIDDIQUI et al., 2007; SEZGIN et al., 2017). A incorporação de AG n-3 nas membranas pode alterar as características das lipid rafts. Pelo fato do domínio ser rígido, os AGPI podem aumentar a fluidez - que diminui a formação de lipid rafts na membrana - alterando a forma, estabilidade e 
composição das proteínas sinalizadoras, diminuindo a transdução de sinal que intensifica a resposta inflamatória da célula e, consequentemente, controlando a inflamação (AHMED et al., 1997; STULNIG et al., 1998; STULNIG et al., 2001; SIDDIQUI et al., 2007).

Os AGPI podem se deslocar da membrana e ficar disponíveis no interior da célula por meio da enzima fosfolipase $\mathrm{A}_{2}\left(\mathrm{PLA}_{2}\right)$, que é ativada por estímulos antigênicos pró-inflamatórios, como lesão celular, estresse oxidativo e lipopolissacarídeos oriundos de microorganismos patogênicos (FITZGERALD, 2003). Esses ácidos graxos desacoplados podem ser transformados em diferentes metabólitos intracelulares e extracelulares que desempenharão funções importantes de sinalização celular. Entre os metabólitos extracelulares gerados estão os eicosanoides, como leucotrienos (LT), tromboxanos (TXA), prostaciclinas (PGI) e prostaglandinas (PGE), que modulam a resposta inflamatória (CALDER, 2015).

Os eicosanoides são derivados de AG de 20 carbonos das famílias n-6 e n-3, sendo que os principais substratos são o C20:4 n-6 e o C20:5 n-3. Esses dois ácidos são bioconvertidos em eicosanoides por dois tipos de enzimas: a lipoxigenase (LIPOOX) ou as cicloxigenases (COX). As PGE, PGI e os TXA são produzidos através das COX, enquanto os LT são produzidos pela LIPOOX. A LIPOOX também dá origem aos hidroxiácidos, como por exemplo hidroxieicosatetraenoico (HETE), o hidroxiperoxieicosatetraenoico (HPETE), que desempenham funções importantes na regulação da resposta inflamatória. Cada metabólito oriundo da LIPOOX apresenta atividades específicas, como capacidade de promover adesão e quimiotaxia de leucócitos, fagocitose, liberação de espécies reativas de oxigênio, entre outras. Já os metabólitos gerados via COX apresentam atividades como controle da vasodilatação ou vasoconstrição, broncodilatação, ativação de células polimorfonucleares, agregação plaquetária, entre outras. Todos os eicosanoides são classificados de acordo com as "séries", que determinam suas funções. Os eicosanoides de série par (2 e 4) são gerados a partir de AG n-6, enquanto os ímpares (3 e 5) são oriundos majoritariamente de AG n-3 (Figura 2). Os eicosanoides de série par desempenham papéis na deflagração da resposta inflamatória, enquanto os de série ímpar desempenham ações anti-inflamatórias. Portanto, o consumo regular de AG n-3 tem potencial modulador da resposta inflamatória e imunológica através de seus mediadores lipídicos sintetizados endogenamente (CAMPOS et al., 2002; CALDER, 2015). 
Os AGPI n-3 também originam outros mediadores lipídicos, além dos mencionados anteriormente. O ácido 15-hidroxieicosapentaenoico (15-HEPE), derivado do C20:5 n-3, e o ácido 17-hidroxidocosaexanoico (17-HDHA), derivado do C22:6 n-3, são potentes inibidores de leucotrienos pares (CAMPOS et al., 2002; CALDER, 2015). As resolvinas participam do controle local da inflamação, inibindo a ativação e a migração de leucócitos polimorfonucleares durante a fase de resolução, possivelmente através da diminuição da atividade do NF-кB (SERHAN et al., 2002; BANNENBERG et al., 2005; ARITA et al., 2006) As resolvinas da série E, oriundas de C20:5 n-3, estão associadas à redução do número de leucócitos e dos níveis das citocinas IL-6 e TNF- $\alpha$. As resolvinas da série D e a protectina D1 são derivadas de C22:6 n-3. A protectina D1 exerce potentes efeitos anti-inflamatórios, como redução da transmigração endotelial de neutrófilos e redução de citocinas pró-inflamatórias. A protectina D1 está associada à potente redução da transcrição do gene de IL-1 $\beta$ estimulada pelo TNF- $\alpha$ (HONG et al., 2003).

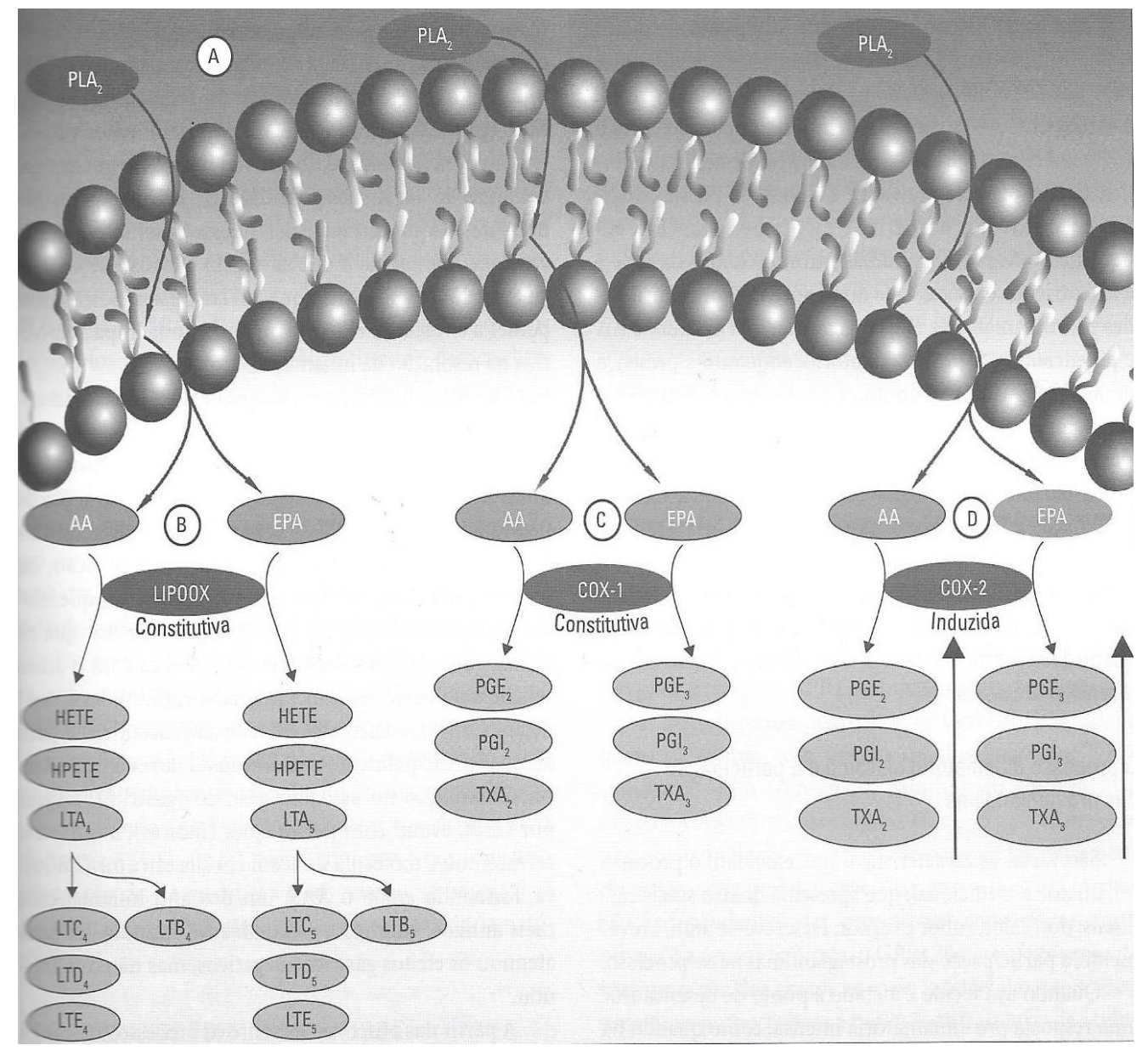


Figura 2 - Biossíntese de eicosanoides derivados de ácidos graxos poli-insaturados ômega-6 e ômega-3. A: A enzima fosfolipase A2 (PLA2) removendo dos fosfolipídeos moléculas de AG para o interior celular. B: Conversão de AGPI em eicosanoides pela LIPOOX. C: Conversão de AGPI em eicosanoides pela COX-1. D: Conversão de AGPI em eicosanoides pela COX-2. Essa enzima é induzida por estresse tecidual. AA: ácido araquidônico; COX: cicloxigenase; EPA: ácido eicosapentaenoico; HETE: hidroxieicosatetraenoico; HPETE: hidroxiperoxieicosatetraenoico; LT: leucotrienos; PGE: prostaglandina; PGI: prostaciclina; PLA2: fosfolipase A2; TXA: tromboxano. Fonte: CINTRA, D. E. et al. Ácidos graxos poli-insaturados. In: COMINETTI, C. et al. Genômica Nutricional: dos Fundamentos à Nutrição Molecular. Barueri, SP. Manole, 2017. p.128-147.

\subsection{3. Ácidos graxos poli-insaturados e expressão gênica}

Anteriormente acreditava-se que os efeitos que os AG n-3 exerciam seu papel somente devido à produção de eicosanoides, porém hoje se sabe os AGPI em geral são ligantes de vários receptores que podem alterar diversas vias metabólicas e inflamatórias.

Os receptores de membranas acoplados à proteína G (GPCR, do inglês, G proteincoupled receptor) são ligantes de várias moléculas, como hormônios, neurotransmissores, peptídeos e esteroides, e participam de vários processos de sinalização celular. Alguns desses GPCR foram reconhecidos como ligantes de ácidos graxos. Os ácidos graxos de cadeia curta são ligantes da GPR41 e GPR43, os de cadeia média de ligam ao GPR84 e os de cadeia longa se ligam ao GPR40 e GPR120. O receptor GPR120 tem afinidade, em ordem decrescente, pelos ácidos graxos C22:6 n-3, C20:5 n-3, C16:1 n-7 e C18:1 n-9, e parece transportá-los para o meio intracelular. Os ácidos graxos n-6 não são ligantes desse receptor (OH et al., 2010).

Quando há sinalização pró-inflamatória relacionada à citocinas e TLR4, as proteínas 1 e 2 de ligação a TAK-1 (TAB-1 e TAB-2) são recrutadas para o citosol e fosforilam a quinase 1 ativada pelo fator de transformação do crescimento beta (TAK1). A TAK-1, por sua vez, fosforila a quinase do inibidor de kappa B (IKK), que posteriormente estimula o NF-кB (ADHIKARI et al., 2007). Quando o GPR120 é ativado pelos AG n-3, antes da captação celular, há uma resposta intracelular de deslocamento da proteína beta arrestina-2, que se liga com o receptor internalizando-o juntamente com seu ligante. A beta arrestina-2, nesse processo se liga com as proteínas TAB-1 TAB-2 que estavam no complexo proteico inflamatório, evitando 
que a TAK-1 seja fosforilada. Portanto, através deste mecanismo, os AG n-3 são capazes de inibir a resposta inflamatória inibindo a TAK-1, que age de forma central na inflamação (OH et al., 2010).

A proteína de ligação ao elemento regulatório de esterol (SREBP) é um fator de transcrição responsável por regular a expressão de genes hepáticos envolvidos no metabolismo de ácidos graxos (SREBF1) e na colesterogênese (SREBF2). A proteína apresenta três isoformas: SREBP-1c, SREBP-1a e SREBP-2. O gene SREBF1 sintetiza as proteínas SREBP-1c e 1a, que estão envolvidas na lipogênese e, essa última, também na colesterogênese. Já a SREBP-2 está envolvida somente na colesterogênese. A SREBP é sintetizada como zimogênio e se encontra na membrana do retículo endoplasmático acoplada à proteína ativadora da clivagem da SREBP (SCAP) e à proteína Insig (insulin-induced gene 1 protein). Em situações de baixas concentrações de esteróis ou alta concentração de insulina, a Insig é dissociada do complexo, que é translocado para o aparelho de Golgi via transportador vesicular. No Golgi, a SREBP dissocia-se da SCAP, desencadeando duas clivagens proteolíticas que acabam liberando o fragmento ativo da SREBP, que é responsável por ligar-se ao elemento de resposta na região promotora dos genes alvos (HORTON, 2002). Os AGPI n-3 são capazes de reduzir a atividade da proteína SREBP-1c por inibirem a expressão gênica de SREBF1 e a clivagem proteolítica no retículo endoplasmático, reduzindo, então, a lipogênese (XU et al., 1999; DAVIDSON, 2006). Os AG n-3 são capazes de inibir a expressão de SREBPF2, genes codificantes do receptor de LDL ( $L d l r)$, da HMG-CoA redutase (Hmgcr) e da ácido graxo sintase (Fas), consequentemente influenciando, além da lipogênese, a colesterogênese (KIM et al., 1999).

Os receptores ativados por proliferadores de peroxissomo (PPAR) pertencem à superfamília dos receptores nucleares induzidos por ligantes. Os PPAR apresentam papel importante na regulação gênica do metabolismo de ácidos graxos e são encontrados em diversos tecidos, na forma de três isotipos: PPAR- $\alpha$, PPAR- $\gamma$ e PPAR$\beta / \delta$. Os AGPI são ligantes naturais dos PPAR, assim como seus eicosanoides e ácidos graxos oxidados. Após a ligação dos ácidos graxos ou de seus metabólitos no sítio de ligação do PPAR, ocorre uma mudança na conformação do receptor que resulta na heterodimerização com o receptor de retinoide $\mathrm{X}(\mathrm{RXR})$. $\mathrm{O}$ heterodímero PPAR-RXR então é ligado ao elemento de resposta ao proliferador de peroxissomo (PPRE) que fica na região promotora do respectivo gene alvo, ativando o recrutamento de 
coativadores e o desligamento de correpressores, que resulta na transcrição gênica (GEORGIADI E KERSTEN, 2012). Por um mecanismo chamado transrepressão os PPAR reprimem a expressão de outros genes interferindo negativamente com outros fatores de transcrição. $\mathrm{O}$ NF-אB e a proteína ativadora 1 (AP-1) são fatores de transcrição de genes pró-inflamatórios que são transreprimidos pelos PPAR (RICOTE E GLASS, 2007).

O PPAR- $\alpha$ age no catabolismo lipídico, regulando indiretamente o metabolismo glicídico e a sensibilidade à insulina. Esse fator de transcrição é expresso nos tecidos muscular, cardíaco, renal e, principalmente, hepático. Os AG n-3 têm mais eficiência que os AG n-6 para ativar esse fator de transcrição. Pelo fato de estimular a betaoxidação dos ácidos, a ativação do PPAR- $\alpha$ acaba reduzindo o substrato para a produção hepática de VLDL, além de estimular a degradação de Apo B e a atividade da enzima LPL, aumentando ainda mais a disponibilidade de ácidos graxos para a oxidação no fígado e no músculo esquelético (DAVIDSON, 2006). O PPAR- $\alpha$ ainda apresenta ação anti-inflamatória pelo fato de reprimir a expressão dos genes das vias NF- $\kappa$ B e AP-1 (RICOTE E GLASS, 2007).

A função do PPAR- $\beta / \delta$ ainda não foi bem estabelecida, porém sugere-se que esteja envolvido na regulação da adipogênese, diferenciação de adipócitos, regulação do metabolismo lipídico e também do gasto energético. Os AG n-3 são os principais ativadores desse fator de transcrição, que, por sua vez, aumenta a expressão da proteína desacopladora 3 (UCP3) no músculo esquelético, da UCP2 no tecido adiposo branco e da UCP1 no tecido adiposo marrom. Essas proteínas estão relacionadas à termogênese, portanto, a ativação do PPAR- $\beta / \delta$ pelos $A G$ n-3 pode ser útil para a diminuição de gordura corporal (MADSEN et al., 2005).

O PPAR- $\gamma$ está relacionado a processos de lipogênese e adipogênese, já que seus genes-alvos incluem proteínas transportadoras de ácidos graxos (FATP), acil-CoA sintase e LPL. Os processos de hipertrofia e hiperplasia do tecido adiposo induzidos pela dieta hiperlipídica estão associados à ativação do PPAR- $\gamma$. Esse fator de transcrição pode participar do desenvolvimento de aterosclerose estimulando a captação de LDLox e ácidos graxos oxidados no endotélio e nos macrófagos, porém o PPAR- $\gamma$ também estimula, nos macrófagos, a expressão de ABCA-1, que participa do transporte reverso de colesterol (MADSEN et al., 2005). O PPAR- $\gamma$ também modula o metabolismo glicídico pelo fato de induzir a expressão do transportador de glicose 4 
(GLUT-4) e sua translocação para a membrana plasmática, assim como induz a expressão de adiponectina, importante adipocina que participa da sensibilização insulínica. De modo semelhante aos outros PPAR, o PPAR- $\gamma$ participa da

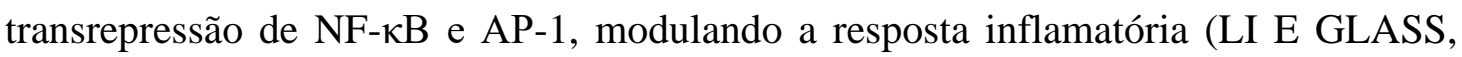
2004).

Os AG n-3 também são capazes de modular a resposta ao estresse oxidativo. O fator de transcrição nuclear eritroide 2 relacionado ao fator 2 (Nrf2) é o principal regulador da resposta oxidativa. Essa proteína permanece ligada à proteína KEAP1 (kelch-like ECH-associated protein 1) no citoplasma. Quando ocorre o estresse oxidativo, o Nrf2 é liberado e translocado ao núcleo, onde forma um heterodímero com outros fatores de transcrição. Na forma de heterodímero ocorre a ligação ao elemento de resposta da região promotora de genes alvos ligados à defesa antioxidante, como a NADPH quinona oxirredutase (NQO1), a heme oxigenase 1 (HO-1) e a gama-glutamato cisteína ligase (GCLM) (VOMHOF-DEKREY E PICKLO, 2012). Estudos mostram que no período pós-prandial, os AG n-3 induzem a ativação de Nrf2 e, consequentemente, a expressão de HO-1, diminuindo quantidade de substâncias oxidantes. Essa ativação de Nrf2 é feita por 4-hidroxihexenal (4-HHE), que é um produto da peroxidação lipídica do C20:5 n-3 e C22:6 n-3 que tem concentração aumentada após ingestão desses AG (ISHIKADO et al., 2013). Dessa forma, a peroxidação lipídica de AG n-3 acaba sendo um fator protetor contra 0 estresse oxidativo, podendo a ingestão habitual de C20:5 n-3 e C22:6 n-3 agir positivamente contra as agressões oxidantes causadas pela disfunção metabólica, mantendo a integridade do tecido vascular (YANG et al., 2013; LEE et al., 2015).

Portanto, considerando as diversas vias metabólicas, oxidativas e inflamatórias moduladas pelos AG da série n-3 ao nível celular e molecular, é plausível que esses exerçam papel cardioprotetor do ponto de vista preventivo, assim como sejam potenciais agentes nutricionais usados no manejo dos fatores de risco cardiometabólicos na prevenção secundária.

\section{2. Ácidos graxos das membranas eritrocitárias como preditores de risco cardiovascular}

Embora estudos experimentais (in vitro e in vivo), observacionais e ensaios clínicos mostrem que os AGPI da série n-3 têm o potencial de modular diversas vias 
metabólicas, não existe consenso na literatura quanto ao seu papel preventivo e o adjuvante ao tratamento das DCV (ENNS et al., 2014; LARSSON e WOLK, 2017; RIZOS et al., 2017; AUNG et al., 2018).

Diversos fatores podem estar associados à inconsistência e limitação na comparação entre esses estudos, a saber: I - estado basal de AGPI não é considerado; II - tempo de intervenção; III - tipo e dose de AG n-3 administrado; IV - uso de fármacos; V - risco cardiovascular basal dos pacientes; VI - utilização de diversos parâmetros bioquímicos de inflamação. Além dessas possibilidades, o monitoramento do consumo, incorporação celular e biodisponibilidade do n-3 representam um relevante diferencial aos estudos envolvendo esses AGPI. Enquanto a avaliação do consumo alimentar, seja por meio do recordatório de 24 h (R24h), registro alimentar de três ou mais dias (RA) ou questionário de frequência alimentar (QFA), envolve vieses de informação - tais como dependência da memória do entrevistado, subrelatos, não refletir hábitos e inexatidão das quantidades (THOMPSON et al., 2010) -, a avaliação da incorporação celular, se apresenta como uma medida livre de interferência individual, capaz de estimar de modo objetivo e direto o consumo habitual de AGPI.

Além dessas características, a incorporação de AGPI sofre influência direta do turnover celular e do padrão dietético. Portanto, as associações e efeito metabólico e celular dos AGPI da série n-3 sofrem múltiplas e complexas influências que podem determinar sua eficácia biológica e seu impacto na prevenção dos fatores de risco cardiometabólicos e na prevenção das DVC.

Baseado nisso, o uso de biomarcadores de consumo que possam refletir o hábito alimentar e sua potencial influência no contexto das DVC tem sido proposto na literatura. Assim, o presente estudo tem como foco a investigação da associação dos AG n-3 incorporados às membranas dos eritrócitos com fatores de risco cardiometabólicos e na estimativa global do risco cardiovascular.

O índice ômega-3 (IO3) é a soma dos percentuais de C20:5 n-3 e C22:6 n-3 presentes nas membranas eritrocitárias. Esse indicador foi proposto como fator de risco cardiovascular por HARRIS e VON SCHACKY (2004). Nesse estudo foi demonstrado que os indivíduos apresentavam risco cardiovascular alto quando o IO3 era baixo, e o aumento desse marcador favoreceu a proteção cardiovascular (Tabela 
1). A composição de $A G$ dos fosfolipídeos das membranas celulares de diversos tecidos é alterada de acordo com a ingestão dietética e fatores metabólicos. Assim, o IO3 parece ser um útil biomarcador de consumo habitual desses ácidos graxos, pois o tempo de vida do eritrócito é de 120 dias. Dessa forma, o IO3 apresenta menos variabilidade que biomarcadores de AG do plasma, podendo apresentar resultados mais consistentes de biodisponibilidade desses nutrientes (HARRIS e VON SCHACKY, 2004).

Tabela 1 - Risco cardiovascular de acordo com o índice ômega-3.

\begin{tabular}{cc}
\hline Índice ômega-3 & Risco cardiovascular \\
\hline$<4 \%$ & Elevado \\
$\geq 4 \% \mathrm{e}<8 \%$ & Moderado \\
$\geq 8 \%$ & Baixo \\
\hline
\end{tabular}

Fonte: HARRIS e VON SCHACKY (2004).

Os requerimentos para se considerar um fator de risco cardiovascular incluem evidência epidemiológica consistente, um mecanismo de ação plausível, boa reprodutibilidade, modificabilidade, independência de fatores de risco clássicos e influência no número de eventos cardiovasculares. Apesar do IO3 atender muitos desses critérios, ainda existem inconsistências nos estudos, devido à escassez de padronização dos métodos de extração e análise de ácidos graxos (HARRIS E VON SCHACKY, 2004).

Diversos estudos corroboram a hipótese de que a elevada quantidade de C20:5 n-3 e C22:6 n-3 nos fosfolipídeos é fator protetor das DCV. BLOCK et al. (2008), em um estudo caso-controle envolvendo 768 indivíduos, avaliaram os ácidos graxos nos fosfolipídeos das membranas eritrocitárias de pacientes com síndrome coronariana aguda e observaram que esses indivíduos apresentavam menores quantidades de C20:5 n-3 e C22:6 n-3 incorporadas às membranas que o grupo controle. O baixo índice ômega-3 foi associado a menor concentração de HDL-C, e maior concentração de LDL-C e TG no plasma. Um resultado importante foi que o aumento de $1 \%$ do IO3 foi associado à redução do risco de síndrome coronariana aguda em $23 \%$. Interessantemente, no grupo controle apenas $1 \%$ dos pacientes que não relataram uso 
óleo de peixe apresentaram IO3 maior que 8\%, à medida que aqueles que relataram uso do suplemento, somente 17\% tinham o IO3 nessa faixa. Em conformidade com esses resultados, um IO3 maior que $8 \%$ dificilmente será atingido por meio da alimentação ou até mesmo suplementação nutricional; fato que sugere que o cut-off proposto anteriormente possa ser revisitado.

Os AG n-6, juntamente AG n-3, incorporados às membranas eritrocitárias também parecem diminuir o risco cardiometabólicos. Foi demonstrado que em pacientes com síndrome metabólica há menor grau de instauração das membranas por meio da razão AGPI/AGS, e menores quantidades de AG n-6 e n-3, comparados ao grupo controle. Além disso, a instauração e as quantidades de AGPI total, AG n-6 e AG n-3 presentes nas membranas apresentaram associação positiva com HDL-C no plasma, enquanto os AGS presentes nas membranas foram associados inversamente, mostrando que o consumo de AGPI é um fator protetor (COLUSSI et al., 2015a). O conteúdo de AG n3 nas membranas maior ou igual a 7\% também foi relacionado com a redução da pressão arterial e espessura das camadas íntima e média das carótidas em pacientes hipertensos (COLUSSI et al., 2014a; COLUSSI et al., 2014b; COLUSSI et al., 2015b). Em homens e mulheres com mais de 65 anos, o IO3 foi associado inversamente com TG e com a razão CT/HDL-C, assim como foi associado positivamente com HDL-C, havendo mais relevância em pacientes com índice maior que 8\% (FERGUSON et al., 2015).

Ao investigarem desfechos cardiovasculares em pacientes da coorte Ludwigshafen Risk and Cardiovascular Health Study (LURIC), KLEBER et al. (2016) constataram que C20:5 n-3, C22:6 n-3 e o IO3 se associaram inversamente com a mortalidade cardiovascular. Os autores mostraram que C20:5 n-3 reduziu significantemente a mortalidade quando sua quantidade foi superior a $1 \%$ nas membranas. Entretanto, o conteúdo de C18:3 n-3 apresentou associação inversa somente com mortalidade geral. A quantidade de cerca de 1\% de C20:5 n-3 nas membranas eritrocitárias foi associada inversamente com o conteúdo lipídico e estabilização das placas de ateroma nas carótidas de idosos com alto risco cardiovascular (BARGALLÓ et al., 2017). O C20:5 n-3 nas membranas também foi eficiente para predizer a mortalidade em pacientes que já tiveram evento cardiovascular, e a quantidade maior de 1\% de C20:5 n-3 também foi associada à redução do risco de evento em 48\% (HARRIS et al., 2013). Em pacientes que realizaram endarterectomia carotídea, a incorporação de C20:5 n-3 nos 
fosfolipídeos das placas ateroscleróticas se associou ao reduzido número de células espumosas, maior instabilidade da placa, menor inflamação, número de células $\mathrm{T}$ e expressão de metaloproteinases (MMP)-7, MMP-9 e MMP-12, IL-6 e ICAM-1 (CAWOOD et al., 2010). O consumo diário de 250 mg C20:5 n-3 e C22:6 n-3 em peixes foi associado à redução de até $36 \%$ da mortalidade por doença coronariana. Esse papel cardioprotetor foi atribuído à modulação positiva das concentrações de lipoproteínas plasmáticas, e diminuição da pressão arterial, da coagulação, melhora da função vascular e também das respostas inflamatórias (JUNG et al., 2008; MOZAFFARIAN, 2008). Com essa dose provavelmente o IO3 ficaria entre 6\% e $8 \%$ (HARRIS E VON SCHACKY, 2004). 


\section{JUSTIFICATIVA E HIPÓTESE}

Apesar das evidências científicas relacionadas à modulação de fatores de risco cardiovascular envolvendo os AG n-3, conforme demonstrado por estudos in vitro, em animais e ensaios clínicos, ainda existem inconsistências, que são encontradas principalmente em estudos de natureza epidemiológica. Não há ainda consenso sobre a dose de AG n-3, nem proporção adequada desses com outros AG capazes de promover redução do risco cardiovascular.

Os inquéritos alimentares, ferramentas tradicionalmente utilizadas para avaliação dietética, contêm vieses e podem estimar erroneamente o consumo de nutrientes, principalmente de AG. Como a maioria dos estudos clínicos se apoia nessas ferramentas, as medidas de associação dos AG dietéticos com as DCV podem estar enfraquecidas ou equivocadas devido a avaliação dietética imprecisa. Desta forma, a utilização de biomarcadores de $\mathrm{AG}$ n-3 pode reduzir os vieses associados aos inquéritos alimentares pelo fato de refletirem o estado nutricional desses AG de maneira mais objetiva. Além disso, a utilização desses biomarcadores facilita a compreensão da relação dos AG n-3 com o metabolismo lipídico, estresse oxidativo e inflamação. Como muitos desses parâmetros têm estreita relação com a fisiopatologia da aterosclerose, elementos associados com esses fatores poderão adquirir grande importância clínica. E através da associação dos AG n-3 de membranas eritrocitárias com escores de risco cardiovascular também é possível observar a influência que esses nutrientes têm na predição dos eventos cardiovasculares.

Tendo por base as evidências científicas e a justificativa do presente projeto de pesquisa, as hipóteses que nortearam a proposta foram:

I- Indivíduos com menor conteúdo de AG n-3 nas membranas eritrocitárias apresentarão um perfil mais aterogênico mensurado por parâmetros bioquímicos de inflamação, estresse oxidativo e metabolismo lipídico, além de perfil antropométrico de risco (sobrepeso ou obesidade).

II- Indivíduos com menor conteúdo de AG n-3 nas membranas eritrocitárias apresentarão classificação do risco cardiovascular global menos favorável. 


\section{OBJETIVO}

O presente estudo objetivou verificar a associação do perfil de AG n-3 de membranas eritrocitárias com o risco cardiovascular de adultos e idosos, testando as hipóteses de que esses nutrientes poderiam influenciar positivamente a estratificação do risco calculado por diferentes equações preditivas e de que se associariam com parâmetros antropométricos, metabolismo lipídico, estresse oxidativo e inflamação de modo mais favorável à cardioproteção. 


\section{METODOLOGIA}

\subsection{Delineamento do estudo}

Estudo transversal formado a partir do tempo basal do ensaio clínico, aleatorizado, controlado, aberto e paralelo denominado CARDIONUTRI (Registro Brasileiro de Ensaios Clínicos - ReBEC: RBR-2vfhfv). O estudo foi de prevenção primária, realizado em uma amostra composta por 356 indivíduos, de ambos os sexos, com idades entre 30 e 74 anos, com pelo menos um dos seguintes fatores de risco: tabagismo, hipertensão, dislipidemia, diabetes mellitus e obesidade. Todos os participantes foram selecionados a partir dos pacientes atendidos no Hospital Universitário da Universidade de São Paulo e por mídias eletrônicas vinculadas à Universidade de São Paulo, assim como divulgação em jornais de circulação local. Todos os interessados passaram por um processo inicial de triagem por telefone, seguido do processo de esclarecimento e assinatura presencial do Termo de Consentimento Livre e Esclarecido (TCLE) (Anexo 1).

\subsection{Cálculo amostral}

O cálculo amostral (Quadro 1) foi baseado em artigos científicos que descreveram a relação do IO3 com variáveis antropométricas, metabolismo lipídico e glicídico, e com parâmetros inflamatórios em pacientes com características semelhantes a dos participantes do presente estudo. Destacamos que não foram encontrados na literatura estudos prévios descrevendo associações entre IO3 de eritrócitos e as equações preditivas usadas na estimativa do risco cardiovascular. Foi utilizada uma tabela elaborada por BROWNER et al. (2008) como referência para o cálculo da amostra. Foi considerado $\alpha$ de $5 \%$ bilateral e poder estatístico de $80 \%(\beta=0,20)$.

Com base nas informações apresentadas no Quadro 1, a amostra do presente estudo, com 356 indivíduos, apresenta poder estatístico para mostrar associações entre IO3 e dados antropométricos, biomarcadores de inflamação e de metabolismo lipídico, ampliando a possibilidade dos parâmetros relacionados ao ômega-3 se associarem com as equações preditivas de risco cardiovascular. 
Quadro 1- Cálculo amostral.

\begin{tabular}{|c|c|c|c|}
\hline Artigo & Variáveis analisadas & $\begin{array}{c}\text { Coeficiente de } \\
\text { correlação }\end{array}$ & Amostra necessária \\
\hline \multirow[t]{4}{*}{$\begin{array}{l}\text { FERGUSON et al., } \\
2015\end{array}$} & $\begin{array}{c}\text { IO3 vs circunferência de } \\
\text { cintura }\end{array}$ & $-0,138$ & 346 \\
\hline & IO3 vs HDL-C & 0,134 & 346 \\
\hline & IO3 vs TAG & $-0,237$ & 123 \\
\hline & IO3 vs CT/HDL-C & $-0,120$ & 782 \\
\hline \multirow[t]{2}{*}{ COLUSSI et al., 2015a } & IO3 vs HDL-C & 0,402 & 47 \\
\hline & IO3 vs CT/HDL-C & $-0,324$ & 85 \\
\hline OLLIVER et al., 2016 & $\mathrm{IO} 3 v s \mathrm{PCR}$ & $-0,190$ & 194 \\
\hline \multirow{2}{*}{$\begin{array}{c}\text { FARZANEH-FAR et } \\
\text { al., } 2009\end{array}$} & IO3 vs PCR & $-0,190$ & 194 \\
\hline & IO3 vs IL-6 & $-0,190$ & 194 \\
\hline \multirow[t]{2}{*}{ HOWE et al., 2014} & $\begin{array}{c}\text { IO3 vs circunferência de } \\
\text { cintura }\end{array}$ & $-0,275$ & 85 \\
\hline & IO3 vs IMC & $-0,154$ & 346 \\
\hline
\end{tabular}

\subsection{Critérios de inclusão}

Para participarem do estudo, os indivíduos deveriam apresentar o TCLE devidamente preenchido e assinado, além de possuir as seguintes características:

1. Sexo masculino ou feminino (independentemente do estado menopausal);

2. Idade de 30 e 74 anos;

3. Possuir pelo menos um dos seguintes fatores de risco: tabagismo, hipertensão, dislipidemia, diabetes mellitus e obesidade.

\subsection{Critérios de não inclusão e exclusão}

Os indivíduos que apresentaram pelo menos uma das seguintes características não participaram do estudo:

- Gravidez ou lactância;

- Participação em outros estudos de intervenção no período da coleta dos dados; 
- Evento cardiovascular prévio. Esse critério foi avaliado pela história clínica e confirmado com a análise do eletrocardiograma (ECG) avaliado por um médico colaborador do estudo e vinculado ao Hospital Universitário;

- Insuficiência cardíaca;

- Possuir doenças graves (agudas ou crônicas) diagnosticadas por meio de avaliação clínica e prontuário eletrônico disponível no sistema interno do Hospital Universitário (sugestiva sobrevida inferior a 6 meses);

- Uso de drogas ilícitas;

- Diagnóstico prévio de dependência química de álcool e/ou outras drogas;

- Alterações psiquiátricas não controladas, que foram investigadas por meio de avaliação clínica;

- Possuir doença infectocontagiosa.

\subsection{Avaliação socioeconômica e clínica}

Para cada paciente foi aplicado, por entrevista direta, um questionário previamente estruturado (Anexo 2), que abordou as seguintes variáveis: sexo, idade, etnia, nível de escolaridade, renda familiar e número de indivíduos que moram na residência, história clínica atual, antecedentes familiares de doenças crônicas não-transmissíveis e uso de medicamentos e/ou suplementos alimentares.

A presença de diabetes foi definida como glicemia $\geq 126 \mathrm{mg} / \mathrm{dL}$ ou uso de medicamentos hipoglicemiantes (D’AGOSTINO et al., 2008). A presença de hipertensão arterial sistêmica foi definida como pressão arterial $\geq 130 / 85 \mathrm{mmHg}$ (ALBERTI et al., 2009). A presença de dislipidemias foi definida como pelo menos um dos seguintes fatores: LDL-C $>100 \mathrm{mg} / \mathrm{dL}$; HDL-C $<40 \mathrm{mg} / \mathrm{dL}$ para homens e $<$ $50 \mathrm{mg} / \mathrm{dL}$ para mulheres; TG $\geq 150 \mathrm{mg} / \mathrm{dL}$ (ALBERTI et al., 2009). A presença de hepatopatias, nefropatias, tireoidopatias e doenças autoimunes foram autorrelatadas.

\subsection{Consumo alimentar}

A avaliação do consumo alimentar foi feita por meio de dois recordatórios de 24 horas (R24h) aplicados no momento basal e em dias alternados (um durante a semana e outro no final de semana), para considerar as variações inter e intra individuais e, desse modo, obter a melhor descrição do hábito alimentar do indivíduo. 
O formulário padrão e seu preenchimento foi baseado no método multiple pass (JOHNSON et al., 1996; GUENTHER et al., 1998). Neste método há três elementos: listagem rápida de alimentos, descrição detalhada e revisão. Desta forma foi possível definir e quantificar todos os alimentos consumidos nas últimas 24 horas. Para reduzir o viés de informação foi utilizado o registro fotográfico alimentar contendo modelos de utensílios com medidas caseiras e porções de alimentos (ZABOTTO et al., 1996). Todos os pesquisadores de campo receberam treinamento para aplicação do inquérito alimentar (Anexo 3).

A energia, os macronutrientes (proteínas, lipídeos e carboidratos), fibras, ácidos graxos (SAFAS, PUFAS, MUFAS) e colesterol foram analisados pelo programa Food Processor (ESHA Research, 2012). Para definir o perfil de ácidos graxos analisados nos alimentos adotou-se como parâmetro aqueles passíveis de serem detectados nas membranas eritrocitárias. Os R24h que apresentaram valores de ingestão energética menor que 500 ou superior a $5000 \mathrm{kcal} / \mathrm{dia}$ foram considerados outliers e foram excluídos do estudo por falta de sensibilidade do método de inquérito nutricional.

Para corrigir a variabilidade intrapessoal, foi utilizado o programa Multiple Source Method (MSM) (Department of Epidemiology of the German Institute of Human Nutrition Postdam-Rehbrücke, versão 1.0.1, 2011), que produz uma estimativa do consumo habitual de cada nutriente e utiliza o método proposto por NUSSER et al. (1996). Posteriormente, aplicou-se o método de ajuste pela energia proposto por WILLETT et al (1997).

\subsection{Atividade física}

Foi aplicado um questionário para avaliação da atividade física habitual (Anexo 4), a partir do qual se obteve o escore total de atividade física, conforme preconizado por BAECKE et al. (1982) e validado para a população brasileira por FLORINDO E LATORRE (2003). O questionário é composto por três níveis de atividade física, sendo formado por 8 perguntas referentes à Atividade Física Ocupacional (AFO), 4 questões relacionadas ao Exercício Físico de Lazer (EFL) e 4 referentes à Atividade de Lazer e Locomoção (ALL). A partir da somatória desses três níveis determinou-se o Escore Total (ET) para atividade física. 


\subsection{Antropometria}

Os parâmetros antropométricos mensurados foram: massa corporal (kg), estatura (m), circunferência de cintura $(\mathrm{cm})$ e dados de composição corporal (percentual de gordura corporal e massa magra). A massa corporal foi aferida com os indivíduos descalços e usando o mínimo de roupas, utilizando a balança digital Toledo ${ }^{\circledR}$, modelo 2096PP/2 (Toledo, São Paulo, Brasil) com limite de capacidade de 200kg e precisão de 50g. A aferição da estatura foi realizada com o estadiômetro portátil Seca ${ }^{\circledR}$ (TBW, São Paulo, Brasil) com limite de 2,0m e precisão de 1,0mm. Esta medida foi feita com os indivíduos descalços e em posição ereta, com os pés paralelos, calcanhares, panturrilha, glúteos e ombros encostados na parede e com a cabeça sob o plano horizontal de Frankfurt (LOHMAN et al., 1988). A classificação do índice de massa corporal (IMC) utilizada para os adultos e idosos encontra-se na Tabela 2.

Tabela 2 - Classificação de IMC de adultos (*) e de idosos $(* *)$.

\begin{tabular}{lll}
$\mathbf{I M C}\left(\mathbf{k g} / \mathbf{m}^{2}\right)^{*}$ & IMC $\left(\mathbf{k g} / \mathbf{m}^{2}\right)^{* *}$ & Classificação \\
\hline$<18,50$ & $<23,00$ & Baixo peso \\
$18,5-24,99$ & $23,00-27,99$ & Eutrofia \\
$25,00-29,99$ & $28,00-29,99$ & Sobrepeso \\
$\geq 30,00$ & $\geq 30,00$ & Obesidade
\end{tabular}

Fonte: WHO (2000); LEBRÃO e DUARTE (2013).

Para aferir a circunferência da cintura, os indivíduos foram posicionados em pé, com os braços paralelos ao corpo e pés unidos, além de permanecerem com o abdômen relaxado. Esta medida foi aferida com uma fita inelástica, flexível e com precisão de $1 \mathrm{~mm}$ (TBW, São Paulo, Brasil), adotando-se como referencial anatômico o ponto médio entre a última costela e a crista ilíaca. A classificação utilizada para a circunferência de cintura encontra-se na Tabela 3.

Tabela 3- Classificação do risco de complicações metabólicas associados à circunferência abdominal de homens e mulheres.

Circunferência de cintura $(\mathrm{cm})$

Risco de complicações metabólicas

\begin{tabular}{lll}
\cline { 2 - 3 } & Homens & Mulheres \\
\hline Sem risco & $<94$ & $<80$ \\
Risco elevado & $\geq 94$ & $\geq 80$ \\
Risco substancialmente elevado & $\geq 102$ & $\geq 88$ \\
\hline
\end{tabular}

Fonte: WHO (2000). 
Para a realização da impedância bioelétrica (BIA), utilizou-se o aparelho Bioelectrical Body Composition Analyzer ${ }^{\circledR}$, modelo Quantum II (RJL Systems, Michigan, USA), no qual foi aplicada uma corrente de $425 \mu \mathrm{A}$, a uma frequência de $50 \mathrm{kHz}$. As medidas foram tomadas do lado direito do corpo e o indivíduo foi orientado a permanecer deitado, com os braços em ângulo de $30^{\circ}$ em relação ao seu corpo e as pernas sem contato entre si. Calçados e meias foram retirados e durante o teste o indivíduo permaneceu imóvel. Como preparo, foi orientado um jejum de 8 horas e evitar o consumo de bebidas alcoólicas e a prática de atividade física pelo mesmo período, além de urinar antes da realização do exame. $\mathrm{O}$ equipamento apresenta os valores brutos de resistência $(\mathrm{R})$, reactância $(\mathrm{Xc})$ e ângulo de fase $\left(^{\circ}\right)$.

O cálculo do percentual de gordura (\%GC) foi realizado pelo programa Cyprus, versão 2.5- Body Composition Analysis System (RJL Systems ${ }^{\circledR}$, Detroit, USA), considerando sexo, idade, massa corporal, estatura, nível de atividade física, resistência e reactância.

\subsection{Análises bioquímicas}

\subsubsection{Coleta de sangue}

Após um jejum de 12 horas, $20 \mathrm{~mL}$ de sangue foram coletados de cada paciente. O sangue foi coletado em tubos com gel de separação para análises que utilizaram o soro. Para obtenção do plasma, o sangue foi coletado em tubos vacutainer contendo o anticoagulante e antioxidante etileno-diamino-tetra-acético (EDTA) (1mg/mL) (BD, Brasil), mantido em gelo e protegido da luz. Para a análise de glicemia o sangue foi coletado em tubos com fluoreto de sódio. Para se obter o plasma ou soro, o sangue total foi centrifugado a $3000 \mathrm{rpm}$ durante 10 minutos a $4^{\circ} \mathrm{C}$. A esses dois componentes sanguíneos foram acrescentados os inibidores de proteases aprotinina $(10 \mu \mathrm{g} / \mathrm{mL})$, benzamidina (10 $\mu \mathrm{M} / \mathrm{mL}$ de plasma) e fluoreto de fenilmetilsulfonila (PMSF) (5 $\mu \mathrm{M} / \mathrm{mL}$ de plasma), além do antioxidante 2,6-di-tert-butil-p-hidroxitolueno (BHT) (100 $\mu \mathrm{M} / \mathrm{mL}$ de plasma). Todas as amostras foram aliquotadas de acordo com o número de análises e armazenadas a $-80^{\circ} \mathrm{C}$ até o momento das análises.

\subsubsection{Metabolismo lipídico}

As concentrações de colesterol total, HDL-C e triglicérides foram determinadas através dos kits Colesterol Liquiform ${ }^{\circledR}$, Colesterol HDL ${ }^{\circledR}$ e Triglicérides Liquiform ${ }^{\circledR}$ (Labtest, Minas Gerais, Brasil), respectivamente. O LDL-C foi calculado com base na 
fórmula de FRIEDEWALD (1972), onde: LDL-C = CT - HDL-C - TAG/5, sendo que essa foi aplicada apenas para aqueles indivíduos com TAG $<400 \mathrm{mg} / \mathrm{dL}$.

As apolipoproteínas Apo A-I e Apo B foram determinadas por meio do método imuno-turbidimétrico utilizando o Autokit APO $\mathrm{AI}^{\circledR}$ e Autokit APO B ${ }^{\circledR}($ Wako Chemicals USA Inc., Richmond, VA, EUA), respectivamente.

A partir das análises bioquímicas acima, os parâmetros de TG/HDL-C, CT/HDLC, LDL-C/HDL-C, não-HDL-C, Apo B/Apo A-I, HDL-C/Apo A-I e LDL-C/Apo B foram calculados.

A concentração de ácidos graxos não esterificados (NEFA) foi determinada pelo kit comercial colorimétrico Free Fatty Acid Quantification Kit (Wako Chemicals USA Inc., Richmond, VA, EUA). As análises foram realizadas no sistema semiautomático Cobas-Mira.

A atividade da paraoxonase (PON1) foi analisada por meio da adição de $500 \mu \mathrm{L}$ de tampão Tris- $\mathrm{HCl}$ 0,1 $\mathrm{M}$ e pH 8,05, contendo $2 \mathrm{mmol} / \mathrm{L}$ de $\mathrm{CaCl}_{2}$ e $1,1 \mathrm{mmol} / \mathrm{L}$ de paraoxon (Sigma ChemicalCo.) em $25 \mu \mathrm{L}$ de soro. Em seguida, $200 \mu \mathrm{L}$ da solução foram distribuídos em placas de fundo plano contendo 96 poços. A leitura foi feita em duplicata utilizando o leitor de microplacas (Microplate Reader, Benchmark, BioRAD) com comprimento de onda de $405 \mathrm{~nm}$, a $37^{\circ} \mathrm{C}$. Para o cálculo da atividade da PON1 foram feitas 6 leituras em intervalos de um minuto cada. Os resultados foram expressos em nmol min $^{-1} \mathrm{x} \mathrm{mL}^{-1}$ (MACKNESS et al., 1991).

A quantidade de proteína de transferência de éster de colesterol (CETP) no plasma foi determinada por meio do kit CETP Activity Assay Kit ${ }^{\circledR}$ (BioVision, Inc., California, EUA).

\subsubsection{Metabolismo glicídico}

A glicose e a insulina plasmáticas foram analisadas pelos kits comerciais Glicose PAP Liquiform ${ }^{\circledR}$ (Labtest, Minas Gerais, Brasil) e Insulin Human Direct ELISA Kit ${ }^{\circledR}$ (Life Technologies, Grand Island, NY, EUA), respectivamente. A resistência à insulina foi calculada pelo índice HOMA-IR (homeostasis model assessment - insulin resistance), sendo que HOMA-IR = [insulina em jejum $(\mu \mathrm{U} / \mathrm{mL}) \times$ glicemia de jejum $(\mathrm{mmol} / \mathrm{L})] / 22,5$. A presença de resistência insulínica foi determinada de acordo com o Modelo 1, adotado pela Sociedade Brasileira de Diabetes (SBD, 2009), e que foi 
proposto por STERN et al. (2005), em que essa é diagnosticada se quaisquer um dos seguintes critérios estiver presente: IMC > 28,9 kg/m², HOMA-IR > 4,65 ou IMC > $27,5 \mathrm{~kg} / \mathrm{m}^{2}$ e HOMA-IR > 3,6.

A hemoglobina glicada (HbA1c) foi determinada pelo método comercial usando o kit HbA1c Turbiquest ${ }^{\circledR}$ (Labtest, Minas Gerais, Brasil).

\subsubsection{Subfrações lipoproteicas}

O tamanho das lipoproteínas (HDL e LDL) foi analisado pelo sistema Lipoprint (Lipoprint System ${ }^{\circledR}$; Quantimetrix, Redondo Beach, CA), que se baseia na separação e quantificação de subfrações de lipoproteínas por meio de gel de poliacrilamida não desnaturante. As subfrações identificadas na eletroforese foram integradas para determinar a área relativa de cada subunidade de lipoproteína (percentual de cada subfração) e, posteriormente, multiplicada pela concentração de CT plasmático para calcular a quantidade de colesterol em cada subfração de LDL ou pelo colesterol na HDL para quantificar a concentração de colesterol em cada subfrações de HDL. Os resultados permitiram a identificação de sete subfrações de LDL, sendo as subfrações LDL-1 e LDL-2 classificadas como grandes e as subfrações LDL-3 a LDL-7 como partículas menores e mais densas. Para a HDL, foram identificadas dez subfrações, sendo as partículas HDL-1 a HDL-3 classificadas como grandes, HDL-4 a HDL-7 como intermediárias e HDL-8 a HDL-10 como pequenas. Fenótipos A e não-A foram determinados para a LDL utilizando o ponto de corte de 25,5 $\mathrm{nm}$. Determinou-se ainda o tamanho médio da LDL (nm). Foi calculada uma razão entre partículas de HDL grandes e pequenas a partir do percentual das subfrações lipoproteicas, sendo ela: $($ HDL-1 + HDL-2) / (HDL-9 + HDL-10). Para as partículas de LDL grandes e pequenas foi calculada a razão: (LDL-1 + LDL-2) / LDL-3 a LDL-7).

\subsubsection{Parâmetros oxidativos}

A LDL eletronegativa [LDL(-)] foi detectada por ELISA sanduíche, seguindo o protocolo adaptado do método validado por FAULIN et al (2008). A sensibilização das placas $\left(\right.$ Costar $^{\circledR}$, modelo 3690, Corning, US) foi feita com anticorpo monoclonal anti-LDL(-) (MAb-1A3) (0,5 $\mu \mathrm{g} / \mathrm{mL}, 50,0 \mu \mathrm{L} /$ poço), diluído em tampão carbonatobicarbonato $(0,25 \mathrm{M}, \mathrm{pH} 9,6)$, sendo as placas incubadas por $12 \mathrm{~h}$ à $4^{\circ} \mathrm{C}$. Após esse período, os sítios livres foram bloqueados com leite desnatado (Molico ${ }^{\circledR}$, Nestlé, São Paulo, Brasil), diluído a 5\% em tampão fosfato salina 0,01 mol/L (PBS - pH 7,4) e incubados à $37^{\circ} \mathrm{C}$ por $2 \mathrm{~h}$. Em seguida, as placas foram lavadas quatro vezes com PBS- 
Tween $(0,05 \%)$. Foi adicionado 50,0 $\mu \mathrm{L}$ poço de plasma diluído (1:1600) em tampão PBS, sendo a placa incubada por $2 \mathrm{~h}$ em temperatura ambiente. Após essa etapa, a placa foi lavada, conforme descrito anteriormente, e foi adicionado 50,0 $\mu \mathrm{L} /$ poço de anticorpo monoclonal anti-LDL(-) biotinilado (MAb-2C7) $(0,5 \mu \mathrm{g} / \mathrm{mL}, 50,0 \mu \mathrm{L} /$ poço). As placas foram novamente incubadas em temperatura ambiente por $2 \mathrm{~h} \mathrm{e}$, em seguida, lavadas conforme descrito anteriormente. Após essa etapa, foram adicionados 50,0 $\mu \mathrm{L} /$ poço de estreptoavidina-peroxidase (1:80000) diluída em PBS. As placas foram incubadas por $1 \mathrm{~h}$ em temperatura ambiente e novamente lavadas, conforme descrito anteriormente. A reação de cor foi desenvolvida por adição de substrato composto por $3,3^{\prime}, 5,5^{\prime}$ - tetrametilbenzina (TMB), tampão citrato-fosfato $(0,1 \mathrm{M}, \mathrm{pH} 4,2)$ e $\mathrm{H} 2 \mathrm{O} 2$ (30\%) $(250 / 12 / 10, \mu \mathrm{L} / \mathrm{mL} / \mu \mathrm{L})$. As placas foram incubadas por 15 minutos em temperatura ambiente e protegidas da luz. A reação foi bloqueada com 50,0 $\mu \mathrm{L} /$ poço de $\mathrm{H}_{2} \mathrm{SO}_{4}(2,0 \mathrm{M})$ e a absorbância monitorada em $450 \mathrm{~nm}$. Os resultados foram expressos pela média das absorbâncias das amostras menos o branco e, posteriormente, aplicados à curva padrão e multiplicados pela respectiva diluição, sendo os resultados expressos em $\mathrm{mg} / \mathrm{ml}$. Os anticorpos utilizados nessa análise foram produzidos no Laboratório de Bioquímica Clínica da Faculdade de Ciências Farmacêuticas da Universidade de São Paulo (FCF-USP), sob a coordenação da Professora Doutora Dulcineia Saes Parra Abdalla.

Os autoanticorpos anti-LDL(-) foram detectados por ELISA de captura de anticorpo. A LDL(-), isolada por fast protein liquid chromatography (FPLC), foi diluída em tampão carbonato-bicarbonato $(0,25 \mathrm{M}, \mathrm{pH} 9,6)$ até concentração final de 1 $\mu \mathrm{g}$ de proteína/poço, e incubada em período overnight $(15 \mathrm{~h})$ a $4^{\circ} \mathrm{C}$. Os espaços livres foram bloqueados com $5 \%$ de leite desnatado diluído em tampão fosfato-salina 0,01 $\mathrm{mol} / \mathrm{L}(\mathrm{PBS}-\mathrm{pH} 7,4)$ e incubados a $37^{\circ} \mathrm{C}$ por 90 minutos. As placas foram lavadas quatro vezes com PBS-tween $(0,05 \%)$. As amostras foram diluídas (1:300) em PBStween $(0,01 \%)$ e incubadas em temperatura de $37^{\circ} \mathrm{C}$ por 90 minutos. As placas foram novamente lavadas, conforme protocolo. Foi adicionado $50,0 \mu \mathrm{L} /$ poço de anti-IgG humana marcada com peroxidase, (1:5000) diluída em PBS. As placas foram incubadas por 90 minutos, à $37^{\circ} \mathrm{C}$, seguida de lavagem, conforme protocolo. A reação de cor se desenvolveu pela adição de substrato composto por 3,3, 5,5' tetrametilbenzina (TMB), tampão citrato-fosfato (0,1 M, pH 4,2) e $\mathrm{H}_{2} \mathrm{O}_{2}$ (30\%) $(250 / 12 / 10, \mu \mathrm{L} / \mathrm{mL} / \mu \mathrm{L})$. As placas foram incubadas por 30 minutos à $37^{\circ} \mathrm{C}$, sob 
proteção da luz. A reação foi bloqueada com $50 \mu \mathrm{L} /$ poço de $\mathrm{H}_{2} \mathrm{SO}_{4}(2,0 \mathrm{M})$ e a absorbância monitorada em $450 \mathrm{~nm}$. Os resultados foram gerados aplicando-se a média das absorbâncias das amostras, descontando o branco, à equação da curva padrão de MAb $2 \mathrm{C} 7(0,004$ - 0,125 um/L). Os autoanticorpos anti-LDL(-) foram determinados segundo FAULIN et al. (2012).

\subsubsection{Parâmetros inflamatórios}

$\mathrm{O}$ conteúdo de proteína $\mathrm{C}$ reativa foi determinado por meio do método imunoenzimático (Diagnostic System Laboratories, Inc., Webster, Texas, EUA). Os valores foram apresentados em concentração (ng/mL).

\subsubsection{Adipocinas}

A concentração de adiponectina no soro dos participantes da pesquisa, utilizando o método ELISA sanduíche (EMD Milipore ${ }^{\circledR}$ ). O imunoensaio apresentou controles positivo, negativo e curva de calibração. Todas as análises foram realizadas em duplicata.

A concentração de leptina no soro dos participantes foi determinada pelo método ELISA sanduíche (Enzo Lifesciences $\left.{ }^{\circledR}\right)$. O imunoensaio apresentou controles positivo, negativo e curva de calibração. Todas as análises foram realizadas em duplicata.

\subsubsection{Perfil de ácidos graxos de membranas eritrocitárias}

A análise de ácidos graxos presentes nas membranas eritrocitárias dos participantes foi realizada através de uma adaptação do método descrito por MASOOD et al. (2005). O método utilizado no estudo está na Figura 3.

Após a centrifugação $\left(3000 \mathrm{~g}, 10 \mathrm{~min}, 4^{\circ} \mathrm{C}\right)$ do sangue e separação do plasma, foi utilizado $300 \mu \mathrm{L}$ do concentrado de hemácias para a etapa de lise dos eritrócitos. Essa primeira etapa foi iniciada com a lavagem do hemoconcentrado com PBS gelado de pH 7,4 (1:10; v/v), sonicação por 5 min e centrifugação de 15 min a 3000 g, com descarte do sobrenadante. Essa etapa foi repetida até completa remoção da hemoglobina e a solução ficar quase livre de hemoglobina.

Após essa fase, os pellets foram transferidos para tubos de ensaio com tampas rosqueadas onde foram acrescentados $1,75 \mathrm{~mL}$ de metanol, $50 \mu \mathrm{L}$ de solução de padrão interno (contendo $1 \mathrm{mg}$ de ácido tridecanoico (C13:0) por $\mathrm{mL}$ de hexano) e 100 $\mu \mathrm{L}$ de cloreto de acetila e depois foram homogeneizados no vórtex por 30 segundos. 
Os tubos então foram aquecidos a $90^{\circ} \mathrm{C}$ por 60 minutos em banho-maria e deixados em temperatura ambiente durante 10 minutos.

Para a etapa de extração, hexano $(1,5 \mathrm{~mL})$ foi adicionado e então os tubos foram homogeneizados no vórtex durante 1 minuto. Foi realizada a centrifugação dos tubos a $1500 \mathrm{~g} \mathrm{e} 4^{\circ} \mathrm{C}$ durante 2 minutos, e o sobrenadante $(800 \mu \mathrm{L})$ foi transferido para um tubo de centrifugação cônico. Esta etapa foi repetida com adição de $750 \mu \mathrm{L}$ de hexano para otimizar a extração lipídica, e mais $800 \mu \mathrm{L}$ de sobrenadante foi transferido ao tubo de centrifugação. Após as coletas do sobrenadante, os tubos foram colocados sem tampa em um concentrador a $40^{\circ} \mathrm{C}$ durante 20 minutos para evaporar o hexano, e então a amostra foi redissolvida em $150 \mu \mathrm{L}$ de hexano e transferida para um insert de vidro em um vial para posterior análise na cromatografia gasosa. 


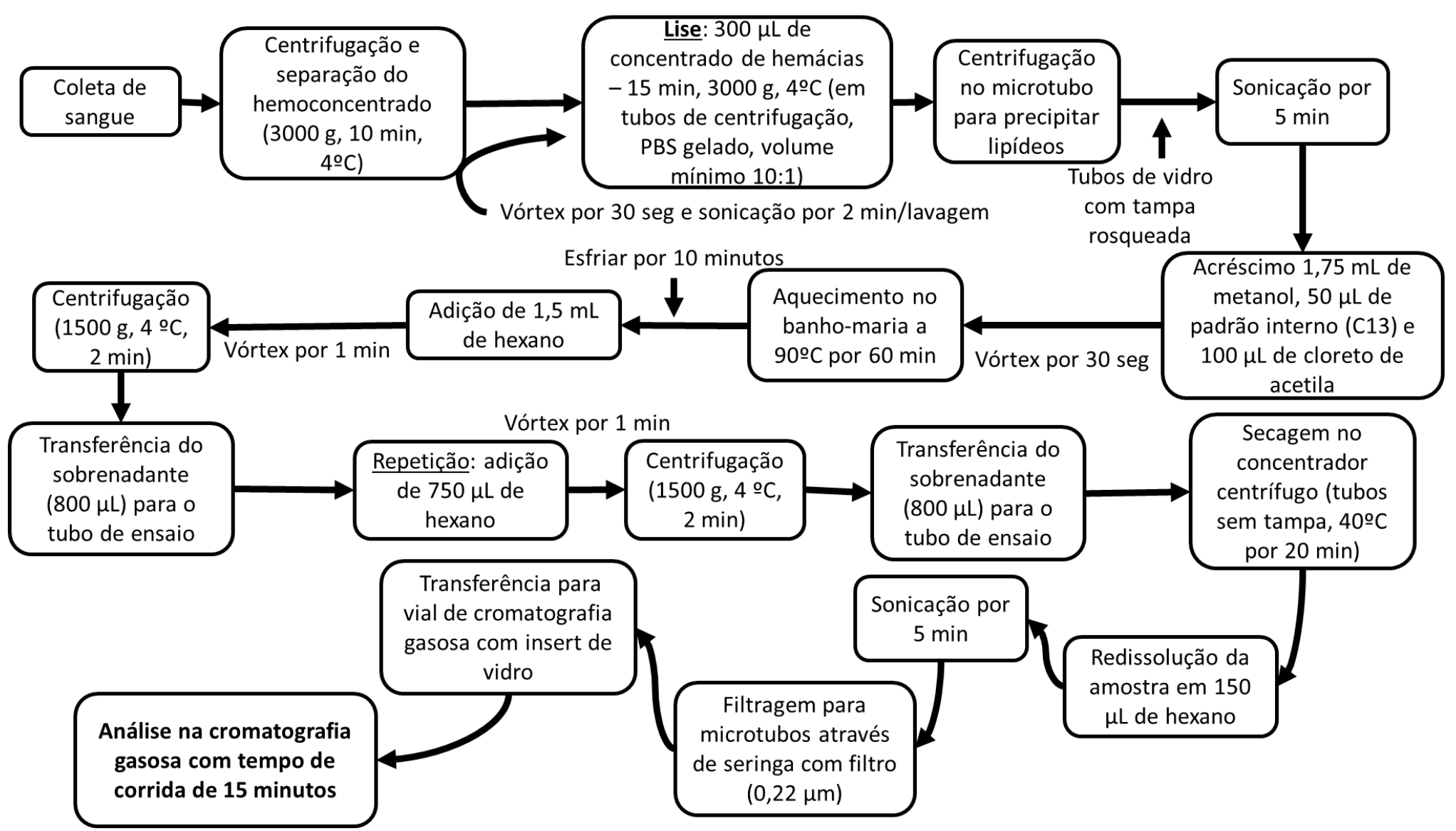

Figura 3 - Método de extração e esterificação dos ácidos graxos das membranas eritrocitárias. 
O perfil de ácidos graxos foi determinado em um cromatógrafo a gás Shimadzu, CG-2010, equipado com uma coluna capilar DB-FFAP (15 m x 0,100 mm x 0,10 $\mu \mathrm{m} 0$ J e W Scientific, Agilent Technologies). O hidrogênio foi utilizado como gás de arraste com fluxo de $0,27 \mathrm{~mL} / \mathrm{min}$, com vazão de $35 \mathrm{~cm} / \mathrm{s}$ e pressão de $187,8 \mathrm{kPa}$. As taxas de fluxo de ar sintético, $\mathrm{N}_{2}$ e $\mathrm{H}_{2}$ foram, respectivamente, 300,30 e $30 \mathrm{~mL} / \mathrm{min}$. As temperaturas do injetor e do detector foram de $250^{\circ} \mathrm{C}$ e $260^{\circ} \mathrm{C}$, respectivamente. A programação de temperaturas da coluna foi de $100^{\circ} \mathrm{C}$ inicial, com retenção de $0,5 \mathrm{~min}$, rampa de $25^{\circ} \mathrm{C} / \mathrm{min}$ a $195^{\circ} \mathrm{C}, 3^{\circ} \mathrm{C} / \mathrm{min}$ a $205^{\circ} \mathrm{C}, 8^{\circ} \mathrm{C} / \mathrm{min}$ a $230^{\circ} \mathrm{C}$, com retenção de 4 $\min , 50^{\circ} \mathrm{C} / \mathrm{min}$ a $245^{\circ} \mathrm{C}$, retendo por $0,5 \mathrm{~min}$. A razão Split utilizada no injetor foi de 1:100 e o tempo de corrida total foi de 15,56 min.

Como padrão externo foi utilizada uma mistura formada por 37 ésteres metílicos de ácidos graxos (FAME 37, código 47885, Sigma ChemicalCo.). O volume de injeção foi de $2 \mu \mathrm{L}$, em injetor automático AOC 20i. Os ácidos graxos foram identificados por meio da comparação dos tempos de retenção do padrão externo com as amostras. Os resultados foram expressos na forma de percentual total de ácidos graxos integrados na amostra.

Com base nas revisões sistemáticas de HODSON et al. (2008) e de STARK et al. (2016), para o presente estudo foram escolhidos os ácidos graxos mais frequentemente analisados nos estudos e predominantes em tecidos biológicos de humanos (Tabela 4)

Tabela 4. Ácidos graxos de membranas analisados no estudo.

\begin{tabular}{cccc}
\hline Ácido graxo & Abreviatura & Ácido graxo & Abreviatura \\
\hline Palmítico & $\mathrm{C} 16: 0$ & Di-homo- $\gamma$-linolênico & $\mathrm{C} 20: 3 \mathrm{n}-6$ \\
Palmitoleico & $\mathrm{C} 16: 1 \mathrm{n}-7$ & Araquidônico & $\mathrm{C} 20: 4 \mathrm{n}-6$ \\
Esteárico & $\mathrm{C} 18: 0$ & Eicosapentaenoico & $\mathrm{C} 20: 5 \mathrm{n}-3$ \\
Oleico & $\mathrm{C} 18: 1 \mathrm{n}-9$ & Behênico & $\mathrm{C} 22: 0$ \\
Linoleico & $\mathrm{C} 18: 2 \mathrm{n}-6$ & Erúcico & $\mathrm{C} 22: 1 \mathrm{n}-9$ \\
$\gamma$-linolênico & $\mathrm{C} 18: 3 \mathrm{n}-6$ & Di-homo-linoleico & $\mathrm{C} 22: 2 \mathrm{n}-6$ \\
$\alpha$-linolênico & $\mathrm{C} 18: 3 \mathrm{n}-3$ & Lignocérico & $\mathrm{C} 24: 0$ \\
Araquídico & $\mathrm{C} 20: 0$ & Docosahexaenoico & $\mathrm{C} 22: 6 \mathrm{n}-3$ \\
Gondoico & $\mathrm{C} 20: 1 \mathrm{n}-9$ & Nervônico & $\mathrm{C} 24: 1 \mathrm{n}-9$ \\
Eicosadienoico & $\mathrm{C} 20: 2 \mathrm{n}-6$ & & \\
\hline
\end{tabular}


A partir da seleção dos ácidos graxos indicados, os seguintes métodos foram adotados para identificar cada ácido graxo incorporado às membranas dos eritrócitos e sua contribuição relativa $(\%)$ :

1. Sobreposição dos cromatogramas com análise visual de reprodutibilidade para verificação de diferenças extremas gerais. Para aqueles que apresentaram essas grandes diferenças, o experimento foi considerado errado e posteriormente refeito.

2. Integração dos 19 ácidos graxos selecionados concomitantemente com o padrão interno C13:0.

3. Cálculo do coeficiente de variação (CV) do valor absoluto de C13:0 entre as duplicatas. A boa reprodutibilidade do experimento foi determinada pelo coeficiente de variabilidade $(\mathrm{CV})>15 \%$.

4. Caso a amostra não apresentasse CV com valor absoluto $>15 \%$, observou-se o $\mathrm{CV}$ do $\mathrm{C} 13: 0$ (\%), com todos os 19 ácidos graxos integrados, também considerando ponto de corte de $15 \%$ para boa reprodutibilidade.

5. No caso de evaporação não uniforme de replicata de alguma amostra, além da análise relativa de ácidos graxos, era feita a comparação do C13:0 absoluto da amostra que não evaporou com o C13:0 absoluto das amostras dos experimentos realizados no mesmo dia, seguido do cálculo do CV interpessoal do bloco diário. Se $\mathrm{CV}<15 \%$, a amostra não evaporada era considerada para o banco de dado, na forma de unicata.

6. Para o banco de dados, foi considerada a média dos valores percentuais de ácidos graxos integrados entre as duplicatas, excluindo o padrão interno C13:0.

\subsection{Estimativa de risco cardiovascular}

O risco cardiovascular global foi obtido pelo cálculo dos Escores de Risco de Framingham (ERF), de Reynolds (ERR) e da Diretriz da ACC/AHA (2013).

Para estimar o risco cardiovascular de homens por meio do ERF foi utilizada a calculadora disponível no site https://www.framinghamheartstudy.org/fhs-riskfunctions/cardiovascular-disease-10-year-risk/, que se baseia na seguinte equação propostas por D'AGOSTINO et al. (2008):

$$
\hat{p}=1-S_{0}(t)^{\exp \left(\Sigma_{i=1}^{p} \beta_{i} X_{i}-\Sigma_{i=1}^{p} \beta_{i} \bar{X}_{i}\right)}
$$


onde:

$\mathrm{S}_{0}(\mathrm{t})$ é a sobrevivência basal no tempo de acompanhamento

$t$ (aqui $t=10$ anos)

$\beta_{i}$ é o coeficiente de regressão estimado (log da taxa de risco)

$X_{i}$ é o valor do fator de risco $i$ transformado em $\log$ (se contínuo)

$\bar{X}_{i}$ é a média correspondente

$p$ é o número de fatores de risco.

Como o risco cardiovascular em mulheres foi subestimado com essa ferramenta, MOSCA et al. (2011) propuseram mudanças na classificação do risco e nos valores dos pontos de corte do risco global calculado, baseando-se no ERF. Para as mulheres desse estudo foi utilizado esse cálculo.

Considerando que não foi localizada nenhuma calculadora dessa referência, optou-se pelo cálculo manual, onde cada variável foi pontuada, segundo os pontos de corte propostos. Após a pontuação e soma de cada variável, o percentual de risco cardiovascular foi determinado com base no risco cardiovascular global apresentado por MOSCA et al. (2011). A atribuição de pontos às variáveis e o risco global resultante da soma do ERF são apresentados nas Tabelas 5-8.

Tabela 5. Atribuição de pontos de acordo com o risco global, para homens.

\begin{tabular}{|c|c|c|c|c|c|c|c|}
\hline Pontos & Idade & HDL-c & CT & $\begin{array}{c}\text { PAS não } \\
\text { tratada }\end{array}$ & $\begin{array}{c}\text { PAS } \\
\text { tratada }\end{array}$ & Tabagismo & Diabetes \\
\hline-2 & & $60+$ & & $<120$ & & & \\
\hline-1 & & $50-59$ & & & & & \\
\hline 0 & $30-34$ & $45-49$ & $<160$ & $120-129$ & $<120$ & Não & Não \\
\hline 1 & & $35-44$ & 160-199 & $130-139$ & & & \\
\hline 2 & $35-39$ & $<35$ & $200-239$ & $140-159$ & $120-129$ & & \\
\hline 3 & & & $240-279$ & $160+$ & $130-139$ & & Sim \\
\hline 4 & & & $280+$ & & $140-159$ & Sim & \\
\hline 5 & $40-44$ & & & & $160+$ & & \\
\hline 6 & $45-49$ & & & & & & \\
\hline 7 & & & & & & & \\
\hline 8 & $50-54$ & & & & & & \\
\hline 9 & & & & & & & \\
\hline 10 & $55-59$ & & & & & & \\
\hline 11 & $60-64$ & & & & & & \\
\hline 12 & $65-69$ & & & & & & \\
\hline 13 & & & & & & & \\
\hline 14 & $70-74$ & & & & & & \\
\hline 15 & $75+$ & & & & & & \\
\hline
\end{tabular}


Tabela 6. Risco cardiovascular global em 10 anos, para homens.

\begin{tabular}{cccc}
\hline Pontos & Risco $(\boldsymbol{\%})$ & Pontos & Risco $(\boldsymbol{\%})$ \\
\hline$\leq-3$ & $<1$ & 8 & 6,7 \\
-2 & 1,1 & 9 & 7,9 \\
-1 & 1,4 & 10 & 9,4 \\
0 & 1,6 & 11 & 11,2 \\
1 & 1,9 & 12 & 13,2 \\
2 & 2,3 & 13 & 15,6 \\
3 & 2,8 & 14 & 18,4 \\
4 & 3,3 & 15 & 21,6 \\
5 & 3,9 & 16 & 25,3 \\
6 & 4,7 & 17 & 29,4 \\
7 & 5,6 & $18+$ & $>30$ \\
\hline
\end{tabular}

Tabela 7. Atribuição de pontos de acordo com o risco global, para mulheres.

\begin{tabular}{|c|c|c|c|c|c|c|c|}
\hline Pontos & Idade & HDL-C & CT & $\begin{array}{c}\text { PAS não } \\
\text { tratada }\end{array}$ & $\begin{array}{c}\text { PAS } \\
\text { tratada }\end{array}$ & Tabagismo & Diabetes \\
\hline-3 & & & & $<120$ & & & \\
\hline-2 & & $60+$ & & & & & \\
\hline-1 & & $50-59$ & & & $<120$ & & \\
\hline 0 & $30-34$ & $45-49$ & $<160$ & $120-129$ & & Não & Não \\
\hline 1 & & $35-44$ & $160-199$ & $130-139$ & & & \\
\hline 2 & $35-39$ & $<35$ & & $140-149$ & $120-129$ & & \\
\hline 3 & & & $200-239$ & & $130-139$ & Sim & \\
\hline 4 & $40-44$ & & $240-279$ & $150-159$ & & & Sim \\
\hline 5 & $45-49$ & & $280+$ & $160+$ & $140-149$ & & \\
\hline 6 & & & & & $150-159$ & & \\
\hline 7 & $50-54$ & & & & $160+$ & & \\
\hline 8 & $55-59$ & & & & & & \\
\hline 9 & $60-64$ & & & & & & \\
\hline 10 & $65-69$ & & & & & & \\
\hline 11 & $70-74$ & & & & & & \\
\hline 12 & $75+$ & & & & & & \\
\hline
\end{tabular}


Tabela 8. Risco cardiovascular global em 10 anos, para mulheres.

\begin{tabular}{cccc}
\hline Pontos & Risco $(\%)$ & Pontos & Risco (\%) \\
\hline$\leq-2$ & $<1,0$ & 10 & 6,3 \\
-1 & 1,0 & 11 & 7,4 \\
0 & 1,1 & 12 & 8,6 \\
1 & 1,5 & 13 & 10,0 \\
2 & 1,8 & 14 & 11,6 \\
3 & 2,1 & 15 & 13,5 \\
4 & 2,5 & 16 & 15,6 \\
5 & 2,9 & 17 & 18,1 \\
6 & 3,4 & 18 & 20,9 \\
7 & 3,9 & 19 & 24,0 \\
8 & 4,6 & 20 & 27,5 \\
9 & 5,4 & $21+$ & $>30$ \\
\hline
\end{tabular}

Os parâmetros utilizados para o cálculo desse escore são sexo, idade, HDL-C, CT, pressão arterial sistólica (PAS) ou uso de anti-hipertensivos, tabagismo (divididos em fumantes e não fumantes; os ex-fumantes foram classificados como não fumantes) e presença de diabetes (confirmada pela glicemia $\geq 126 \mathrm{mg} / \mathrm{dL}$ ou uso de medicamentos hipoglicemiantes). Após o cálculo, o risco cardiovascular global em 10 anos foi estratificado de acordo com a Diretriz Brasileira de Dislipidemias e Prevenção da Aterosclerose de 2017 (SBC, 2017). Essa diretriz ressalta que os pacientes diabéticos devem ser automaticamente classificados como alto risco cardiovascular. Dessa forma, considerou-se que os indivíduos diabéticos tinham 30\% de risco cardiovascular em 10 anos. Essa estratificação está apresentada na Tabela 9.

Tabela 9. Classificação do risco cardiovascular global em 10 anos de homens e mulheres segundo ERF.

\begin{tabular}{ccc}
\hline Risco & Homens & Mulheres \\
\hline Baixo & $<5 \%$ & $<5 \%$ \\
Intermediário & $\geq 5 \% \mathrm{a} \leq 20 \%$ & $\geq 5 \% \mathrm{a} \leq 10 \%$ \\
Alto & $>20 \%$ & $>10 \%$ \\
\hline
\end{tabular}

Para fazer o cálculo do risco cardiovascular em 10 anos estimado pelo ERR, foi utilizada a calculadora disponível no site http://www.reynoldsriskscore.org/, que tem como base as fórmulas propostas por RIDKER et al. (2007; 2008). Os parâmetros utilizados para o cálculo desse escore são sexo, idade, PAS, CT, HDL-C, tabagismo, PCR e antecedentes familiares de DCV. Indivíduos diabéticos (com glicemia $\geq 126$ 
$\mathrm{mg} / \mathrm{dL}$ ou uso de medicamentos hipoglicemiantes) automaticamente foram classificados como alto risco cardiovascular. A investigação dos antecedentes familiares para doenças cardiovasculares foi realizada por entrevista por telefone, onde se questionou se o pai e/ou mãe haviam falecido por algum tipo de DCV antes dos 60 anos de idade. Essa calculadora foi desenvolvida para indivíduos sem diabetes, pois o diagnóstico prévio classifica o indivíduo com alto risco cardiovascular, ou seja, a esses indivíduos foram automaticamente atribuídos um risco de $20 \%$. Para as mulheres, foi utilizada a fórmula:

Risco cardiovascular em 10 anos $(\%)=\left[1-0,98634^{(\exp [B-22.325])}\right] \times 100 \%$, onde:

$B=0,0799 \times$ idade $+3,137 \times$ logaritmo natural (pressão arterial sistólica) + $0,180 \times$ logaritmo natural $(P C R)+1,382 \times$

logaritmo natural(colesterol total) $-1,172 \times$ logaritmo natural $(H D L)+$ $0,134 \times H b A_{1 c}(\%)($ se for diabética $)+0,818($ se fuma $)+$

0,438 (se houver histórico familiar de infarto do miocárdio precoce)

Para os homens, foi utilizada a equação:

Risco cardiovascular em 10 anos $(\%)=\left[1-0,8990^{(\exp [B-33,097])}\right] \times 100 \%$, onde:

$B=4,385 \times$ logaritmo natural (idade) $+2,607 \times$

logaritmo natural (pressão arterial sistólica) $+0,963 \times$

logaritmo natural (colesterol total) $-0,772 \times$ logaritmo natural $(H D L)+$ 0,405 (se fuma) $+0,102 \times$ logaritmo natural $(P C R)+$

0,541 (se houver histórico familiar de infardo do miocárdio precoce)

Para cada variável a calculadora apresenta uma faixa de valores que ela utiliza nos cálculos. Se algum valor não estiver dentro dessa faixa, automaticamente a calculadora utiliza o valor mais próximo do observado. Desta forma, a faixa de idade considerada na calculadora é de 45 a 80 anos. A faixa da pressão arterial sistólica é de 105 a 200 mm/Hg. A faixa do CT é de 140 a 400 mg/dL. Já a de HDL-C é de 30 a 150 mg/dL. Finalmente, a faixa dos valores de PCR é de 0 a $20 \mathrm{mg} / \mathrm{L}$. Então, por exemplo, se calcularmos o risco cardiovascular de um indivíduo com 35 anos, a calculadora irá considerar 45 anos automaticamente, pois o valor se encontra fora da faixa utilizada. 
A classificação do risco cardiovascular global em 10 anos para homens e mulheres utilizada por RIDKER et al. $(2007 ; 2008)$ é apresentada na Tabela 10. Para o presente estudo, adotou-se a classificação apresentada na Tabela 11.

Tabela 10. Classificação do risco cardiovascular global em 10 anos de homens e mulheres segundo ERR.

\begin{tabular}{cc}
\hline Classificação & Risco \\
\hline Baixo & $<5 \%$ \\
Baixo a intermediário & $\geq 5 \% \mathrm{a}<10 \%$ \\
Intermediário & $\geq 10 \% \mathrm{a}<20 \%$ \\
Alto & $\geq 20 \%$ \\
\hline
\end{tabular}

Tabela 11. Classificação do risco cardiovascular global em 10 anos de homens e mulheres do ERR utilizada no estudo.

\begin{tabular}{cc}
\hline Classificação & Risco \\
\hline Baixo & $<5 \%$ \\
Intermediário & $\geq 5 \% \mathrm{a}<20 \%$ \\
Alto & $\geq 20 \%$ \\
\hline
\end{tabular}

Para calcular o risco cardiovascular em 10 anos através do da Diretriz de 2013 da ACC/AHA (GOFF et al., 2014; STONE et al., 2014), foi utilizada a calculadora do site

https://professional.heart.org/professional/GuidelinesStatements/PreventionGuidelines/

UCM_457698_ASCVD-Risk-Calculator.jsp. Esse cálculo utiliza sexo, idade, etnia (dividida entre negros e não negros), CT, HDL-C, PAS, uso de anti-hipertensivos, tabagismo, e presença de diabetes determinada pela glicemia $\geq 126 \mathrm{mg} / \mathrm{dL}$ ou uso de medicamentos hipoglicemiantes. Os indivíduos diabéticos foram classificados como grupo de alto risco, então automaticamente considerou-se risco de 7,5\% a esses pacientes. A estratificação de risco se encontra na Tabela 12.

Tabela 12. Classificação do risco cardiovascular global em 10 anos de homens e mulheres segundo ACC/AHA (2013) utilizado no presente estudo.

\begin{tabular}{cc}
\hline Classificação & Risco \\
\hline Baixo & $<5 \%$ \\
Intermediário & $\geq 5 \% \mathrm{a}<7,5 \%$ \\
Alto & $\geq 7,5 \%$ \\
\hline
\end{tabular}

Nesta calculadora também se utiliza o valor mais próximo para variáveis fora da faixa considerada para o cálculo. Assim, as faixas de idade são de 20 a 79 anos, de TC são de 130 a 320 mg/dL, de HDL-c são de 20 a 100 mg/dL e de PAS são de 90 a 200 $\mathrm{mm} / \mathrm{Hg}$. 


\subsection{Análises estatísticas}

Para caracterizar a amostra, segundo sexo, foi utilizado o teste Qui-quadrado $\left(\chi^{2}\right) \mathrm{em}$ variáveis qualitativas, com apresentação de dados na forma de valor absoluto (n), seguido do respectivo valor percentual (\%). Nas variáveis contínuas foi aplicado o teste Kolmogorov-Smirnov para determinar suas respectivas distribuições, e posteriormente foi realizado o Teste $t$ independente ou Mann-Whitney para avaliar a diferença entre os sexos. As variáveis paramétricas estão apresentadas na forma de média, seguidas pelo desvio padrão, e as não-paramétricas estão forma de mediana, seguidas pelo intervalo interquartil (IIQ).

Para a análise de concordância entre a classificação dos três escores de risco utilizou-se a análise de concordância de kappa (k). A força de concordância de cada análise foi descrita segundo as categorias propostas por LANDIS e KOCH (1977) como: pobre $(\mathrm{k}=0,00)$; fraca $(0,00<\mathrm{k}<0,20)$; razoável $(0,21<\mathrm{k}<0,40)$; moderada $(0,41<\mathrm{k}<0,60)$; substancial $(0,61<\mathrm{k}<0,80)$; e quase perfeita $(0,81<\mathrm{k}<1,00)$.

Para verificar a relação dos ácidos graxos dietéticos com os ácidos graxos de membrana eritrocitária, foram feitas correlações de Pearson e de Spearman.

Para testar associação entre os parâmetros bioquímicos e clínicos com os AG n-3, o IO3, os AG n-6 e a razão n-6/n-3 das membranas eritrocitárias foram divididos em tercis, e para verificar a diferença entre os grupos os testes ANOVA Oneway e Kruskall-Wallis foram aplicados. O teste de Bonferroni foi utilizado para os testes posthoc. Essas análises foram realizadas tanto para a amostra total como para homens e mulheres.

Para entender como os AG n-3 e suas relações com os AG n-6 influenciam o a estratificação do risco cardiovascular global, foram feitas regressões logísticas binárias com os escores de risco supracitados como variáveis dependentes (no modelo de regressão, $0=\mathrm{RCV}$ baixo e $1=\mathrm{RCV}$ moderado e alto) e os ácidos individualmente como variáveis independentes. As variáveis que foram utilizadas para o cálculo dos escores de risco, como por exemplo o tabagismo, não foram utilizadas como ajustes dos modelos a fim de se evitar colinearidade. Desta forma, apenas IMC, atividade física e escolaridade foram utilizados como ajustes nos modelos múltiplos.

Como as membranas celulares são compostas por AG com diferentes características físico-químicas e metabólicas, a associação isolada de AG ou pequenos grupos de AG 
pode não refletir como a composição geral das membranas influencia os biomarcadores e o risco cardiovascular global. Desta forma, foi feita análise fatorial dos ácidos graxos como técnica redutora de variáveis (HAIR et al., 2006). A adequação dos dados para análise fatorial foi verificada pelo teste Kaiser-Meyer-Olklin (KMO) e pelo teste de esfericidade de Barlett. Inicialmente, os dados foram considerados inadequados para esta análise pelo fato de o KMO estar menor que 0,50. Após a remoção dos ácidos graxos saturados, os dados se tornaram adequados com KMO de 0,63. Para identificar o número de padrões de ácidos graxos insaturados de membranas eritrocitárias a serem retidos, foi utilizado como critério de significância o valor do Eigenvalue maior que 1,0 e a coerência dos padrões gerados. A rotação ortogonal VARIMAX foi realizada para isolamento das maiores cargas fatoriais. Cargas fatoriais maiores que 0,20 foram consideradas significantes com o propósito de interpretação dos padrões de AG insaturados de membranas encontrados. Foram gerados, então, 3 fatores que refletem os padrões de AG de membrana da amostra. Esses fatores foram nomeados Membrana 1, Membrana 2 e Membrana 3. Então, para verificar a influência desses padrões no risco cardiovascular global, foram feitas correlações ponto-bisserial e regressões logísticas com os três escores de risco.

Os testes estatísticos foram realizados através do programa Statistical Package for the Social Sciences ${ }^{\circledR}$ (SPSS), versão 20.0 e Stata ${ }^{\circledR}$ versão 14.0.

\subsection{Aspectos éticos}

Este estudo foi aprovado pelos Comitês de Ética em Pesquisa com Seres Humanos da Faculdade de Saúde Pública (COEP/FSP) e do Hospital Universitário (Anexos 5 e 6).

\subsection{Suporte financeiro}

Este estudo contou com apoio da Coordenação de Aperfeiçoamento de Pessoal de Nível Superior (CAPES - 8882.330835/2019-01), do Conselho Nacional de Desenvolvimento Científico e Tecnológico (CNPq - 465259/2014-6), Fundação de Amparo à Pesquisa (FAPESP - 2014/50983-3) e Instituto Nacional de Ciência e Tecnologia de Fluidos Complexos (INCT-FCx). 


\section{RESULTADOS}

As caracterizações clínica e demográfica da amostra estão apresentadas na Tabela 13. Houve diferenças entre homens e mulheres na idade, tabagismo, consumo de álcool, escolaridade, hipotireoidismo, uso de estatinas e uso de hormônios tireoidianos. 
Tabela 13. Caracterização clínica e sociodemográfica, segundo sexo.

\begin{tabular}{|c|c|c|c|c|}
\hline Variáveis & Total & Homens $(n=133)$ & Mulheres $(n=223)$ & p-valor \\
\hline Idade, anos & $52,5(10,4)$ & $49,4(11,1)$ & $54,4(9,5)$ & $<0,001 *$ \\
\hline Etnia & & & & 0,191 \\
\hline Brancos & $238(66,9)$ & $87(24,4)$ & $151(42,4)$ & \\
\hline Negros & $31(8,7)$ & $8(2,2)$ & $23(6,5)$ & \\
\hline Pardos & $76(21,3)$ & $31(8,7)$ & $45(12,6)$ & \\
\hline Asiáticos & $9(2,5)$ & $6(1,7)$ & $3(0,8)$ & \\
\hline Indígenas & $2(0,6)$ & $1(0,3)$ & $1(0,3)$ & \\
\hline Tabagismo & & & & $0,003 *$ \\
\hline Tabagista & $70(19,7)$ & $35(9,8)$ & $35(9,8)$ & \\
\hline Não tabagista & $188(52,8)$ & $55(15,4)$ & $133(37,4)$ & \\
\hline Ex-tabagista & $98(27,5)$ & $43(12,1)$ & $55(15,4)$ & \\
\hline Consumo de álcool & & & & $<0.001 *$ \\
\hline Sim & $164(46,1)$ & $86(24,2)$ & $78(21,9)$ & \\
\hline Não & $192(53,9)$ & $47(13,2)$ & $145(40,7)$ & \\
\hline Escolaridade & & & & $0,035 *$ \\
\hline Fundamental incompleto & $48(13,5)$ & $11(3,1)$ & $37(10,4)$ & \\
\hline Fundamental & $21(5,9)$ & $10(2,8)$ & $11(3,1)$ & \\
\hline Ensino médio incompleto & $12(3,4)$ & $3(0,8)$ & $9(2,5)$ & \\
\hline Ensino médio & $95(26,7)$ & $32(9,0)$ & $63(17,7)$ & \\
\hline Ensino superior incompleto & $32(9,0)$ & $16(4,5)$ & $16(4,5)$ & \\
\hline Ensino superior & $105(29,5)$ & $38(10,7)$ & $67(18,8)$ & \\
\hline Pós-graduação & $43(12,1)$ & $23(6,5)$ & $20(5,6)$ & \\
\hline \multicolumn{5}{|l|}{ Doenças autorrelatadas } \\
\hline Diabetes Mellitus & $72(20,2)$ & $33(9,3)$ & $39(11,0)$ & 0,103 \\
\hline Hipertensão & $203(57,0)$ & $76(21,3)$ & $127(35,7)$ & 1,000 \\
\hline Hipotireoidismo & $43(12,1)$ & $3(0,8)$ & $40(11,2)$ & $<0,001^{*}$ \\
\hline Hepatopatias & $7(2,0)$ & $5(1,4)$ & $2(0,6)$ & 0,107 \\
\hline Doença renal crônica & $3(0,8)$ & $2(0,6)$ & $1(0,3)$ & 0,558 \\
\hline Dislipidemias & $192(53,9)$ & $72(20,2)$ & $120(33,7)$ & 1,000 \\
\hline Doenças autoimunes & $3(0,8)$ & $1(0,3)$ & $2(0,6)$ & 1,000 \\
\hline \multicolumn{5}{|l|}{ Uso de medicamentos } \\
\hline Estatinas & $98(27,5)$ & $28(7,9)$ & $70(19,7)$ & $0,037 *$ \\
\hline Anti-hipertensivos & $184(51,7)$ & $65(18,3)$ & $119(33,4)$ & 0,444 \\
\hline Hipoglicemiantes & $74(20,8)$ & $30(8,4)$ & $44(12,4)$ & 0,589 \\
\hline Fibratos & $9(2,5)$ & $3(0,8)$ & $6(1,7)$ & 0,549 \\
\hline Hormônios tireoidianos & $45(12,6)$ & $3(0,8)$ & $42(11,8)$ & $<0,001 *$ \\
\hline \multicolumn{5}{|l|}{ Antecedentes familiares } \\
\hline Obesidade & $64(18,0)$ & $28(7,9)$ & $36(10,1)$ & 0,256 \\
\hline Hipertensão & $232(65,2)$ & $84(23,6)$ & $148(41,6)$ & 0,566 \\
\hline Infarto & $100(28,1)$ & $38(10,7)$ & $62(17,4)$ & 0,903 \\
\hline Acidente vascular encefálico & $68(19,1)$ & $25(7,0)$ & $43(12,1)$ & 1,000 \\
\hline Diabetes Mellitus & $134(37,6)$ & $49(13,8)$ & $85(23,9)$ & 0,822 \\
\hline \multicolumn{5}{|l|}{ Características clínicas } \\
\hline Escore de atividade física & $7,18(1,39)$ & $7,19(1,36)$ & $7,17(1,40)$ & 0,911 \\
\hline Frequência cardíaca, bpm & $67(11)$ & $67(12)$ & 67 (10) & 0,525 \\
\hline $\begin{array}{r}\text { Pressão arterial sistólica, } \\
\mathrm{mmHg}\end{array}$ & $133(18)$ & $135(16)$ & 133 (19) & 0,248 \\
\hline $\begin{array}{r}\text { Pressão arterial diastólica, } \\
\mathrm{mmHg}\end{array}$ & $81(10)$ & $82(10)$ & $81(10)$ & 0,163 \\
\hline
\end{tabular}

Para fazer a comparação entre os sexos, foram utilizados os testes t-independente ou Mann-Whitney para variáveis contínuas e o teste de Qui-quadrado para variáveis categóricas. Os dados estão apresentados na forma de média (desvio padrão) ou mediana (intervalo interquartil) para as variáveis contínuas; e $n(\%)$ para variáveis categóricas; as porcentagens são referentes ao total da amostra. $p$ valor $<0,05$. 
Quanto aos parâmetros antropométricos, os homens apresentaram maior peso $(89,7$ $\pm 17,7 \mathrm{~kg}$ versus $77,1 \pm 16,1 \mathrm{~kg} ; \mathrm{p}<0,001)$ e circunferência de cintura $(104 \pm 13 \mathrm{~cm}$ versus $99 \pm 13 \mathrm{~cm} ; \mathrm{p}<0,001)$ em relação às mulheres, conforme esperado; enquanto essas apresentaram maior adiposidade corporal $(44,1 \pm 7,4 \%$ versus $22,3 \pm 4,7 \%$; $<$ < 0,001) (Tabela 14).

Tabela 14. Caracterização da composição corporal, segundo sexo.

\begin{tabular}{|c|c|c|c|c|}
\hline Variáveis & Total & Homens $(\mathrm{n}=133)$ & Mulheres $(n=223)$ & p-valor \\
\hline Peso, $\mathrm{kg}$ & $81,8(17,7)$ & $89,7(17,6)$ & $77,1(16,1)$ & $<0,001^{*}$ \\
\hline $\mathrm{IMC}, \mathrm{kg} / \mathrm{m}^{2}$ & $30,9(5,8)$ & $30,4(5,4)$ & $31,1(6,0)$ & 0,268 \\
\hline Classificação do IMC & & & & 0,864 \\
\hline Abaixo do peso & $5(1,4)$ & $1(0,3)$ & $4(1,1)$ & \\
\hline Eutrofia & $67(18,8)$ & $26(7,3)$ & $41(11,5)$ & \\
\hline Sobrepeso & $102(28,7)$ & $40(11,2)$ & $62(17,4)$ & \\
\hline Obesidade & $182(51,1)$ & $66(18,5)$ & $116(32,6)$ & \\
\hline $\begin{array}{l}\text { Circunferência de cintura, cm } \\
\text { Classificacão da }\end{array}$ & $101(14)$ & $104(13)$ & $99(13)$ & $<0,001 *$ \\
\hline circunferência de cintura & & & & $<0,001 *$ \\
\hline Normal & $48(13,5)$ & $32(9,0)$ & $16(4,5)$ & \\
\hline Alta & $59(16,6)$ & $28(7,9)$ & $31(8,7)$ & \\
\hline Muito alta & $248(69,9)$ & $73(20,6)$ & $175(49,3)$ & \\
\hline $\begin{array}{l}\text { Adiposidade corporal, \% } \\
\text { Classificação da adiposidade }\end{array}$ & $36,3(12,0)$ & $22.3(4,7)$ & $44.1(7,4)$ & $<0,001 *$ \\
\hline corporal & & & & $<0,001^{*}$ \\
\hline Baixa & $7(2,0)$ & $6(1,7)$ & $1(0,3)$ & \\
\hline Normal & $83(23,9)$ & $79(22,8)$ & $4(1,1)$ & \\
\hline Alta & $257(74,1)$ & $44(12,7)$ & $213(61,4)$ & \\
\hline
\end{tabular}

Para fazer a comparação entre os sexos, foram utilizados os testes t-independente ou Mann-Whitney para variáveis contínuas e o teste de qui-quadrado para variáveis categóricas. Os dados estão apresentados na forma de média (desvio padrão) ou mediana (intervalo interquartil) para as variáveis contínuas; e $n$ (\%) para variáveis categóricas. As porcentagens são referentes ao total da amostra. $p$-valor $<0,05$.

Apesar dos homens consumirem mais energia que as mulheres, as calorias ajustadas pelo peso corporal não diferiram entre os sexos. As mulheres, por outro lado, apresentaram maior consumo de AG trans (0,81\%, IIQ: 0,63-1,09\% versus 0,73\%, IIQ: 0,54-0,93 \%; p < 0,001), C20:3 n-3 (10,0 mg, IIQ: 9,9-10,1 mg versus 9,9 mg, IIQ: 9,8-10,0 mg; $\mathrm{p}<0,001$ ) e C22:5 n-3 (7,9 mg, IIQ: 7,3-15,3 mg versus 7,6 mg, IIQ: 7,014,4 mg; $\mathrm{p}=0,030)($ Tabela 15). 
Tabela 15. Caracterização dos nutrientes dietéticos, segundo sexo.

\begin{tabular}{|c|c|c|c|c|}
\hline Variáveis & Total & Homens $(n=133)$ & Mulheres $(n=223)$ & p-valor \\
\hline $\begin{array}{l}\text { Energia/peso, } \\
\mathrm{kcal} / \mathrm{kg}\end{array}$ & $20(16 ; 24)$ & $20(16 ; 25)$ & $20(15 ; 24)$ & 0,396 \\
\hline Energia, kcal & $1634(448)$ & $1839(469)$ & $1514(389)$ & $<0,001 *$ \\
\hline Proteínas, \% & $18,09(4,77)$ & $17,90(3,32)$ & $18,23(3,68)$ & 0,407 \\
\hline Carboidratos, $\%$ & $54,47(9,81)$ & $54,19(8,37)$ & $54,39(7,26)$ & 0,822 \\
\hline Lipídeos, \% & $28,78(8,11)$ & $28,48(5,63)$ & $29,75(5,94)$ & 0,052 \\
\hline AGS, $\%$ & $9,67(3,81)$ & $9,55(2,39)$ & $9,99(2,87)$ & 0,126 \\
\hline AGMI, \% & $7,40(3,83)$ & $7,47(2,21)$ & $7,77(2,49)$ & 0,269 \\
\hline AGPI, \% & $3,36(2,11)$ & $3,38(1,40)$ & $3,49(1,19)$ & 0,458 \\
\hline AG trans, \% & $0,81(0,77)$ & $0,73(0,54 ; 0,93)$ & $0,81(0,63 ; 1,09)$ & $0,001 *$ \\
\hline Colesterol, mg & $201(158 ; 243)$ & $200(156 ; 247)$ & $201(159 ; 236)$ & 0,734 \\
\hline Fibras, $\mathrm{g}$ & $16(4)$ & $16(5)$ & $16(4)$ & 0,751 \\
\hline Açúcares, g & $78(24)$ & $77(26)$ & $79(23)$ & 0,336 \\
\hline \multicolumn{5}{|l|}{$A G S, m g$} \\
\hline C16:0 & $5714,0(1998,5)$ & $5687,2(1940,6)$ & $5729,8(2035,9)$ & 0,850 \\
\hline C18:0 & $2580,6(1002,6)$ & $2571,4(980,0)$ & $2585,9(1017,9)$ & 0,898 \\
\hline C20:0 & $11,8(5,3)$ & $11,7(5,4)$ & $11,9(5,3)$ & 0,721 \\
\hline $\mathrm{C} 22: 0$ & $11,2(6,7 ; 14,3)$ & $11,8(6,5 ; 14,8)$ & $8,0(6,9 ; 14,2)$ & 0,672 \\
\hline C24:0 & $10,0(9,8 ; 10,3)$ & $9,9(9,7 ; 10,1)$ & $10,1(9,8 ; 10,3)$ & 0,089 \\
\hline \multicolumn{5}{|l|}{$A G M I, m g$} \\
\hline C16:1 n-7 & $1296,7(954,7 ; 1647,3)$ & $1329,2(996,7 ; 1733,5)$ & $1259,8(952,6 ; 1620,9)$ & 0,286 \\
\hline C18:1 n-9 & $8920,9(3199,1)$ & $8955,8(3171,2)$ & $8900,4(3222,5)$ & 0,878 \\
\hline C20:1 n-11 & $141,2(89,3 ; 207,7)$ & $138,8(84,5 ; 202,3)$ & $142,9(89,9 ; 209,0)$ & 0,623 \\
\hline C22:1 n-9 & $141,0(170,2)$ & $57,6(99,1)$ & $182,7(185,5)$ & 0,114 \\
\hline C24:1 n-9 & $28,1(17,0)$ & $53,2(\mathrm{n} / \mathrm{a})$ & $19,7(3,7)$ & $0,016^{*}$ \\
\hline \multicolumn{5}{|l|}{$A G P I n-6, m g$} \\
\hline C18:2 n-6 & $4037,4(1751,9)$ & $4061,5(1947,2)$ & $4023,2(1631,3)$ & 0,846 \\
\hline C20:4 n-6 & $204,5(134,0 ; 289,0)$ & $215,4(152,2 ; 295,4)$ & $197,9(123,2 ; 287,4)$ & 0,134 \\
\hline$n-6$ total & $4024,2(1705,0)$ & $4048,1(1901,0)$ & $4010,1(1583,4)$ & 0,843 \\
\hline \multicolumn{5}{|l|}{$A G P I n-3, m g$} \\
\hline C18:3 n-3 & $466,1(365,9 ; 603,4)$ & $460,4(357,6 ; 607,1)$ & $474,3(366,0 ; 602,7)$ & 0,864 \\
\hline $\mathrm{C} 20: 3 \mathrm{n}-3$ & $10,0(9,9 ; 10,1)$ & $9,9(9,8 ; 10,0)$ & $10,0(9,9 ; 10,1)$ & $<0,001 *$ \\
\hline$C 20: 5 n-3$ & $12,0(6,4 ; 21,9)$ & $13,0(8,5 ; 23,7)$ & $11,7(6,2 ; 21,7)$ & 0,291 \\
\hline$C 22: 5 n-3$ & $7,8(7,2 ; 14,7)$ & $7,6(7,0 ; 14,4)$ & $7,9(7,3 ; 15,3)$ & $0,030 *$ \\
\hline $\mathrm{C} 22: 6 \mathrm{n}-3$ & $33,3(15,5 ; 59,7)$ & $34,1(18,2 ; 59,4)$ & $33,0(14,8 ; 59,8)$ & 0,945 \\
\hline$n-3$ total & $537,0(404,2 ; 724,1)$ & $524,4(400,5 ; 676,5)$ & $548,3(406,5 ; 749,7)$ & 0,311 \\
\hline \multicolumn{5}{|l|}{ Razão de $A G$} \\
\hline$n-6 / n-3$ & $4,5(3,3 ; 5,7)$ & $4,5(3,2 ; 5,7)$ & $4,5(3,3 ; 5,7)$ & 0,785 \\
\hline
\end{tabular}

Quanto ao perfil de AG nas membranas eritrocitárias, observou-se que as mulheres apresentaram mais C18:0 (25,14 \%, IIQ: 23,23-27,68 \% versus 24,47 \%, IIQ: 22,53$26,28 \%$; $=0,041), \mathrm{C} 20: 0$ (0,69 \%, IIQ: 0,61-0,80 \% versus 0,66 \%, IIQ: 0,57-0,73\%; $\mathrm{p}=0,018$ ), e menor atividade de desaturase de estearoil-CoA 1 (SCD-1), mensurada pela razão C18:0/C18:1 n-9 (2,62 \%, IIQ:2,07-3,61 \% versus 2,28 \%, IIQ: 1,88-3,14 \%; $\mathrm{p}=0,028$ ) (Tabela 16). Não houve correlação entre os AG n-6 e n-3 de membranas e AG n-6 e n-3 dietéticos (resultados não apresentados). 
Tabela 16. Perfil de ácidos graxos de membrana eritrocitária, segundo sexo.

\begin{tabular}{|c|c|c|c|c|}
\hline Variáveis & Total & Homens (n = 133) & Mulheres $(n=223)$ & p-valor \\
\hline \multicolumn{5}{|l|}{$A G S, \%$} \\
\hline C16:0 & $43,62(41,10 ; 47,54)$ & $43,21(41,26 ; 47,33)$ & $43,79(40,95 ; 47,72)$ & 0,824 \\
\hline C18:0 & $24,81(22,90 ; 27,27)$ & $24,47(22,53 ; 26,28)$ & $25,14(23,23 ; 27,68)$ & $0,041 *$ \\
\hline C20:0 & $0,67(0,60 ; 0,78)$ & $0,66(0,57 ; 0,73)$ & $0,69(0,61 ; 0,80)$ & $0,018 *$ \\
\hline $\mathrm{C} 22: 0$ & $1,10(0,90 ; 1,37)$ & $1,08(0,89 ; 1,30)$ & $1,12(0,91 ; 1,43)$ & 0,179 \\
\hline $\mathrm{C} 24: 0$ & $0,26(0,14 ; 0,67)$ & $0,31(0,14 ; 0,74)$ & $0,23(0,14 ; 0,61)$ & 0,244 \\
\hline \multicolumn{5}{|l|}{$A G M I, \%$} \\
\hline C16:1 n-7 & $0,34(0,20 ; 0,64)$ & $0,33(0,19 ; 0,65)$ & $0,34(0,20 ; 0,63)$ & 0,982 \\
\hline C18:1 n-9 & $10,00(3,54)$ & $10,45(3,15)$ & $9,74(3,73)$ & 0,076 \\
\hline C20:1 n-9 & $0,08(0,06 ; 0,11)$ & $0,07(0,05 ; 0,11)$ & $0,08(0,06 ; 0,11)$ & 0,360 \\
\hline C22:1 n-9 & $0,14(0,11 ; 0,19)$ & $0,14(0,12 ; 0,19)$ & $0,15(0,11 ; 0,19)$ & 0,678 \\
\hline C24:1 n-9 & $1,31(0,53)$ & $1,32(0,46)$ & $1,31(0,56)$ & 0,774 \\
\hline \multicolumn{5}{|l|}{$A G P I n-6, \%$} \\
\hline C18:2 n-6 & 4,70 (1,83) & $4,87(1,82)$ & 4,60 (1,83) & 0,191 \\
\hline C18:3 n-6 & $0,16(0,12 ; 0,22)$ & $0,16(0,11 ; 0,22)$ & $0,16(0,12 ; 0,22)$ & 0,246 \\
\hline C20:2 n-6 & $0,09(0,06 ; 0,15)$ & $0,09(0,06 ; 0,14)$ & $0,10(0,06 ; 0,15)$ & 0,422 \\
\hline$C 20: 3 n-6$ & $0,55(0,33)$ & $0,57(0,34)$ & $0,54(0,33)$ & 0,305 \\
\hline C20:4 n-6 & $2,50(1,43 ; 5,14)$ & $2,59(1,54 ; 5,36)$ & $2,42(1,41 ; 5,13)$ & 0,420 \\
\hline $\mathrm{C} 22: 2 \mathrm{n}-6$ & $0,38(0,25 ; 0,56)$ & $0,36(0,24 ; 0,54)$ & $0,39(0,25 ; 0,60)$ & 0,600 \\
\hline n-6 total & $9,36(3,82)$ & $9,64(3,86)$ & $9,20(3,79)$ & 0,311 \\
\hline \multicolumn{5}{|l|}{$A G P I n-3, \%$} \\
\hline C18:3 n-3 & $1,96(1,53 ; 2,36)$ & $2,00(1,28 ; 2,47)$ & $1,94(1,25 ; 2,65)$ & 0,825 \\
\hline$C 20: 5 n-3$ & $0,22(0,14 ; 0,32)$ & $0,21(0,14 ; 0,31)$ & $0,22(0,13 ; 0,32)$ & 0,815 \\
\hline$C 22: 6 n-3$ & $3,35(2,71 ; 4,21)$ & $3,52(2,76 ; 4,29)$ & $3,24(2,62 ; 4,11)$ & 0,350 \\
\hline IO3 & $3,59(2,97 ; 4,47)$ & $3,69(3,05 ; 4,57)$ & $3,55(2,96 ; 4,40)$ & 0,350 \\
\hline n-3 total & $5,65(4,76 ; 6,67)$ & $5,69(4,94 ; 6,64)$ & $5,58(4,62 ; 6,70)$ & 0,373 \\
\hline \multicolumn{5}{|l|}{ Relações de $A G$} \\
\hline AGS/AGI & $2,53(2,18 ; 3,06)$ & $2,49(2,18 ; 2,88)$ & $2,56(2,17 ; 3,23)$ & 0,111 \\
\hline AGS/AGMI & $5,76(4,73 ; 7,23)$ & $5,49(4,61 ; 6,81)$ & $5,89(4,78 ; 7,62)$ & 0,070 \\
\hline AGS/AGPI & $4,68(3,92 ; 5,72)$ & $4,64(3,92 ; 5,58)$ & $4,69(3,93 ; 5,94)$ & 0,329 \\
\hline C16:0/C16:1 n-7 & $130,71(67,94 ; 232,56)$ & $130,71(67,36 ; 231,92)$ & $129,61(69,08 ; 233,24)$ & 0,881 \\
\hline C16:0/C18:1 n-9 & $4,26(3,59 ; 5,56)$ & $4,10(3,51 ; 5,27)$ & $4,31(3,68 ; 5,94)$ & 0,050 \\
\hline C18:0/C18:1 n-9 & $2,50(2,00 ; 3,44)$ & $2,28(1,88 ; 3,14)$ & $2,62(2,07 ; 3,61)$ & $0,028 *$ \\
\hline C20:0/C20:1 n-9 & $8,95(5,96 ; 12,29)$ & $8,98(6,16 ; 12,16)$ & $8,94(5,75 ; 12,37)$ & 0,928 \\
\hline C22:0/C22:1 n-9 & $7,50(5,04 ; 10,91)$ & $7,75(4,83 ; 9,84)$ & $7,48(5,08 ; 12,08)$ & 0,345 \\
\hline C24:0/C24:1 n-9 & $0,22(0,12 ; 0,52)$ & $0,23(0,13 ; 0,58)$ & $0,21(0,11 ; 0,49)$ & 0,380 \\
\hline C20:0/C20:2 n-6 & $7,08(4,23 ; 11,16)$ & $6,98(4,70 ; 10,66)$ & $7,24(4,05 ; 11,45)$ & 0,830 \\
\hline $\mathrm{C} 22: 0 / \mathrm{C} 22: 2 \mathrm{n}-6$ & $3,05(1,93 ; 4,59)$ & $2,80(1,97 ; 4,83)$ & $3,28(1,89 ; 4,44)$ & 0,636 \\
\hline$n-6 / n-3$ & $1,66(1,02 ; 2,35)$ & $1,63(1,13 ; 2,48)$ & $1,68(0,97 ; 2,31)$ & 0,645 \\
\hline C20:4 n-6/C20:5 n-3 & $12,94(5,58 ; 27,60)$ & $14,31(6,06 ; 27,54)$ & $12,68(5,11 ; 28,30)$ & 0,630 \\
\hline C20:4 n-6/(IO3) & $0,72(0,37 ; 1,55)$ & $0,73(0,39 ; 1,53)$ & $0,71(0,35 ; 1,59)$ & 0,828 \\
\hline C18:3 n-3/C20:5 n-3 & $9,05(5,70 ; 13,98)$ & $9,26(5,58 ; 14,11)$ & $8,51(5,72 ; 14,00)$ & 0,921 \\
\hline C18:2 n-6/C20:4 n-6 & $1,82(1,03 ; 2,80)$ & $1,66(1,03 ; 2,89)$ & $1,84(1,02 ; 2,78)$ & 0,978 \\
\hline C18:2 n-6/C18:3n-3 & $2,39(1,42 ; 4,21)$ & $2,39(1,62 ; 4,31)$ & $2,39(1,39 ; 4,17)$ & 0,486 \\
\hline
\end{tabular}

Para fazer a comparação entre os sexos, foram utilizados os testes t-independente ou Mann-Whitney. Os dados estão apresentados na forma de média (desvio padrão) ou mediana (intervalo interquartil) dependendo da distribuição da variável contínua. $p$-valor: significância estatística em p<0,05. AGI: ácidos graxos insaturados; AGMI: ácidos graxos monoinsaturados; AGPI: ácidos graxos poli-insaturados; AGS: ácidos graxos saturados; IO3: índice ômega-3. 
As mulheres do estudo apresentaram mais colesterol total, HDL-c, LDL-c, ácidos graxos não esterificados (AGNE), mais Apo A-I, atividade de PON1, HDL grande, LDL(-), adiponectina, leptina, PCR e maior tamanho de LDL em relação aos homens, enquanto que os homens apresentaram mais TG, HDL pequena e intermediária e LDL pequena (Tabela 17).

Tabela 17. Caracterização bioquímica dos indivíduos, segundo sexo.

\begin{tabular}{|c|c|c|c|c|}
\hline Variáveis & Total & Homens $(n=133)$ & Mulheres $(n=223)$ & p-valor \\
\hline Colesterol total, $\mathrm{mg} / \mathrm{dL}$ & $205(43)$ & $199(39)$ & $209(44)$ & $0,039 *$ \\
\hline $\mathrm{HDL}-\mathrm{c}, \mathrm{mg} / \mathrm{dL}$ & $36(30 ; 42)$ & $31(27 ; 36)$ & $39(33 ; 45)$ & $<0,001 *$ \\
\hline LDL-c, mg/dL & $137(39)$ & $131(35)$ & $141(40)$ & $0,032 *$ \\
\hline Triglicerídeos, mg/dL & $131(98 ; 191)$ & $151(109 ; 221)$ & $125(91 ; 176)$ & $<0,001 *$ \\
\hline Não-HDL-c, mg/dL & $168(42)$ & $167(39)$ & $169(43)$ & 0,702 \\
\hline AGNE, mEq/dL & $0,65(0,29)$ & $0,58(0,30)$ & $0,69(0,28)$ & $0,001 *$ \\
\hline Apo A-I, mg/dL & $132(26)$ & $123(22)$ & $138(26)$ & $<0,001 *$ \\
\hline Apo B, mg/dL & $104(25)$ & $102(23)$ & $105,75(25,87)$ & 0,170 \\
\hline PON1, nmol $\min ^{-1} * \mathrm{ml}^{-1}$ & $55(24 ; 81)$ & $50(22 ; 76)$ & $60(26 ; 83)$ & $0,032 *$ \\
\hline HDL grande, $\%$ & $29(9)$ & $27(8)$ & $30(9)$ & $<0,001 *$ \\
\hline HDL intermediária, \% & $50(5)$ & $51(4)$ & $50(5)$ & $0,023 *$ \\
\hline HDL pequena, $\%$ & $21(7)$ & $22(7)$ & $20(7)$ & $0,006^{*}$ \\
\hline HDL grande, mg/dL & $10(7 ; 14)$ & $8(6 ; 10)$ & $11(8 ; 16)$ & $<0,001 *$ \\
\hline $\mathrm{HDL}$ intermediária, $\mathrm{mg} / \mathrm{dL}$ & $18(15 ; 21)$ & $16(14 ; 18)$ & $19(17 ; 22)$ & $<0,001 *$ \\
\hline HDL pequena, mg/dL & $7(5 ; 9)$ & $7(5 ; 9)$ & $7(6 ; 10)$ & $0,011 *$ \\
\hline LDL pequena, $\%$ & $2(1 ; 5)$ & $2(1 ; 6)$ & $1(1 ; 4)$ & $<0,001 *$ \\
\hline LDL grande \% & $26(5)$ & $26(5)$ & $26(5)$ & 0,719 \\
\hline LDL pequena, mg/dL & $3(1 ; 9)$ & $5(2 ; 14)$ & $3(1 ; 8)$ & $<0,001 *$ \\
\hline LDL grande, mg/dL & $53(17)$ & $51(14)$ & $54(18)$ & 0,139 \\
\hline Tamanho de LDL, nm & $270(266 ; 272)$ & $269(263 ; 271)$ & $270(267 ; 272)$ & $<0,001 *$ \\
\hline $\mathrm{LDL}(-), \mu \mathrm{g} / \mathrm{mL}$ & $5,39(1,86 ; 18,00)$ & $4,41(1,49 ; 11,03)$ & $6,45(2,15 ; 23,26)$ & $0,008 *$ \\
\hline Anti-LDL(-), $\mu \mathrm{g} / \mathrm{mL}$ & $7,59(4,41 ; 11,43)$ & $7,88(5,05 ; 11,43)$ & $7,48(3,99 ; 11,43)$ & 0,316 \\
\hline $\mathrm{CETP}, \mathrm{pmol} / \mu \mathrm{L} / \mathrm{h}$ & $50,35(37,71 ; 66,77)$ & $55,79(39,14 ; 67,46)$ & $46,57(37,07 ; 66,43)$ & 0,076 \\
\hline Glicemia, mg/dL & $98(91 ; 108)$ & $100(91 ; 116)$ & $97(91 ; 106)$ & 0,087 \\
\hline Insulina, $\mu \mathrm{UI} / \mathrm{mL}$ & $16(13 ; 22)$ & $15(13 ; 22)$ & $17(13 ; 22)$ & 0,658 \\
\hline HOMA-IR & $4,04(2,98 ; 5,86)$ & $4,16(3,10 ; 5,93)$ & $3,96(2,93 ; 5,73)$ & 0,524 \\
\hline HbA1c, $\%$ & $5,00(4,70 ; 5,28)$ & $4,90(4,70 ; 5,30)$ & $5,00(4,80 ; 5,20)$ & 0,292 \\
\hline Adiponectina, ng/mL & $8,30(4,70 ; 12,90)$ & $6,16(4,02 ; 10,12)$ & $9,23(5,54 ; 13,80)$ & $<0,001 *$ \\
\hline Leptina, $\mathrm{ng} / \mathrm{mL}$ & $34,50(11,10 ; 65,13)$ & $9,80(5,95 ; 19,93)$ & $50,55(27,85 ; 83,08)$ & $<0,001 *$ \\
\hline $\mathrm{PCR}, \mathrm{mg} / \mathrm{L}$ & $2,84(1,20 ; 5,95)$ & $2,04(0,95 ; 5,37)$ & $3,33(1,43 ; 6,38)$ & $0,006 *$ \\
\hline
\end{tabular}

Para fazer a comparação entre os sexos, foram utilizados os testes t-independente ou Mann-Whitney. Os dados estão apresentados na forma de média (desvio padrão) ou mediana (intervalo interquartil) dependendo da distribuição da variável contínua. $p$-valor: significância estatística em $\mathrm{p}<0,05$.

Ao comparar a frequência dos fatores de risco cardiovascular, observamos que na amostra houve diferença na hipertrigliceridemia e tabagismo, sendo essas mais prevalentes nos homens (Tabela 18). 
Tabela 18. Frequência de fatores de risco cardiovascular, segundo sexo.

\begin{tabular}{lcccc}
\hline \multicolumn{1}{c}{ Variáveis } & Total & Homens $(\mathbf{n = 1 3 3 )}$ & Mulheres $(\mathbf{n}=\mathbf{2 2 3})$ & p-valor \\
\hline Diabetes & $84(23,6)$ & $37(27,8)$ & $47(21,1)$ & 0,147 \\
PA $\geq 130 / 85 \mathrm{mmHg}$ & $160(71,7)$ & 0,624 \\
$\mathrm{LDL}-\mathrm{c}>100 \mathrm{mg} / \mathrm{dL}$ & $259(72,8)$ & $99(74,4)$ & $185(83,0)$ & 0,649 \\
HDL-c baixo & $283(79,5)$ & $98(73,7)$ & $197(88,3)$ & 1,000 \\
Triglicerídeos $\geq 150 \mathrm{mg} / \mathrm{dL}^{\mathrm{a}}$ & $315(88,5)$ & $118(88,7)$ & $79(35,4)$ & $0,004^{*}$ \\
Não-HDL-c $\geq 130 \mathrm{mg} / \mathrm{dL}$ & $147(41,3)$ & $68(51,1)$ & $182(81,6)$ & 0,664 \\
Obesidade visceral & $293(82,3)$ & $111(83,5)$ & $205(91,9)$ & 0,970 \\
IMC $\geq 25 \mathrm{~kg} / \mathrm{m}^{2}$ & $320(89,9)$ & $115(86,5)$ & $189(84,8)$ & 0,881 \\
Glicemia > $100 \mathrm{mg} / \mathrm{dL}^{\mathrm{a}}$ & $301(84,6)$ & $112(84,2)$ & $111(49,8)$ & 0,154 \\
Histórico familiar de IAM & $188(52,8)$ & $77(57,9)$ & $62(27,8)$ & 0,903 \\
PCR $>1 \mathrm{mg} / \mathrm{L}^{\mathrm{b}}$ & $100(28,1)$ & $38(28,6)$ & $178(79,8)$ & 0,076 \\
Tabagismo & $275(77,2)$ & $97(72,9)$ & $35(15,7)$ & $0,015^{*}$ \\
\hline
\end{tabular}

Para fazer a comparação entre os sexos, foi utilizado o teste de Qui-quadrado. Os dados estão apresentados na forma de $n(\%)$; os percentuais são relativos ao sexo. $p$-valor: significância estatística em $\mathrm{p}<0,05$. Diabetes foi definida como glicemia $\geq 126 \mathrm{mg} / \mathrm{dL}$ ou uso de medicamentos hipoglicemiantes (D'AGOSTINO et al., 2008). Obesidade visceral foi definida como circunferência de cintura $\geq 94 \mathrm{~cm}$ em homens e $\geq 80 \mathrm{~cm}$ em mulheres (WHO, 2000). HDLc baixo: $40 \mathrm{mg} / \mathrm{dL}$ para homens e $<50 \mathrm{mg} / \mathrm{dL}$ para mulheres. ${ }^{\text {a }}$ : pontos de corte de acordo com ALBERTI et al., 2009. b: ponto de corte de acordo com AHA (2003). c: de acordo com RIDKER et al., 2007 e RIDKER et al., 2008.

Após a estratificação do risco cardiovascular global observamos que o Escore de Risco de Framingham foi a equação que mais classificou os indivíduos como alto e intermediário risco cardiovascular ( $\mathrm{n}=186$ e 127, respectivamente), enquanto que o Escore de Risco de Reynolds foi a equação que mais classificou os indivíduos como baixo risco cardiovascular $(\mathrm{n}=154)$ (Figura 4). Os escores que apresentaram maior grau de concordância foram o ACC/AHA 2013 e o ERR, com concordância moderada de 67,24\% ( $\mathrm{k}=$ 0,50). O ERF e ACC/AHA 2013 também apresentaram concordância moderada, sendo de 63,56\% $(\mathrm{k}=0,43)$. Já a concordância entre ERF e ERR foi razoável, sendo de $51,00 \%(\mathrm{k}=0,30)$.

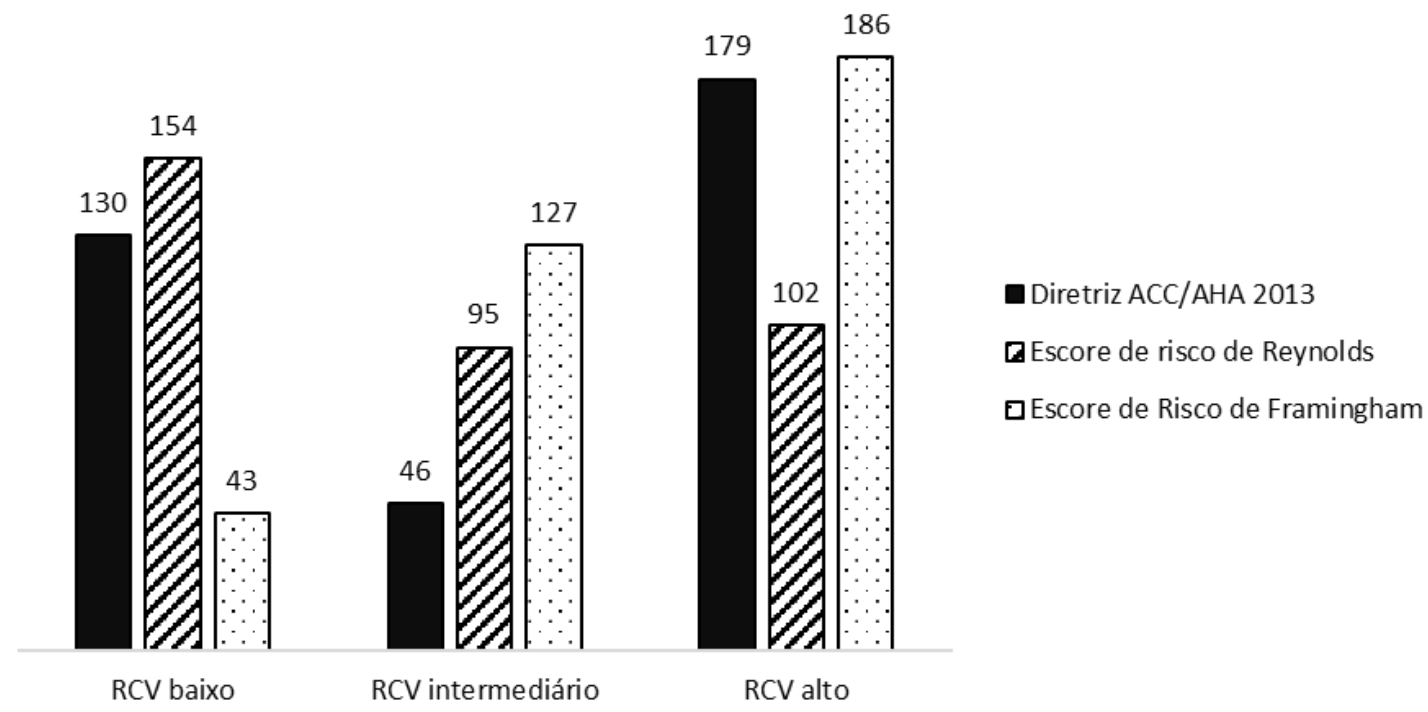

Figura 4. Estratificação do risco cardiovascular global dos indivíduos de acordo com as diferentes equações preditivas. 
Visando avaliar como as quantidades de AG incorporados às membranas eritrocitárias capazes de se associar com o perfil bioquímico, estratificamos a amostra em tercis. Os resultados mostraram que os indivíduos que apresentaram nas membranas eritrocitárias, AG n-3 total maior que 6,24\% tinham menos CT, LDL-c, TG, não-HDLc, Apo B, LDL pequena, relações Apo B/Apo A-I e TG/HDL-c e maior tamanho de LDL em relação aos indivíduos com ômega-3 total menor que 5\%. Ainda em relação aos indivíduos com ômega-3 total menor que 5\%, os indivíduos do $2^{\text {o }}$ tercil apresentaram menor adiposidade corporal, LDL-c, HDL intermediária e relação Apo B/Apo A-I (Tabela 19). 
Tabela 19. Comparação de parâmetros clínicos e bioquímicos segundo tercis de ômega-3 total de membranas eritrocitárias.

\begin{tabular}{|c|c|c|c|}
\hline \multirow[b]{2}{*}{ Variáveis } & \multicolumn{3}{|c|}{ Ômega-3 total } \\
\hline & $\begin{array}{c}1^{\circ} \text { tercil } \\
(\leq 5,00 \%)\end{array}$ & $\begin{array}{c}2^{\circ} \text { tercil } \\
(>5,00 \% \text { a } \leq 6,24 \%)\end{array}$ & $\begin{array}{c}3^{\circ} \text { tercil } \\
(>6,24 \%)\end{array}$ \\
\hline $\mathrm{IMC}, \mathrm{kg} / \mathrm{m}^{2}$ & $31,6(5,2)$ & $29,9(5,2)$ & $31,7(6,5)$ \\
\hline $\mathrm{CC}, \mathrm{cm}$ & $102(12)$ & $98(13)$ & $102(15)$ \\
\hline Adiposidade corporal, $\%$ & $38,3(11,8)$ & $33,9(11,1)^{*}$ & $36,6(12,8)$ \\
\hline PA sistólica, mmHg & $131(17)$ & $134(18)$ & $134(20)$ \\
\hline PA diastólica, $\mathrm{mmHg}$ & $81(9)$ & $82(10)$ & $81(10)$ \\
\hline Frequência cardíaca, bpm & $67(12)$ & $65(9)$ & $68(11)$ \\
\hline Colesterol total, $\mathrm{mg} / \mathrm{dL}$ & $215(44)$ & $204(38)$ & $194(41)^{*}$ \\
\hline $\mathrm{HDL}-\mathrm{c}, \mathrm{mg} / \mathrm{dL}$ & $37(30 ; 43)$ & $35(30 ; 45)$ & $36(31 ; 42)$ \\
\hline $\mathrm{LDL}-\mathrm{c}, \mathrm{mg} / \mathrm{dL}$ & $147(41)$ & $134(34)^{*}$ & $131(39)^{*}$ \\
\hline Triglicerídeos, mg/dL & $149(112 ; 211)$ & $132(92 ; 205)$ & $116(91 ; 167)^{*}$ \\
\hline Não-HDL-c, mg/dL & $179(44)$ & $167(37)$ & $158(40)^{*}$ \\
\hline AGNE, $\mathrm{mEq} / \mathrm{dL}$ & $0,63(0,27)$ & $0,66(0,28)$ & $0,68(0,34)$ \\
\hline Apo A-I, mg/dL & $131(26)$ & $137(27)$ & $130(25)$ \\
\hline Apo B, mg/dL & $111(26)$ & $103(23)$ & $98(24)^{*}$ \\
\hline PON1, nmol min ${ }^{-1} * \mathrm{ml}^{-1}$ & $54,46(31,60)$ & $53,42(32,96)$ & $56,42(31,21)$ \\
\hline HDL grande, $\%$ & $28(7)$ & $29(9)$ & $30(9)$ \\
\hline HDL intermediária, \% & $51(5)$ & $49,34(5)^{*}$ & $49(5)^{*}$ \\
\hline HDL pequena, $\%$ & $20(8)$ & $21(7)$ & $21(7)$ \\
\hline HDL grande, $\mathrm{mg} / \mathrm{dL}$ & $10(8 ; 13)$ & $10(7 ; 15)$ & $10(7 ; 15)$ \\
\hline HDL intermediária, $\mathrm{mg} / \mathrm{dL}$ & $18(15 ; 22)$ & $17(15 ; 21)$ & $17(15 ; 20)$ \\
\hline HDL pequena, $\mathrm{mg} / \mathrm{dL}$ & $7(5 ; 9)$ & $7(6 ; 10)$ & $7(6 ; 9)$ \\
\hline LDL pequena, $\%$ & $2(1 ; 6)$ & $2(1 ; 6)$ & $1(1 ; 3) * * *$ \\
\hline LDL grande $\%$ & $26(6)$ & $25(5)$ & $26(5)$ \\
\hline LDL pequena, mg/dL & $4(2 ; 12)$ & $4(1 ; 12)$ & $2(1 ; 6) * * *$ \\
\hline LDL grande, $\mathrm{mg} / \mathrm{dL}$ & $56(19)$ & $51(13)$ & $51(16)$ \\
\hline Tamanho de LDL, nm & $269(264 ; 271)$ & $270(264 ; 272)$ & $270(268 ; 272) * * *$ \\
\hline $\mathrm{LDL}(-), \mu \mathrm{g} / \mathrm{mL}$ & $7,75(2,12 ; 25,31)$ & $5,16(1,65 ; 13,87)$ & $4,47(1,77 ; 14,21)$ \\
\hline Anti-LDL( $(-), \mu \mathrm{g} / \mathrm{mL}$ & $6,76(4,03 ; 11,50)$ & $8,77(5,26 ; 11,60)$ & $8,32(5,00 ; 11,54)$ \\
\hline $\mathrm{CETP}, \mathrm{pmol} / \mu \mathrm{L} / \mathrm{h}$ & $47,39(37,10 ; 64,41)$ & $50,52(37,46 ; 72,47)$ & $52,11(37,69 ; 67,83)$ \\
\hline Glicemia, mg/dL & $98(91 ; 111)$ & $98(90 ; 107)$ & $98(92 ; 108)$ \\
\hline Insulina, $\mu \mathrm{UI} / \mathrm{mL}$ & $17(13 ; 22)$ & $15(12 ; 22)$ & $17(13 ; 22)$ \\
\hline HOMA-IR & $4,48(3,11 ; 5,91)$ & $3,83(2,79 ; 6,15)$ & $4,13(3,19 ; 5,41)$ \\
\hline $\mathrm{HbA} 1 \mathrm{c}, \%$ & $5,00(4,80 ; 5,30)$ & $5,00(4,70 ; 5,30)$ & $4,90(4,70 ; 5,20)$ \\
\hline Adiponectina, ng/mL & $8,46(4,63 ; 13,69)$ & $7,62(3,97 ; 12,44)$ & $8,28(5,14 ; 12,95)$ \\
\hline Leptina, $\mathrm{ng} / \mathrm{mL}$ & $40,20(15,10 ; 68,40)$ & $24,85(10,03 ; 56,65)$ & $39,70(10,70 ; 73,60)$ \\
\hline PCR, mg/L & $2,70(1,32 ; 5,96)$ & $2,81(1,33 ; 4,95)$ & $2,55(0,86 ; 6,56)$ \\
\hline Apo B/Apo A-I & $0,87(0,25)$ & $0,78(0,21)^{*}$ & $0,77(0,22)^{*}$ \\
\hline TG/HDL-c & $4(3 ; 6)$ & $4(3 ; 6)$ & $3(2 ; 5)^{*}$ \\
\hline CT/HDL & $6(5 ; 7)$ & $6(4 ; 7)$ & $5(4 ; 7)$ \\
\hline LDL-c/HDL-c & $4(3 ; 5)$ & $4(3 ; 5)$ & $4(3 ; 4)$ \\
\hline \multicolumn{4}{|l|}{ ACC/AHA 2013} \\
\hline Risco baixo, $n$ & $43(34,7)$ & $35(28,2)$ & $46(37,1)$ \\
\hline Risco intermediário, $n$ & $20(44,4)$ & $14(31,1)$ & $11(24,4)$ \\
\hline Risco alto, $n$ & $48(29,1)$ & $63(38,2)$ & $54(32,7)$ \\
\hline \multicolumn{4}{|l|}{ ERR } \\
\hline Risco baixo, $n$ & $50(34,0)$ & $43(29,3)$ & $54(36,7)$ \\
\hline Risco intermediário, $n$ & $26(29,2)$ & $41(46,1)$ & $22(24,7)$ \\
\hline Risco alto, $n$ & $32(34,0)$ & $28(29,8)$ & $34(36,2)$ \\
\hline \multicolumn{4}{|l|}{ ERF } \\
\hline Risco baixo, $n$ & $11(26,2)$ & $11(26,2)$ & $20(47,6)$ \\
\hline Risco intermediário, $n$ & $43(36,1)$ & $43(36,1)$ & $33(27,7)$ \\
\hline Risco alto, $n$ & $57(32,9)$ & $58(33,5)$ & $58(33,5)$ \\
\hline
\end{tabular}

As comparações entre os tercis foram feitas através dos testes ANOVA Oneway ou Kruskall-Wallis, dependendo da distribuição da variável. *diferença significativa $(\mathrm{p}<0,05)$ em relação ao $1^{\circ}$ tercil. 
**diferença significativa $(\mathrm{p}<0,05)$ em relação ao $2^{\circ}$ tercil. Os dados estão apresentados na forma de média (desvio padrão) ou mediana (intervalo interquartil) dependendo da distribuição da variável contínua. Ômega3 total $=\mathrm{C} 18: 3 \mathrm{n}-3+\mathrm{C} 20: 5 \mathrm{n}-3+\mathrm{C} 22: 6 \mathrm{n}-3$.

De modo contrário, os indivíduos que apresentaram nas membranas eritrocitárias ômega-6 total maior que 11,09\% tinham mais CT, LDL-c, não-HDL-c, Apo A-I, Apo B, HDL pequena, LDL pequena, LDL(-), além de um menor IMC, tamanho de LDL e leptinemia em relação aos indivíduos com valores menores que 7,64\%. Em relação ao $2^{\circ}$ tercil, esses indivíduos também apresentaram mas CT, Apo AI, Apo B, HDL pequena e LDL grande (Tabela 20). 
Tabela 20. Comparação de parâmetros clínicos e bioquímicos segundo tercis de ômega-6 total de membranas eritrocitárias.

\begin{tabular}{|c|c|c|c|}
\hline \multirow[b]{2}{*}{ Variáveis } & \multicolumn{3}{|c|}{ Ômega-6 total } \\
\hline & $\begin{array}{c}1^{\circ} \text { tercil } \\
(\leq 7,64 \%)\end{array}$ & $\begin{array}{c}2^{\circ} \text { tercil } \\
(>7,64 \% \text { a } \leq 11,09 \%)\end{array}$ & $\begin{array}{c}3^{\circ} \text { tercil } \\
(>11,09 \%)\end{array}$ \\
\hline $\mathrm{IMC}, \mathrm{kg} / \mathrm{m}^{2}$ & $31,8(6,1)$ & $31,3(5,9)$ & $29,7(4,9)^{*}$ \\
\hline $\mathrm{CC}, \mathrm{cm}$ & $102(14)$ & $101(14)$ & $98(12)$ \\
\hline Adiposidade corporal, \% & $39,2(27,9 ; 47,38)$ & $36,0(23,8 ; 48,3)$ & $36,4(24,2 ; 43,6)$ \\
\hline PA sistólica, mmHg & $132(19)$ & $136(19)$ & $4(3 ; 5)$ \\
\hline PA diastólica, $\mathrm{mmHg}$ & $80(10)$ & $83(10)$ & $80(9)$ \\
\hline Frequência cardíaca, bpm & $68(10)$ & $67(11)$ & $66(11)$ \\
\hline Colesterol total, $\mathrm{mg} / \mathrm{dL}$ & $196(37)$ & $201(42)$ & $216(45)^{* * *}$ \\
\hline HDL-c, mg/dL & $35(32 ; 42)$ & $35(28 ; 43)$ & $38(30 ; 42)$ \\
\hline LDL-c, mg/dL & $131(35)$ & $135(39)$ & $146(41)^{*}$ \\
\hline Triglicerídeos, mg/dL & $120(92 ; 175)$ & $132(95 ; 188)$ & $135(102 ; 210)$ \\
\hline Não-HDL-c, mg/dL & $160(36)$ & $166(41)$ & $178(45)^{*}$ \\
\hline $\mathrm{AGNE}, \mathrm{mEq} / \mathrm{dL}$ & $0,68(0,32)$ & $0,64(0,28)$ & $0,66(0,29)$ \\
\hline Apo A-I, mg/dL & $131(25)$ & $126(26)$ & $141(25)^{* * *}$ \\
\hline Apo B, mg/dL & $101(25)$ & $100(23)$ & $111(25)^{* * *}$ \\
\hline PON1, nmol min ${ }^{-1} * \mathrm{ml}^{-1}$ & $43,67(21,66 ; 76,89)$ & $55,03(24,09 ; 79,63)$ & $58,17(25,64 ; 81,25)$ \\
\hline HDL grande, $\%$ & $29(23 ; 36)$ & $29(21 ; 35)$ & $27(23 ; 33)$ \\
\hline HDL intermediária, \% & $49(5)$ & $50(5)$ & $50(5)$ \\
\hline HDL pequena, $\%$ & $21(8)$ & $20(7)$ & $22(6)$ \\
\hline $\mathrm{HDL}$ grande, $\mathrm{mg} / \mathrm{dL}$ & $10(7 ; 15)$ & $9(6 ; 14)$ & $10(8 ; 13)$ \\
\hline HDL intermediária, mg/dL & $17(16 ; 20)$ & $17(15 ; 21)$ & $18(15 ; 22)$ \\
\hline HDL pequena, mg/dL & $7(5 ; 9)$ & $7(5 ; 9)$ & $8(6 ; 10)^{* *}$ \\
\hline LDL pequena, $\%$ & $1(0 ; 3)$ & $2(1 ; 5)$ & $2(1 ; 6)^{*}$ \\
\hline LDL grande $\%$ & $26(5)$ & $26(5)$ & $26(6)$ \\
\hline LDL pequena, mg/dL & $2(0 ; 6)$ & $3(2 ; 11)$ & $4(2 ; 12)$ \\
\hline $\mathrm{LDL}$ grande, $\mathrm{mg} / \mathrm{dL}$ & $51(15)$ & $51(15)$ & $57(18) * * *$ \\
\hline Tamanho de LDL, nm & $270(267 ; 273)$ & $270(265 ; 272)$ & $269(264 ; 271)^{*}$ \\
\hline $\mathrm{LDL}(-), \mu \mathrm{g} / \mathrm{mL}$ & $3,62(1,61 ; 11,84)$ & $4,79(1,92 ; 13,94)$ & $9,27(2,27 ; 31,91)^{*}$ \\
\hline Anti-LDL( $(-), \mu \mathrm{g} / \mathrm{mL}$ & $7,54(3,10 ; 11,58)$ & $8,41(5,33 ; 11,49)$ & $7,88(5,47 ; 11,35)$ \\
\hline $\mathrm{CETP}, \mathrm{pmol} / \mu \mathrm{L} / \mathrm{h}$ & $49,49(36,59 ; 65,81)$ & $53,90(38,61 ; 68,18)$ & $47,39(37,57 ; 65,36)$ \\
\hline Glicemia, mg/dL & $99(93 ; 113)$ & $100(92 ; 112)$ & $96(87 ; 106)$ \\
\hline Insulina, $\mu \mathrm{UI} / \mathrm{mL}$ & $16(13 ; 23)$ & $17(13 ; 23)$ & $15(12 ; 20)$ \\
\hline HOMA-IR & $4,34(3,32 ; 6,09)$ & $4,04(3,01 ; 5,93)$ & $3,70(2,72 ; 5,22)$ \\
\hline $\mathrm{HbA1c}, \%$ & $4,90(4,80 ; 5,20)$ & $5,10(4,80 ; 5,30)$ & $4,90(4,70 ; 5,20)$ \\
\hline Adiponectina, ng/mL & $8,47(4,90 ; 13,53)$ & $8,06(4,44 ; 13,26)$ & $7,69(4,69 ; 11,51)$ \\
\hline Leptina, ng/mL & $42,00(17,10 ; 81,40)$ & $29,60(8,00 ; 58,00)$ & $25,30(10,43 ; 56,78)^{*}$ \\
\hline PCR, mg/L & $2,62(1,46 ; 6,11)$ & $3,73(1,06 ; 6,66)$ & $2,14(1,14 ; 4,42)$ \\
\hline Apo B/Apo A-I & $0,79(0,22)$ & $0,82(0,26)$ & $0,81(0,21)$ \\
\hline TG/HDL-c & $3(2 ; 6)$ & $4(3 ; 6)$ & $4(3 ; 6)$ \\
\hline $\mathrm{CT} / \mathrm{HDL}$ & $5(4 ; 6)$ & $6(5 ; 7)$ & $6(5 ; 7)$ \\
\hline LDL-c/HDL-c & $4(3 ; 4)$ & $4(3 ; 5)$ & $4(3 ; 5)$ \\
\hline \multicolumn{4}{|l|}{ ACC/AHA $2013 \dagger$} \\
\hline Risco baixo, $n$ & $42(33,6)$ & $40(32,0)$ & $43(34,4)$ \\
\hline Risco intermediário, $n$ & $22(48,9)$ & $6(13,3)$ & $17(37,8)$ \\
\hline Risco alto, $n$ & $48(29,3)$ & $65(39,6)$ & $51(31,1)$ \\
\hline \multicolumn{4}{|l|}{ ERR } \\
\hline Risco baixo, $n$ & $57(38,5)$ & $42(28,4)$ & $49(33,1)$ \\
\hline Risco intermediário, $n$ & $22(25,0)$ & $34(38,6)$ & $32(36,4)$ \\
\hline Risco alto, $n$ & $32(34,0)$ & $35(37,2)$ & $27(28,7)$ \\
\hline \multicolumn{4}{|l|}{ ERF } \\
\hline Risco baixo, $n$ & $20(46,5)$ & $11(25,6)$ & $12(27,9)$ \\
\hline Risco intermediário, $n$ & $37(31,4)$ & $36(30,5)$ & $45(38,1)$ \\
\hline Risco alto, $n$ & $55(31,8)$ & $64(37,0)$ & $54(31,2)$ \\
\hline
\end{tabular}

As comparações entre os tercis foram feitas através dos testes ANOVA Oneway ou Kruskall-Wallis, dependendo da distribuição da variável. *: diferença significante $(\mathrm{p}<0,05)$ em relação ao $1^{\circ}$ tercil. **: 
diferença significante $(\mathrm{p}<0,05)$ em relação ao $2^{\circ}$ tercil. $\dagger$ : significância estatística no teste Qui-Quadrado. Os dados estão apresentados na forma de média (desvio padrão) ou mediana (intervalo interquartil) dependendo da distribuição da variável contínua. Ômega-6 total $=$ C18:2 n-6 + C18:3 n-6 + C20:2 n-6 + C20:3 n-6 + $\mathrm{C} 20: 4 \mathrm{n}-6+\mathrm{C} 22: 2 \mathrm{n}-6$.

Ao fazer a comparação, segundo o IO3 incorporado às membranas, observou-se que os indivíduos com valores acima de 4,16\% apresentaram menos CT, TG, não-HDLc e Apo B que os indivíduos que tinham IO3 menor que 4,16\% e menos CT, não-HDLc, Apo B em relação ao grupo intermediário (Tabela 21). 
Tabela 21. Comparação de parâmetros clínicos e bioquímicos segundo tercis de Índice Ômega-3 de membranas eritrocitárias.

\begin{tabular}{|c|c|c|c|}
\hline \multirow[b]{2}{*}{ Variáveis } & \multicolumn{3}{|c|}{ Índice Ômega-3 } \\
\hline & $\begin{array}{c}1^{\circ} \text { tercil } \\
(\leq 3,18 \%)\end{array}$ & $\begin{array}{c}2^{\circ} \text { tercil } \\
(>3,18 \% \text { a } \leq 4,16 \%)\end{array}$ & $\begin{array}{c}3^{\circ} \text { tercil } \\
(>4,16 \%) \\
\end{array}$ \\
\hline $\mathrm{IMC}, \mathrm{kg} / \mathrm{m}^{2}$ & $30,3(5,5)$ & $31,5(5,7)$ & $31,0(5,7)$ \\
\hline $\mathrm{CC}, \mathrm{cm}$ & $98(13)$ & $102(13)$ & $101(14)$ \\
\hline Adiposidade corporal, \% & $36,2(11,8)$ & $38,0(12,1)$ & $34,5(12,1)$ \\
\hline PA sistólica, mmHg & $131(18)$ & $134(17)$ & $134(20)$ \\
\hline PA diastólica, mmHg & $81(10)$ & $81(11)$ & $81(9)$ \\
\hline Frequência cardíaca, bpm & $67(11)$ & $67(11)$ & $67(11)$ \\
\hline Colesterol total, $\mathrm{mg} / \mathrm{dL}$ & $206(40)$ & $212(44)$ & $195(41)^{* *}$ \\
\hline HDL-c, mg/dL & $37(31 ; 44)$ & $37(30 ; 43)$ & $35(30 ; 42)$ \\
\hline LDL-c, mg/dL & $137(38)$ & $143(20)$ & $132(38)$ \\
\hline Triglicerídeos, mg/dL & $138(105 ; 197)$ & $131(96 ; 206)$ & $117(93 ; 170)^{*}$ \\
\hline Não-HDL-c, mg/dL & $169(40)$ & $175(43)$ & $159(41)^{* *}$ \\
\hline $\mathrm{AGNE}, \mathrm{mEq} / \mathrm{dL}$ & $0,64(0,43 ; 0,84)$ & $0,64(0,46 ; 0,81)$ & $0,59(0,45 ; 0,84)$ \\
\hline Apo A-I, mg/dL & $134(29)$ & $135(25)$ & $129(24)$ \\
\hline Apo B, mg/dL & $104(24)$ & $108(26)$ & $99(24)^{* *}$ \\
\hline PON1, nmol $\min ^{-1} * \mathrm{ml}^{-1}$ & $55,98(23,39 ; 79,47)$ & $53,66(23,75 ; 74,46)$ & $53,97(24,28 ; 83,77)$ \\
\hline HDL grande, $\%$ & $29(9)$ & $29(8)$ & $29(9)$ \\
\hline HDL intermediária, \% & $50(5)$ & $50(5)$ & $50(5)$ \\
\hline HDL pequena, $\%$ & $21(7)$ & $21(7)$ & $21(7)$ \\
\hline HDL grande, $\mathrm{mg} / \mathrm{dL}$ & $10(7 ; 14)$ & $10(8 ; 14)$ & $10(7 ; 14)$ \\
\hline HDL intermediária, mg/dL & $18(15 ; 21)$ & $18(15 ; 2)$ & $17(15 ; 20)$ \\
\hline HDL pequena, $\mathrm{mg} / \mathrm{dL}$ & $8(5 ; 10)$ & $7(6 ; 10)$ & $7(6 ; 9)$ \\
\hline LDL pequena, $\%$ & $2(1 ; 5)$ & $2(1 ; 6)$ & $2(1 ; 3)$ \\
\hline LDL grande $\%$ & $26(5)$ & $25(6)$ & $26(5)$ \\
\hline LDL pequena, mg/dL & $3(1 ; 9)$ & $3(2 ; 14)$ & $3(1 ; 7)$ \\
\hline LDL grande, $\mathrm{mg} / \mathrm{dL}$ & $53(16)$ & $54(18)$ & $52(16)$ \\
\hline Tamanho de LDL, nm & $269(265 ; 272)$ & $270(264 ; 272)$ & $270(267 ; 272)$ \\
\hline $\mathrm{LDL}(-), \mu \mathrm{g} / \mathrm{mL}$ & $5,11(2,12 ; 17,67)$ & $8,02(2,18 ; 23,48)$ & $4,41(1,55 ; 13,39)$ \\
\hline Anti-LDL( $(-), \mu \mathrm{g} / \mathrm{mL}$ & $9,55(5,13 ; 11,57)$ & $8,58(5,43 ; 11,72)$ & $6,93(3,86 ; 10,69)$ \\
\hline $\mathrm{CETP}, \mathrm{pmol} / \mu \mathrm{L} / \mathrm{h}$ & $51,10(35,87 ; 68,52)$ & $52,52(37,63 ; 66,57)$ & $48,51(38,64 ; 63,66)$ \\
\hline Glicemia, mg/dL & $98(91 ; 107)$ & $97(91 ; 109)$ & $98(90 ; 113)$ \\
\hline Insulina, $\mu \mathrm{UI} / \mathrm{mL}$ & $16(12 ; 22)$ & $17(13 ; 23)$ & $16(13 ; 22)$ \\
\hline HOMA-IR & $3,93(2,94 ; 5,91)$ & $4,31(2,96 ; 6,32)$ & $4,00(3,01 ; 5,28)$ \\
\hline $\mathrm{HbA} 1 \mathrm{c}, \%$ & $5,00(4,80 ; 5,25)$ & $5,00(4,70 ; 5,30)$ & $4,90(4,70 ; 5,20)$ \\
\hline Adiponectina, ng/mL & $9,21(4,69 ; 13,80)$ & $7,69(4,45 ; 11,31)$ & $7,67(4,69 ; 12,95)$ \\
\hline Leptina, $\mathrm{ng} / \mathrm{mL}$ & $31,15(10,10 ; 65,38)$ & $36,40(13,55 ; 71,70)$ & $36,05(9,80 ; 58,23)$ \\
\hline $\mathrm{PCR}, \mathrm{mg} / \mathrm{L}$ & $2,60(1,30 ; 5,57)$ & $2,98(1,30 ; 5,90)$ & $2,35(0,91 ; 5,67)$ \\
\hline Apo B/Apo A-I & $0,81(0,26)$ & $0,82(0,21)$ & $0,79(0,22)$ \\
\hline TG/HDL-c & $4(3 ; 6)$ & $4(3 ; 6)$ & $3(2 ; 6)$ \\
\hline $\mathrm{CT} / \mathrm{HDL}$ & $6(5 ; 7)$ & $6(5 ; 7)$ & $5(4 ; 7)$ \\
\hline LDL-c/HDL-c & $4(3 ; 5)$ & $4(3 ; 5)$ & $4(3 ; 5)$ \\
\hline \multicolumn{4}{|l|}{ ACC/AHA 2013} \\
\hline Risco baixo, $n$ & $49(39,5)$ & $32(25,8)$ & $43(34,7)$ \\
\hline Risco intermediário, $n$ & $13(29,5)$ & $18(40,9)$ & $13(29,5)$ \\
\hline Risco alto, $n$ & $50(30,9)$ & $58(35,8)$ & $54(33,3)$ \\
\hline \multicolumn{4}{|l|}{ ERR } \\
\hline Risco baixo, $n$ & $57(38,8)$ & $41(27,9)$ & $49(33,3)$ \\
\hline Risco intermediário, $n$ & $25(29,4)$ & $34(40,0)$ & $26(30,6)$ \\
\hline Risco alto, $n$ & $27(28,7)$ & $33(35,1)$ & $34(36,2)$ \\
\hline \multicolumn{4}{|l|}{ ERF } \\
\hline Risco baixo, $n$ & $15(34,9)$ & $10(23,3)$ & $18(41,9)$ \\
\hline Risco intermediário, $n$ & $42(35,9)$ & $38(32,5)$ & $37(31,6)$ \\
\hline Risco alto, $n$ & $55(32,4)$ & $60(35,3)$ & $55(32,4)$ \\
\hline
\end{tabular}

As comparações entre os tercis foram feitas através dos testes ANOVA Oneway ou Kruskall-Wallis, dependendo da distribuição da variável. *diferença significante $(\mathrm{p}<0,05)$ em relação ao $1^{\circ}$ tercil. **diferença 
significante $(\mathrm{p}<0,05)$ em relação ao $2^{\circ}$ tercil. Os dados estão apresentados na forma de média (desvio padrão) ou mediana (intervalo interquartil) dependendo da distribuição da variável contínua. Índice Ômega-3 = C20:5 n-3 + C22:6 n-3.

A comparação da razão n-6/n-3 nas membranas eritrocitárias mostrou que os indivíduos com a razão maior que 2,10 apresentaram mais CT, LDL-c, TG, Apo B, LDL pequena, LDL(-) e CT/HDL e menor tamanho de LDL em relação aos indivíduos com razão menor ou igual a 1,27. Já em relação aos indivíduos intermediários, o $3^{\circ}$ tercil apresentou mais LDL grande no plasma (Tabela 22). 
Tabela 22. Comparação de parâmetros clínicos e bioquímicos segundo tercis da razão ômega-6/ômega-3 nas membranas eritrocitárias.

\begin{tabular}{|c|c|c|c|}
\hline \multirow[b]{2}{*}{ Variáveis } & \multicolumn{3}{|c|}{ Ômega-6/ômega-3 } \\
\hline & $\begin{array}{l}1^{\circ} \text { tercil } \\
(\leq 1,27)\end{array}$ & $\begin{array}{c}2^{\circ} \text { tercil } \\
(>1,27 \mathrm{a} \leq 2,10)\end{array}$ & $\begin{array}{l}3^{\circ} \text { tercil } \\
(>2,10)\end{array}$ \\
\hline $\mathrm{IMC}, \mathrm{kg} / \mathrm{m}^{2}$ & $30,9(26,7 ; 35,8)$ & $30,4(26,6 ; 35,1)$ & $29,9(26,4 ; 33,7)$ \\
\hline $\mathrm{CC}, \mathrm{cm}$ & $101(91 ; 115)$ & $100(91 ; 109)$ & $100(91 ; 109)$ \\
\hline Adiposidade corporal, $\%$ & $36,9(12,1)$ & $37,0(12,3)$ & $34,9(11,6)$ \\
\hline PA sistólica, mmHg & $132(19)$ & $136(18)$ & $131(17)$ \\
\hline PA diastólica, $\mathrm{mmHg}$ & $80(10)$ & $83(10)$ & $81(10)$ \\
\hline Frequência cardíaca, bpm & $67(10)$ & $67(11)$ & $66(12)$ \\
\hline Colesterol total, mg/dL & $196(38)$ & $203(42)$ & $215(44)^{*}$ \\
\hline HDL-c, mg/dL & $36(31 ; 44)$ & $35(30 ; 44)$ & $37(30 ; 42)$ \\
\hline LDL-c, mg/dL & $131(36)$ & $135(38)$ & $147(41)^{*}$ \\
\hline Triglicerídeos, mg/dL & $116(91 ; 173)$ & $135(98 ; 195)$ & $143(102 ; 210)^{*}$ \\
\hline Não-HDL-c, mg/dL & $159(38)$ & $166(40)$ & $179(44)$ \\
\hline AGNE, $\mathrm{mEq} / \mathrm{dL}$ & $0,67(0,33)$ & $0,67(0,29)$ & $0,63(0,27)$ \\
\hline Apo A-I, mg/dL & $131(24)$ & $134(27)$ & $133(27)$ \\
\hline Apo B, mg/dL & $99(25)$ & $103(24)$ & $109(25)^{*}$ \\
\hline PON1, nmol min ${ }^{-1} * \mathrm{ml}^{-1}$ & $52,07(22,65 ; 81,74)$ & $50,57(23,08 ; 78,04)$ & $59,21(28,52 ; 80,27)$ \\
\hline HDL grande, $\%$ & $29(23 ; 37)$ & $29(22 ; 35)$ & $27(23 ; 33)$ \\
\hline HDL intermediária, \% & $49(5)$ & $50(5)$ & $51(4)$ \\
\hline HDL pequena, $\%$ & $21(7)$ & $20(8)$ & $21(7)$ \\
\hline HDL grande, $\mathrm{mg} / \mathrm{dL}$ & $10(7 ; 16)$ & $10(7 ; 14)$ & $10(7 ; 13)$ \\
\hline HDL intermediária, mg/dL & $18(16 ; 20)$ & $17(15 ; 21)$ & $18(15 ; 21)$ \\
\hline HDL pequena, $\mathrm{mg} / \mathrm{dL}$ & $7(6 ; 9)$ & $7(5 ; 9)$ & $7(6 ; 10)$ \\
\hline LDL pequena, $\%$ & $1(0 ; 3)$ & $1(1 ; 6)$ & $2(1 ; 6)^{*}$ \\
\hline LDL grande $\%$ & $27(23 ; 30)$ & $25(22 ; 28)$ & $28(23 ; 31)^{* *}$ \\
\hline LDL pequena, mg/dL & $2(0 ; 6)$ & $3(2 ; 12)$ & $5(2 ; 12)^{*}$ \\
\hline LDL grande, mg/dL & $51(42 ; 61)$ & $51(40 ; 58)$ & $55(45 ; 69)^{* *}$ \\
\hline Tamanho de LDL, nm & $271(267 ; 273)$ & $270(264 ; 272)$ & $269(264 ; 271)^{*}$ \\
\hline $\operatorname{LDL}(-), \mu \mathrm{g} / \mathrm{mL}$ & $3,78(1,64 ; 12,62)$ & $5,23(1,91 ; 15,19)$ & $8,45(2,18 ; 26,10)^{*}$ \\
\hline Anti-LDL( $(-), \mu \mathrm{g} / \mathrm{mL}$ & $7,61(3,60 ; 11,44)$ & $9,07(5,05 ; 11,68)$ & $7,79(5,49 ; 11,34)$ \\
\hline $\mathrm{CETP}, \mathrm{pmol} / \mu \mathrm{L} / \mathrm{h}$ & $47,28(34,92 ; 65,52)$ & $52,07(37,67 ; 71,40)$ & $51,10(39,31 ; 63,85)$ \\
\hline Glicemia, mg/dL & $98(92 ; 112)$ & $101(92 ; 111)$ & $96(89 ; 106)$ \\
\hline Insulina, $\mu \mathrm{UI} / \mathrm{mL}$ & $16(13 ; 23)$ & $17(13 ; 22)$ & $15(12 ; 20)$ \\
\hline HOMA-IR & $4,14(3,18 ; 5,92)$ & $4,03(2,96 ; 6,12)$ & $3,83(2,80 ; 5,82)$ \\
\hline $\mathrm{HbA} 1 \mathrm{c}, \%$ & $4,90(4,80 ; 5,20)$ & $5,00(4,80 ; 5,30)$ & $4,90(4,70 ; 5,30)$ \\
\hline Adiponectina, ng/mL & $8,49(5,41 ; 13,65)$ & $8,06(4,33 ; 12,95)$ & $7,61(4,40 ; 12,57)$ \\
\hline Leptina, ng/mL & $40,70(12,20 ; 81,10)$ & $31,00(9,20 ; 66,60)$ & $27,10(10,88 ; 56,35)$ \\
\hline PCR, mg/L & $2,43(0,98 ; 5,83)$ & $3,72(1,08 ; 6,61)$ & $2,51(1,24 ; 5,00)$ \\
\hline Apo B/Apo A-I & $0,78(0,22)$ & $0,79(0,23)$ & $0,85(0,25)$ \\
\hline TG/HDL-c & $3(2 ; 5)$ & $4(3 ; 6)$ & $4(3 ; 6)$ \\
\hline $\mathrm{CT} / \mathrm{HDL}$ & $5(4 ; 6)$ & $6(4 ; 7)$ & $6(5 ; 7)^{*}$ \\
\hline LDL-c/HDL-c & $4(3 ; 4)$ & $4(3 ; 5)$ & $4(3 ; 5)$ \\
\hline \multicolumn{4}{|l|}{ ACC/AHA $2013 \dagger$} \\
\hline Risco baixo, $n$ & $41(33,3)$ & $43(35,0)$ & $39(31,7)$ \\
\hline Risco intermediário, $n$ & $21(47,7)$ & $4(9,1)$ & $19(43,2)$ \\
\hline Risco alto, $n$ & $48(29,3)$ & $63(38,4)$ & $53(32,3)$ \\
\hline \multicolumn{4}{|l|}{ ERR } \\
\hline Risco baixo, $n$ & $55(39,0)$ & $43(29,5)$ & $46(31,5)$ \\
\hline Risco intermediário, $n$ & $20(23,0)$ & $33(37,9)$ & $34(39,1)$ \\
\hline Risco alto, $n$ & $32(34,0)$ & $34(36,2)$ & $28(29,8)$ \\
\hline \multicolumn{4}{|l|}{ ERF } \\
\hline Risco baixo, $n$ & $21(50,0)$ & $10(23,8)$ & $11(26,2)$ \\
\hline Risco intermediário, $n$ & $34(29,3)$ & $37(31,9)$ & $45(38,8)$ \\
\hline Risco alto, $n$ & $55(31,8)$ & $63(36,4)$ & $55(31,8)$ \\
\hline
\end{tabular}

As comparações entre os tercis foram feitas através dos testes ANOVA Oneway ou Kruskall-Wallis, dependendo da distribuição da variável. *diferença significante $(\mathrm{p}<0,05)$ em relação ao $1^{\circ}$ tercil. **diferença 
significante $(\mathrm{p}<0,05)$ em relação ao $2^{\circ}$ tercil. $\dagger$ : significância estatística no teste Qui-Quadrado. Os dados estão apresentados na forma de média (desvio padrão) ou mediana (intervalo interquartil) dependendo da distribuição da variável contínua. Ômega- $6=$ C18:2 n-6 + C18:3 n-6 + C20:2 n-6 + C20:3 n-6 + C20:4 n-6 + C22:2 n-6. Ômega-3 = C18:3 n-3 + C20:5 n-3 + C22:6 n-3.

Nas análises separadas por sexo, os homens com ômega-3 total maior que 6,24\% apresentaram menores níveis plasmáticos de Apo B e LDL pequena quando comparados com os homens dos outros tercis. Ainda, esses indivíduos apresentaram maior tamanho de LDL (Tabela 23). Já as mulheres do maior tercil $(>6,26 \%)$ apresentaram menor colesterol total, TG, não-HDL-c, Apo B, LDL grande e TG/HDL-c quando comparadas com o primeiro tercil $(\leq 4,89 \%)$. As mulheres com ômega-3 total $>4,89 \%$ também apresentaram menos Apo B, LDL grande que o primeiro tercil, além de menor insulinemia, Apo B/Apo A-I e CT/HDL-c (Tabela 24). 
Tabela 23. Comparação dos parâmetros clínicos e bioquímicos segundo tercis de ômega-3 total de membranas eritrocitárias de homens.

\begin{tabular}{|c|c|c|c|}
\hline \multirow[b]{2}{*}{ Variáveis } & \multicolumn{3}{|c|}{ Ômega-3 total } \\
\hline & $\begin{array}{c}1^{\circ} \text { tercil } \\
(\leq 5,24 \%)\end{array}$ & $\begin{array}{c}2^{\circ} \text { tercil } \\
(>5,24 \% \text { a } \leq 6,24 \%)\end{array}$ & $\begin{array}{c}3^{\circ} \text { tercil } \\
(>6,24 \%)\end{array}$ \\
\hline $\mathrm{IMC}, \mathrm{kg} / \mathrm{m}^{2}$ & $30,8(5,5)$ & $30,5(5,0)$ & $30,4(5,7)$ \\
\hline $\mathrm{CC}, \mathrm{cm}$ & $105(13)$ & $103(13)$ & $104(15)$ \\
\hline Adiposidade corporal, $\%$ & $23,5(4,3)$ & $23,1(4,9)$ & $22,8(5,0)$ \\
\hline PA sistólica, $\mathrm{mmHg}$ & $133(16)$ & $136(16)$ & $134(19)$ \\
\hline PA diastólica, mmHg & $81(9)$ & $84(10)$ & $82(11)$ \\
\hline Frequência cardíaca, bpm & $67(16)$ & $65(9)$ & $67(9)$ \\
\hline Colesterol total, mg/dL & $207(39)$ & $199(37)$ & $188(36)$ \\
\hline HDL-c, mg/dL & $32(8)$ & $32(7)$ & $32(6)$ \\
\hline $\mathrm{LDL}-\mathrm{c}, \mathrm{mg} / \mathrm{dL}$ & $138(36)$ & $131(32)$ & $126(35)$ \\
\hline Triglicerídeos, mg/dL & $175(114 ; 320)$ & $152(114 ; 223)$ & $141(103 ; 192)$ \\
\hline Não-HDL-c, mg/dL & $175(38)$ & $168(39)$ & $156(34)$ \\
\hline AGNE, $\mathrm{mEq} / \mathrm{dL}$ & $0,55(0,28)$ & $0,54(0,23)$ & $0,67(0,39)$ \\
\hline Apo A-I, mg/dL & $122(26)$ & $127(21)$ & $122(21)$ \\
\hline Apo B, mg/dL & $106(22)$ & $106(24)$ & $93(19)^{* * *}$ \\
\hline PON1, nmol $\min ^{-1} * \mathrm{ml}^{-1}$ & $54,77(24,17 ; 79,48)$ & $37,62(18,35 ; 64,69)$ & $39,49(22,07 ; 78,33)$ \\
\hline HDL grande, $\%$ & $28(7)$ & $25(8)$ & $28(7)$ \\
\hline HDL intermediária, \% & $51(4)$ & $51(5)$ & $51(4)$ \\
\hline HDL pequena, $\%$ & $21(6)$ & $24(7)$ & $22(6)$ \\
\hline HDL grande, $\mathrm{mg} / \mathrm{dL}$ & $8(6 ; 10)$ & $7(5 ; 9)$ & $8(6 ; 12)$ \\
\hline HDL intermediária, mg/dL & $16(4)$ & $16(3)$ & $16(3)$ \\
\hline HDL pequena, $\mathrm{mg} / \mathrm{dL}$ & $7(2)$ & $7(3)$ & $7(2)$ \\
\hline LDL pequena, $\%$ & $4(1 ; 8)$ & $3(1 ; 8)$ & $2(1 ; 3) * * *$ \\
\hline LDL grande $\%$ & $25(6)$ & $26(4)$ & $27(4)$ \\
\hline LDL pequena, mg/dL & $7(3 ; 18)$ & $6(3 ; 16)$ & $3(2 ; 6) * * *$ \\
\hline LDL grande, $\mathrm{mg} / \mathrm{dL}$ & $51(15)$ & $51(14)$ & $51(13)$ \\
\hline Tamanho de LDL, nm & $267(262 ; 270)$ & $267(261 ; 271)$ & $270(267 ; 272) * * *$ \\
\hline $\mathrm{LDL}(-), \mu \mathrm{g} / \mathrm{mL}$ & $5,38(2,03 ; 12,63)$ & $4,19(1,30 ; 10,87)$ & $3,71(1,19 ; 9,98)$ \\
\hline Anti-LDL( $(-), \mu \mathrm{g} / \mathrm{mL}$ & $7,66(4,16)$ & $8,96(3,46)$ & $7,54(3,55)$ \\
\hline $\mathrm{CETP}, \mathrm{pmol} / \mu \mathrm{L} / \mathrm{h}$ & $56,51(23,43)$ & $59,17(28,20)$ & $54,85(19,79)$ \\
\hline Glicemia, mg/dL & $105(91 ; 119)$ & $99(92 ; 113)$ & $100(91 ; 117)$ \\
\hline Insulina, $\mu \mathrm{UI} / \mathrm{mL}$ & $15(12 ; 19)$ & $15(13 ; 24)$ & $17(13 ; 22)$ \\
\hline HOMA-IR & $4,67(2,18)$ & $4,94(2,41)$ & $4,73(2,00)$ \\
\hline $\mathrm{HbA1c}, \%$ & $5,10(4,78 ; 5,43)$ & $4,90(4,70 ; 5,13)$ & $4,80(4,65 ; 5,20)$ \\
\hline Adiponectina, ng/mL & $6,79(4,00 ; 11,94)$ & $5,24(2,80 ; 9,70)$ & $6,09(4,52 ; 8,89)$ \\
\hline Leptina, $\mathrm{ng} / \mathrm{mL}$ & $8,35(5,83 ; 16,43)$ & $10,60(6,25 ; 19,70)$ & $8,40(5,75 ; 30,75)$ \\
\hline PCR, mg/L & $2,09(1,05 ; 4,61)$ & $1,88(0,94 ; 4,04)$ & $2,02(0,51 ; 6,11)$ \\
\hline Apo B/Apo A-I & $0,92(0,28)$ & $0,86(0,25)$ & $0,78(0,21)^{*}$ \\
\hline TG/HDL-c & $5(3 ; 11)$ & $5(3 ; 8)$ & $4(3 ; 8)$ \\
\hline $\mathrm{CT} / \mathrm{HDL}$ & $6(6 ; 8)$ & $7(5 ; 8)$ & $6(5 ; 7)$ \\
\hline LDL-c/HDL-c & $4(4 ; 5)$ & $4(3 ; 5)$ & $4(3 ; 5)$ \\
\hline
\end{tabular}

As comparações entre os tercis foram feitas através dos testes ANOVA Oneway ou Kruskall-Wallis, dependendo da distribuição da variável. *diferença significante $(\mathrm{p}<0,05)$ em relação ao $1^{\circ}$ tercil. **diferença significante $(\mathrm{p}$ $<0,05)$ em relação ao $2^{\circ}$ tercil. Os dados estão apresentados na forma de média (desvio padrão) ou mediana (intervalo interquartil) dependendo da distribuição da variável contínua. Ômega-3 total = C18:3 n-3 + C20:5 n-3 $+\mathrm{C} 22: 6$ n-3. 
Tabela 24. Comparação dos parâmetros clínicos e bioquímicos segundo tercis de ômega-3 total de membranas eritrocitárias de mulheres.

\begin{tabular}{|c|c|c|c|}
\hline \multirow[b]{2}{*}{ Variáveis } & \multicolumn{3}{|c|}{ Ômega-3 total } \\
\hline & $\begin{array}{c}1^{\circ} \text { tercil } \\
(\leq 4,89 \%)\end{array}$ & $\begin{array}{c}2^{\circ} \text { tercil } \\
(>4,89 \% \text { a } \leq 6,26 \%)\end{array}$ & $\begin{array}{c}3^{\circ} \text { tercil } \\
(>6,26 \%)\end{array}$ \\
\hline $\mathrm{IMC}, \mathrm{kg} / \mathrm{m}^{2}$ & $31,4(5,2)$ & $29,7(5,3)$ & $32,3(6,9)^{* *}$ \\
\hline $\mathrm{CC}, \mathrm{cm}$ & $100(11)$ & $95(12)$ & $101(15)^{* *}$ \\
\hline Adiposidade corporal, $\%$ & $44,9(7,3)$ & $42,4(6,8)$ & $44,9(7,9)$ \\
\hline PA sistólica, $\mathrm{mmHg}$ & $130(17)$ & $132(19)$ & $134(21)$ \\
\hline PA diastólica, mmHg & $81(9)$ & $80(10)$ & $81(10)$ \\
\hline Frequência cardíaca, bpm & $67(9)$ & $66(10)$ & $68(11)$ \\
\hline Colesterol total, mg/dL & $219(46)$ & $206(41)$ & $199(43)^{*}$ \\
\hline HDL-c, mg/dL & $39(7)$ & $42(12)$ & $39(10)$ \\
\hline $\mathrm{LDL}-\mathrm{c}, \mathrm{mg} / \mathrm{dL}$ & $151(43)$ & $136(37)$ & $135(40)$ \\
\hline Triglicerídeos, mg/dL & $143(111 ; 189)$ & $128(90 ; 176)$ & $104(87 ; 138)^{*}$ \\
\hline Não-HDL-c, mg/dL & $181(46)$ & $165(39)$ & $160(43)^{*}$ \\
\hline AGNE, $\mathrm{mEq} / \mathrm{dL}$ & $0,69(0,25)$ & $0,73(0,28)$ & $0,68(0,31)$ \\
\hline Apo A-I, mg/dL & $136(25)$ & $144(28)$ & $134(26)$ \\
\hline Apo B, mg/dL & $113(27)$ & $101(23)^{*}$ & $101(26)^{*}$ \\
\hline PON1, nmol $\min ^{-1} * \mathrm{ml}^{-1}$ & $51,32(23,42 ; 77,91)$ & $54,58(25,25 ; 77,95)$ & $65,06(31,86 ; 85,80)$ \\
\hline HDL grande, $\%$ & $28(8)$ & $32(9)$ & $31(10)$ \\
\hline HDL intermediária, \% & $51(5)$ & $48(5)^{*}$ & $48(5)^{*}$ \\
\hline HDL pequena, $\%$ & $20(8)$ & $20(7)$ & $20(7)$ \\
\hline HDL grande, $\mathrm{mg} / \mathrm{dL}$ & $10(9 ; 14)$ & $13(9 ; 17)$ & $11(8 ; 17)$ \\
\hline HDL intermediária, mg/dL & $20(17 ; 23)$ & $19(16 ; 23)$ & $18(17 ; 20)$ \\
\hline HDL pequena, $\mathrm{mg} / \mathrm{dL}$ & $7(5 ; 11)$ & $7(6 ; 10)$ & $8(6 ; 10)$ \\
\hline LDL pequena, $\%$ & $2(1 ; 4)$ & $1(1 ; 4)$ & $1(0 ; 2)$ \\
\hline LDL grande $\%$ & $27(6)$ & $25(5)$ & $26(5)$ \\
\hline LDL pequena, mg/dL & $4(2 ; 9)$ & $2(1 ; 8)$ & $2(0 ; 5)$ \\
\hline LDL grande, $\mathrm{mg} / \mathrm{dL}$ & $59(21)$ & $51(14)^{*}$ & $52(17)^{*}$ \\
\hline Tamanho de LDL, nm & $269(266 ; 272)$ & $270(265 ; 272)$ & $271(268 ; 273)$ \\
\hline $\mathrm{LDL}(-), \mu \mathrm{g} / \mathrm{mL}$ & $10,30(1,97 ; 29,04)$ & $6,24(2,17 ; 23,03)$ & $4,61(2,07 ; 17,67)$ \\
\hline Anti-LDL( $(-), \mu \mathrm{g} / \mathrm{mL}$ & $6,66(4,20 ; 11,01)$ & $8,51(4,19 ; 11,46)$ & $9,17(4,99 ; 11,57)$ \\
\hline $\mathrm{CETP}, \mathrm{pmol} / \mu \mathrm{L} / \mathrm{h}$ & $51,02(26,70)$ & $54,21(31,46)$ & $51,36(19,36)$ \\
\hline Glicemia, mg/dL & $104(24)$ & $101(26)$ & $103(34)$ \\
\hline Insulina, $\mu \mathrm{UI} / \mathrm{mL}$ & $21(10)$ & $17(8)^{*}$ & $18(8)$ \\
\hline HOMA-IR & $5,41(3,89)$ & $4,25(2,39)$ & $4,65(2,86)$ \\
\hline $\mathrm{HbA1c}, \%$ & $5,07(0,48)$ & $5,09(0,4)$ & $5,07(0,6)$ \\
\hline Adiponectina, ng/mL & $8,46(4,37 ; 12,94)$ & $9,80(5,70 ; 15,92)$ & $9,11(6,13 ; 15,53)$ \\
\hline Leptina, $\mathrm{ng} / \mathrm{mL}$ & $53,15(33,20 ; 82,93)$ & $54,90(24,18 ; 81,65)$ & $51,90(26,35 ; 91,30)$ \\
\hline PCR, mg/L & $2,956(1,65 ; 6,13)$ & $3,39(1,93 ; 5,58)$ & $3,16(0,88 ; 6,59)$ \\
\hline Apo B/Apo A-I & $0,84(0,22)$ & $0,72(0,17)^{*}$ & $0,77(0,22)$ \\
\hline TG/HDL-c & $4(3 ; 5)$ & $3(2 ; 5)$ & $3(2 ; 4)^{*}$ \\
\hline CT/HDL & $5(5 ; 7)$ & $5(4 ; 6)^{*}$ & $5(4 ; 6)$ \\
\hline LDL-c/HDL-c & $4(3 ; 5)$ & $3(3 ; 4)$ & $3(3 ; 4)$ \\
\hline
\end{tabular}

As comparações entre os tercis foram feitas através dos testes ANOVA Oneway ou Kruskall-Wallis, dependendo da distribuição da variável. *diferença significante $(\mathrm{p}<0,05)$ em relação ao $1^{\circ}$ tercil. **diferença significante $(\mathrm{p}$ $<0,05)$ em relação ao $2^{\circ}$ tercil. Os dados estão apresentados na forma de média (desvio padrão) ou mediana (intervalo interquartil) dependendo da distribuição da variável contínua. Ômega-3 total = C18:3 n-3 + C20:5 n-3 $+\mathrm{C} 22: 6$ n-3.

Os homens com ômega-6 total > 11,26\% apresentaram maior colesterol total, Apo A-I e atividade de PON1 quando comparados com o primeiro tercil $(<7,78 \%)$, e neste último parâmetro, os homens com ômega-6 total > 7,78\% também tiveram essa diferença (Tabela 25). Já as mulheres do maior tercil de ômega-6 total (> 11,08\%) apresentaram maior colesterol total e LDL(-) em relação ao primeiro tercil $(\leq 7,32 \%)$. As mulheres do 
segundo tercil apresentaram maior Apo B e Apo A-I quando comparadas com as do primeiro tercil, além de menores níveis plasmáticos de HDL grande (Tabela 26).

Tabela 25. Comparação dos parâmetros clínicos e bioquímicos segundo tercis de ômega-6 total de membranas eritrocitárias de homens.

\begin{tabular}{|c|c|c|c|}
\hline \multirow[b]{2}{*}{ Variáveis } & \multicolumn{3}{|c|}{ Ômega-6 total } \\
\hline & $\begin{array}{l}1^{\circ} \text { tercil } \\
(\leq 7,78 \%)\end{array}$ & $\begin{array}{c}2^{\circ} \text { tercil } \\
(>7,78 \% \text { a } \leq 11,26 \%)\end{array}$ & $\begin{array}{c}3^{\circ} \text { tercil } \\
(>11,26 \%)\end{array}$ \\
\hline $\mathrm{IMC}, \mathrm{kg} / \mathrm{m}^{2}$ & $32,2(5,7)$ & $29,9(5,4)$ & $29,6(4,9)$ \\
\hline $\mathrm{CC}, \mathrm{cm}$ & $108(14)$ & $103(14)$ & $103(12)$ \\
\hline Adiposidade corporal, \% & $24,5(5,2)$ & $22,8(4,6)$ & $22,3(4,0)$ \\
\hline PA sistólica, mmHg & $135(18)$ & $137(16)$ & $132(16)$ \\
\hline PA diastólica, mmHg & $83(11)$ & $84(11)$ & $80(9)$ \\
\hline Frequência cardíaca, bpm & $69(11)$ & $66(11)$ & $65(14)$ \\
\hline Colesterol total, mg/dL & $187(36)$ & $199(33)$ & $209(42)^{*}$ \\
\hline HDL-c, mg/dL & $31(6)$ & $31(8)$ & $33(7)$ \\
\hline LDL-c, mg/dL & $123(35)$ & $132(33)$ & $139(34)$ \\
\hline Triglicerídeos, mg/dL & $143(108 ; 200)$ & $158(103 ; 246)$ & $170(114 ; 232)$ \\
\hline Não-HDL-c, mg/dL & $156(36)$ & $169(34)$ & $176(41)$ \\
\hline $\mathrm{AGNE}, \mathrm{mEq} / \mathrm{dL}$ & $0,69(0,31)$ & $0,49(0,27)^{*}$ & $0,59(0,32)$ \\
\hline Apo A-I, mg/dL & $122(22)$ & $117(22)$ & $132(21)^{* *}$ \\
\hline Apo B, mg/dL & $98(24)$ & $98(20)$ & $109(22)$ \\
\hline PON1, nmol $\min ^{-1} * \mathrm{ml}^{-1}$ & $25,64(18,92 ; 55,15)$ & $55,30(23,17 ; 83,49)^{*}$ & $55,87(27,02 ; 81,69)^{*}$ \\
\hline HDL grande, $\%$ & $28(8)$ & $27(8)$ & $26(7)$ \\
\hline HDL intermediária, \% & $51(5)$ & $51(4)$ & $51(4)$ \\
\hline HDL pequena, $\%$ & $22(7)$ & $22(7)$ & $23(6)$ \\
\hline HDL grande, $\mathrm{mg} / \mathrm{dL}$ & $8(6 ; 10)$ & $7(5 ; 10)$ & $8(7 ; 11)$ \\
\hline HDL intermediária, mg/dL & $16(3)$ & $16(3)$ & $17(3)$ \\
\hline HDL pequena, $\mathrm{mg} / \mathrm{dL}$ & $7(2)$ & $7(2)$ & $8(2)$ \\
\hline LDL pequena, $\%$ & $2(1 ; 4)$ & $3(1 ; 8)$ & $3(1 ; 6)$ \\
\hline LDL grande \% & $26(5)$ & $26(5)$ & $26(5)$ \\
\hline LDL pequena, mg/dL & $3(1 ; 7)$ & $5(2 ; 16)$ & $6(3 ; 15)$ \\
\hline LDL grande, $\mathrm{mg} / \mathrm{dL}$ & $48(14)$ & $51(13)$ & $54(15)$ \\
\hline Tamanho de LDL, nm & $270(266 ; 272)$ & $268(262 ; 271)$ & $267(263 ; 271)$ \\
\hline $\mathrm{LDL}(-), \mu \mathrm{g} / \mathrm{mL}$ & $3,66(1,24 ; 9,08)$ & $4,03(1,49 ; 10,17)$ & $6,00(1,46 ; 14,53)$ \\
\hline Anti-LDL( $(-), \mu \mathrm{g} / \mathrm{mL}$ & $8,44(3,73)$ & $7,48(3,93)$ & $8,27(3,63)$ \\
\hline $\mathrm{CETP}, \mathrm{pmol} / \mu \mathrm{L} / \mathrm{h}$ & $55,30(20,62)$ & $57,80(26,85)$ & $57,72(24,59)$ \\
\hline Glicemia, mg/dL & $103(92 ; 119)$ & $102(94 ; 117)$ & $97(87 ; 110)$ \\
\hline Insulina, $\mu \mathrm{UI} / \mathrm{mL}$ & $16(13 ; 23)$ & $16(12 ; 22)$ & $15(13 ; 20)$ \\
\hline HOMA-IR & $4,93(2,12)$ & $5,06(2,49)$ & $4,29(1,86)$ \\
\hline HbA1c, $\%$ & $4,90(4,70 ; 5,30)$ & $5,00(4,70 ; 5,30)$ & $4,80(4,60 ; 5,25)$ \\
\hline Adiponectina, $\mathrm{ng} / \mathrm{mL}$ & $6,63(4,12 ; 9,42)$ & $6,15(3,30 ; 11,89)$ & $5,39(4,18 ; 10,57)$ \\
\hline Leptina, $\mathrm{ng} / \mathrm{mL}$ & $11,35(7,05 ; 40,38)$ & $7,50(5,78 ; 16,08)$ & $10,10(5,60 ; 15,45)$ \\
\hline $\mathrm{PCR}, \mathrm{mg} / \mathrm{L}$ & $2,24(1,06 ; 5,64)$ & $2,89(0,47 ; 5,58)$ & $1,65(0,93 ; 2,79)$ \\
\hline Apo B/Apo A-I & $0,83(0,25)$ & $0,89(0,31)$ & $0,84(0,19)$ \\
\hline TG/HDL-c & $5(3 ; 8)$ & $6(3 ; 10)$ & $5(3 ; 8)$ \\
\hline $\mathrm{CT} / \mathrm{HDL}$ & $6(5 ; 7)$ & $7(5 ; 8)$ & $6(5 ; 7)$ \\
\hline LDL-c/HDL-c & $4(3 ; 5)$ & $4(3 ; 5)$ & $4(3 ; 5)$ \\
\hline
\end{tabular}

As comparações entre os tercis foram feitas através dos testes ANOVA Oneway ou Kruskall-Wallis, dependendo da distribuição da variável. *diferença significante $(\mathrm{p}<0,05)$ em relação ao $1^{\circ}$ tercil. **diferença significante $(\mathrm{p}$ $<0,05)$ em relação ao $2^{\circ}$ tercil. Os dados estão apresentados na forma de média (desvio padrão) ou mediana (intervalo interquartil) dependendo da distribuição da variável contínua. Ômega-6 total = C18:2 n-6 + C18:3 n-6 + C20:2 n-6 + C20:3 n-6 + C20:4 n-6 + C22:2 n-6. 
Tabela 26. Comparação dos parâmetros clínicos e bioquímicos segundo tercis de ômega-6 total de membranas eritrocitárias de mulheres.

\begin{tabular}{|c|c|c|c|}
\hline \multirow[b]{2}{*}{ Variáveis } & \multicolumn{3}{|c|}{ Ômega-6 total } \\
\hline & $\begin{array}{c}1^{\circ} \text { tercil } \\
(\leq 7,32 \%)\end{array}$ & $\begin{array}{c}2^{\circ} \text { tercil } \\
(>7,32 \% \text { a } \leq 11,08 \%)\end{array}$ & $\begin{array}{c}3^{\circ} \text { tercil } \\
(>11,08 \%)\end{array}$ \\
\hline $\mathrm{IMC}, \mathrm{kg} / \mathrm{m}^{2}$ & $31,7(6,3)$ & $31,9(6,2)$ & $29,8(5,0)$ \\
\hline $\mathrm{CC}, \mathrm{cm}$ & $100(14)$ & $100(14)$ & $97(12)$ \\
\hline Adiposidade corporal, $\%$ & $45,2(6,8)$ & $44,6(8,3)$ & $42,4(6,8)$ \\
\hline PA sistólica, $\mathrm{mmHg}$ & $131(21)$ & $136(20)$ & $129(16)$ \\
\hline PA diastólica, $\mathrm{mmHg}$ & $79(9)$ & $82(10)$ & $80(10)$ \\
\hline Frequência cardíaca, bpm & $68(10)$ & $68(10)$ & $66(10)$ \\
\hline Colesterol total, mg/dL & $202(36)$ & $203(46)$ & $220(47)^{*}$ \\
\hline HDL-c, mg/dL & $40(8)$ & $39(11)$ & $41(10)$ \\
\hline $\mathrm{LDL}-\mathrm{c}, \mathrm{mg} / \mathrm{dL}$ & $135(34)$ & $138(42)$ & $149(44)$ \\
\hline Triglicerídeos, mg/dL & $114(88 ; 172)$ & $127(91 ; 163)$ & $131(96 ; 193)$ \\
\hline Não-HDL-c, mg/dL & $162(36)$ & $164(45)$ & $179(47)$ \\
\hline AGNE, $\mathrm{mEq} / \mathrm{dL}$ & $0,68(0,34)$ & $0,71(0,25)$ & $0,71(0,26)$ \\
\hline Apo A-I, mg/dL & $137(24)$ & $132(27)$ & $146(26) * *$ \\
\hline Apo B, mg/dL & $103(25)$ & $100(25)$ & $112(27)^{* *}$ \\
\hline PON1, nmol $\min ^{-1} * \mathrm{ml}^{-1}$ & $62,15(27,13 ; 86,30)$ & $53,63(24,12 ; 77,95)$ & $60,43(25,26 ; 81,78)$ \\
\hline HDL grande, $\%$ & $32(10)$ & $31(9)$ & $29(7)$ \\
\hline HDL intermediária, \% & $48(6)$ & $50(5)$ & $50(5)$ \\
\hline HDL pequena, $\%$ & $20(8)$ & $19(7)$ & $21(7)$ \\
\hline HDL grande, $\mathrm{mg} / \mathrm{dL}$ & $12(8 ; 17)$ & $10(9 ; 16)^{*}$ & $11(8 ; 15)$ \\
\hline HDL intermediária, mg/dL & $19(17 ; 21)$ & $18(16 ; 22)$ & $20(17 ; 24)$ \\
\hline HDL pequena, $\mathrm{mg} / \mathrm{dL}$ & $8(6 ; 10)$ & $7(5 ; 9)$ & $8(6 ; 11)$ \\
\hline LDL pequena, $\%$ & $1(0 ; 3)$ & $1(1 ; 3)$ & $2(1 ; 4)$ \\
\hline LDL grande $\%$ & $26(5)$ & $25(5)$ & $26(6)$ \\
\hline LDL pequena, mg/dL & $2(0 ; 6)$ & $2(1 ; 7)$ & $4(2 ; 10)$ \\
\hline LDL grande, $\mathrm{mg} / \mathrm{dL}$ & $52(15)$ & $52(17)$ & $58(20)$ \\
\hline Tamanho de LDL, nm & $271(268 ; 273)$ & $271(268 ; 272)$ & $270(265 ; 272)$ \\
\hline $\mathrm{LDL}(-), \mu \mathrm{g} / \mathrm{mL}$ & $3,55(1,71 ; 13,78)$ & $5,89(2,68 ; 19,56)$ & $13,53(2,71 ; 47,38)^{*}$ \\
\hline Anti-LDL( $(-), \mu \mathrm{g} / \mathrm{mL}$ & $6,89(2,48 ; 11,57)$ & $8,47(5,62 ; 11,60)$ & $7,22(5,25 ; 11,33)$ \\
\hline $\mathrm{CETP}, \mathrm{pmol} / \mu \mathrm{L} / \mathrm{h}$ & $51,02(26,70)$ & $54,21(31,46)$ & $51,36(19,36)$ \\
\hline Glicemia, mg/dL & $105(34)$ & $102(21)$ & $101(28)$ \\
\hline Insulina, $\mu \mathrm{UI} / \mathrm{mL}$ & $19(9)$ & $20(10)$ & $17(6)$ \\
\hline HOMA-IR & $4,94(3,03)$ & $5,07(3,81)$ & $4,08(1,93)$ \\
\hline $\mathrm{HbA1c}, \%$ & $5,06(0,57)$ & $5,14(0,54)$ & $5,04(0,48)$ \\
\hline Adiponectina, ng/mL & $9,29(5,75 ; 15,00)$ & $9,39(5,13 ; 14,13)$ & $8,97(5,23 ; 12,94)$ \\
\hline Leptina, $\mathrm{ng} / \mathrm{mL}$ & $59,55(35,53 ; 92,60)$ & $53,70(24,10 ; 81,05)$ & $43,60(24,88 ; 75,40)$ \\
\hline PCR, mg/L & $2,65(1,36 ; 6,38)$ & $3,87(1,39 ; 6,92)$ & $2,87(1,43 ; 5,37)$ \\
\hline Apo B/Apo A-I & $0,76(0,19)$ & $0,78(0,22)$ & $0,79(0,23)$ \\
\hline TG/HDL-c & $3(2 ; 5)$ & $4(2 ; 5)$ & $3(2 ; 5)$ \\
\hline CT/HDL & $5(4 ; 6)$ & $5(4 ; 7)$ & $5(5 ; 7)$ \\
\hline LDL-c/HDL-c & $3(3 ; 4)$ & $4(3 ; 5)$ & $3(3 ; 5)$ \\
\hline
\end{tabular}

As comparações entre os tercis foram feitas através dos testes ANOVA Oneway ou Kruskall-Wallis, dependendo da distribuição da variável. *diferença significante $(\mathrm{p}<0,05)$ em relação ao $1^{\circ}$ tercil. **diferença significante $(\mathrm{p}<0,05)$ em relação ao $2^{\circ}$ tercil. Os dados estão apresentados na forma de média (desvio padrão) ou mediana (intervalo interquartil) dependendo da distribuição da variável contínua. Ômega- 6 total $=\mathrm{C} 18: 2 \mathrm{n}$ $6+C 18: 3 n-6+C 20: 2$ n-6 + C20:3 n-6 + C20:4 n-6 + C22:2 n-6.

Os homens do maior tercil de IO3 (> 4,34\%) apresentaram maiores níveis de AGNE no plasma em relação aos do primeiro tercil $(<3,24 \%)$, além de menores níveis de LDL pequena em relação aos do segundo tercil (Tabela 27). As mulheres do maior tercil de IO3 (> 4,05\%) apresentaram menor LDL(-) em relação ao segundo tercil (Tabela 28). 
Tabela 27. Comparação dos parâmetros clínicos e bioquímicos segundo tercis de Índice Ômega-3 de membranas eritrocitárias de homens.

\begin{tabular}{|c|c|c|c|}
\hline \multirow[b]{2}{*}{ Variáveis } & \multicolumn{3}{|c|}{ Índice Ômega-3 } \\
\hline & $\begin{array}{c}1^{\circ} \text { tercil } \\
(\leq 3,24 \%)\end{array}$ & $\begin{array}{c}2^{\circ} \text { tercil } \\
(>3,24 \% \text { a } \leq 4,34 \%)\end{array}$ & $\begin{array}{c}3^{\circ} \text { tercil } \\
(>4,34 \%)\end{array}$ \\
\hline $\mathrm{IMC}, \mathrm{kg} / \mathrm{m}^{2}$ & $30,0(5,6)$ & $30,9(5,1)$ & $30,9(5,7)$ \\
\hline $\mathrm{CC}, \mathrm{cm}$ & $102(13)$ & $106(12)$ & $105(15)$ \\
\hline Adiposidade corporal, $\%$ & $22,7(4,8)$ & $23,4(4,2)$ & $23,4(5,2)$ \\
\hline PA sistólica, mmHg & $134(16)$ & $135(18)$ & $135(16)$ \\
\hline PA diastólica, $\mathrm{mmHg}$ & $84(10)$ & $81(11)$ & $82(10)$ \\
\hline Frequência cardíaca, bpm & $66(14)$ & $67(13)$ & $67(9)$ \\
\hline Colesterol total, $\mathrm{mg} / \mathrm{dL}$ & $205(37)$ & $203(40)$ & $186(33)$ \\
\hline HDL-c, mg/dL & $33(8)$ & $31(6)$ & $32(8)$ \\
\hline LDL-c, mg/dL & $137(35)$ & $133(35)$ & $125(34)$ \\
\hline Triglicerídeos, mg/dL & $152(113 ; 304)$ & $170(117 ; 246)$ & $137(103 ; 205)$ \\
\hline Não-HDL-c, mg/dL & $172(37)$ & $173(40)$ & $154(33)$ \\
\hline $\mathrm{AGNE}, \mathrm{mEq} / \mathrm{dL}$ & $0,51(0,29)$ & $0,58(0,23)$ & $0,68(0,37)^{*}$ \\
\hline Apo A-I, mg/dL & $124(25)$ & $125(21)$ & $121(22)$ \\
\hline Apo B, mg/dL & $103(25)$ & $107(21)$ & $95(21)$ \\
\hline PON1, nmol $\min ^{-1} * \mathrm{ml}^{-1}$ & $43,53(20,26 ; 67,86)$ & $52,76(20,55 ; 65,24)$ & $39,49(22,07 ; 80,83)$ \\
\hline HDL grande, $\%$ & $28(8)$ & $27(8)$ & $26(7)$ \\
\hline HDL intermediária, \% & $51(4)$ & $50(4)$ & $51(4)$ \\
\hline HDL pequena, $\%$ & $21(7)$ & $23(7)$ & $22(6)$ \\
\hline HDL grande, $\mathrm{mg} / \mathrm{dL}$ & $9(6 ; 11)$ & $8(6 ; 9)$ & $7(6 ; 11)$ \\
\hline HDL intermediária, mg/dL & $16(3)$ & $15(3)$ & $16(16)$ \\
\hline HDL pequena, $\mathrm{mg} / \mathrm{dL}$ & $7(2)$ & $7(3)$ & $7(2)$ \\
\hline LDL pequena, $\%$ & $2(1 ; 7)$ & $3(2 ; 7)$ & $2(1 ; 4) * *$ \\
\hline LDL grande $\%$ & $25(5)$ & $25(6)$ & $27(4)$ \\
\hline LDL pequena, mg/dL & $4(2 ; 16)$ & $6(3 ; 15)$ & $4(2 ; 8) * *$ \\
\hline LDL grande, mg/dL & $51(13)$ & $51(15)$ & $51(14)$ \\
\hline Tamanho de LDL, nm & $269(263 ; 272)$ & $267(263 ; 270)$ & $269(266 ; 272)$ \\
\hline $\mathrm{LDL}(-), \mu \mathrm{g} / \mathrm{mL}$ & $4,19(1,52 ; 10,38)$ & $4,81(1,39 ; 13,95)$ & $3,85(1,35 ; 10,19)$ \\
\hline Anti-LDL(-), $\mu \mathrm{g} / \mathrm{mL}$ & $8,88(3,64)$ & $8,30(3,90)$ & $6,98(3,56)$ \\
\hline $\mathrm{CETP}, \mathrm{pmol} / \mu \mathrm{L} / \mathrm{h}$ & $59,49(23,73)$ & $61,37(28,75)$ & $50,42(18,33)$ \\
\hline Glicemia, mg/dL & $100(92 ; 113)$ & $102(90 ; 116)$ & $101(93 ; 118)$ \\
\hline Insulina, $\mu \mathrm{UI} / \mathrm{mL}$ & $15(13 ; 20)$ & $18(12 ; 24)$ & $15(13 ; 22)$ \\
\hline HOMA-IR & $4,83(2,39)$ & $4,91(2,23)$ & $4,60(1,95)$ \\
\hline HbA1c, $\%$ & $4,90(4,70 ; 5,23)$ & $4,90(4,70 ; 5,33)$ & $4,90(4,70 ; 5,25)$ \\
\hline Adiponectina, ng/mL & $7,38(4,00 ; 11,18)$ & $7,14(3,38 ; 13,18)$ & $5,76(3,96 ; 8,09)$ \\
\hline Leptina, ng/mL & $9,20(5,55 ; 15,88)$ & $13,00(6,33 ; 19,70)$ & $7,70(5,75 ; 27,80)$ \\
\hline $\mathrm{PCR}, \mathrm{mg} / \mathrm{L}$ & $1,78(1,01 ; 4,40)$ & $1,91(1,01 ; 3,96)$ & $2,09(0,51 ; 6,11)$ \\
\hline Apo B/Apo A-I & $0,88(0,30)$ & $0,87(0,20)$ & $0,82(0,25)$ \\
\hline TG/HDL-c & $4(3 ; 10)$ & $5(4 ; 9)$ & $4(3 ; 8)$ \\
\hline $\mathrm{CT} / \mathrm{HDL}$ & $6(5 ; 8)$ & $7(6 ; 8)$ & $6(5 ; 7)$ \\
\hline LDL-c/HDL-c & $4(3 ; 5)$ & $4(3 ; 5)$ & $4(3 ; 5)$ \\
\hline
\end{tabular}

As comparações entre os tercis foram feitas através dos testes ANOVA Oneway ou Kruskall-Wallis, dependendo da distribuição da variável. *diferença significante $(\mathrm{p}<0,05)$ em relação ao $1^{\circ}$ tercil. **diferença significante $(\mathrm{p}$ $<0,05)$ em relação ao $2^{\circ}$ tercil. Os dados estão apresentados na forma de média (desvio padrão) ou mediana (intervalo interquartil) dependendo da distribuição da variável contínua. Índice Ômega-3 = C20:5 n-3 + C22:6 n3. 
Tabela 28. Comparação dos parâmetros clínicos e bioquímicos segundo tercis de Índice Ômega-3 de membranas eritrocitárias de mulheres.

\begin{tabular}{|c|c|c|c|}
\hline \multirow[b]{2}{*}{ Variáveis } & \multicolumn{3}{|c|}{ Índice Ômega-3 } \\
\hline & $\begin{array}{l}1^{\circ} \text { tercil } \\
(\leq 3,13 \%)\end{array}$ & $\begin{array}{c}2^{\circ} \text { tercil } \\
(>3,13 \% \text { a } \leq 4,05 \%)\end{array}$ & $\begin{array}{c}3^{\circ} \text { tercil } \\
(>4,05 \%)\end{array}$ \\
\hline $\mathrm{IMC}, \mathrm{kg} / \mathrm{m}^{2}$ & $30,3(5,6)$ & $31,8(5,9)$ & $31,3(6,2)$ \\
\hline $\mathrm{CC}, \mathrm{cm}$ & $96(13)$ & $100(13)$ & $99(14)$ \\
\hline Adiposidade corporal, $\%$ & $43,0(7,8)$ & $45,2(6,8)$ & $43,9(7,5)$ \\
\hline PA sistólica, mmHg & $128(18)$ & $133(17)$ & $135(22)$ \\
\hline PA diastólica, $\mathrm{mmHg}$ & $79(9)$ & $81(10)$ & $82(10)$ \\
\hline Frequência cardíaca, bpm & $67(10)$ & $66(8)$ & $68(12)$ \\
\hline Colesterol total, $\mathrm{mg} / \mathrm{dL}$ & $207(41)$ & $215(46)$ & $202(44)$ \\
\hline HDL-c, mg/dL & $40(9)$ & $40(11)$ & $39(10)$ \\
\hline LDL-c, mg/dL & $137(39)$ & $147(42)$ & $137(40)$ \\
\hline Triglicerídeos, mg/dL & $134(104 ; 187)$ & $125(90 ; 185)$ & $108(90 ; 147)$ \\
\hline Não-HDL-c, mg/dL & $167(41)$ & $175(45)$ & $163(44)$ \\
\hline $\mathrm{AGNE}, \mathrm{mEq} / \mathrm{dL}$ & $0,73(0,30)$ & $0,66(0,22)$ & $0,71(0,31)$ \\
\hline Apo A-I, mg/dL & $141(29)$ & $139(24)$ & $134(26)$ \\
\hline Apo B, mg/dL & $104(24)$ & $110(28)$ & $101(25)$ \\
\hline PON1, nmol $\mathrm{min}^{-1} * \mathrm{ml}^{-1}$ & $61,54(24,98 ; 81,53)$ & $55,16(29,66 ; 76,44)$ & $57,41(24,86 ; 86,30)$ \\
\hline HDL grande, $\%$ & $30(9)$ & $30(8)$ & $32(10)$ \\
\hline HDL intermediária, \% & $50(5)$ & $50(5)$ & $49(5)$ \\
\hline HDL pequena, $\%$ & $20(7)$ & $20(7)$ & $20(8)$ \\
\hline HDL grande, $\mathrm{mg} / \mathrm{dL}$ & $11(9 ; 16)$ & $11(9 ; 15)$ & $12(8 ; 17)$ \\
\hline HDL intermediária, mg/dL & $20(17 ; 23)$ & $19(17 ; 22)$ & $19(16 ; 21)$ \\
\hline HDL pequena, $\mathrm{mg} / \mathrm{dL}$ & $8(6 ; 10)$ & $7(7 ; 10)$ & $7(6 ; 10)$ \\
\hline LDL pequena, $\%$ & $2(0 ; 4)$ & $1(1 ; 3)$ & $1(1 ; 3)$ \\
\hline LDL grande $\%$ & $26(5)$ & $25(6)$ & $26(5)$ \\
\hline $\mathrm{LDL}$ pequena, mg/dL & $3(1 ; 8)$ & $2(1 ; 8)$ & $3(1 ; 7)$ \\
\hline LDL grande, mg/dL & $55(16)$ & $55(20)$ & $53(16)$ \\
\hline Tamanho de LDL, nm & $270(266 ; 272)$ & $271(267 ; 272)$ & $271(267 ; 272)$ \\
\hline $\mathrm{LDL}(-), \mu \mathrm{g} / \mathrm{mL}$ & $5,11(2,18 ; 27,55)$ & $12,99(2,73 ; 28,01)$ & $4,48(1,77 ; 13,78)^{* *}$ \\
\hline Anti-LDL( $(-), \mu \mathrm{g} / \mathrm{mL}$ & $8,09(4,18 ; 11,55)$ & $8,03(5,10 ; 11,32)$ & $7,52(3,67 ; 11,57)$ \\
\hline $\mathrm{CETP}, \mathrm{pmol} / \mu \mathrm{L} / \mathrm{h}$ & $52,84(29,44)$ & $48,63(27,26)$ & $54,41(20,23)$ \\
\hline Glicemia, mg/dL & $103(27)$ & $103(22)$ & $102(34)$ \\
\hline Insulina, $\mu \mathrm{UI} / \mathrm{mL}$ & $18(7)$ & $19(11)$ & $18(9)$ \\
\hline HOMA-IR & $4,53(2,06)$ & $4,99(3,83)$ & $4,69(3,17)$ \\
\hline HbA1c, $\%$ & $5,08(0,41)$ & $5,07(0,44)$ & $5,09(0,70)$ \\
\hline Adiponectina, $\mathrm{ng} / \mathrm{mL}$ & $9,75(5,13 ; 14,40)$ & $8,17(5,01 ; 11,30)$ & $9,62(5,91 ; 16,14)$ \\
\hline Leptina, $\mathrm{ng} / \mathrm{mL}$ & $52,00(24,10 ; 83,15)$ & $54,35(30,65 ; 86,03)$ & $50,65(27,65 ; 84,98)$ \\
\hline $\mathrm{PCR}, \mathrm{mg} / \mathrm{L}$ & $2,72(1,33 ; 5,79)$ & $3,59(1,95 ; 6,59)$ & $3,12(1,24 ; 6,53)$ \\
\hline Apo B/Apo A-I & $0,77(0,23)$ & $0,80(0,20)$ & $0,77(0,21)$ \\
\hline TG/HDL-c & $4(2 ; 5)$ & $3(2 ; 5)$ & $3(2 ; 4)$ \\
\hline $\mathrm{CT} / \mathrm{HDL}$ & $5(4 ; 6)$ & $5(4 ; 7)$ & $5(4 ; 6)$ \\
\hline LDL-c/HDL-c & $3(3 ; 5)$ & $4(3 ; 5)$ & $3(3 ; 5)$ \\
\hline
\end{tabular}

As comparações entre os tercis foram feitas através dos testes ANOVA Oneway ou Kruskall-Wallis, dependendo da distribuição da variável. *diferença significante $(\mathrm{p}<0,05)$ em relação ao $1^{\circ}$ tercil. **diferença significante $(\mathrm{p}$ $<0,05)$ em relação ao $2^{\circ}$ tercil. Os dados estão apresentados na forma de média (desvio padrão) ou mediana (intervalo interquartil) dependendo da distribuição da variável contínua. Índice Ômega-3 = C20:5 n-3 + C22:6 n3.

Em relação aos homens com a razão AG n-6/n-3 menor que 1,27, os que tinham o valor acima de 2,23 apresentaram maior colesterol total, não-HDL-c, Apo B, LDL pequena, além de menor tamanho de LDL (Tabela 29). Já as mulheres com a razão acima de 2,06 apresentaram mais LDL pequena e LDL(-) quando comparadas com as mulheres do primeiro tercil $(<1,26)$ (Tabela 30). 
Tabela 29. Comparação dos parâmetros clínicos e bioquímicos segundo tercis da razão ômega-6/ômega-3 de membranas eritrocitárias de homens.

\begin{tabular}{|c|c|c|c|}
\hline \multirow[b]{2}{*}{ Variáveis } & \multicolumn{3}{|c|}{ Ômega-6/ômega-3 } \\
\hline & $\begin{array}{l}1^{\circ} \text { tercil } \\
(\leq 1,27)\end{array}$ & $\begin{array}{c}2^{\circ} \text { tercil } \\
(>1,27 \mathrm{a} \leq 2,23)\end{array}$ & $\begin{array}{l}3^{\circ} \text { tercil } \\
(>2,23)\end{array}$ \\
\hline $\mathrm{IMC}, \mathrm{kg} / \mathrm{m}^{2}$ & $31,7(6,0)$ & $29,8(5,2)$ & $30,2(4,9)$ \\
\hline $\mathrm{CC}, \mathrm{cm}$ & $107(16)$ & $102(12)$ & $104(11)$ \\
\hline Adiposidade corporal, $\%$ & $24,0(5,5)$ & $22,4(4,4)$ & $23,1(3,9)$ \\
\hline PA sistólica, mmHg & $134(17)$ & $137(18)$ & $133(15)$ \\
\hline PA diastólica, $\mathrm{mmHg}$ & $82(11)$ & $84(11)$ & $81(9)$ \\
\hline Frequência cardíaca, bpm & $67(10)$ & $66(11)$ & $66(15)$ \\
\hline Colesterol total, $\mathrm{mg} / \mathrm{dL}$ & $187(34)$ & $198(36)$ & $210(40)^{*}$ \\
\hline HDL-c, mg/dL & $32(7)$ & $33(8)$ & $31(6)$ \\
\hline LDL-c, mg/dL & $124(33)$ & $131(36)$ & $141(33)$ \\
\hline Triglicerídeos, mg/dL & $148(105 ; 200)$ & $136(101 ; 216)$ & $186(119 ; 305)$ \\
\hline Não-HDL-c, mg/dL & $155(34)$ & $166(37)$ & $179(39)^{*}$ \\
\hline AGNE, $\mathrm{mEq} / \mathrm{dL}$ & $0,66(0,33)$ & $0,54(0,28)$ & $0,56(0,31)$ \\
\hline Apo A-I, mg/dL & $122(22)$ & $125(22)$ & $123(24)$ \\
\hline Apo B, mg/dL & $95(22)$ & $102(22)$ & $102(23)^{*}$ \\
\hline PON1, nmol min ${ }^{-1} * \mathrm{ml}^{-1}$ & $29,74(20,34 ; 63,70)$ & $55,30(22,42 ; 82,92)$ & $53,21(25,11 ; 68,58)$ \\
\hline HDL grande, $\%$ & $27(8)$ & $28(8)$ & $26(7)$ \\
\hline HDL intermediária, \% & $50(5)$ & $51(4)$ & $51(4)$ \\
\hline HDL pequena, $\%$ & $23(7)$ & $21(7)$ & $23(6)$ \\
\hline $\mathrm{HDL}$ grande, $\mathrm{mg} / \mathrm{dL}$ & $8(6 ; 11)$ & $8(6 ; 11)$ & $8(6 ; 10)$ \\
\hline $\mathrm{HDL}$ intermediária, $\mathrm{mg} / \mathrm{dL}$ & $16(3)$ & $16(3)$ & $16(3)$ \\
\hline HDL pequena, mg/dL & $7(2)$ & $7(2)$ & $7(2)$ \\
\hline LDL pequena, $\%$ & $2(1 ; 4)$ & $2(1 ; 8)$ & $4(2 ; 8)^{*}$ \\
\hline LDL grande $\%$ & $27(5)$ & $25(4)$ & $26(6)$ \\
\hline LDL pequena, mg/dL & $3(2 ; 7)$ & $4(2 ; 16)$ & $7(3 ; 18)^{*}$ \\
\hline LDL grande, $\mathrm{mg} / \mathrm{dL}$ & $6(7)$ & $10(13)$ & $12(13)$ \\
\hline Tamanho de LDL, nm & $269(266 ; 272)$ & $270(262 ; 271)$ & $266(262 ; 269)^{*}$ \\
\hline $\operatorname{LDL}(-), \mu \mathrm{g} / \mathrm{mL}$ & $3,66(1,19 ; 9,83)$ & $4,78(1,49 ; 12,02)$ & $5,44(1,44 ; 11,41)$ \\
\hline Anti-LDL(-), $\mu \mathrm{g} / \mathrm{mL}$ & $7,81(3,68)$ & $8,50(3,93)$ & $7,87(3,72)$ \\
\hline $\mathrm{CETP}, \mathrm{pmol} / \mu \mathrm{L} / \mathrm{h}$ & $53,47(19,54)$ & $58,87(28,32)$ & $58,81(23,45)$ \\
\hline Glicemia, mg/dL & $105(95 ; 118)$ & $101(92 ; 117)$ & $98(87 ; 110)$ \\
\hline Insulina, $\mu \mathrm{UI} / \mathrm{mL}$ & $16(13 ; 23)$ & $16(12 ; 24)$ & $15(13 ; 20)$ \\
\hline HOMA-IR & $4,81(2,02)$ & $5,01(2,48)$ & $4,53(2,11)$ \\
\hline $\mathrm{HbA} 1 \mathrm{c}, \%$ & $4,90(4,70 ; 5,20)$ & $5,00(4,70 ; 5,30)$ & $4,90(4,65 ; 5,40)$ \\
\hline Adiponectina, ng/mL & $7,11(4,53 ; 10,42)$ & $5,37(3,22 ; 9,70)$ & $6,23(4,02 ; 11,30)$ \\
\hline Leptina, $\mathrm{ng} / \mathrm{mL}$ & $10,75(6,63 ; 40,38)$ & $8,15(5,80 ; 16,30)$ & $10,10(5,70 ; 15,80)$ \\
\hline $\mathrm{PCR}, \mathrm{mg} / \mathrm{L}$ & $2,10(0,94 ; 5,42)$ & $2,23(0,46 ; 5,55)$ & $1,79(1,05 ; 2,98)$ \\
\hline Apo B/Apo A-I & $0,80(0,24)$ & $0,84(0,24)$ & $0,92(0,2 \times 7)$ \\
\hline TG/HDL-c & $5(3 ; 8)$ & $4(3 ; 8)$ & $5(4 ; 11)$ \\
\hline $\mathrm{CT} / \mathrm{HDL}$ & $6(5 ; 7)$ & $6(5 ; 8)$ & $7(6 ; 8)$ \\
\hline LDL-c/HDL-c & $4(3 ; 5)$ & $4(3 ; 5)$ & $4(4 ; 5)$ \\
\hline
\end{tabular}

As comparações entre os tercis foram feitas através dos testes ANOVA Oneway ou Kruskall-Wallis, dependendo da distribuição da variável. *diferença significante $(\mathrm{p}<0,05)$ em relação ao $1^{\circ}$ tercil. **diferença significante $(\mathrm{p}$ $<0,05)$ em relação ao $2^{\circ}$ tercil. Os dados estão apresentados na forma de média (desvio padrão) ou mediana (intervalo interquartil) dependendo da distribuição da variável contínua. Ômega- 6 total = C18:2 n- $6+C 18: 3 n-6$ + C20:2 n-6 + C20:3 n-6 + C20:4 n-6 + C22:2 n-6. Ômega-3 = C18:3 n-3 + C20:5 n-3 + C22:6 n-3. 
Tabela 30. Comparação dos parâmetros clínicos e bioquímicos segundo tercis da razão ômega-6/ômega-3 de membranas eritrocitárias de mulheres.

\begin{tabular}{|c|c|c|c|}
\hline \multirow[b]{2}{*}{ Variáveis } & \multicolumn{3}{|c|}{ Ômega-6/ômega-3 } \\
\hline & $\begin{array}{l}1^{\circ} \text { tercil } \\
(\leq 1,26)\end{array}$ & $\begin{array}{c}2^{\circ} \text { tercil } \\
(>1,26 \mathrm{a} \leq 2,06)\end{array}$ & $\begin{array}{l}3^{\circ} \text { tercil } \\
(>2,06)\end{array}$ \\
\hline $\mathrm{IMC}, \mathrm{kg} / \mathrm{m}^{2}$ & $31,7(6,6)$ & $31,6(6,1)$ & $30,1(4,8)$ \\
\hline $\mathrm{CC}, \mathrm{cm}$ & $100(15)$ & $99(12)$ & $97(12)$ \\
\hline Adiposidade corporal, $\%$ & $44,8(7,1)$ & $44,3(8,2)$ & $43,0(6,7)$ \\
\hline PA sistólica, mmHg & $131(21)$ & $136(18)$ & $130(18)$ \\
\hline PA diastólica, $\mathrm{mmHg}$ & $79(9)$ & $83(10)^{*}$ & $80(10)$ \\
\hline Frequência cardíaca, bpm & $67(10)$ & $69(10)$ & $66(10)$ \\
\hline Colesterol total, $\mathrm{mg} / \mathrm{dL}$ & $202(40)$ & $207(43)$ & $216(48)$ \\
\hline HDL-c, mg/dL & $41(9)$ & $40(11)$ & $40(10)$ \\
\hline LDL-c, mg/dL & $136(38)$ & $139(37)$ & $147(46)$ \\
\hline Triglicerídeos, mg/dL & $105(86 ; 148)$ & $132(92 ; 176)$ & $131(98 ; 187)$ \\
\hline Não-HDL-c, mg/dL & $161(40)$ & $167(41)$ & $177(48)$ \\
\hline AGNE, $\mathrm{mEq} / \mathrm{dL}$ & $0,68(0,33)$ & $0,73(0,27)$ & $0,69(0,24)$ \\
\hline Apo A-I, mg/dL & $136(24)$ & $139(27)$ & $139(28)$ \\
\hline Apo B, mg/dL & $102(26)$ & $104(25)$ & $109(27)$ \\
\hline PON1, nmol min ${ }^{-1} * \mathrm{ml}^{-1}$ & $62,15(28,00 ; 86,30)$ & $51,32(23,60 ; 79,98)$ & $59,97(25,59 ; 78,19)$ \\
\hline HDL grande, $\%$ & $32(10)$ & $31(9)$ & $29(7)$ \\
\hline HDL intermediária, \% & $48(5)$ & $49(5)$ & $51(5)^{*}$ \\
\hline HDL pequena, $\%$ & $20(7)$ & $20(8)$ & $20(7)$ \\
\hline $\mathrm{HDL}$ grande, $\mathrm{mg} / \mathrm{dL}$ & $13(8 ; 18)$ & $10(9 ; 16)$ & $11(8 ; 14)$ \\
\hline $\mathrm{HDL}$ intermediária, $\mathrm{mg} / \mathrm{dL}$ & $19(17 ; 21)$ & $19(16 ; 22)$ & $19(17 ; 23)$ \\
\hline $\mathrm{HDL}$ pequena, $\mathrm{mg} / \mathrm{dL}$ & $8(6 ; 10)$ & $7(5 ; 10)$ & $7(6 ; 11)$ \\
\hline LDL pequena, $\%$ & $1(0 ; 2)$ & $1(1 ; 4)$ & $2(1 ; 4)^{*}$ \\
\hline LDL grande $\%$ & $26(5)$ & $25(4)$ & $26(6)$ \\
\hline LDL pequena, mg/dL & $2(0 ; 5)$ & $2(1 ; 8)$ & $4(2 ; 9)^{*}$ \\
\hline LDL grande, $\mathrm{mg} / \mathrm{dL}$ & $52(16)$ & $52(14)$ & $58(22)$ \\
\hline Tamanho de LDL, nm & $271(268 ; 273)$ & $271(266 ; 272)$ & $270(266 ; 272)$ \\
\hline $\operatorname{LDL}(-), \mu \mathrm{g} / \mathrm{mL}$ & $4,48(1,86 ; 13,78)$ & $6,91(1,97 ; 24,77)$ & $10,30(2,56 ; 37,22)^{*}$ \\
\hline Anti-LDL(-), $\mu \mathrm{g} / \mathrm{mL}$ & $8,12(3,00 ; 11,57)$ & $7,87(5,10 ; 11,52)$ & $7,47(5,39 ; 11,40)$ \\
\hline $\mathrm{CETP}, \mathrm{pmol} / \mu \mathrm{L} / \mathrm{h}$ & $48,06(18,08)$ & $52,58(23,07)$ & $56,76(35,14)$ \\
\hline Glicemia, mg/dL & $102(32)$ & $105(24)$ & $101(28)$ \\
\hline Insulina, $\mu \mathrm{UI} / \mathrm{mL}$ & $19(9)$ & $18(7)$ & $18(10)$ \\
\hline HOMA-IR & $4,85(3,00)$ & $4,66(2,42)$ & $4,62(3,70)$ \\
\hline $\mathrm{HbA} 1 \mathrm{c}, \%$ & $5,06(0,61)$ & $5,12(0,48)$ & $5,05(0,49)$ \\
\hline Adiponectina, ng/mL & $9,36(5,95 ; 15,74)$ & $9,31(5,42 ; 13,62)$ & $8,74(4,53 ; 13,40)$ \\
\hline Leptina, $\mathrm{ng} / \mathrm{mL}$ & $51,20(27,85 ; 92,00)$ & $55,70(31,55 ; 84,25)$ & $43,60(24,88 ; 70,10)$ \\
\hline $\mathrm{PCR}, \mathrm{mg} / \mathrm{L}$ & $2,51(1,14 ; 6,12)$ & $3,91(1,82 ; 7,54)$ & $3,00(1,73 ; 5,76)$ \\
\hline Apo B/Apo A-I & $0,76(0,20)$ & $0,77(0,21)$ & $0,80(0,22)$ \\
\hline TG/HDL-c & $3(2 ; 4)$ & $4(2 ; 5)$ & $4(3 ; 5)$ \\
\hline $\mathrm{CT} / \mathrm{HDL}$ & $5(4 ; 6)$ & $5(4 ; 7)$ & $5(5 ; 7)$ \\
\hline LDL-c/HDL-c & $3(3 ; 4)$ & $4(3 ; 5)$ & $3(3 ; 5)$ \\
\hline
\end{tabular}

As comparações entre os tercis foram feitas através dos testes ANOVA Oneway ou Kruskall-Wallis, dependendo da distribuição da variável. *diferença significante $(\mathrm{p}<0,05)$ em relação ao $1^{\circ}$ tercil. **diferença significante $(\mathrm{p}$ $<0,05)$ em relação ao $2^{\circ}$ tercil. Os dados estão apresentados na forma de média (desvio padrão) ou mediana (intervalo interquartil) dependendo da distribuição da variável contínua. Ômega- 6 total = C18:2 n- $6+C 18: 3 n-6$ + C20:2 n-6 + C20:3 n-6 + C20:4 n-6 + C22:2 n-6. Ômega-3 = C18:3 n-3 + C20:5 n-3 + C22:6 n-3. 
Considerando ainda que o efeito biológico dos AG na modulação dos fatores de risco modificáveis resulta da interação dos diferentes $A G$ incorporados às membranas celulares, realizamos uma análise fatorial visando identificar padrões de AG incorporados às membranas celulares que resumisse o perfil cardioprotetor e aterogênico desse conjunto da AG. Desse modo, a Tabela 31 mostra as cargas fatoriais dos AG insaturados que determinam os padrões de AG de membranas eritrocitárias, aqui, didaticamente denominados: Membrana 1, Membrana 2 e Membrana 3. O padrão Membrana 1 foi caracterizado principalmente por menor conteúdo de C22:6 n-3 e maior conteúdo de C18:2 n-6, C20:3 n-6 e C20:4 n-6, ou seja, é um padrão com mais AG n-6. O padrão Membrana 2 foi caracterizado principalmente pelo maior conteúdo de C18:3 n-3, C18:3 n-6, C18:1 n-9, C16:1 n-7 e C20:1 n-9, sendo um padrão com mais AGMI. Já o padrão Membrana 3 foi caracterizado principalmente pelo maior conteúdo de C18:3 n-3, C20:5 n-3 e menor conteúdo de C22:6 n-3, C20:2 n-6, C20:3 n-6 e C20:4 n-6, sendo um padrão com mais AG n-3.

Tabela 31. Cargas fatoriais dos padrões de ácidos graxos insaturados de membranas eritrocitárias.

\begin{tabular}{lcccc}
\hline Variáveis & Membrana 1 & Membrana 2 & Membrana 3 & Singularidade \\
\hline C18:3 n-3 & & 0,2831 & 0,3870 & 0,7660 \\
C20:5 n-3 & & & 0,7322 & 0,4483 \\
C22:6 n-3 & $-0,5140$ & & $-0,4340$ & 0,5187 \\
C18:2 n-6 & 0,8685 & 0,7620 & & 0,2378 \\
C18:3 n-6 & & & $-0,5528$ & 0,4031 \\
C20:2 n-6 & $-0,4115$ & & $-0,2087$ & 0,5007 \\
C20:3 n-6 & 0,8438 & $-0,2362$ & $-0,3197$ & 0,2244 \\
C20:4 n-6 & 0,7743 & & 0,7386 & 0,2425 \\
C22:2 n-6 & $-0,4253$ & 0,7515 & & 0,2527 \\
C16:1 n-7 & & 0,4663 & & 0,4228 \\
C18:1 n-9 & 0,6623 & 0,7516 & & 0,3349 \\
C20:1 n-9 & & & & 0,3978 \\
C22:1 n-9 & & & & 0,9822 \\
C24:1 n-9 & 0,4839 & & & 0,7612 \\
\hline
\end{tabular}

Cargas fatoriais após rotação ortogonal VARIMAX. Espaços em branco representam cargas fatoriais não significantes $(<0,20)$.

O padrão de Membrana 1 apresentou correlações positivas com CT $(\mathrm{r}=0,170 ; \mathrm{p}=$ 0,002), LDL-c ( $\mathrm{r}=0,137 ; \mathrm{p}=0,014)$, TG $(\mathrm{r}=136 ; \mathrm{p}=0,013)$, não-HDL-c $(\mathrm{r}=0,181 ; \mathrm{p}$ $=0,001)$, Apo B $(0,152 ; \mathrm{p}=0,005), \operatorname{LDL}(-)(\mathrm{r}=0,137 ; \mathrm{p}=0,012)$, anticorpo anti-LDL() $(\mathrm{r}=0,133 ; \mathrm{p}=0,015)$, e apresentou correlações negativas com leptina $(\mathrm{r}=-0,141 ; \mathrm{p}=$ 0,010) e tamanho de LDL $(r=-0,168 ; p=0,002)$. Já o padrão de Membrana 2 foi associado positivamente com glicemia $(\mathrm{r}=0,143 ; \mathrm{p}=0,009)$, HbA1c $(\mathrm{r}=0,162 ; \mathrm{p}=$ 0,003, anticorpo anti-LDL(-) $(r=0,113 ; p=0,040)$, e negativamente com AGNE $(r=-$ 
0,113; $\mathrm{p}=0,048)$, Apo A-I $(\mathrm{r}=-0,214 ; \mathrm{p}<0,001)$, HDL pequena $(\mathrm{r}=-0,155 ; \mathrm{p}=$ $0,004), \operatorname{LDL}(-)(\mathrm{r}=-0,185 ; \mathrm{p}=0,001)$ e adiponectina $(\mathrm{r}=-0,153 ; \mathrm{p}=0,007)$.

Finalmente, o padrão Membrana 3 foi associado positivamente com HOMA-IR ( $\mathrm{r}=$ 0,134, $\mathrm{p}=0,001)$, HbA1c $(\mathrm{r}=0,178 ; \mathrm{p}=0,001)$, anticorpo anti-LDL(-) $(\mathrm{r}=0,121 ; \mathrm{p}=$ 0,027), e negativamente com Apo A-I ( $\mathrm{r}=-0,140 ; \mathrm{p}=0,010)$, Apo B ( $\mathrm{r}=-0,184 ; \mathrm{p}=$ $0,001)$, LDL grande $(r=-0,110 ; p=0,044)$, LDL pequena $(r=-0,125 ; p=0,022)$, e $\operatorname{LDL}(-)(\mathrm{r}=-0,127 ; \mathrm{p}=0,020)$.

Considerando as correlações observadas entre os padrões de membranas com marcadores bioquímicos, testamos correlações ponto-bisseriais desses padrões com os escores de risco utilizados no trabalho. O padrão Membrana 1 correlacionou-se positivamente de maneira fraca com o $\operatorname{ERR~}(\mathrm{r}=0,093 ; \mathrm{p}=0,046)$ e o $\operatorname{ERF}(\mathrm{r}=0,121$; p=0,014). Já o padrão Membrana 3 correlacionou-se negativamente de maneira fraca com ERR $(r=-0,149 ; p=0,003)$ (Tabela 32).

Tabela 32. Correlações dos padrões de ácidos graxos insaturados de membranas eritrocitárias com diferentes escores de risco cardiovascular.

\begin{tabular}{lcccccc}
\hline \multirow{2}{*}{ Variáveis } & \multicolumn{2}{c}{ ACC/AHA 2013 } & \multicolumn{2}{c}{ ERR } & \multicolumn{2}{c}{ ERF } \\
\cline { 2 - 7 } & $\boldsymbol{r}$ & $\mathbf{p}$-valor & $\boldsymbol{r}$ & $\mathbf{p}$-valor & $\boldsymbol{r}$ & p-valor \\
\hline Membrana 1 & 0,064 & 0,120 & 0,093 & $0,046^{*}$ & 0,121 & $0,014^{*}$ \\
Membrana 2 & 0,049 & 0,188 & 0,045 & 0,206 & 0,084 & 0,062 \\
Membrana 3 & $-0,069$ & 0,103 & $-0,149$ & $0,003^{*}$ & $-0,027$ & 0,313 \\
\hline
\end{tabular}

ACC/AHA 2013: Escore de risco da American College of Cardiology e American Heart Association. ERF: Escore de Risco de Framingham. ERR: Escore de Risco de Reynolds.

Em relação ao escore de risco ACC/AHA 2013, os AG n-3, n-6 e os padrões de AG de membranas não se associaram com a chance dos indivíduos apresentarem RCV moderado ou alto (Tabela 33). 
Tabela 33. Associações dos ácidos graxos de membranas eritrocitárias com Escore de Risco da ACC/AHA 2013.

\begin{tabular}{lcccc}
\hline \multirow{2}{*}{ Ácidos graxos } & \multicolumn{3}{c}{ Escore de risco ACC/AHA 2013 } \\
\cline { 2 - 5 } & OR & IC (95\%) & OR & Modelo ajustado \\
\cline { 2 - 4 } & 0,926 & $0,779-1,102$ & 0,951 & $0,791-1,142$ \\
C18:3 n-3 & 0,726 & $0,163-3,243$ & 0,678 & $0,137-3,343$ \\
C20:5 n-3 & 0,965 & $0,809-1,152$ & 0,976 & $0,813-1,172$ \\
C22:6 n-3 & 0,936 & $0,821-1,068$ & 0,956 & $0,833-1,097$ \\
n-3 total & 1,005 & $0,948-1,065$ & 1,009 & $0,949-1,072$ \\
n-6 total & 0,960 & $0,802-1,149$ & 0,971 & $0,807-1,168$ \\
IO3 & 1,006 & $0,811-1,247$ & 0,983 & $0,785-1,231$ \\
n-6/n-3 & 0,997 & $0,986-1,008$ & 0,998 & $0,987-1,010$ \\
C20:4 n-6/C20:5 n-3 & 0,980 & $0,957-1,004$ & 0,982 & $0,958-1,006$ \\
C18:3 n-3/C20:5 n-3 & 1,023 & $0,682-1,536$ & 1,082 & $0,706-1,659$ \\
C18:3 n-3/C22:6 n-3 & 1,004 & $0,988-1,021$ & 0,999 & $0,983-1,015$ \\
C18:2 n-6/C18:3 n-3 & 1,142 & $0,915-1,424$ & 1,168 & $0,925-1,475$ \\
Membrana 1 & 1,115 & $0,875-1,419$ & 1,095 & $0,851-1,408$ \\
Membrana 2 & 0,866 & $0,693-1,083$ & 0,897 & $0,708-1,136$ \\
Membrana 3 & & & \\
\hline
\end{tabular}

Modelo ajustado por IMC, atividade física e escolaridade.

No ERR, o padrão de Membrana 3 (n-3) foi associado à redução de 26,6\% da chance de RCV moderado ou alto. Porém, após os ajustes por IMC, atividade física e escolaridade, o padrão de Membrana 1 (n-6) foi associado ao aumento de 27,6\% da chance de RCV moderado ou alto, enquanto o padrão de Membrana 3 (n-3) continuou como fator protetor $(-25,3 \%)$ (Tabela 34).

Tabela 34. Associações dos ácidos graxos de membranas eritrocitárias com Escore de Risco de Reynolds.

\begin{tabular}{|c|c|c|c|c|}
\hline \multirow{3}{*}{ Ácidos graxos } & \multicolumn{4}{|c|}{ Escore de Risco de Reynolds } \\
\hline & \multicolumn{2}{|c|}{ Modelo sem ajuste } & \multicolumn{2}{|c|}{ Modelo ajustado } \\
\hline & OR & IC $(95 \%)$ & OR & IC $(95 \%)$ \\
\hline C18:3n-3 & 0,911 & $0,766-1,082$ & 0,925 & $0,772-1,108$ \\
\hline$C 20: 5 n-3$ & 0,417 & $0,095-1,835$ & 0,378 & $0,078-1,823$ \\
\hline$C 22: 6 n-3$ & 1,033 & $0,867-1,232$ & 1,033 & $0,861-1,239$ \\
\hline n-3 total & 0,959 & $0,842-1,091$ & 0,968 & $0,845-1,108$ \\
\hline n-6 total & 1,033 & $0,975-1,094$ & 1,049 & $0,987-1,115$ \\
\hline IO3 & 1,021 & $0,855-1,220$ & 1,020 & $0,849-1,226$ \\
\hline$n-6 / n-3$ & 1,099 & $0,886-1,363$ & 1,117 & $0,890-1,403$ \\
\hline C20:4 n-6/C20:5 n-3 & 1,005 & $0,994-1,016$ & 1,008 & 0,996-1,019 \\
\hline C18:3 n-3/C20:5n-3 & 0,989 & $0,966-1,012$ & 0,990 & $0,966-1,014$ \\
\hline$C 18: 3 n-3 / C 22: 6 n-3$ & 0,888 & $0,599-1,317$ & 0,923 & $0,613-1,391$ \\
\hline C18:2 n-6/C18:3n-3 & 0,995 & $0,980-1,009$ & 0,988 & $0,970-1,006$ \\
\hline Membrana 1 & 1,208 & $0,969-1,507$ & 1,276 & $1,010-1,612$ \\
\hline Membrana 2 & 1,099 & $0,876-1,378$ & 1,087 & $0,860-1,375$ \\
\hline Membrana 3 & 0,734 & $0,585-0,921 *$ & 0,747 & $0,589-0,948 *$ \\
\hline
\end{tabular}

Modelo ajustado por IMC, atividade física e escolaridade. $* \mathrm{P}<0,05$.

Em relação ao ERF, o AG C18:3 n-3 e o total de n-3 das membranas foram associados à redução de 20,8\% e 20,2\% na chance dos indivíduos apresentarem RCV moderado ou alto, respectivamente, enquanto que as maiores razões de n-6/n-3 e C18:2 
n-6/C18:3 n-3 e o padrão de Membrana 1 (n-6) foram associados ao aumento de 47,3\%, $27,6 \%$ e 40,8\% da chance dos indivíduos apresentarem RCV moderado ou alto, respectivamente. No entanto, após os modelos de regressão logística serem ajustados por IMC, atividade física e escolaridade, apenas o n-3 total foi fator protetor $(-18,9 \%)$, enquanto que o padrão Membrana 1 (n-6) foi associado ao aumento na chance de RCV moderado ou alto $(46,9 \%)$ (Tabela 35).

Tabela 35. Associações dos ácidos graxos de membranas eritrocitárias com Escore de Risco de Framingham.

\begin{tabular}{lcccc}
\hline \multirow{2}{*}{ Ácidos graxos } & \multicolumn{3}{c}{ Escore de Risco de Framingham } \\
\cline { 2 - 5 } & OR & IC (95\%) & OR & Modelo ajustado \\
\cline { 2 - 4 } IC (95\%) \\
\hline C18:3 n-3 & 0,792 & $0,635-0,988^{*}$ & 0,819 & $0,642-1,046^{*}$ \\
C20:5 n-3 & 5,016 & $0,409-61,557$ & 6,176 & $0,374-102,027$ \\
C22:6 n-3 & 0,830 & $0,655-1,052$ & 0,833 & $0,654-1,062$ \\
n-3 total & 0,798 & $0,672-0,946^{*}$ & 0,811 & $0,675-0,976^{*}$ \\
n-6 total & 1,077 & $0,986-1,176$ & 1,079 & $0,984-1,183$ \\
IO3 & 0,840 & $0,660-1,069$ & 0,844 & $0,660-1,079$ \\
n-6/n-3 & 1,473 & $1,021-2,126^{*}$ & 1,421 & $0,972-2,078$ \\
C20:4 n-6/C20:5 n-3 & 1,002 & $0,986-1,020$ & 1,002 & $0,985-1,020$ \\
C18:3 n-3/C20:5 n-3 & 0,972 & $0,945-1,000$ & 0,973 & $0,945-1,003$ \\
C18:3 n-3/C22:6 n-3 & 0,764 & $0,455-1,285$ & 0,856 & $0,482-1,521$ \\
C18:2 n-6/C18:3 n-3 & 1,276 & $1,043-1,561 *$ & 1,229 & $0,995-1,518$ \\
Membrana 1 & 1,408 & $1,036-1,913 *$ & 1,469 & $1,056-2,043^{*}$ \\
Membrana 2 & 1,577 & $0,878-2,831$ & 1,516 & $0,812-2,832$ \\
Membrana 3 & 0,923 & $0,671-1,271$ & 0,992 & $0,697-1,411$ \\
\hline
\end{tabular}

Modelo ajustado por IMC, atividade física e escolaridade. 


\section{DISCUSSÃO}

O presente estudo mostrou que um padrão de $A G$ de membranas eritrocitárias que contém mais AG n-3 e menos AG n-6 está associado a menor risco cardiovascular, evidenciado por um perfil lipídico com menos lipoproteínas aterogênicas, menos TG e menor modificação de LDL. Esse padrão de membrana também foi associado a menor chance dos indivíduos apresentarem risco cardiovascular moderado ou alto estimado pelos Escores de Risco de Reynolds e de Framingham.

O total de AG n-3 nas membranas dos indivíduos do presente estudo foi de 5,65\% (IIQ: 4,76; 6,67\%), com predominância de C22:6 n-3 [3,35\% (IIQ: 2,71\%; 4,21\%)], seguido por C18:3 n-3 [1,96\% (IIQ: $1,53 \% ; 2,36 \%$ )] e por C20:5 n-3 [0,22\% (IIQ: $0,14 \% ; 0,32 \%)$ ]. Os valores de AG n-3 de membranas eritrocitárias encontrados no atual estudo são semelhantes aqueles descritos na literatura, com exceção de C18:3 n-3, que está um pouco maior (HODSON et al., 2008; STARK et al., 2016). O valor de IO3 da amostra total foi de 3,59\% (IIQ: 2,97\%; 4,47\%), inferior à média de 6,1\% $( \pm 2,1 \%)$ descrito por HARRIS et al. (2017) ao avaliarem 10 coortes. O total de AG n-6 de membranas dos indivíduos da amostra foi de 9,36\% ( $\pm 3,82 \%)$, sendo composto principalmente por C18:2 n-6 e C20:4 n-6, com média e mediana de 4,70\% $( \pm 1,83 \%)$ e 2,50\% (IIQ: 1,43\%; 5,14\%), respectivamente. Apesar dos valores de C18:2 n-6 e/ou C20:4 n-6 serem próximos aos de alguns estudos (ELIZONDO et al., 2007; GERASIMOVA et al., 1991; KEMP et al., 2019; MURPHY et al., 2007; PAUNESCU et al., 2013), ainda são mais baixos que aqueles citados por HODSON et al., (2008) e STARK et al., (2016). Importante destacar que as diferenças encontradas refletem o padrão de dieta das distintas populações; fato que pode parcialmente explicar os diferentes níveis de risco cardiovascular nesses estudos, assim como os métodos analíticos adotados por cada estudo.

A importância dos AG n-3 na prevenção de doenças cardiovasculares tem aumentado nos últimos tempos, devido a evidências que os associa a ações antiarrítmicas, melhora da função autonômica, diminuição da agregação plaquetária, promoção da vasodilatação, diminuição da pressão arterial, melhora da função endotelial, estabilização das placas ateroscleróticas, aumento da síntese de adiponectina, redução do depósito de colágeno na artéria, efeitos anti-inflamatórios, redução da trigliceridemia, redução da colesterolemia, e, por fim, redução da aterosclerose (LAVIE et al., 2009). Esses estudos contrariam recentes revisões sistemáticas e meta-análises 
que mostraram que os ácidos graxos n-3 exercem discreto ou nulo efeito nos fatores de risco cardiovascular e desfechos clínicos (ABDELHAMID et al., 2018; AUNG et atl., 2018).

Como as dislipidemias são um dos principais fatores de risco modificáveis para as doenças ateroscleróticas, diversos mecanismos de ação dos AG n-3 sobre o metabolismo lipídico têm sido propostos. O principal efeito desses ácidos sobre os lipídeos plasmáticos é a redução da trigliceridemia. Sabe-se que os AG n-3, assim com os AG n-6, reduzem a glicólise hepática e a lipogênese através da inibição da síntese de enzimas envolvidas na utilização da glicose, como a piruvato quinase, ácido graxo sintase e acetil-CoA carboxilase. Com a consequente redução de malonil-CoA, a atividade da enzima carnitina-palmitoil transferase se eleva, aumentando a transferência de AG para a beta-oxidação (POSTIC et al., 2007). Os AGPI são ligantes da proteína ligadora ao elemento de resposta a carboidratos (ChREBP), uma enzima chave na regulação da glicólise e lipogênese. Ao se ligarem a essa proteína no citosol, os AG impedem sua translocação para o núcleo, reduzindo a síntese de AG, com aumento da oxidação desses (POSTIC et al., 2007). Além disso, os AGPI são preferencialmente oxidados ao invés de serem esterificados, principalmente o C18:3 n-3, que tem oxidação de aproximadamente $70 \%$ do que foi ingerido (POUMÈS-BALLIHAUT et al., 2001), levando a um menor acúmulo desse AG nos tecidos (HODSON et al., 2008; STARK et al., 2016). Os AGPI, principalmente os n-3, podem inibir a lipogênese e colesterogênese através da inativação dos SREBP-1a e SREBP-1c, ao inibirem a heterodimerização dos receptores hepáticos $\mathrm{X}$ (LXR) com os receptores de retinoides X (RXR) (CLARKE, 2004; DAVIDSON, 2006; PAWAR et al., 2002). Embora os AG n-3 e n-6 sejam ligantes e ativadores naturais dos PPAR, esses últimos apresentam menor afinidade. Ao ativarem o PPAR- $\alpha$ nos hepatócitos e nos músculos ocorre a oxidação dos AG pelas vias peroxissomal, microssomal e mitocondrial, além da própria inibição do SREBP-1c pelos PPAR. Os peróxidos gerados a partir dos AG n-3 então estimulam a degradação da Apo B. Concomitantemente ocorre a redução de substrato para produção de VLDL que leva a menor secreção dessa lipoproteína pelo fígado. Os AG n-3 também estimulam a atividade das lipases lipoproteicas (LPL) no fígado e no músculo, contribuindo para a captação de AG nesses tecidos, gerando remanescentes de quilomícrons, que são captados rapidamente pelos hepatócitos, e remanescentes de 
VLDL. A diminuição da VLDL no plasma implica em menor geração de seus produtos, inclusive a LDL (CLARKE, 2004; DAVIDSON, 2006).

Os AG n-3 atuam também modulando o transporte reverso de colesterol. Esses lipídeos estão associados ao aumento da síntese de Apo A-I, que induz a maturação da HDL por meio do efluxo de colesterol mediado pela ABCA-1, além de aumentarem a síntese de LCAT, que participa da esterificação de colesterol durante o efluxo. A indução da expressão de Apo A-I pelos AG n-3 pode ainda influenciar os efeitos antioxidantes das HDLs, aumentando a atividade de paraoxonase 1 (PON1) (PIZZINI et al., 2017).

Um outro mecanismo de transporte reverso de colesterol modulado pelos AG n-3 é a ativação de PPAR- $\gamma$ nos macrófagos, que por sua vez aumenta a expressão de ABCA-1, facilitando a remoção de colesterol através da HDL, que posteriormente é captada pelo receptor SR-BI no fígado. Os AG n-3 aumentam a expressão de SR-BI, favorecendo a captação hepática de colesterol. Através do aumento da expressão da enzima colesterol 7-alfa-hidroxilase 1 (CYP7A1), de receptores hepáticos e intestinais ABCG-5 e ABCG8, e da inibição da proteína Niemann-Pick Cl-like protein 1 (NPC1L1), os AG n-3 são capazes de aumentar o fluxo hepatobiliar de colesterol, fazendo com que a excreção de colesterol seja estimulada. Ainda, os AG n-3 são capazes de aumentar a atividade de CETP, que transfere colesterol da HDL para lipoproteínas contendo Apo B, que posteriormente são captadas pelo fígado através de receptores B/E (PIZZINI et al., 2017).

Os resultados do presente estudo corroboram com o papel hipolipemiante dos AG n3 encontrado na literatura e amplia o atual estado da arte ao mostrar que os indivíduos com AG n-3 total (C18:3 n-3 + C20:5 n-3 + C22:6 n-3) de membranas > 6,24\% e os indivíduos com a razão AG n-6:n-3 $\leq 1,27$ de membranas apresentaram menor conteúdo de colesterol e Apo B no plasma, além de menor conteúdo de LDL pequenas e densas. No entanto, essas diferenças ficaram mais sutis quando os tercis de IO3 foram comparados, indicando que o C18:3 n-3 tem papel tão importante quanto C20:5 n-3 e C22:6 n-3 na modulação de lipoproteínas (YANG, 2015). Em homens, AG n-3 total > 6,24\% foi associado simultaneamente a menores níveis plasmáticos de Apo B e LDL pequena e a maior tamanho das partículas LDL. Já as mulheres com AG n-3 total > 6,26\% apresentaram menor conteúdo de colesterol, Apo B e TG no plasma, assim como menor presença de partículas LDL pequenas e densas. Essas diferenças sugerem sutis 
diferenças no metabolismo de n-3 entre os sexos. A análise fatorial mostrou que o padrão de membranas com mais AG n-3 e menos AG n-6 (Membrana 3) foi associado a menor conteúdo de LDL-c e Apo B.

Os PPARs têm uma afinidade muito maior pelos AG n-3 e seus derivados, porém uma típica dieta ocidental, com a razão n-6:n-3 por volta de 20:1, diminui a disponibilidade dos AG n-3 a esses ligantes. Esse perfil favorece a maior ativação de vias moduladas pelos AG n-6 e, consequentemente, levando ao aumento da síntese de colesterol e lipogênese (PATTERSON et al., 2012). Assim, nossos resultados mostraram que os indivíduos com valores maiores que 11,09\% de AG n-6 nas membranas eritrocitárias e maior razão de AG n-6:n-3 $(>2,10)$ apresentaram um perfil lipídico mais aterogênico (mais colesterol total, Apo B e LDL menores), quando comparados aos indivíduos nos menores tercis. Esse perfil foi reforçado ao observarmos que indivíduos com perfil de Membrana 1 (maior conteúdo de AG n-6 e menos AG n-3) também apresentaram maior conteúdo de TG e não-HDL-c no plasma, assim como maior conteúdo de LDLs pequenas e densas. As associações se mostraram mais diluídas quando foram feitas separadas por sexo. Os homens com valores de AG n-6 de membranas eritrocitárias maiores que $11,26 \%$ apresentaram maior conteúdo de colesterol no plasma, porém encontramos maior atividade de PON1 nos homens com AG n-6 a partir de 7,78\%. Homens com a razão AG n-6:n-3 maior que 2,23 tinham no plasma mais colesterol, Apo B, LDL pequenas e densas e menor tamanho geral das partículas de LDL. Já as mulheres com valores de AG n-6 maiores que 11,08\% apresentaram mais colesterol no plasma, enquanto as que tinham a razão AG n-6:n-3 maior que 2,06 apresentaram mais partículas de LDL pequenas e densas. Em ambos os sexos, o conteúdo de n-6 se associou negativamente a múltiplos marcadores de risco cardiometabólico.

Postula-se que o consumo elevado de AG n-6 possa aumentar a síntese autacoides de série par derivados do C20:4 n-6 que estão envolvidos diretamente em vias prótrombóticas e pró-inflamatórias e na disfunção endotelial (PATTERSON et al., 2012). Como as enzimas COX 1 e 2 têm mais afinidade pelo C20:4 n-6 que pelo C20:5 n-3, alta proporção de AG n-6:n-3, comum nas dietas ocidentais, reduz drasticamente a metabolização dos AG n-3 por essas enzimas, resultando no aumento de derivados de AG n-6, cujo potencial inflamatório é mais elevado (LANDS, 2012; PATTERSON et al., 2012). Essa predominância de derivados dos AG n-6 é caracterizada principalmente 
pela síntese de LTB4, um dos mais potentes agentes quimiotáticos e inflamatórios nos tecidos. De modo contrário, a oferta de AG n-3 é capaz de aumentar LTB5 nos tecidos, que por sua vez exerce uma ação antagônica ao LTB4 por meio do receptor de leucotrieno B (BLT-1), reduzindo o estímulo quimiotático. O receptor BLT-1, por sua vez, apresenta relação com a resistência insulínica, inflamação no tecido adiposo e hepático, e acúmulo de TG hepático. No entanto, a alta oferta de AG n-6 na dieta inibe a resposta antagônica do LTB5 (LANDS, 2012). Por sua vez, o aumento na síntese de LTB4 diminui a ligação dos AG n-3 com os PPARs, levando à redução na oxidação de AG e favorecendo a lipogênese e colesterogênese hepática (ARAYA et al., 2004; MALAISSE et al., 2009; PACHIKIAN et al., 2011).

O aumento na inflamação sistêmica gera peróxidos lipídicos e autacoides oriundos da oxidação dos AG n-6, mantendo a resposta inflamatória. A incorporação de AG n-6, principalmente C18:2 n-6 nas lipoproteínas aumenta a suscetibilidade dessas à oxidação (DINICOLANTONIO e O'KEEFE, 2018). Uma vez que o C18:2 n-6 presente na LDL é oxidado, aldeídos se ligam à Apo $\mathrm{B}$, desestruturando essa proteína e diminuindo seu reconhecimento pelos receptores de LDL, gerando então inúmeras partículas de LDL modificadas. Em uma LDL modificada, assim como em placas ateroscleróticas, o AG mais oxidado presente é o C18:2 n-6, evidenciando que esse AG pode ter uma participação importante no processo aterosclerótico (DINICOLANTONIO e O'KEEFE, 2018). As LDL eletronegativas [LDL(-)] possuem características oxidativas, próinflamatórias e imunogênicas que contribuem para a inflamação sistêmica e aterosclerose, sendo também biomarcadores importantes de peroxidação lipídica (MELLO et al., 2011). O presente estudo mostrou que o aumento de AG n-3 nas membranas eritrocitárias protege a LDL de modificações oxidativas, visto que o padrão de membranas que contém mais AG n-3 (Membrana 3) foi associado negativamente com LDL(-), enquanto que o padrão com mais AG n-6 (Membrana 1) foi associado positivamente. Os indivíduos com maior razão n-6:n-3 de AG de membranas (> 2,10), apresentavam um conteúdo de LDL(-) superior aquele observado nos indivíduos nos menores tercis, assim como os indivíduos que apresentaram mais AG n-6 nas membranas (> 11,09\%). Essa modificação das LDL se mostrou presente apenas em mulheres com AG n-6 maior que 11,08\% e razão n-6:n-3 maior que 2,06. Esses resultados corroboram com a hipótese da oxidação de AG n-6 nas LDL (DINICOLANTONIO e O'KEEFE, 2018) e que o aumento da incorporação de AG n-3 
às lipoproteínas reduz a suscetibilidade à oxidação (MASON et al., 2016; VENTURINI et al., 2015).

Com a elevação da LDL(-), a indução da resposta inflamatória sistêmica amplifica a expressão de SREBP e HMG-CoA redutase no fígado, exacerbando o acúmulo hepático de colesterol e TG (DINICOLANTONIO e O'KEEFE, 2018; ZHAO et al., 2011). Esse estímulo se traduz em colesterolemia e trigliceridemia aumentadas, conforme observado em indivíduos com elevado conteúdo de AG n-6 e menos AG n-3 nas membranas eritrocitárias monitorados no presente estudo.

$\mathrm{Na}$ literatura tem sido demonstrado AG n-6 também podem apresentar atividades anti-inflamatórias, antiplaquetárias e vasodilatadoras via metabólitos como a prostaciclina, a lipoxina A4 (LXA4) e os ácidos epoxieicosatrienoicos, derivados de C20:4 n-6. Apesar do C18:2 n-6, o AG n-6 mais abundante na dieta, ser precursor metabólico do C20:4 n-6, que por sua vez dá origem aos mediadores lipídicos mencionados, essa biotransformação é limitada, chegando a uma taxa de aproximadamente 0,2\% (HARRIS et al., 2009). Em uma dieta com baixo consumo de AG n-3, seus mediadores anti-inflamatórios e de resolução da inflamação estarão consequentemente mais baixos, causando um desequilíbrio que não permite que os mediadores derivados de AG n-6 reduzam as vias de sinalização inflamatória (PATTERSON et al., 2012). De modo oposto a esses estudos, nossos resultados mostraram que a presença de mais AG n-6 nas membranas eritrocitárias se associou ao maior concentração de LDL(-), especialmente em mulheres, indicando que as propriedades anti-inflamatórias desses AG não foram encontradas no presente estudo, pois sabe-se que a presença de produtos de oxidação exerce papel pró-inflamatório ao nível sistêmico.

Diante das diversas vias metabólicas antiaterogênicas moduladas pelos AG n-3, a literatura tem mostrado associações inversas entre os eventos cardiovasculares e esses, principalmente em estudos de prevenção primária. Uma meta-análise que avaliou a suplementação de EPA em uma quantidade que variou de 226 a 1800 mg/d e envolveu 77917 participantes com presença ou risco alto de DCV mostrou que não houve associação com eventos coronarianos ou outros eventos vasculares maiores (AUNG et al., 2018). Outra meta-análise incluindo 19 estudos e mais de 45637 participantes de 16 países e que apresentou 8000 eventos coronarianos ao longo do seguimento, os biomarcadores de n-3 C18:3 n-3, C20:5 n-3, C22:5 n-3, C22:6 n-3 foram associados 
modestamente com menor risco de evento coronariano fatal. A magnitude do efeito foi a redução do risco relativo em aproximadamente $9 \%$ de eventos fatais a cada aumento de 1 desvio padrão para cada $\mathrm{AG}$, com efeitos mais modestos para C18:3 n-3 (DEL GOBBO et al., 2016). Essa redução de risco foi semelhante à diminuição de risco com suplementação de EPA e DHA $(1,0 \mathrm{~g} / \mathrm{d}$; IIQ: 0,53-1,80 g/d) na prevenção cardiovascular secundária encontrada em uma meta-análise que selecionou ensaios clínicos randomizados (68680 participantes inclusos) (RIZOS et al., 2012). No entanto, os diversos estudos se mostraram heterogêneos quanto às metodologias de extração dos AG e a avaliação em diferentes compartimentos foram realizadas (DEL GOBBO et al., 2016). Um outro estudo (HARRIS et al., 2017) baseado em 10 coortes dos 19 estudos incluídos na meta-análise de DEL GOBBO et al. (2016) estimou os AG dos eritrócitos através de equações baseadas nos AG do plasma e do tecido adiposo e mostrou que indivíduos com maior risco cardiovascular apresentavam IO3 de 4,2\%, enquanto aqueles com menor risco tinham $8,3 \%$, corroborando com os pontos de corte propostos anteriormente para risco cardiovascular (HARRIS e VON SCHACKY, 2004). De acordo com os resultados, para um indivíduo com $4 \%$ de IO3 dobrar a quantidade e diminuir o risco coronariano, seria necessário aumentar o consumo de EPA e DHA por volta de 1,5 g diariamente (HARRIS et al., 2017). Nesse estudo também foi observado que em países ocidentais o IO3 tendeu a ser menor que 4\%, perfil semelhante ao observado no IO3 da amostra do presente estudo.

Na coorte do estudo de Framingham, envolvendo 2500 pessoas sem DCV, o IO3 maior que $6,8 \%$ foi associado a risco $39 \%$ menor de eventos cardiovasculares quando comparado com o menor quintil $(<4,2 \%)$. Ainda nesse estudo, o C22:6 n-3 de membranas eritrocitárias maior que 5,96\% foi associado a $43 \%$ de redução de eventos cardiovasculares, $59 \%$ de redução de acidente vascular encefálico e redução de $32 \%$ do risco de mortalidade total em relação aqueles com C22:6 n-3 menor que 3,69\%. Entretanto, o C20:5 n-3 (0,68\%-0,92\%) foi associado à redução do risco coronariano em $55 \%$, e mortalidade total em $42 \%$, em relação ao menor quintil $(<0,44 \%)$ (HARRIS et al., 2018a). Na mesma coorte, o IO3 foi associado inversamente com alguns biomarcadores de inflamação, como isoprostanos urinários, IL-6, PCR, receptor 2 de TNF- $\alpha$, ICAM-1, P-selectina, Lp-PLA 2 e sua atividade, MCP-1 e osteoprotegerina, evidenciando as propriedades anti-inflamatórias de C20:5 n-3 e C22:6 n-3 (FONTES et al., 2015). Em uma outra meta-análise que avaliou 17 estudos observacionais com 
biomarcadores de AG e prevenção primária de doença coronariana em 25271 indivíduos, os AG n-3 circulantes não apresentaram associação, porém quando analisados isoladamente o C20:5 n-3 e o C22:6 n-3 reduziram o risco em $22 \%$ e $21 \%$, respectivamente (CHOWDHURY, 2014).

Considerando esse conjunto de vias metabólicas antiaterogênicas moduladas pelos AG n-3 e os resultados obtidos em nosso estudo, é plausível que o maior consumo e biodisponibilidade desses AG possa modificar o risco cardiovascular estimado pelas equações preditivas. A natureza transversal do nosso estudo impossibilitou a obtenção de informações sobre mortalidade e/ou eventos cardiovasculares e, por isso foram realizadas associações indiretas com eventos através dessas equações. A utilização de algoritmos de risco cardiovascular é vantajosa por trabalhar com fatores de risco que representam maior parte das causas de eventos cardiovasculares, como foi demonstrado em estudos prospectivos, e também por estimar o risco cardiovascular absoluto (HARDOON et al., 2008; STAMLER et al., 1986; UNAL et al., 2004). O risco cardiovascular absoluto considera múltiplos fatores, e assim apresenta maior precisão tanto para estratificação do risco dos indivíduos como para a indicação do melhor tratamento em relação a utilização isolada de fatores de risco (DE GOMA et al., 2013). Por exemplo, a utilização isolada da PCR para classificar como baixo risco $(<1,0 \mathrm{mg} / \mathrm{L})$ ou alto risco (> 3,0 mg/L), de acordo com PEARSON et al (2003), não implica em risco cardiovascular absoluto baixo ou alto (DE GOMA et al., 2013). Isso resulta em subestimação ou superestimação do risco, que ocasiona subtratamento ou tratamento excessivo, levando a ineficácia terapêutica ou custos desnecessários para o sistema de saúde e exposição indevida aos efeitos colaterais dos medicamentos (DE GOMA et al., 2013). O risco cardiovascular absoluto, portanto, é a melhor abordagem, quando utilizado concomitantemente com testes de refinamento de risco, para avaliação do risco que se aproxima do risco verdadeiro. Entretanto, na literatura existem inúmeras equações que fazem essa estimativa com validação baseada em coortes de diversas populações, impossibilitando a extrapolação para todas as populações (DE GOMA et al., 2013). Para a validação em diferentes populações existe a necessidade da calibração da ferramenta, ou seja, verificar o quanto o modelo identifica corretamente o risco absoluto através da relação entre eventos previstos e observados, e a necessidade de analisar a acurácia discriminatória, que é a capacidade do modelo em diferenciar quem vai ter ou não o evento de interesse ou identificar corretamente qual o risco do indivíduo 
(PETTERLE e POLANCZYK, 2011), e uma das limitações do estudo atual é que não há validação dos escores ERF, ERR e 2013 ACC/AHA para a população brasileira.

Apesar de essas ferramentas serem boas preditoras de eventos cardiovasculares, cada algoritmo leva em consideração desfechos diferentes, sendo que existe superestimação do risco quando a equação abrange mais doenças (DE GOMA et al., 2013). As equações preditivas utilizadas no estudo atual têm poucas diferenças nos desfechos, podendo ter classificações similares. No entanto, no presente estudo as concordâncias entre as classificações dos escores foram moderadas e baixas. O ERR avalia o risco de infarto do miocárdio, acidente vascular encefálico isquêmico, revascularização coronária e morte cardiovascular (RIDKER et al., 2007; RIDKER et al., 2008), enquanto as equações preditivas da ACC/AHA e do ERF avaliam o risco de eventos de doenças ateroscleróticas, definidas como DAC, doença cerebrovascular, doença vascular periférica, e insuficiência cardíaca (D'AGOSTINO et al., 2008; GOFF et al., 2014; MOSCA et al., 2011; STONE et al., 2014). Apesar da diferença dos desfechos avaliados pelas equações utilizadas no estudo, os escores da ACC/AHA e ERF foram os que mais classificaram os indivíduos como alto risco $(n=179$ e $n=186$, respectivamente), enquanto o ERR foi o que mais classificou como baixo risco $(\mathrm{n}=$ 154). O ERF foi o que mais classificou como risco intermediário $(\mathrm{n}=127)$. Com o limite de 7,5\% para risco alto do escore da ACC/AHA seria esperado mais indivíduos classificados como alto risco. Esse escore apresentou boa calibração e discriminação em brancos e negros de uma coorte nos Estados Unidos (MUNTNER et al., 2014), mas a aplicação em uma população europeia classificou 96,4\% dos homens e 65,8\% das mulheres como alto risco (KAVOUSI et al., 2014). Quando aplicado em 6814 indivíduos autorreferidos como brancos, negros, hispânicos ou chineses da coorte multicêntrica e multiétnica do Multi-Ethnic Study of Atherosclerosis (MESA) dos Estados Unidos, observou-se que a equação da ACC/AHA apresentou pior calibração e discriminação em relação aos escores ERF, ERR e ATPIII, além de ter maior superestimação do risco tanto em homens (154\%) como em mulheres $(67 \%)$, com um discordância geral de 115\% (DE FILIPPIS et al., 2015). Nesse mesmo estudo o ERF superestimou o risco de homens em $37 \%$ e o de mulheres em $8 \%$, com discordância geral de $25 \%$, enquanto o ERR superestimou o risco de homens em apenas $9 \%$ e subestimou o risco de mulheres em $21 \%$, além de apresentar menor discordância de todas (-3\%) (DE FILIPPIS et al., 2015). Entretanto, na coorte multiétnica da Women's 
Health Initiative Observational Cohort o ERF superestimou o risco de mulheres e apresentou pior calibração e discriminação quando comparado com o ERR (COOK et al., 2012). Ainda na coorte MESA, o ERR se mostrou melhor que o ERF em predizer a progressão da aterosclerose subclínica avaliada pela quantificação da calcificação arterial coronariana (CAC) através de tomografia computadorizada (DE FILIPPIS et al., 2011). Pelo fato do ERF ter tendência de superestimação do risco em populações em prevenção primária e de classificar mais os homens como alto risco quando comparado com ERR, foi esperado que no presente estudo houvesse mais indivíduos com alto risco calculados pelo ERF do que pelo ERR (PETTERLE e POLANCZYK, 2011; TATTERSALL et al., 2012).

Apesar dos algoritmos utilizarem fatores de risco que exercem grande influência nos desfechos cardiovasculares, eles podem não refletir o risco real dos indivíduos, evidenciando a complexidade das DCV e a presença de outros fatores de risco não incluídos nas equações. Na literatura muitos estudos carecem da informação do efeito dos tratamentos farmacológicos. Idealmente, as coortes deveriam trabalhar apenas com pacientes sem tratamento, mas isso é inviável e antiético, e como resultado das terapias mais agressivas que atualmente estão sendo disponibilizadas, o efeito real dos fatores de risco é diminuído. Outra limitação dessas ferramentas é que elas não conciliam terapias que funcionam independentemente da modificação dos fatores de risco, como a inibição plaquetária (LIEW et al., 2011). Dessa forma, o efeito dos AG n-3 sobre o risco cardiovascular pode estar sendo subestimado se esse for mensurado pelos algoritmos, visto que as terapias medicamentosas podem estar diminuindo seu efeito (BIRD et al., 2018) e também há mecanismos que atuam independentemente da alteração de fatores de risco, como diminuição da atividade plaquetária e redução de arritmias (LAVIE et al., 2009).

Diante disso, os resultados do trabalho mostram que C18:3 n-3 e n-3 total reduziram as chances de o indivíduo apresentar, pelo menos, risco cardiovascular moderado em $20,8 \%$ e 20,2\% respectivamente, conforme estimado pelo ERF. Depois dos ajustes apenas n-3 total permaneceu significativo com redução de 18,9\%, evidenciando a influência da soma de C18:3 n-3, C20:5 n-3 e C22:6 n-3 na estimativa do risco cardiovascular. Perfil oposto foi observado para as razões n-6/n-3 e C18:2 n-6/C18:3 n3 cujo aumento elevou as chances em $47,3 \%$ e $27,6 \%$, respectivamente; embora o ajuste posterior do modelo tenha levado a perda da significância. 
A análise do conjunto dos AG mostrou que o padrão de AG de membranas contendo mais n-6 e menos n-3 (Membrana 1) aumentou o risco calculado pelo ERF em 40,8\%, e no modelo ajustado, 46,9\%. Os resultados com o ERR mostram que o padrão de AG de membranas contendo mais n-3 e menos n-6 (Membrana 3) foi fator protetor $(-26,6 \%$ sem ajuste e $-25,3 \%$ no modelo ajustado) de risco cardiovascular, ao mesmo tempo em que o padrão com mais n-6 e menos n-3 (Membrana 1) foi associado positivamente com o risco (27,6\% no modelo ajustado).

Esse estudo tem como vantagem a utilização de biomarcadores de AG, que têm se mostrado na literatura como uma ferramenta mais precisa para avaliação do consumo desses nutrientes do que as tradicionais abordagens nutricionais. Através das análises fatoriais mostramos que a determinação dos padrões de AG nos tecidos pode ser uma estratégia relevante que caracterize as interações dos diferentes AG incorporados, pois a análise isolada desses nutrientes pode não refletir o efeito biológico da composição geral do tecido analisado. Outra vantagem foi a utilização de diversos biomarcadores não tradicionais relacionados à aterosclerose que permitem uma avaliação mais aprofundada do metabolismo, da inflamação e estresse oxidativo.

Como o risco cardiovascular absoluto, se validado para a população de estudo, reflete os desfechos e trabalha com os principais fatores de risco causais da mortalidade cardiovascular, a utilização deste parâmetro pode ser útil em estudos que não têm dados de mortalidade, como por exemplo ensaios clínicos com intervenções de curta duração. Esse parâmetro tem como desvantagens a necessidade de validação para a população estudada e o fato de não abranger muitos fatores que influenciam os desfechos independentemente dos fatores de risco clássicos. A falta de validação das equações preditivas na população brasileira é uma limitação importante do atual estudo. Pelo fato de as equações terem sido criadas em populações caucasianas, a aplicação destas em populações diferentes pode não ser adequada, já que frequentemente superestimam o risco em brasileiros (PETTERLE e POLANCZYK, 2011). Outras limitações do estudo foram a ausência de dados de eventos cardiovasculares e de progressão da aterosclerose, ainda que avaliada de maneira subclínica. 


\section{CONCLUSÃO}

O presente estudo mostrou que os AG n-3 C18:3 n-3, C20:5 n-3 e C22:6 n-3 nas membranas eritrocitárias estão associados a menor risco cardiovascular global estimado pelas equação do ERF e ERR e através da relação com um perfil lipídico mais favorável, caracterizada por menores concentrações de lipoproteínas aterogênicas contendo Apo B e TG. Esse estudo mostrou também houve associação desses AG com maior tamanho das partículas de LDL e com menor concentração de LDL(-), especialmente em mulheres, mostrando uma potencial redução de risco cardiovascular quando marcadores não clássicos foram monitorados. Essas relações parecem ser dependentes da quantidade incorporada de AG n-6, que apresentaram resultados opostos aos do AG n-3 ao se associarem com maior risco cardiovascular. Interessantemente, o C18:3 n-3 associou-se a proteção cardiovascular de maneira isolada, mostrando a importância do aumento do consumo de AG n-3 de origem vegetal, além dos de origem animal.

Dessa forma nossos resultados reforçam a importância da utilização de biomarcadores de incorporação tecidual de AG em estudos futuros, pois diversos fatores influenciam a biodisponibilidade desses nutrientes e podem distorcer a interpretação do efeito real desses nutrientes. Até onde se sabe, esse foi o único trabalho que relacionou biomarcadores de AG presentes nas membranas eritrocitárias com múltiplos marcadores cardiometabólicos e com o risco cardiovascular absoluto estimado por meio de múltiplas equações preditivas. 


\section{REFERÊNCIAS}

ABDELHAMID, A. S.; BROWN, T. J.; BRAINARD, J. S.; BISWAS, P.; THORPE, G. C.; MOORE, H. J.; DEANE, K.; AL ABDUlGHAFOOR, F. K.; SUMMERBELl, C. D.; WORTHINGTON, H. V.; SONG, F.; HOOPER, L. Omega-3 fatty acids for the primary and secondary prevention of cardiovascular disease. Cochrane Database of Systematic Reviews, vol. 11, 2018.

ADHIKARI, A.; XU, M.; CHEN, Z. J. Ubiquitin-mediated activation of TAK1 and IKK. Oncogene, vol. 26, n. 22, p.3214-3226, 2007.

AHA - AMERICAN HEART ASSOCIATION. CDC Scientific Statements: Markers of inflammation and cardiovascular disease. Circulation, vol. 207, p.499-511, 2003.

AHA - AMERICAN HEART ASSOCIATION. Heart Disease and Stroke Statistics - 2018 Update. Circulation, vol. 137, 2018.

AHMED, S. N.; BROWN, D. A.; LONDON, E. On the origin of sphingolipid/cholesterol-rich detergent insoluble cell membranes: physiological concentrations of cholesterol and sphingolipid induce formation of a detergent-insoluble, liquid-ordered lipid phase in model membranes. Biochemistry, vol. 36, p.1094410953, 1997.

ALBERTI, K. G.; ECKEL, R. H.; GRUNDY, S. M.; et al. Harmonizing the Metabolic Syndrome: A Joint Interim Statement of the International Diabetes Federation Task Force on Epidemiology and Prevention; National Heart, Lung and Blood Institute; American Heart Association; World Heart Association; International Atherosclerosis Society; and International Association for the Study of Obesity. Circulation, vol. 120, p.1640-1645, 2009.

ARAYA, J.; RODRIGO, R.; VIDELA, L. A.; THIELEMANN, J.; ORELLANA, M.; PETTINELLI, P.; PONIACHIK, J. Increase in long-chain polyunsaturated fatty acids $n-6 / n-3$ ratio in relation to hepatic steatosis in patients with non-alcoholic fatty liver disease. Clinical Science, vol. 106, nº, p.635-643, 2004.

ARITA, M.; OH, S. F.; CHONAN, T.; HONG, S.; ElANGOVAN, S.; SUN, Y. P.; UDDIN, J.; PETASIS, N. A.; SERGAN, C. N. Metabolic inactivation of resolvin E1 and stabilization of its antiinflammatory actions. J Biol Chem, vol. 281, p.22847-22854, 2006.

ARTERBURN, L. M.; HALL, E. B.; OKEN, H. Distribution, interconversion, and dose response of n-3 fatty acids in humans. Am J Clin Nutr, vol. 83, p.1467-1476, 2006.

AUNG, T.; HALSEY, J.; KROMHOUT, D.; GERSTEIN, H. C.; MARCHIOLI, R.; TAVAZZI, L.; GELEIJNSE, J. M.; RAUCH, B.; NESS, A.; GALAN, P.; CHEW, E. Y.; BOSCH, J.; COLLINS, R.; LEWINGTON, S.; ARMITAGE, J.; CLARKE, R. Associations of Omega-3 Fatty Acid Supplement Use With Cardiovascular Disease Risks: Meta-analysis of 10 Trials Involving 77917 Individuals. JAMA Cardiology, 2018.

BAECKE, J. A.; BUREMA, J.; FRIJTERS, J. E. A short questionnaire for the measurement of habitual physical activity in epidemiological studies. Am J Clin Nutr, vol. 36, p.936-942, 1982. 
BAKER, E. J.; MILES, E. A.; BURDGE, G. C.; YAQOOB, P.; CALDER, P. C. Metabolism and functional effects of plant-derived omega-3 fatty acids in humans. Prog Lipid Res, vol. 64, p.30-56, 2016.

BANNENBERG, G. L.; CHIANG, N.; ARIEL, A.; ARITA, M.; TJONAHEN, E.; GOTLINGER, K. H.; HONG, S.; SERHAN, C. N. Molecular circuits of resolution: formation and actions of resolvins and protectins. J Immunol, vol. 174, p.4345-4355, 2005.

BARGAlló, N.; GILABERT, R.; ROMERO-MAMANI, E. S.; COFÁN, M.; CALDER, P. C.; FITÓ, M.; CORELlA, D.; SALAS-SALVADÓ, J.; RUIZ-CANELA, M.; ESTRUCH, R.; ROS, E.; SALAVILA, A. Red Blood Cell Eicosapentaenoic Acid Inversely Relates to MRI-Assessed Carotid Plaque Lipid Core Burden in Elders at High Cardiovascular Risk. Nutrients, vol. 9, p.1-13, 2017.

BATlle, J.; SAULEDA, J.; BALCELlS, E.; GÓMEZ, F. P.; MÉNDEZ, M.; RODRIGUEZ, E.; BARREIRO, E.; FERRER, J.; ROMIEU, I.; GEA, J.; ANTÓ, J.; GARCIA-AYERMICH, J. Association between $\Omega 3$ and $\Omega 6$ fatty acid intakes and serum inflammatory markers on COPD. The Journal of Nutritional Biochemistry, vol. 23, nº

BAZO-AlVAREZ, J. C.; QUISPE, R.; PERAlTA, F.; POTERICO, J. A.; VAlle, G. A.; BURROUGHS, M.; PIllAY, T.; GILMAN, R. H.; CHECKLEY, W.; MALAGA, G.; SMEETH, L.; BERNABÉ-ORTIZ, A.; MIRANDA, J. J. Agreement Between Cardiovascular Disease Risk Scores in Resource-Limited Settings: Evidence from Five Peruvian Sites. Critical Pathways in Cardiology, vol. 14, n. 2, p.74-80, 2015.

BERGER, S.; RAMAN, G.; VISHWANATHAN, R.; JACQUES, P. F.; JOHNSON, E. J. Dietary cholesterol and cardiovascular disease: a systematic review and meta-analysis. Am J Clin Nutr, vol. 102, p.276-94, 2015.

BERGOUIGNAN, A.; MOMKEN, I.; SCHOELlER, D. A.; SIMON, C.; BLANC, S. Metabolic fate of saturated and monounsaturated dietary fats: the Mediterranean diet revisited from epidemiological evidence to cellular mechanisms. Prog Lipid Res, vol. 48, n. 3-4, p.128-147, 2009.

BIRD, J. K.; CALDER, P. C.; EGGERSDORFER, M. The Role of $n$-3 Long Chain Polyunsaturated Fatty Acids in Cardiovascular Disease Prevention, and Interactions with Statins. Nutrients, vol. 10, nº, p.775, 2018.

BLOCK, R. C.; HARRIS, W. S.; REID, K. J.; SANDS, S. A.; SPERTUS, J. A. EPA and DHA in blood cell membranes from acute coronary syndrome patients and controls. Atherosclerosis, vol. 197, p.821828,2008

BOWEN, K. J.; SUllivAN, V. K.; KRIS-ETHERTON, P. M.; PETERSEN, K. S. Nutrition and Cardiovascular Disease - an Update. Current Atherosclerosis Report. vol. 20, n. 8, p.1-11, 2018.

BRIGGS, M. A.; PETERSEN, K. S.; KRIS-ETHERTON, P. M. Saturated Fatty Acids and Cardiovascular Disease: Replacement for Saturated Fat to Reduce Cardiovascular Risk. Healthcare, vol. 5, n. 29, p.1-29, 2017. 
BROWNER, W. S.; NEWMAN, T. B.; HULlEY, S. B. Estimando o Tamanho de Amostra e o Poder Estatístico: Aplicações e Exemplos. In: HULLEY, S. B.; CUMMINGS, S. R.; BROWNER, W. S.; GRADY, D. G.; NEWMAN, T. B. Delineando a pesquisa clínica: uma abordagem epidemiológica. $3^{\text {a }}$ ed. Porto Alegre: Artmed; 2008. p.83-112.

CALDER, P. C. Functional Roles of Fatty Acids and Their Effect on Human Health. Journal of Parenteral and Enteral Nutrition, vol. 39, p.18-32, 2015.

CAMPOS, F. G.; WAITZBERG, D. L.; LOGUlO, A. F.; TORRINHAS, R. S.; TEIXEIRA, W. G.; HABR-GAMA, A. Immunonutrition in experimental colitis: beneficial effects of omega-3 fattyacids. Arq Gastroenterol, vol. 39, p.48-54, 2002.

CAWOOD, A. L.; DING, R.; NAPPER, F. L.; YOUNG, R. H.; WILlIAMS, J. A.; WARD, M. J. A.; GUDMUNDSEN, O.; VIGE, R. PAYNE, S. P. K.; YE, S.; SHEARMAN, C. P.; GALLAGHER, P. J.; GRIMBLE, R. F.; CALDER, P. C. Eicosapentaenoic acid (EPA) from highly concentrated n-3 fatty acid ethyl esters is incorporated into advanced atherosclerotic plaques and higher plaque EPA is associated with decreased plaque inflammation and increased stability. Atherosclerosis, vol. 212, p.252-259, 2010.

CHOWDHURY, R.; WARNAKULA, S.; KUNUTSOR, S.; CROWE, F.; WARD, H. A.; JOHNSON, L.; FRANCO, O. H.; BUTTERWORTH, A. S.; FOROUHI, N. G.; THOMPSON, S. G.; KHAW, K. T.; MOZAFFARIAN, D.; DANESH, J.; DI ANGELANTONIO, E. Association of dietary, circulating, and supplement fatty acids with coronary risk: a systematic review and meta-analysis. Ann Intern Med, vol. 160, p.398-406, 2014.

CLARKE, S. D. The multi-dimensional regulation of gene expression by fatty acids: polyunsaturated fats as nutrient sensors. Current Opinion in Lipidology, vol. 15, p.13-18, 2004.

COLUSSI, G.; CATENA, C.; DIALTI, V.; MOS, L.; SECHI, L. A. Effects of the comsumption of fish meals on the carotid intimamedia thickness in patients with hypertension: A prospective study. J Atheroscler Thromb, vol. 21, p.941-956, 2014a.

COLUSSI, G.; CATENA, C.; DIALTI, V.; MOS, L.; SECHI, L. A. The vascular response to vasodilators is related to membrane content of polyunsaturated fatty acids in hypertensive patients. J Hypertens, vol. 33, p.993-1000, 2015 b.

COlussi, G.; CATENA, C.; DiAlTi, V.; PEZZUTTO, F.; MOS, L.; SECHI, L. A. Fish meal supplementation and ambulatory blood pressure in patients with hypertension: Relevance of baseline fatty acid composition. Am J Hypertens, vol. 27, p.471-481, 2014 b.

COLUSSI, G.; CATENA, C.; MOS, L.; SECHI, L. A. The Metabolic Syndrome and the Membrane Content of Polyunsaturated Fatty Acids in Hypertensive Patients. Metabolic Syndrome and Related Disorders, vol. 10, n. 10, p.1-9, 2015a.

COOK, N. R.; PAYNTER, N. P.; EATON, C. B.; MANSON, J. E.; MARTIN, L. W.; ROBINSON, J. G.; ROSSOUW, J. E.; WASSERTHEIL-SMOLLER, S.; RIDKER, P. M. Comparison of the Framingham 
and Reynolds Risk Scores for Global Cardiovascular Risk Prediction in the Multiethnic Women's Health Initiative. Circulation, vol. 125, p.1748-1756, 2012.

D’AgOstino, R. B.; VASAN, R. S.; PENCINA, M. J.; WOLF, P. A.; COBAIN, M.; MASSARO, J. M. KANNEL, W. B. General Cardiovascular Risk Profile for Use in Primary Care: The Framingham Heart Study. Circulation, vol. 117, p.743-753, 2008.

DAVIDSON, M. H. Mechanisms for the Hypotriglyceridemic Effect of Marine Omega-3 Fatty Acids. Am J Cardiol, vol. 98, n. 4, p.27-33, 2006.

DE FILIPPIS, A.; BLAHA, M. J.; NDUMELE, C. E.; BUDOFF, M. J.; LLOYD-JONES, D. M.; MCCLELlAND, R. L., LAKOSKI, S. G.; CUSHMAN, M.; WONG, N. D.; BLUMENTHAL, R. S.; LIMA, J.; NASIR, K. The Association of Framingham and Reynolds Risk Scores With Incidence and Progression of Coronary Artery Calcification in MESA (Multi-Ethnic Study of Atherosclerosis). Journal of the American College of Cardiology, vol. 58, n²0, p.2076-2083, 2011.

DE FILIPPIS, A.; YOUNG, R.; CARRUBBA, C. J.; MCEVOY, J. W.; BUDOFF, M.; BLUMENTHAL, R. S.; KRONMAL, R. A.; MCClELlAND, R. L.; NASIR, K.; BLAHA, M. J. An Analysis of Calibration and Discrimination among Multiple Cardiovascular Risk Scores in a Modern Multiethnic Cohort. Ann Intern Med, vol. 162, nº4, p.266-275, 2015.

DE GOMA, E. M.; DUNBAR, R. L.; JACOBY, D.; FRENCH, B. Differences in absolute risk of cardiovascular events using risk-refinement tests: A systematic analysis of four cardiovascular risk equations. Atherosclerosis, vol. 227, p.172-177, 2013.

DEL GOBBO, L. C.; et al. $\omega-3$ Polyunsaturated Fatty Acid Biomarkers and Coronary Heart Disease: Pooling Project of 19 Cohort Studies. JAMA Intern Med, vol. 176, nº, p.1155-1166, 2016.

DIETARY GUIDELINES ADVISORY COMMITTEE. Scientific report of the 2015 dietary guidelines advisory committee. USDA and US Department of Health and Human Services, 2015.

DINICOLANTONIO, J. J.; O’KEEFE, J. Omega-6 vegetable oils as a driver of coronary heart disease: the oxidized linoleic acid hypothesis. Open Heart, vol. 5, e000898, 2018.

DRAPER, HH. Nutritional modulation of oxygen radical pathology. Adv Nutr Res, vol. 8, p.118-145, 1990.

ELIZONDO, A.; ARAYA, J.; RODRIGO, R., et al. Polyunsaturated fatty acid pattern in liver and erythrocyte phospholipids from obese patients. Obesity, vol. 15, p.24-31, 2007.

ENNS, J. E.; YEGANEH, A.; ZARYCHANSKI, R.; ABOU-SETTA, A. M.; FRIESEN, C.; ZAHRADKA, P.; TAYLOR, C. G. The impact of omega-3 fatty acid supplementation on the incidence of cardiovascular events and complications in peripheral arterial disease: a systematic review and metaanalysis. BMC Cardiovasc Disord, vol. 14, n.70, 2014. 
FARZANEH-FAR, R.; HARRIS, W. S.; GARG, S.; NA, B.; WHOOLEY, M. A. Inverse association of erythrocyte n-3 fatty acid levels with inflammatory biomarkers in patients with stable coronary artery disease: The Heart and Soul Study. Atherosclerosis, vol. 205, n. 2, p.538-543, 2009.

FAUliN, T. E. N; SENA, K. C.; TELlES, A. E. R.; GROSSO, D. M.; FAULIN, E. J. B.; ABDALLA, D. S. P. Validation of a novel ELISA for measurement of electronegative low-density lipoprotein. ClinChem Lab Med, vol. 46, n. 12, p.1769-1775, 2008.

FERGUSON, J. J. A.; VEYSEY, M.; LUCOCK, M.; NIBLETT, S.; KING, K.; MACDONALD-WICKS, L.; GARG, M. L. Association between omega-3 index and blood lipids in older Australians. Journal of Nutritional Biochemistry, vol. 27, p.233-240, 2015.

FITZGERALD, G. A. COX-2 and beyond: approaches to prostaglandin inhibition in human disease. Nature Reviews Drug Discovery, vol. 2, p.879-890, 2003.

FLORINDO, A. A.; LATORRE, M. R. D. O. Validação e Reprodutibilidade do Questionário de Baecke de avaliação da atividade física habitual em homens adultos. Ver Bras Med Esporte, vol. 9, p.121-129, 2003.

FONTES, J. D.; RAHMAN, F.; LACEY, S.; LARSON, M. G.; VASAN, R. S.; BENJAMIN, E. J.; HARRIS, W. S.; ROBINS, S. J. Red Blood Cell Fatty Acids and Biomarkers of Inflammation: A Crosssectional Study in a Community-based Cohort. Atherosclerosis, vol. 240, n², p.431-436, 2015.

FRIEDEWALD, W. T.; LEVY, R. I.; FREDRICKSON, D. S. Estimation of the concentration of lowdensity lipoprotein cholesterol in plasma, without use of the preparative ultracentrifuge.ClinChem, vol. 18, p.499-502, 1972.

GEORGIADI, A.; KERSTEN, S. Mechanisms of gene regulation by fatty acids. Adv Nutr, vol. 3, n. 2, p.127-134, 2012.

GERASIMOVA, E.; PEROVA, N. OZEROVA, I., et al. The effect of dietary n-3 polyunsaturated fatty acids on HDL cholesterol in Chukot residents vs muscovites. Lipids, vol. 26, p.261-265, 1991.

GIRELli, D.; OLIVIERI, O.; STANZIAL, A. M.; GUARINI, P.; TREVISAN, M. T.; BASSI, A.; CORROCHER, R. Factors affecting the thiobarbituric acid test as index of red blood cell susceptibility to lipid peroxidation: a multivariate analysis. ClinChim Acta, vol. 227, p.45-57, 1994.

GOFF, D. C.; et al. 2013 ACC/AHA Guideline on the Assessment of Cardiovascular Risk: A Report of the American College of Cardiology/American Heart Association Task Force on Practice Guidelines. Journal of the American College of Cardiology, vol. 63, n²5, 2014.

GRUNDY, S. M.; CleEMAN, J. I.; MERZ, C. N. B.; BREWER JR., H. B.; CLARK, L. T.; HUNNINGHAKE, D. B.; PASTERNAK, R. C.; SMITH JR., S. C.; STONE, N. J. Implications of Recent Clinical Trials for the National Cholesterol Education Program Adult Treatment Panel III Guidelines. Circulation, vol. 110, p.227-239, 2004. 
GUENTHER, P. M. et al. Questionnaire design and data collection procedures. In: Design and Operation: The Continuing Survey of Food Intakes by Individuals and the Diet and Health Knowledge Survey. U.S.: 1998. p. 42-63.

HACKAM, D. G.; ANAND, S. S. Emerging Risk Factors for Atherosclerotic Vascular Disease: A Critical Review of the Evidence. JAMA, vol. 290, n. 7, p.932-940, 2003.

HARDOON, S. L.; WHINCUP, P. H.; LENNON, L. T.; WANNAMETHEE, S. G.; CAPEWELL, S.; MORRIS, R. W. How much of the recent decline in the incidence of myocardial infarction in British men can be explained by chances in cardiovascular risk factors? Evidence from a prospective population-based study. Circulation, vol. 117, nº5, p.598-704, 2008.

HARRIS, W. S.; DEL GOBBO, L.; TINTLE, N. L. The Omega-3 Index and relative risk for coronary heart disease mortality: Estimation from 10 cohort studies. Atherosclerosis, vol. 262, p.51-54, 2017.

HARRIS, W. S.; KENNEDY, K. F.; O'KEEFE, J. O.; SPERTUS, J. A. Red blood cell fatty acid levels improve GRACE score prediction of 2-yr mortality in patients with myocardial infarction. Int J Cardiol, vol. 168, n. 1, p.53-59, 2013.

HARRIS, W. S.; MOZAFFARIAN, D.; RIMM, E., et al. Omega-6 Fatty Acids and Risk for Cardiovascular Disease: A Science Advisory From the American Heart Association Nutrition Subcommittee of the Council on Nutrition, Physical Activity, and Metabolism; Council on Cardiovascular Nursing; and Council on Epidemiology and Prevention. Circulation, vol. 119, p.902-907, 2009.

HARRIS, W. S.; TINTLE, N. L.; ETHERTON, M. R.; VASAN, R. S. Erythrocyte long-chain omega-3 fatty acid levels are inversely associated with mortality and with incident cardiovascular disease: The Framingham Heart Study. Journal of Clinical Lipidology, vol. 12, p.718-727, 2018a.

HARRIS, W. S.; VON SCHACKY, C. The Omega-3 Index: a new risk factor for death from coronary heart disease? Preventive Medicine, vol. 39, p.212-220, 2004.

HODSON, L.; SKEAFF, C. M.; FIELDING, B. A. Fatty acid composition of adipose tissue and blood in humans and its use as a biomarker of dietary intake. Progress in Lipid Research, vol. 47, p.348-380, 2008.

HONG, S.; GRONERT, L.; DEVCHAND, P. R.; MOUSSIGNAC, R. L. SERHAN, C. N. Novel docosatrienes and 17 Sresolvins generated from docosahexaenoic acid in murine brain, human blood, and glial cells. J BiolChem, vol. 278, p.14677-14687, 2003.

HORTON, J. D. Sterol regulatory element-binding proteins: transcriptional activators of lipid synthesis. BiochemSoc Trans, vol. 30, n. 6, p.1091-1095, 2002.

HOWE, P. R. C.; BUCKLEY, J. D.; MURPhY, K. J.; PETTMAN, T.; MiLTE, C.; COATES, A. M. Relationship between Erythrocyte Omega-3 Content and Obesity Is Gender Dependent. Nutrients, vol. 6, p.1850-1860, 2014. 
IGGMAN, D.; RISÉRUS, U. Role of Different Dietary Saturated Fatty Acids for Cardiometabolic Risk. Clinical Lipidology, vol. 6, n. 2, p.209-223, 2011.

ISHIKADO, A.; MORINO, K.; NISHIO, Y.; NAKAGAWA, F.; MUKOSE, A.; SONO, Y. 4-Hydroxy hexenal derived from docosahexaenoic acid protects endothelial cells via Nrf2 activation. PLoS One, vol. 8, n. 7, 2013.

JACOBSON, T. A.; MAKI, K. C.; ORRINGER, C. E.; JONES, P. H.; KRIS-ETHERTON, P.; SIKAND, G. National Lipid Association recommendations for patient-centered management of dyslipidemia: part 2. Journal of Clinical Lipidology, vol. 9, n. 6, p.S1-S122, 2015.

JANES, P.; LEY, S.; MAGEE, A. Aggregation of lipid rafts accompanies signaling via the T cell antigen receptor. J Cell Biol, vol. 147, p.447-461, 1999.

JOHNSON, R. K.; DRISCOLL, P.; GORAN, M. I. Comparison of multiple pass 24-hour recall estimates of energy intake with total energy expenditure determined by doubly labeled water method in young children. J Am Diet Assoc, vol. 96, p.1140-1144, 1996.

JONES, P. J. H.; MACKAY, D. S.; SENANAYAKE, V. K.; PU, S.; JENKINS, D. J. A.; CONNELLY, P. W.; LAMARCHE, B.; COUTURE, P.; KRIS-ETHERTON, P. M.; WEST, S. G.; LIU, X.; FLEMING, J. A.; HANTGAN, R. R.; RUDEL, L. L. High-oleic canola oil consumption enriches LDL particle cholesteryl oleate content and reduces LDL proteoglycan binding in humans. Atherosclerosis, vol. 238, p.231-238, 2015.

JUNG, U. J.; TORREJON, C.; TIGHE, A. P.; DECKELBAUM, R. J. n-3 Fatty acids and cardiovascular disease: mechanisms underlying beneficial effects. Am J ClinNutr, vol. 83, n. 6, p.2003S-2009S, 2008.

KANNEL, W. B.; MCGEE, D.; GORDON, T. A general cardiovascular risk profile: the Framingham Study. Am J Cardiol, vol. 38, p.46-51, 1976.

KARNOVSKY, M. J.; KLEINFIELD, A. M.; HOOVER, R. L.; KLAUSNER, R. D. The concept of lipid domains in membranes. J Cell Biol, vol. 94, p.1-6, 1982.

KAVOUSI, M.; LEENING, M. J.; NANCHEN, D. Comparison of Application of the ACC/AHA Guidelines, Adult Treatment Panel III Guidelines, and European Society of Cardiology Guidelines for Cardiovascular Disease Prevention in a European Cohort. JAMA, vol. 311, nº14, p.1416-1423, 2014.

KEMP, J. A.; ESGALHADO, M.; MACEDO, R. A.; REGIS, B.; DAMASCENO, N. R. T.; DA SILVA TORRES, E. A. F.; GONÇALINHO, G. H. F.; BORGES, N. A.; NAKAO, L. S.; FOUQUE, D.; MAFRA, D. A possible link between polyunsaturated fatty acids and uremic toxins from the gut microbiota in hemodialysis patients: A hyposthesis. Hemodialysis International, vol. 23, p.189-197, 2019.

KENNEDY, A.; MARTINEZ, K.; CHUANG, C. C.; LAPOINT, K.; MCINTOSH, M. Saturated Fatty Acid-Mediated Inflammation and Insulin resistance in Adipose Tissue: Mechanisms of Action and Implications. Journal of Nutrition, vol. 139, p.1-4, 2009. 
KIM, H. J.; TAKAHASHI, M.; EZAKI, O. Fish oil feeding decreases mature sterol regulatory elementbinding protein 1 (SREBP-1) by down-regulation of SREBP-1c mRNA in mouse liver. A possible mechanism for down-regulation of lipogenic enzyme mRNAs. J BiolChem, vol. 274, n. 36, p.25892$25898,1999$.

KLEBER, M. E.; DELGADO, G. E.; LORKOWSKI, S.; MÄRZ, W.; VON SCHACKY, C. Omega-3 fatty acids and mortality in patients referred for coronary angiography. The Ludwigshafen Risk and Cardiovascular Health Study. Atherosclerosis, vol. 252, p.175-181, 2016.

KRATZ, M. Dietary cholesterol, atherosclerosis and coronary heart disease. Handb Exp Pharmacol, vol. 170, p.195-213, 2005.

LANDIS, J. R.; KOCH, G. G. The measurement of observer agreement for categorical data. Biometrics, vol. 33, n. 1, p.159-174, 1977.

LANDS, B. Consequences of Essential Fatty Acids. Nutrients, vol. 4, p.1338-1357, 2012.

LARSSON, S. C.; WOLK, A. Fish, long-chain omega-3 polyunsaturated fatty acid intake and incidence of atrial fibrillation: A pooled analysis of two prospective studies. Clinical Nutrition, 2016.

LAVIE, C. J.; MILANI, R. V.; MEHRA, M. R.; VENTURA, H. O. Omega-3 polyunsaturated fatty acids and cardiovascular diseases. J Am Coll Cardiol, vol. 54, n. 7, p.585-594, 2009.

LEBRÃO ML, DUARTE YAO. Organização Pan-Americana de Saúde (OPAS/OMS), Saúde, Bem-Estar e Envelhecimento (SABE). O Projeto Sabe no município de São Paulo: uma abordagem inicial. São Paulo: Athalaia Bureau, 2013.

LEE, J. Y.; CARR, T. P. Dietary fatty acids regulate acyl-CoA:cholesterol acyltransferase and cytosolic cholesteryl ester hydrolase in hamsters. J Nutr, vol. 134, n. 12, p.3239-3244, 2004.

LEE, S. E.; KIM, G. D.; YANG, H.; SON, G. W.; PARK, H. R.; CHO, J. J. Effects of eicosapentaenoic acid (EPA) on the cytoprotection via Nrf2-mediated heme oxygenase-1 in human endothelial cells. J Cardiovasc Pharmacol, vol. 66, n. 1, p.108-117, 2015

LI, A. C.; GLASS, C. K. PPAR- and LXR-dependent pathways controlling lipid metabolism and the development of atherosclerosis. J Lipid Res, vol. 45, p.2161-2173, 2004.

LICHTENSTEIN, A. H.; APPEL, L. J.; BRANDS, M.; CARNETHON, M.; DANIELS, S.; FRANCH, H. A. Diet and lifestyle recommendations revision 2006: a scientific statement from the American Heart Association Nutrition Committee. Circulation, vol. 114, n. 1, p.82-96, 2006.

LIEW, S. M.; DOUST, J.; GLASZIOU, P. Cardiovascular risk scores do not account for the effect of treatment: a review. Heart, vol. 97, p.689-697, 2011.

LOHMAN, T.; GOINS, S. Assesment of body composition and energy balance. In: LAMB, D.; MURRAY, R. (Ed.). Perspective in Exercise Science and Sports Medicine. Carmel, IN: Cooper Publishing. P.61-105, 1988. 
MACKNESS, M. I.; HARTY, D.; BHATNAGAR, D.; WINOCOUR, P. H.; ARROL, S.; ISHOLA, M.; DURRINGTON, P. N. Serum paraoxonase activity in familial hypercholesterolaemia and insulindependent diabetes mellitus. Atherosclerosis, vol. 86, p.193-199, 1991.

MADSEN, L.; PETERSEN, R. K.; KRISTIANSEN, K. Regulation of adipocyte differentiation and function by polyunsaturated fatty acids. Biochim Biophys Acta, vol. 1740, n. 2, p.266-286, 2005.

MAKI, K. C.; EREN, F.; CASSENS, M.; DICKLIN, M. R.; DAVIDSON, M. H. $\omega-6$ Polyunsaturated Fatty Acids and Cardiometabolic Health: Current Evidence, Controversies, and Research Gaps. Adv Nutr, vol. 9, p.688-700, 2018.

MALAISSE, W. J.; BULUR, N.; ZHANG; et al. The metabolic syndrome of $\omega-3$ depleted rats. International Journal of Molecular Medicine, vol. 24, nº1, p.111-123, 2009

MASON, R. P.; SHERRATT, S. C.; JACOB, R. F. Eicosapentaenoic Acid Inhibits Oxidation of ApoBcontaining Lipoprotein Particles of Different Size In Vitro When Administered Alone of in Combination With Atorvastatin Active Metabolite Compared With Other Triglyceride-lowering Agents. J Cardiovasc Pharmacol, vol. 68, nº1, p.33-40, 2016.

MASOOD, A.; STARK, K. D.; SALEM JR, N. A simplified and efficient method for the analysis of fatty acid methyl esters suitable for large clinical studies. Journal of Lipid Research, vol. 46, p.2299-2305, 2005.

MELLO, A. P. Q.; SILVA, I. T.; ABDALLA, D. S. P.; DAMASCENO, N. R. T. Electronegative lowdensity lipoprotein: Origin and impact on health and disease. Atherosclerosis, vol. 215, p.257-265, 2011.

MOSCA, L. et al. Effectiveness-Based Guidelines for the Prevention of Cardiovascular Disease in Women - 2011 Update: A Guideline From the American Heart Association. Circulation, vol. 123, n. 11, p.1243-1262, 2011.

MOZAFFARIAN, D. Fish and n-3 fatty acids for the prevention of fatal coronary heart disease and sudden cardiac death. Am J Clin Nutr, vol. 87, n. 6, p.1991S-1996S, 2008.

MUNTNER, P.; COLANTONIO, L. D.; CUSHMAN, M.; et al. Validation of the Atherosclerotic Cardiovascular Disease Pooled Cohort Risk Equations. JAMA, vol. 311, nº4, p.1406-1415, 2014.

MURPHY, K. J.; MEYER, B. J.; MORI, T. A.; BURKE, V.; MANSOUR, J.; PATCH, C. S., et al. Impact of foods enriched with n-3 long-chain polyunsaturated fatty acids on erythrocyte n-3 levels and cardiovascular risk factors. Br J Nutr, vol. 97, p.749-757, 2007.

NCEP - NATIONAL CHOLESTEROL EDUCATION PROGRAM EXPERT PANEL ON DETECTION, EVALUATION AND TREATMENT OF HIGH BLOOD CHOLESTEROL IN ADULTS (ADULT TREATMENT PANEL III). Third Report of the National Cholesterol Education Program (NCEP) Expert Panel on Detection, Evaluation, and Treatment of High Blood Cholesterol in Adults (Adult Treatment Panel III) final report. Circulation, vol. 106, p.3143-3421, 2002. 
NUSSER, S. M.; FULLER, W. A.; GUENTHER, P. M. Estimation of usual dietary intake distributions: Adjusting for measurement error and nonnormality in 24 hour food intake data. In: TREWIN, D. (Ed.). Survey Measurement and Process Quality. New York: NY: Wiley. p.689-709, 1996.

OH, D. Y.; TALUKDAR, S.; BAE, E. J.; IMAMURA, T.; MORINAGA, H.; OLEFSKY, J. M. GPR120 is an omega-3 fatty acid receptor mediating potent anti-inflammatory and insuling-sensitizing effects. Cell, vol. 142, n. 5, p.687-698, 2010.

OLLIVER, M.; VEYSEY, M.; LUCOCK, M.; NIBLETT, S.; KING, K.; MACDONALDS-WICKS, L.; GARG, M. L. Erythrocyte omega-3 polyunsaturated fatty acid levels are associated with biomarkers of inflammation in older Australians. Journal of Nutrition \& Intermediary Metabolism, vol. 5, p.61-69, 2016.

OPARIL, S.; OBERMAN, A. Nontraditional Cardiovascular Risk Factors. Am J Med Sci, vol. 317, n. 3, p.193-207, 1999.

PACHIKIAN, B. D.; ESSAGHIR, A.; DEMOULIN, B.; et al. Hepatic n-3 polyunsaturated fatty acid depletion promotes steatosis and insulin resistance in mice: genomic analysis of cellular targets. PLoS ONE, vol. 6, nº, article e23365, 2011.

PARK, H. G.; LAWRENCE, P.; ENGEL, M. G.; KOTHAPALLI, K.; BRENNA, J. T. Metabolic fate of docosahexaenoic acid (DHA; 22:6n-3) in human cells: direct retroconversion of DHA to eicosapentaenoic acid (20:5n-3) dominates over elongation to tetracosahexaenoic acid (24:6n-3). FEBS Lett, vol. 590, n.18, p.3188-3194, 2016.

PATTERSON, E.; WALL, R.; FITZGERALD, G. F.; ROSS, R. P.; STANTON, C. Health Implications of High Dietary Omega-6 Polyunsaturated Fatty Acids. Journal of Nutrition and Metabolism, vol. 2012, doi:10.1155/2012/539426, 2012.

PAUNESCU, A. C.; AYOTTE, P.; DEWAILLY, E., et al. Polyunsaturated fatty acids and calcaneal unltrasound parameters among Inuit womem from Nuul (Greenland): a longitudinal study. Int J Circumpolar Health, vol. 72, 2013.

PAWAR, A.; XU, J.; JERKS, E.; MANGELSDORF, D. F.; JUMP, D. B. Fatty acid regulation of liver X receptors (LXR) and peroxisome proliferator-activated receptor alpha (PPARalpha) in HEK293 cells. J Biol Chem, vol. 277, n42, p.39243-39250, 2002.

PEARSON, T. A.; MENSAH, G. A.; ALEXANDER, R. W.; et al. Markers of inflammation and cardiovascular disease: application to clinical and public health practice: a statement for healthcare professionals from the Centers for Disease Control and Prevention and the American Heart Association. Circulation, vol. 107, p.499-511, 2003.

PETTERlE, W. C.; POLANCZYK, C. A. Avaliação crítica dos escores de risco. Revista da Sociedade de Cardiologia do Estado do Rio Grande do Sul, vol. 23, 2011. 
PIZZINI, A.; LUNGER, L.; DEMETZ, E.; HILBE, R.; WEISS, G.; EBENBICHLER, C.; TANCEVSKI, I. The Role of Omega-3 Fatty Acids in Reverse Cholesterol Transport: A Review. Nutrients, vol. 9, 2017.

POSTIC, C.; DENTIN, R.; DENECHAUD, P. D.; GIRARD, J. ChREBP, a transcriptional regulator of glucose and lipid metabolism. Annu Rev Nutr, vol. 27, p.179-192, 2007.

POUMÈS-BALLIHAUT, C.; LANGELIER, B.; HOULIER, F.; ALESSANDRI, J. M.; DURAND, G.; LATGE, C; GUESNET, P. Comparative bioavailability of dietary $\alpha$-linolenic and docosahexaenoic acids in the growing rat. Lipids, vol. 36, nº, p.793-800, 2001.

RHEE, E. J.; RYU, S.; LEE, J. Y.; LEE, S. H.; CHEONG, E. S.; PARK, S. E.; PARK, C. Y.; WON, Y. S.; KIM, J. M.; CHO, D. S.; CHUNG, H. K.; SUNG, K. C. The association between dietary cholesterol intake and subclinical atherosclerosis in Korean adults: The Kangbuk Samsung Health Study. Journal of Clinical Lipidology, vol. 11, n. 2, p.432-441, 2017.

RIBEIRO, A. L. P.; DUNCAN, B. B.; BRANT, L. C. C.; LOTUFO, P. A.; MILL, J. G.; BARRETO, S. M. Cardiovascular Health in Brazil: Trends and Perspectives. Circulation, vol. 133, p.422-433, 2016.

RICOTE, M.; GLASS, C. K. PPARs and molecular mechanisms of transrepression. Biochim Biophys Acta, vol. 1771, n. 8, p.926-935, 2007.

RIDKER, P. M.; BURING, J. E.; RIFAI, N.; COOK, N. R. Development and Validation of Improved Algorithms for the Assessment of Global Cardiovascular Risk in Women: The Reynolds Risk Score. JAMA, vol. 297, n. 6, p.611-619, 2007.

RIDKER, P. M.; PAYNTER, N. P.; RIFAI, N.; GAZIANO, J. M.; COOK, N. R. C-Reactive Protein and Parental History Improve Global Cardiovascular Risk Prediction: The Reynolds Risk Score for Men. Circulation, vol. 118, p.2243-2251, 2008.

RIZOS, E. C.; NTZANI, E. E.; BIKA, E.; KOSTAPANOS, M. S.; ELISAF, M. S. Association Between Omega-3 Fatty Acid Supplementation and Risk of Major Cardiovascular Disease Events: A Systematic Review and Meta-analysis. JAMA, vol. 308, nº10, p1024-1033, 2012.

RIZOS, E.; MARKOZANNES, K. K.; TSILIDIS, A.; TSAPAS, C. S.; MANTZOROS, M.; ELISAF, M.; NTZANI, E. E. Meta-analysis of omega-3 supplementation and cardiovascular disease. European Heart Journal, vol. 38, n. 1, 2017.

ROCHA, D. M.; CALDAS, A. P.; OLIVEIRA, L. L.; BRESSAN, J.; HERMSDORFF, H. H. Saturated fatty acids trigger TLR4-mediated inflammatory response. Atherosclerosis, vol. 244, p.211-215, 2016.

ROTH, G. A.; HUFFMAN, M. D.; MORAN, A. E.; FEIGIN, V.; MENSAH, G. A.; NAGHAVI, M.; MURRAY, C. J. L. Global and Regional Patterns in Cardiovascular Mortality From 1990 to 2013. Circulation, vol. 132, p.1667-1678, 2015. 
RUIZ-NÚÑEZ, B.; DIJCK-BROUWER, D. A. J.; MUSKIET, F. A. J. The relation of saturated fatty acids with low-grade inflammation and cardiovascular disease. Journal of Nutritional Biochemistry, vol. 36, p.1-20, 2016.

SBC - SOCIEDADE BRASILEIRA DE CARDIOLOGIA. Atualização da Diretriz Brasileira de Dislipidemias e Prevenção da Aterosclerose. Arquivos Brasileiros de Cardiologia, Sociedade Brasileira de Cardiologia, vol. 109, n. 2, supl. 1, 2017.

SBD - SOCIEDADE BRASILEIRA DE DIABETES. Diretrizes da Sociedade Brasileira de Diabetes, $3^{\mathrm{a}}$ edição. Sociedade Brasileira de Diabetes. São Paulo, 2009.

SERHAN, C. N.; HONG, S.; GRONERT, K.; COLGAN, S. P. DEVCHAND, P. R.; MIRICK, G. MOUSSIGNAC, R. L. Resolvins: a family of bioactive products of omega-3 fatty acid transformation circuits initiated by aspirin treatment that cauter proinflammation signal. J Exp Med, vol. 196, p.10251037, 2002.

SEZGIN, E.; LEVENTAL, I.; MAYOR, S.; EGGELING, C. The mystery of membrane organization: composition, regulation and roles of lipid rafts. Nature Reviews Molecular Cell Biology, vol. 1, p.31$39,2017$.

SIDDIQUI, R. A.; HARVEY, K. A.; ZALOGA, G. P.; STILLWELL, W. Modulation of Lipid Rafts by n3 Fatty Acids in Inflammation and Cancer: Implications for Use of Lipids During Nutrition Support. Nutr Clin Practice, vol. 22, p.74-88, 2007.

SIRI-TARINO, P. W.; SUN, Q.; HU, F. B.; KRAUSS, R. M. Saturated Fatty Acids and Risk of Coronary Heart Disease: Modulation by Replacement Nutrients. Current Atherosclerosis Report, vol. 12, p.384$390,2010$.

STAMLER, J.; WENTWORTH, D.; NEATON, J. D. Is relationship between serum cholesterol and risk of premature atherosclerosis from coronary heart disease continuous and graded? Findings in 356,222 primary screenes of the Multiple Risk Factor Intervention Trial (MRFIT). JAMA, vol. 256, n²0, p.28232828, 1986.

STARK, K. D.; ELSWYK, M. E. V.; HIGGINS, M. R.; WEATHERFORD, C. A.; SALEM JR., N. Global survey of the omega-3 fatty acids, docosahexaenoic acid and eicosapentaenoic acid in the blood stream of healthy adults. Progress in Lipid Research, vol. 63, p.132-152, 2016.

STERN, E. S.; WILLIAMS, K.; FERRANNINI, E.; DEFRONZO, R. A.; BOGARDUS, C.; STERN, M. P. Identification of Individuals With Insulin Resistance Using Routine Clinical Measurements. Diabetes, vol. 54, p.333-339, 2005.

STONE, N. J.; ROBINSON, J.; LICHTENSTEIN, A. H.; MERZ, C. N. B.; BLUM, C. B.; ECKEL, R. H.; GOLDBERG, A. C.; GORDON, D.; LEVY, D.; LLOYD-JONES, D. M.; MCBRIDE, P.; SCHWARTZ, S.; SHERO, S. T.; SMITH, S. C.; WATSON, J.; WILSON, P. W. F. 2013 ACC/AHA Guideline on the Treatment of Blood Cholesterol to Reduce Atherosclerotic Cardiovascular Risk in Adults: A Report of 
the American College of Cardiology/American Heart Association Task Force on Practice Guidelines. Circulation, vol. 129, p.S49-S73, 2014.

STRANDBERG, U.; TAIPALE, S. J.; KAINZ, M. J.; BRETT, M. T. Retroconversion of docosapentaenoic acid (n-6): an alternative pathway for biosynthesis of arachidonic acid in Daphnia magna. Lipids, vol. 49, n. 6, p.591-595, 2014.

STULNIG, T. M.; BERGER, M.; SIGMUND, T.; RAEDERSTORFF, D.; STOCKINGER, H.; WALDHAUSL, W. Polyunsaturated fatty acids inhibit T cell signal transduction by modification of detergent-insoluble membrane domains. J Cell Biol, vol. 143, p.637-644, 1998.

STUlNiG, T. M.; HUBER, J.; LEITINGER, N.; IMRE, E. M.; ANGELISOVÁ, P.; NOWOTNY, P.; WALDHÄUSL, W. Polyunsaturated eicosapentaenoic acid displaces proteins from membrane rafts by altering raft lipid composition. J Biol Chem, vol. 276, p.37335-37340, 2001.

TALWALKAR, P. G.; SREENIVAS, C. G.; GULATI, A.; BAXI, H. Journey in guidelines for lipid management: From adult treatment panel (ATP)-I to ATP-III and what to expect in ATP-IV. Indian Journal of Endocrinology and Metabolism, vol. 17, n. 4, p.628-635, 2013.

TATTERSALL, M. C.; GANGNON, R. E.; KARMALI, K. N.; KEEVIL, J. G. Women Up, Men Down: The Clinical Impact of Replacing the Framingham Risk Score with the Reynolds Risk Score in the United States Population. PLOS ONE, vol. 7, nº9, e44347, 2012.

THOMPSON, F. E.; SUBAR, A. F.; LORIA, C. M.; REEDY, J. L.; BARANOWSKI, T. Need for technological innovation in dietary assessment. J Am Diet Assoc, vol. 110, n. 48, 2010.

UNAL, B.; CRITCHLEY, J. A.; CAPEWELL, S. Explaining the decline in coronary heart disease mortality in England and Wales between 1981 and 2000. Circulation, vol. 109, nº9, p.1101-1107, 2004.

VENTURINI, D.; SIMÃO, A. N.; URBANO, M. R.; DICHI, I. Effects of extra virgin oil and fish oil on lipid profile and oxidative stress in patients with metabolic synderome. Nutrition, vol. $31, \mathrm{n}^{\circ} 6$, p.834$840,2015$.

VOMHOF-DEKREY, E. E.; PICKLO, M. J. The Nrf2-antioxidant response element pathway: a target for regulating energy metabolism. J Nutr Biochem, vol. 23, n. 10, p.1201-1206, 2012.

WILlETT, W. C.; HOWE, G. R.; KUSHI, L. W. Adjustment for total energy intake in epidemiologic studies. Am J Clin Nutr, vol. 65, n.4, p.1220S-1228, 1997.

WILSON, P. W. F.; D’AGOSTINO, R. B.; LEVY, D.; BELANGER, A. M.; SILBERSHATZ, H.; KANNEL, W. B. Prediction of coronary heart disease using risk factor categories. Circulation, vol. 97, p.1837-1847, 1998.

WORLD HEALTH ORGANIZATION (WHO). Global Atlas on Cardiovascular Disease Prevention and Control. Mendis, S.; Puska, P., Norrvig, B. (editors). World Health Organization, Geneva, 2011. 
WORLD HEALTH ORGANIZATION (WHO). Noncommunicable Diseases Country Profiles 2014. World Health Organization, Geneva, 2014.

WORLD HEALTH ORGANIZATION (WHO). Obesity: preventing and managing the global epidemic. Report of a WHO Consultation. WHO Technical Report Series 894. Geneva: World Health Organization, 2000 .

XAVIER, R.; BRENNAN, T.; LI, Q.; MCCORMACK, C.; SEED, B. Membrane compartmentation is required for efficient T cell activation. Immunity, vol. 8, p.723-732, 1998.

XU, J.; NAKAMURA, M. T.; CHO, H. P.; CLARKE, S. D. Sterol regulatory element binding protein-1 expression is suppressed by dietary polyunsaturated fatty acids. A mechanism for the coodinatesupression of lipogenic genes by polyunsaturated fats. J BiolChem, vol. 274, n. 33, p.23577-23583, 1999.

YANG, L. G.; SONG, Z. X.; YIN, H.; WANG, Y. Y.; SHU, G. F.; LU, H. X.; WANG, S. K.; SUN, G. J. Low n-6/n3 PUFA Ratio Improves Lipid Metabolism, Inflammation, Oxidative Stress and Endothelial Function in Rats Using Plant Oils as n-3 Fatty Acid Source. Lipids, doi: 10.1007/s11745-015-4091-z, 2015.

YANG, Y. C.; LII, C. K.; WEI, Y. L.; LI, C. C.; LU, C. Y.; LIU, K. L. Docosahexaenoic acid inhibition of inflammation is partially via cross-talk between Nrf2/heme oxygenase 1 and IKK/NF-kB pathways. J Nutr Biochem, vol. 24, n. 1, p.204-12, 2013.

ZABOTTO, C. B.; VIANNA, R. P. T.; GIL, M. F. Registro Fotográfico para Inquéritos Dietéticos Utensílios e Porções. Goiânia: Nepa - UNICAMP, 1996.

ZHAO, L.; CHEN, Y.; TANG, R.; CHEN, Y; LI, Q.; GONG, J.; HUANG, A.; VARGHESE, Z.; MOORHEAD, J. F.; RUAN, X. Z. Inflammatory stress exacerbates hepatic cholesterol accumulation via increasing cholesterol uptake and de novo synthesis. Journal of Gastroenterology and Hepatology, vol. 26, p.875-883, 2011. 


\title{
10. ANEXOS
}

\subsection{Anexo 1 - Termo de Consentimento Livre e Esclarecido (TCLE)}

\author{
Universidade de São Paulo \\ Faculdade de Saúde Pública \\ Av. Dr. Arnaldo, 715 - CEP 01246-904 - São Paulo- Brasil \\ TERMO DE CONSENTIMENTO LIVRE E ESCLARECIDO
}

Você está sendo convidado(a) como voluntário(a) a participar da pesquisa: Propriedades físicoquímicas da LDL e da HDL, marcadores cardiometabólicos e oxidativos podem ser modulados pelo consumo de ômega-3, ômega-6 e ômega-9 em indivíduos com risco cardiovascular intermediário?

O motivo que nos leva a estudar esses pacientes é o fato de que as doenças do coração e das veias são um dos principais problemas de Saúde Pública no mundo, sendo provável que os hábitos alimentares mudem a ocorrência dessas doenças. A pesquisa se justifica pela necessidade de avaliar o efeito do consumo de diferentes tipos de gordura sobre os fatores de risco (colesterol alto, pressão e outros parâmetros clínicos e laboratoriais). Portanto, o objetivo desse projeto é avaliar o efeito do consumo de cápsulas de ômega-3, ômega- 6 ou ômega-9 sobre fatores de risco cardíacos de indivíduos sob atendimento ambulatorial. O procedimento de coleta de material será da seguinte forma: será coletada uma amostra de sangue e também serão aplicados questionários para avaliar seu nível socioeconômico, clinico, nível de atividade física habitual e sua dieta. Esses questionários serão aplicados em três momentos (Basal, 4 semanas e 8 semanas). Após a coleta dos dados basais, cada indivíduo será incluído aleatoriamente num dos quatro grupos de intervenção (Ômega-3, Ômega-6, Ômega-9, Placebo).

DESCONFORTOS, RISCOS E BENEFÍCIOS: Existem desconfortos e riscos mínimos que envolvem mudanças no hálito, coceira e eventualmente pequeno aumento no tempo necessário para parar um sangramento. Além disso, pequenas manchas no local de punção, relacionada a coleta de sangue. Entretanto, esses desconfortos se justificam pelo beneficio que essa pesquisa trará se identificarmos o papel desses ácidos graxos nos fatores de risco para doença do coração. O risco com a intervenção é considerado mínimo, pois as gorduras a serem fornecidas já fazem parte do hábito alimentar da população brasileira. Além da disponibilização de meios de contato $24 \mathrm{~h}$ com a equipe de pesquisadores, ao término do estudo, você receberá os resultados de todos os exames, assim como será oferecida orientação nutricional verbal e documentada de modo a permitir que você incorpore a melhor intervenção ao seu hábito alimentar

FORMA DE ACOMPANHAMENTO E ASSISTÊNCIA: Em caso de algum efeito adverso a sua saúde, os pesquisadores devem ser avisados imediatamente e esses darão orientação e assistência clínica e nutriciona a você.

GARANTIA DE ESCLARECIMENTO, LIBERDADE DE RECUSA E GARANTIA DE SIGILO: Você será esclarecido(a) sobre a pesquisa em qualquer aspecto que desejar. Você é livre para recusar-se a participar, retirar seu consentimento ou interromper a participação a qualquer momento. A sua participação é voluntária $e$ a recusa em participar não irá acarretar qualquer penalidade ou perda de benefícios.

$\mathrm{O}(\mathrm{s})$ pesquisador(es) irá(ão) tratar a sua identidade com padrões éticos de sigilo. Os resultados dos exames clinicos e laboratoriais não serão revelados. Seu nome ou o material que indique a sua participação não será liberado sem a sua permissão. Você não será identificado(a) em nenhuma publicação que possa resultar deste estudo. Uma cópia deste consentimento informado será arquivada no Departamento de Nutrição da Faculdade de Saúde Pública da Universidade de São Paulo e outra será fornecida a você.

RESSARCIMENTO: A participação no estudo não acarretará custos para você e não será oferecida nenhuma compensação financeira adicional. Os eventuais gastos com transporte serão ressarcidos a você e ao término de cada etapa será oferecido gratuitamente um lanche, pois em todos os dias de coleta você precisará vir ao hospital em jejum.

DECLARAÇÃO DA(O) PARTICIPANTE:

Eu, $\mathrm{CPF} \mathrm{n}^{\circ}$ fui informada(o) dos objetivos da pesquisa acima de maneira clara e detalhada e esclareci minhas dúvidas. Sei que em qualquer momento poderei solicitar novas informações ou desistir de participar desta pesquisa se assim o desejar. A professora coordenadora do estudo Profa. Dra. Nagila Raquel Teixeira Damasceno ou um dos membros da equipe certificou-me de que todos os dados desta pesquisa serão confidenciais.

Em caso de dúvidas poderei chamar qualquer membro da equipe ou a coordenadora do estudo Profa. Dra. Nágila Raquel Teixeira Damasceno nos telefones (11) 3061-7865, 30919538 , ou entrar em contato com o Comitê de Ética em Pesquisa da Faculdade de Saúde Pública (telefones 30617779 ou 30617742 ) ou o Comitê de Ética do Hospital Universitário (telefones 309194573091 9479) da Universidade de São Paulo.

Declaro que concordo em participar desse estudo. Recebi uma cópia deste termo de consentimento livre e esclarecido e me foi dada a oportunidade de ler e esclarecer as minhas dúvidas.

\begin{tabular}{|ccc|}
\hline Nome & Assinatura do Participante & Data \\
\hline Nome & Assinatura do Pesquisador & Data \\
\hline Nome & Assinatura da Testemunha & Data \\
\hline
\end{tabular}


10.2. Anexo 2 - Questionário para avaliações socioeconômica e clínica QUESTIONÁRIO SÓCIO-ECONÔMICO E CLÍNICO

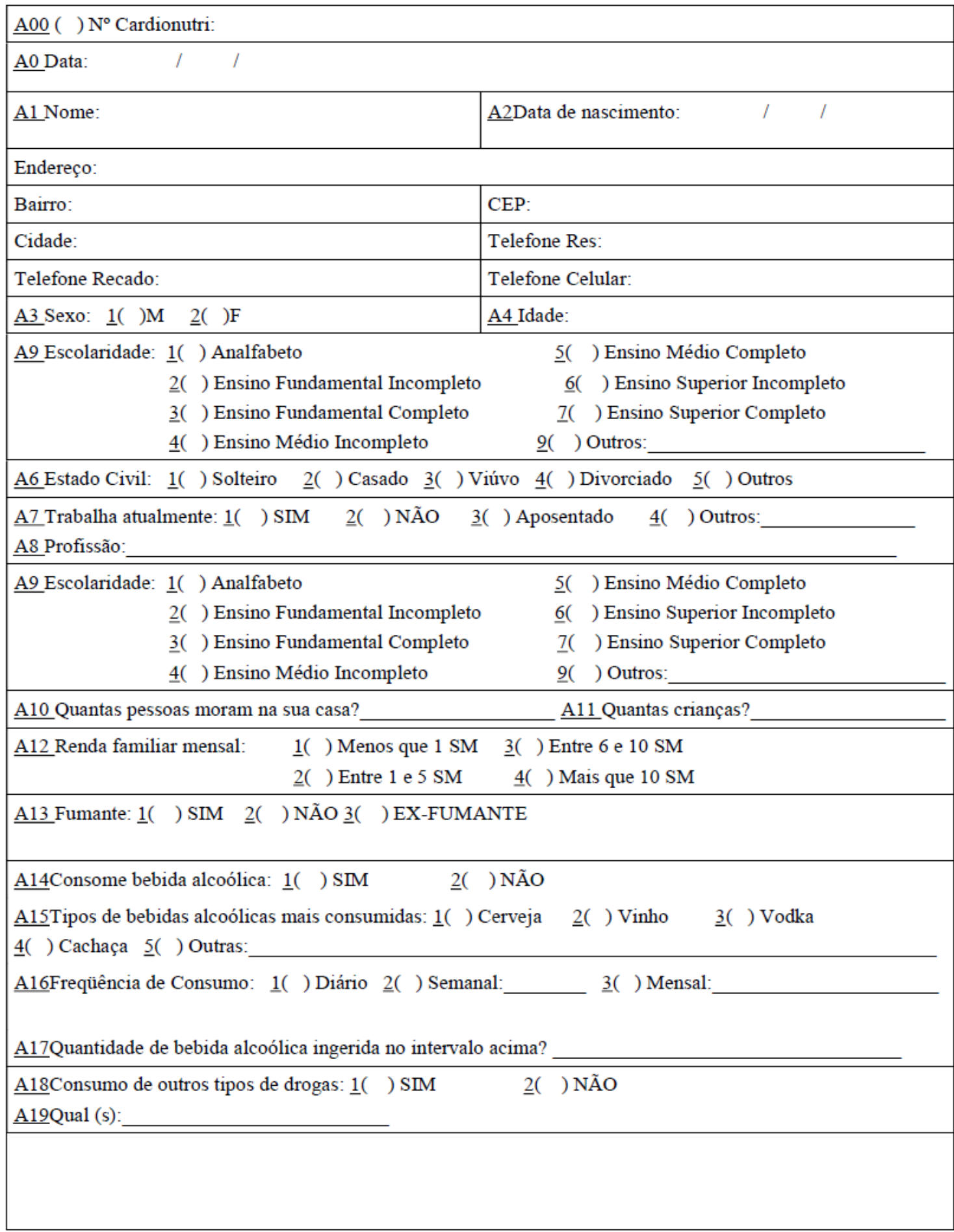




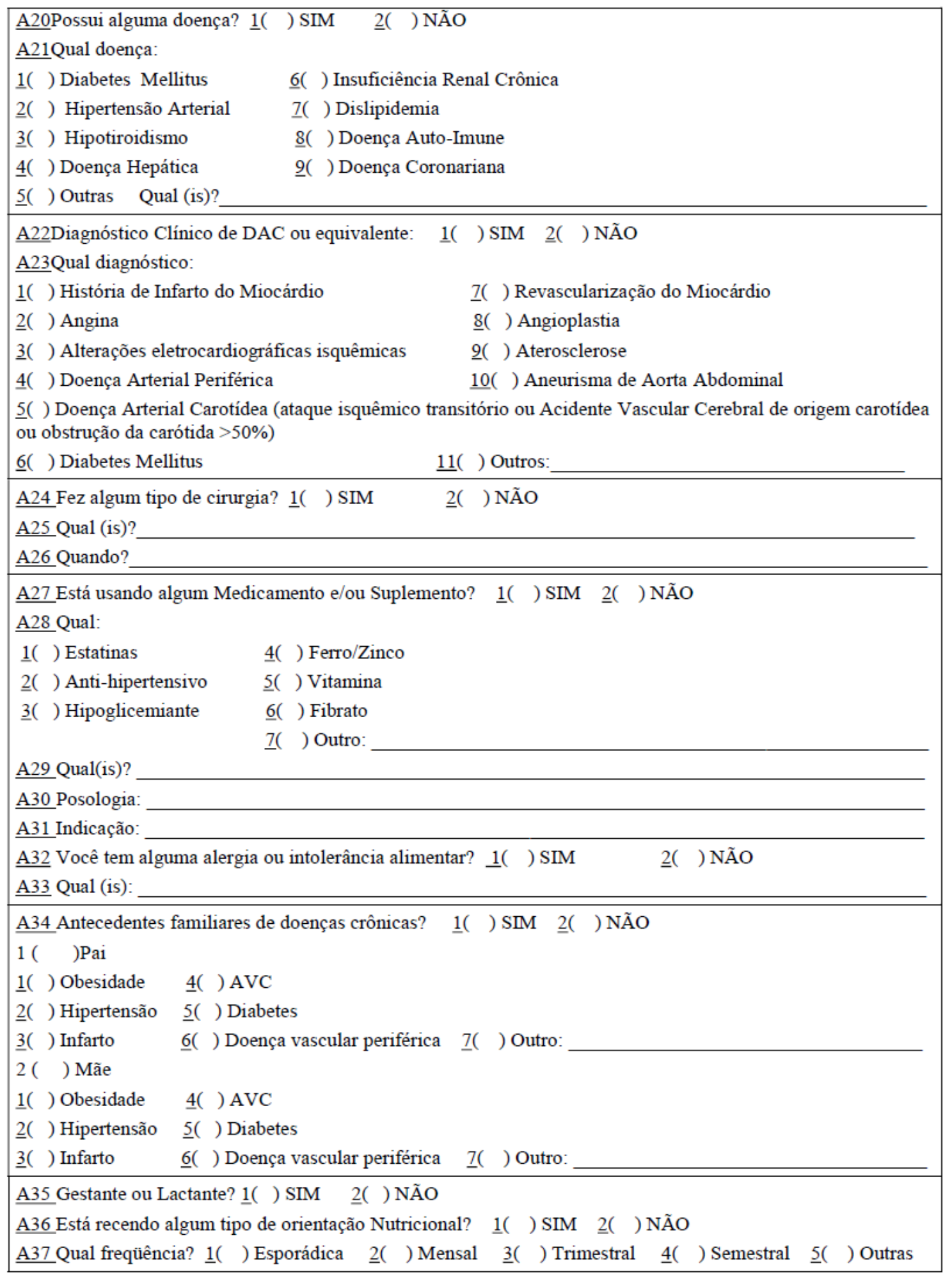

Entrevistador: 


\subsection{Anexo 3 - Treinamento para aplicação dos inquéritos alimentares e recordatório de 24 horas $(\mathbf{R} 24 h)$}

\section{Manual do Entrevistador}

Para o sucesso da aplicação do método de inquérito alimentar escolhido, é preciso que o entrevistador atente-se a algumas questões, que serão descritas ao longo deste manual.

Apresentação inicial do entrevistador:

É de extrema importância, antes da aplicação do inquérito alimentar, que o entrevistador se apresente, explicando os objetivos da entrevista e informando ao entrevistado a duração média da mesma.

Esclarecer que todos os dados coletados são de ordem confidencial.

Expor ao entrevistado o direito à não participação, sem qualquer prejuízo.

Considerações importantes:

Os entrevistadores deverão estar treinados e com amplo conhecimento dos hábitos e costumes da comunidade em estudo, assim como dos alimentos e modo de prepará-los.

Para auxiliar na quantificação do tamanho e volume das porções consumidas, será utilizado material de suporte com registros fotográficos.

O entrevistador deverá estabelecer um canal de comunicação em que se obtenha a informação por meio de um diálogo agradável, uma vez que a qualidade da informação dependerá da memória e da cooperação do entrevistado.

$>$ Respostas precisas e não tendenciosas exigem respeito e atitude neutra diante de hábitos e consumo de alimentos do entrevistado. Para tanto, o entrevistador deverá evitar expressar sentimentos de surpresa, tristeza ou decepção, o que poderia induzir o entrevistado a subestimar ou superestimar a quantidade de alimentos, dependendo da reação que ele observe. 


\section{Recordatório de 24 horas}

\section{Definição:}

O Recordatório de 24 horas é um método de inquérito alimentar realizado mediante uma entrevista pessoal, na qual o entrevistado relata detalhadamente os alimentos consumidos no dia anterior, desde o primeiro alimento ingerido após acordar até a última refeição antes de dormir, incluindo os alimentos consumidos dentro e fora do domicílio.

\section{Metodologia:}

A aplicação do Recordatório de 24 horas deve obedecer a seguinte metodologia:

Passo 1: Pergunte ao indivíduo:

"O Sr(a) pode, por favor, me dizer tudo o que comeu ou bebeu ontem, desde o momento que acordou até antes de dormir, começando pelo primeiro alimento ou bebida consumida?".

Transcreva tudo o que for dito, sem preocupação com quantidade, por enquanto. Não interrompa a informante.

Passo 2: Pergunte o horário e local da refeição.

"O Sr(a) pode lembrar o horário (mais ou menos) e em que lugar?"

Anote os horários e o local referido.

Passo 3: Volte à descrição dos alimentos e pergunte as quantidades em medidas caseiras consumidas, de cada alimento ou preparação.

a. No caso de alimentos como frutas, pães, biscoitos e ovos, pergunte quantas unidades foram consumidas. Exemplo: 1 fatia de pão de forma, 1 pão francês, 1 pão de queijo, 1 biscoito recheado, etc.

b. Se possível, registre a marca comercial e variedade dos alimentos. Exemplo: banana nanica, prata, maçã.

c. No caso de alimentos compostos, como por exemplo, café com leite, mingaus, vitaminas e sopas, pergunte os ingredientes, quantidades e medidas utilizadas na preparação.

d. Para alimentos como carnes (vaca, frango, porco, peixe) utilize unidades como: fatia (pequena, média, grande), pedaço (pequeno, médio, grande), posta (pequena, média, grande).

e. Registre se a preparação da carne foi frita, assada, à milanesa ou grelhada. 
f. No caso de verduras e legumes, pergunte os ingredientes da salada. Legumes (cenoura, abobrinha, berinjela, milho, etc): registre em colheres de sopa ou de servir e pergunte o tipo de preparação (cozidos ou refogados).

g. Para preparações habituais como arroz, feijão e macarrão utilize as medidas caseiras de referência (colher de sopa, de servir, concha, pegador de macarrão).

h. Certifique-se da presença ou não de temperos nas saladas, açúcar/adoçante nas bebidas, manteiga/requeijão/outros no pão/biscoito/ou torrada e suas quantidades.

i. Não faça perguntas tendenciosas. Exemplo: "Você tomou café da manhã? Você come pouco?".

j. Ao longo da entrevista, lembre-se de perguntar se houve sobras e quantificá-las.

\section{Revisão do recordatório:}

Ao final da entrevista é importante que o entrevistador dê ao entrevistado a oportunidade para lembrar-se de algum alimento que porventura tenha consumido, mas esquecido de referir por ocasião da entrevista.

Por fim, é importante anotar o nome do entrevistador e quanto tempo durou a entrevista. 


\section{RECORDATÓRIO ALIMENTAR DE 24H}

NOME: $\mathrm{N}^{\circ}$ CARDIONUTRI:

RECORDATÓRIO: 1 ( ) 2( )

DATA: DIA DA SEMANA: ( )dom ( )seg ( )ter ( )qua ( )qui ( )sex ( )Sab

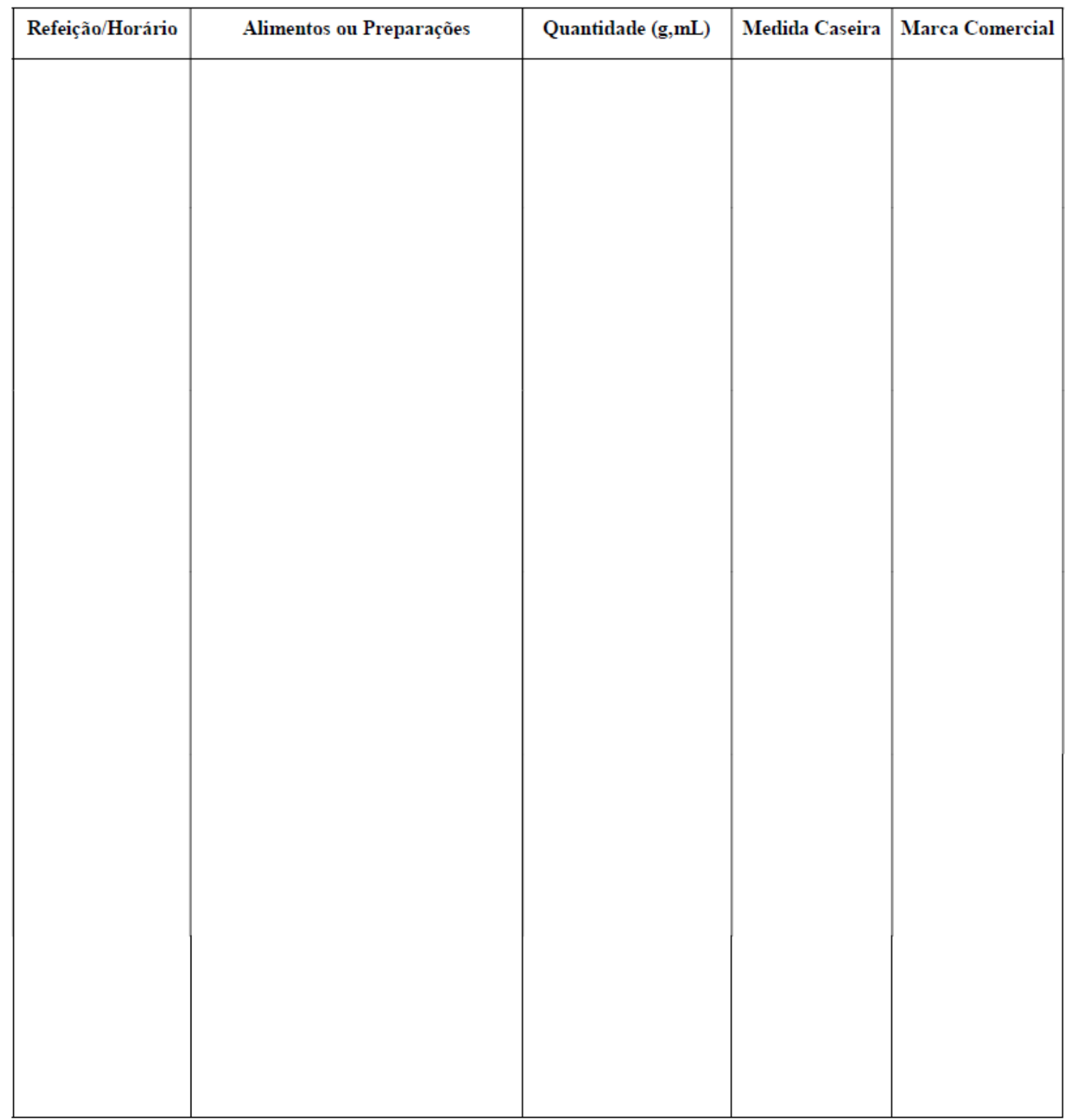

Entrevistador:

Tempo da entrevista: 
10.4. Anexo 4 - Questionário para avaliação de atividade física

\section{QUESTIONÁRIO DE AVALIAÇÃO DE ATIVIDADE FÍSICA HABITUAL}

NOME:

$\mathrm{N}^{\circ}$ CARDIONUTRI

ENTREVISTADOR

DATA

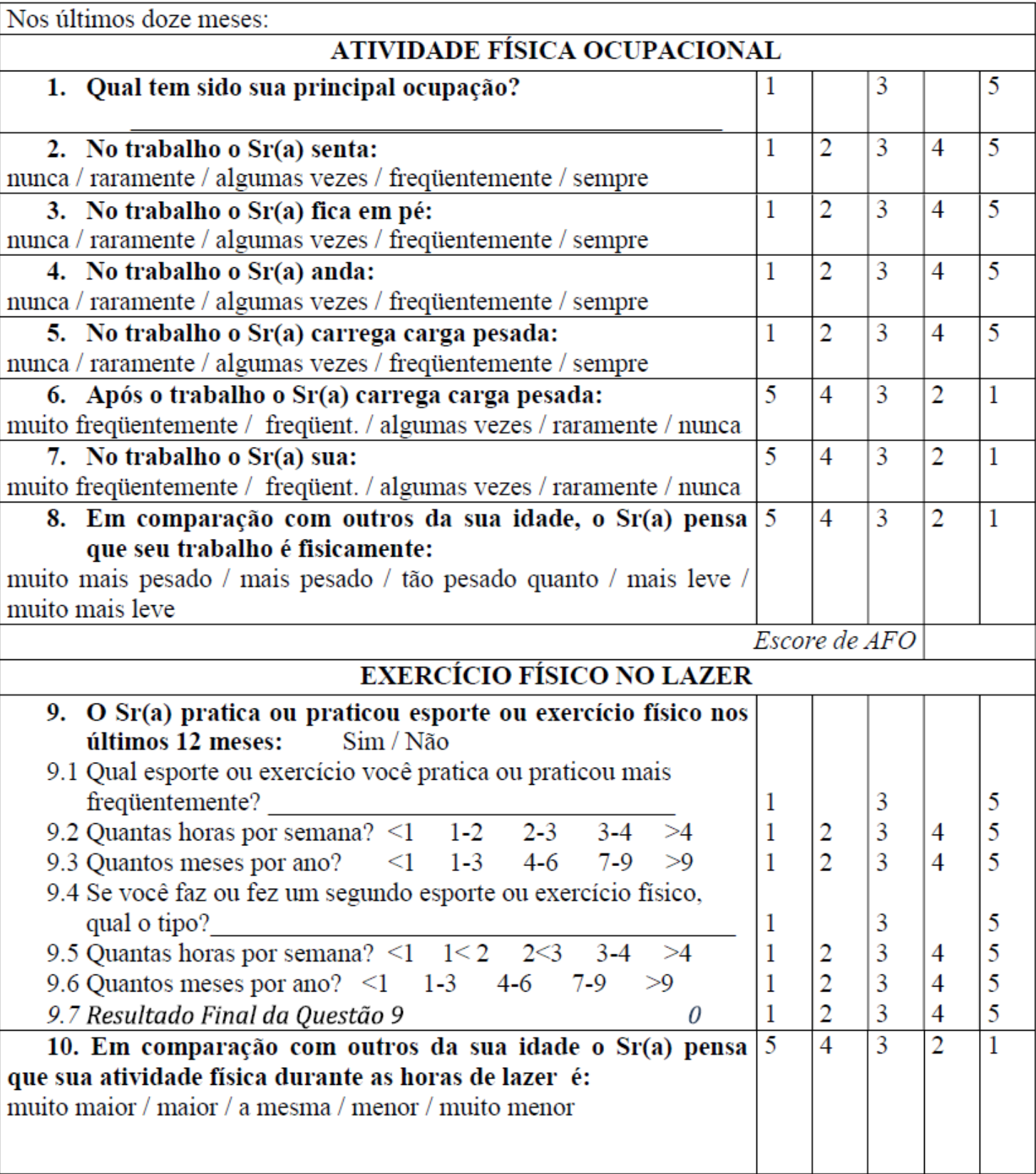




\begin{tabular}{|c|c|c|c|c|c|}
\hline $\begin{array}{l}\text { 11. Durante a horas de lazer o Sr(a) sua: } \\
\text { muito freqüentemente / freqüentemente / algumas vezes / raramente / } \\
\text { nunca }\end{array}$ & 5 & 4 & 3 & 2 & 1 \\
\hline $\begin{array}{l}\text { 12. Durante as horas de lazer o } \mathrm{Sr}(\mathrm{a}) \text { pratica esporte ou } \\
\text { exercício fisico: } \\
\text { nunca / raramente / algumas vezes / freqüentemente / muito } \\
\text { freqüentemente }\end{array}$ & \begin{tabular}{|l|l|l|l}
1 & 2 \\
& & \\
\end{tabular} & 2 & 3 & 4 & 5 \\
\hline \multicolumn{6}{|c|}{$\begin{array}{lll}1 & \text { Escore de EFL }\end{array}$} \\
\hline \multicolumn{6}{|c|}{ ATIVIDADE FÍSICA DE LAZER E LOCOMOÇÃOO } \\
\hline $\begin{array}{l}\text { 13. Durante as horas de lazer o } \mathrm{Sr}(\mathbf{a}) \text { vê televisão: } \\
\text { nunca / raramente / algumas vezes / freqüentemente / muito } \\
\text { freqüentemente }\end{array}$ & \begin{tabular}{|l|l|l|l}
1 & 2 \\
\end{tabular} & 2 & 3 & 4 & 5 \\
\hline $\begin{array}{l}\text { 14. Durante as horas de lazer o } \operatorname{Sr}(\mathbf{a}) \text { anda: } \\
\text { nunca / raramente / algumas vezes / freqüentemente / muito } \\
\text { freqüentemente }\end{array}$ & 1 & 2 & 3 & 4 & 5 \\
\hline $\begin{array}{l}\text { 15. Durante as horas de lazer o } \mathrm{Sr}(a) \text { anda de bicicleta: } \\
\text { nunca / raramente / algumas vezes / freqüentemente / muito } \\
\text { frequientemente }\end{array}$ & 1 & 2 & 3 & 4 & 5 \\
\hline $\begin{array}{l}\text { 16.Durante quantos minutos por dia o Sr(a) anda a pé ou de } \\
\text { bicicleta indo e voltando do trabalho, escola ou compras? } \\
<5 / 5-15 / 16-30 / 31-45 />45\end{array}$ & 1 & 2 & 3 & 4 & 5 \\
\hline \multicolumn{6}{|c|}{ Escore de $A L L$} \\
\hline 17. Somatória Total dos Pontos & & & & & \\
\hline 18. ESCORE TOTAL & & & & & \\
\hline
\end{tabular}




\subsection{Anexo 5 - Aprovação do Comitê de Ética em Pesquisa da Faculdade de Saúde}

\section{Pública}

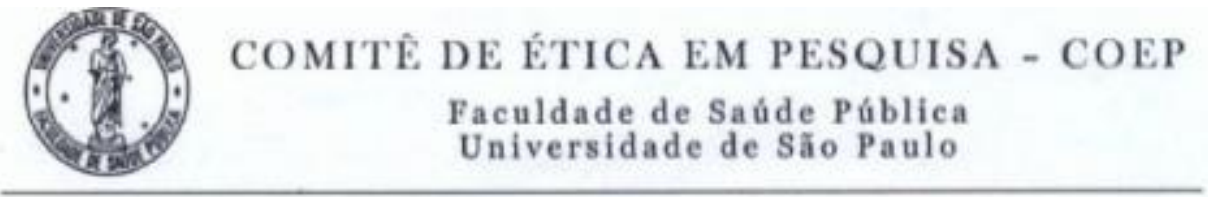

OF.COEP/208/12

27 de novembro de 2012.

Prezada pesquisadora,

o Cumitê ue Euca em Pesquisa Ua faculuade de Saúde Pública da Universidade de săo Paulo, em sua $10, \% / 12$ Sessão Extraordinárla. realizada em $23 / 11 / 2012$, analisou de acordo com a Resoluçà n." 196/96 do Conselho Nacional de Saúde e suas complementares, o protocolo de pesquisa n." 2264, intitulado "PROPRIEDADES FísICO-QUIMICAS DA LDL E DA HDL, MARCADORES CARDIOMETABÓLICOS E OXIDATIVOS PODEM SER MODULADOS PELO CONSUMO DE OMEGA.3, OMEGA.6 E OMEGA.9 EM INDIVIDUOS COM RISCO CARDIOVASCULAR INTERMEDIÁRIOr, do grupo III, sob responsabilidade da pesquisadora Nágila Raquel Teixeira Damasceno, considerando APROVADO a inclusăo de novas análises no projeto.

Cabe lembrar que, de acordo com a Res. CNS 196/96, sao deveres do(a) pesquisador(a): 1) Comunicar de imediato qualquer alteraçăo no projeto e aguardar manifestaçăo deste Comitế de Etica em Pesquisa para dar continuidade à pesquisa: 2) Manter sob sua guarda e em local seguro, pelo prazo de 5 (cinco) anos, os dados da pesquisa, contendo fichas individuais e todos os demais documentos recomendados pelo cutr, no caso eventual auditoria; 3) Comunicar formalmente a este Comitê per ecasiāo de encerramente da pesquisa; 4) Elaborar e apresentar relatórios parciais e final; 5) Justificar perante o COEP interrupçà do projeto ou a năo publicaçăo dos resultados.

Atenciosamente,

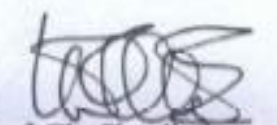

Prof. Tit. Claud to Leone

Coordenador do Comité de Ética em Pesquisa - FSP/USP

IIm.* Sr.*

Prof." Dr," Nagila Raquel Teixeira Damasceno

Departamento de Nutriçăo

Faculdade de Saúde Poblica/usp

Av, Dr. Arnaldo, 715 - Cerqueira César - CEP 01246.904 - Sto Paulo - SP

Contate: (55 11) 30617770 | eaepafsp.usp.hr | www.fsp.usp.hr 


\subsection{Anexo 6 - Aprovação do Comitê de Ética em Pesquisa do Hospital}

\section{Universitário}

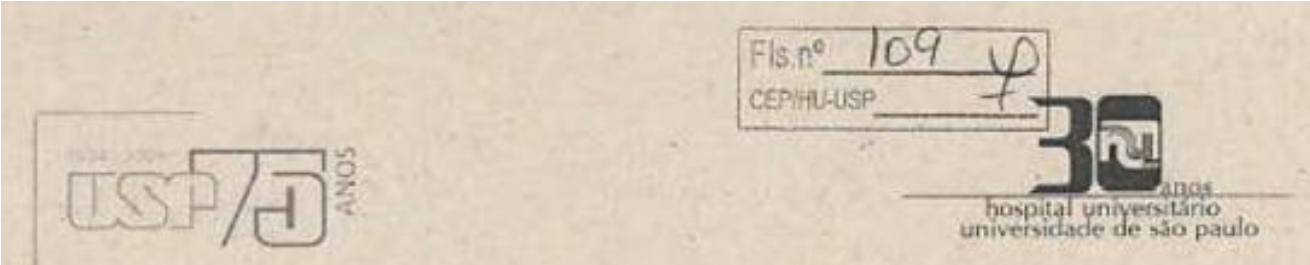

São Paulo, 6 de agosto de 2011.

$I^{\text {mo(a) }}, S^{\text {r(a) }}$.

Dra. Nágila Raquel Telxeira Damasceno

Serviço de Nutrição e Dietética do Hospital Universitário

UNTVERSIDADE DE SÃO PAULO

REFERENTE: Projeto de Pesquisa "Propriedade físico-químicas da LDL e da HDL, marcadores cardiometabólicos e oxidativos podem ser modulados pelo consumo de ômega-3, ômega-6 e ômega-9 em individúos com risco cardiovascular intermediário?" Pesquisador(a) responsável: Dra. Nágila Raquel Teixeira Damasceno - Co-Autor(es): Dr. Antonio Figueiredo, Dr. Magnus Ake Gidlund, Dra. Sayuri Miyamoto, Dr. Raul Cavaleante Maranhão, Dra. Dulcineia S. P. Abdalla, Dr. Rodrigo Diaz Olmos, Marlene Nuñez Aldin, Adriane Bueno Marangoni, Caroline Pappiane, Claudia Assef Sanibal Registro CEP-HU/USP: $1126 / 11$-SISNEP CAAE: 0063.0.207.198-11.

\section{Prezado(a) Senhor(a)}

O Comitê de Ética em Pesquisa do Hospital Universitário da Universidade de São Paulo, em reuniăo ordinária fealizada no dia 5 de agosto de 2011 , analisou ó Projeto de Pesquisa acima citado, considerando-o como APROVADO, bem como o seu Termo de Consentimento Livre e Esclarecido.

Lembramos que cabe ao pesquisador elaborar e apresentar a este Comitê, relatórios anuais (parciais ou final, em função da duração da pesquisa), de acordo com a Resoluçăo n० 196/96 do Conselho Nacional de Saúde, inciso IX.2, letra "c".

O primeiro relatório está previsto para 5 de agosto de 2012.

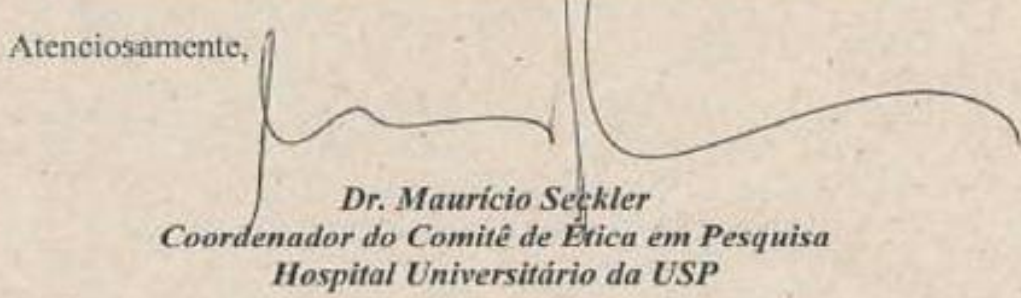

CONIIÉ DY ÉTICA EM PESQULSA DO HOSPTIL L NIVERSHTEKO DA USP

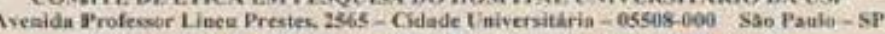

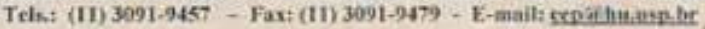

